Portland State University

PDXScholar

6-3-2005

\title{
Visualizing Complexity : A Spatial Analysis of Decorative Geometric Pattern in the Islamic World, 900-1400 AD
}

Tracy Elizabeth Harrison

Portland State University

Follow this and additional works at: https://pdxscholar.library.pdx.edu/open_access_etds

Part of the Architectural History and Criticism Commons, Geographic Information Sciences

Commons, History of Art, Architecture, and Archaeology Commons, Islamic World and Near East History

Commons, and the Near and Middle Eastern Studies Commons

Let us know how access to this document benefits you.

\section{Recommended Citation}

Harrison, Tracy Elizabeth, "Visualizing Complexity : A Spatial Analysis of Decorative Geometric Pattern in the Islamic World, 900-1400 AD" (2005). Dissertations and Theses. Paper 2434.

https://doi.org/10.15760/etd.2431

This Thesis is brought to you for free and open access. It has been accepted for inclusion in Dissertations and Theses by an authorized administrator of PDXScholar. Please contact us if we can make this document more accessible: pdxscholar@pdx.edu. 


\section{THESIS APPROVAL}

The abstract and thesis of Tracy Elizabeth Harrison for the Master of Science in

Geography were presented June 3, 2005, and accepted by the thesis committee and the department.

COMMITTEE APPROVALS:
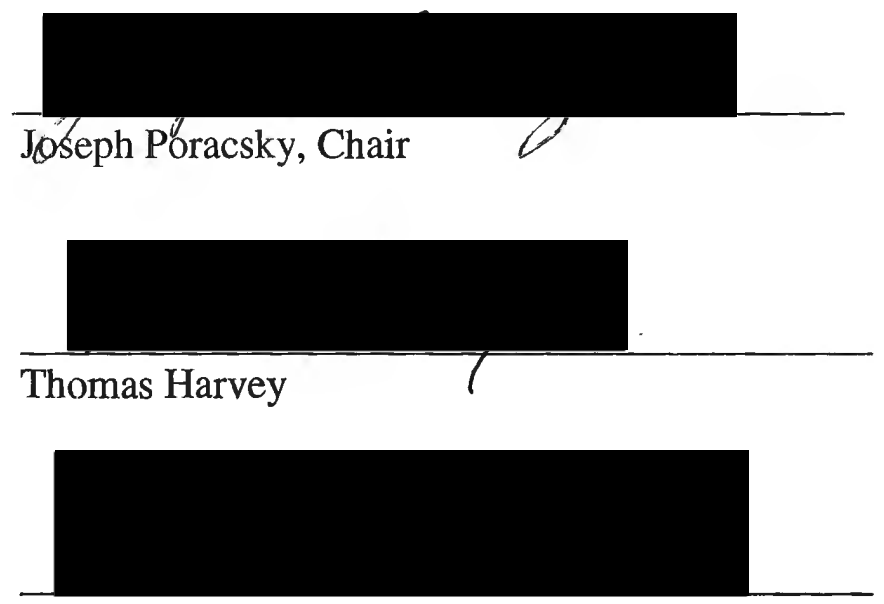

Martha Works

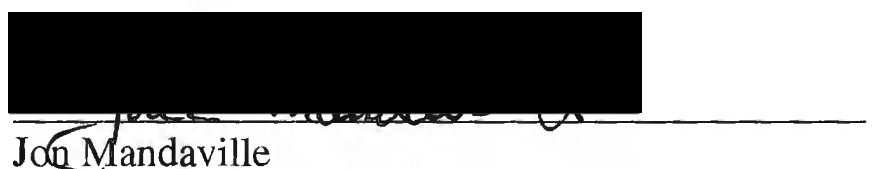

Jon Mandaville

Representative of the Office of Graduate Studies

\section{DEPARTMENT APPROVAL:}

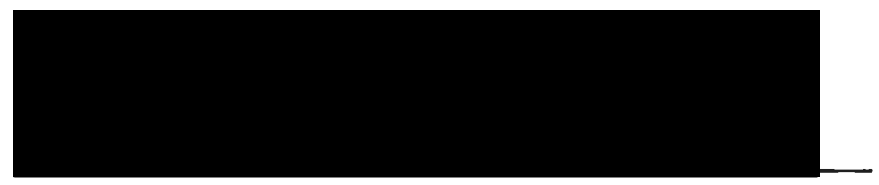

Martha Works, Chair

Department of Geography 


\begin{abstract}
An abstract of the thesis of Tracy Elizabeth Harrison for the Master of Science in Geography presented June 3, 2005.

Title: Visualizing Complexity: A Spatial Analysis of Decorative Geometric Pattern In the Islamic World, 900-1400 AD
\end{abstract}

This study explores how the use of complex decorative geometric patterns in Islamic architecture spatially relates to advances in the fields of science and philosophy in the Islamic world between the ninth and fourteenth centuries. This project examines hypotheses developed by various scholars on the forces that shaped the use of these patterns (known as the geometric mode) in Islamic architecture. The prevailing assumption that advances in mathematics contributed to the use of the geometric mode is used as a starting point for subsequent analysis.

For this study, two spatial databases were created. One contains over two hundred and twenty monuments of Islamic architecture exhibiting the geometric mode, while the other contains over one hundred records of activity in the sciences and philosophy. From these databases, decorative geometric pattern types were classified and ranked, and scholarly activities were classified. Density maps were developed from these classes and ranks for each century, and were compared in a series of analytical overlay maps. Each map depicts the spatial relationships of the activities in question over a span of three centuries, enabling a spatio-temporal 
analysis of the connections between disciplines within the context of the broader cultural elements at work.

These maps allow for examination of these disciplines in a new way; there has never been a spatial analysis testing the existing hypotheses until now. The density overlay maps show that some of the prevailing hypotheses are partially supported by the data, but the primary hypothesized relationship_-that activity in mathematics prompted use of the geometric mode-is not applicable to all regions of the Islamic world during this time period. The spatial analysis exposes the previously overlooked possibility that the geometric mode could have influenced activity in the sciences and philosophy.

This study provides tools to better understand the complex relationships among art, science, and philosophy: two spatial databases, a geographic information systems (GIS) model, and resulting analytical overlay maps. The maps produced in this project reveal examples where the quality of contact among disciplines in these very specific times and places is worth examining in greater detail. 


\section{VISUALIZING COMPLEXITY: \\ A SPATIAL ANALYSIS OF DECORATIVE GEOMETRIC PATTERN \\ IN THE ISLAMIC WORLD, 900-1400 AD}

by

TRACY ELIZABETH HARRISON

A thesis submitted in partial fulfillment of the requirements for the degree of

\section{MASTER OF SCIENCE \\ in GEOGRAPHY}

Portland State University 2005 


\section{ACKNOWLEDGEMENTS}

I would like to recognize and thank the people who helped me with this thesis. I must first thank the members of my committee: Dr. Joseph Poracsky for his willingness to indulge this project in the first place; Dr. Martha Works for her help in connecting my ideas back to cultural geographers; Dr. Tom Harvey for his insightful questions; and Dr. Jon Mandaville for his championing of interdisciplinary work. I also wish to thank them for the countless hours they all spent commenting on my very long drafts.

I also need to thank those family and friends who jumped in without hesitation when pressed into service on this project. They critiqued maps, figures, and rambling texts; they worked tirelessly with me through many iterations of ideas. Specifically, Taylor Harrison, David Banis, and Justin Limoges provided me with invaluable assistance and encouragement.

Finally, my husband Ezra Ereckson must be commended above all others for his infinite patience, perpetual optimism, and unending support. Without his contributions I could not have made it through this process. 
TABLE OF CONTENTS

PAGE

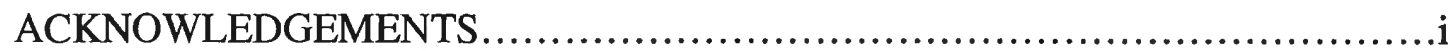

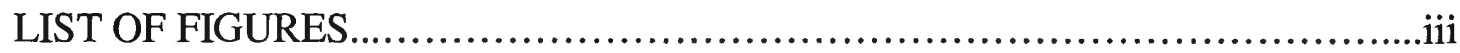

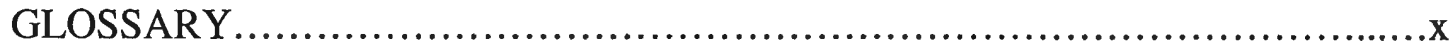

CHAPTER

INTRODUCTION AND CONTEXTS: LITERATURE REVIEW ......1 REGIONAL AND ARCHITECTURAL HISTORY..................24

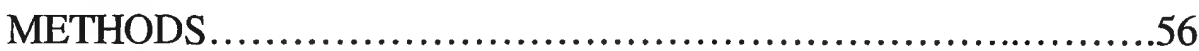

DISCUSSION: NINTH CENTURY..............................79

DISCUSSION: TENTH CENTURY................................99

DISCUSSION: ELEVENTH CENTURY ........................116

DISCUSSION: TWELFTH CENTURY...........................146

DISCUSSION: THIRTEENTH CENTURY........................179

DISCUSSION: FOURTEENTH CENTURY........................202

CONCLUSIONS .................................................213

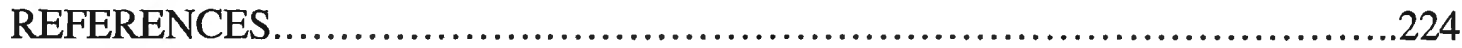

APPENDIX A: PATTERN DATABASE .........................................234

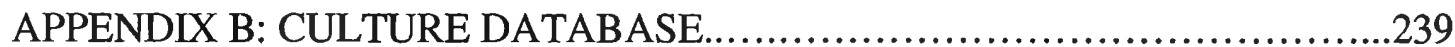

APPENDIX C: CARTOGRAPHIC MODEL.....................................247 


\section{LIST OF FIGURES}

FIGURE

PAGE

1.1 Illustrations of geometric pattern, in schematic form and as found in Islamic architecture .6

1.2 The chart shows use of the different forms of the geometric mode compared to other types of cultural activity—math, astronomy, and

philosophy. 18

2.1 Extent of the Islamic empire in the mid-eighth century. .25

2.2 The origins of the congregational style mosque, as seen in the home of the Prophet Muhammad and the Umayyad Mosque of Damascus

2.3. Extent of 'Abbasid Caliphate in the early ninth century.

2.4 Congregational style mosques found throughout the 'Abbasid empire in the ninth century. 30

2.5 'Abbasid Caliphate and emerging dynasties................................32

2.6 Chronological chart of the principal Islamic dynasties .........................33

2.7 The Tomb of the Samanids (Bukhara, 920), the earliest example of Islamic tomb architecture to survive.

2.8 Courtyard of the Great Mosque of Isfahan, (twelfth century and later), showing north and west iwans. 36

2.9 Ruling entities of the late tenth century. 37

2.10 Almoravid, Fatimid, Seljuq, and Ghaznavid empires in 1100. .37 
2.11 Examples of carved stucco (left) and stone decoration (right) in Buyid architecture. 39

2.12 Examples of Fatimid architecture show the variety of decorative styles

used .40

2.13 Examples of Seljuq architecture from Isfahan and Ardistan, Iran..............41

2.14 Examples from the height of Ayyubid architecture...........................42

2.15 Distinctive interior and exterior muqarnas decoration as used in Zangid architecture.............................................................. 43

2.16 Examples of Almoravid architecture......................................44

2.17 Examples from Almohad architecture......................................45

2.18 Extent of Muslim world in 1300, showing the borders within the empire.............................................................46

2.19 The Mausoleum of Sultan Muhammad Oljeitu Khudabanda, at Sultaniyya, Iran (1307-1313), represents the pinnacle of Il-khanid architectural achievement..............................................48

2.20 Mamluk mosque complexes..............................................49

2.21 Examples of Marninid architectural decoration...............................50

2.22 Spectacular muqarnas and ceiling decoration in Nasrid architecture............51

2.23 Ottoman architecture, characterized by multiple domes and floral arabesque decoration, as seen in the interior of the domes...................53

2.24 Examples of extensive use of multicolored decorative tiling found in Safavid architecture; floral arabesque patterns dominate. .54 
3.1 Map of cities in pattern database, showing number of monuments in each location.

3.2 Map of cities in culture database, showing number of entries in each location 61

3.3 Triangular and radial grid systems (shown by dotted lines) underlying polygon and star-and-polygon patterns..............................66

3.4 Radial grid systems underlying star-and-polygon patterns...................68

3.5 Pattern types and complexity ranking.................................. 70

3.6 Pattern Database "Count" Density with major cities included for reference .74

3.7 Culture Database "Count" Density with major cities included for reference .74

3.8 Eleventh Century Pattern Complexity Density shown with cities in the

Eleventh Century Culture Database....................................... 75

Eleventh century density overlay map................................ 77

4.1 Timeline for ninth century............................................ 80

4.2 Ninth century density overlay map, showing three centuries of

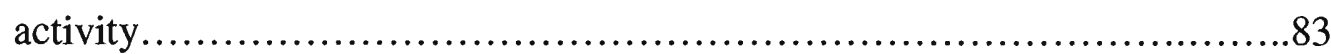

4.3 Page from a book of astronomical tables by al-Khwarizmi.................93

4.4 'Samarra style' decoration found in ninth century, Samarra, Iraq.............95

4.5 Two kinds of decoration at the Mosque of Ibn Tulun (876-879, Cairo) 
5.1 Tenth century density overlay map, showing three centuries of

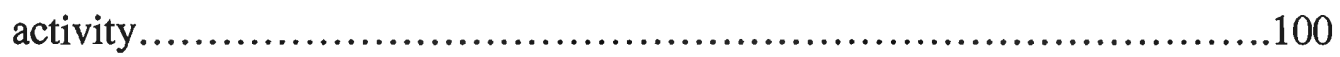

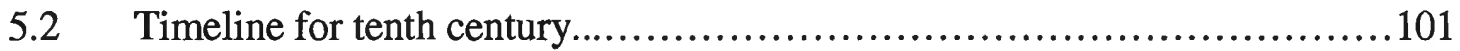

5.3 Detail of tenth century density overlay map................................105

5.4 Pages from al-Buzjani's What the Artisan Needs of Geometric

Operations, written in the late tenth century in Rayy, Iran....................108

5.5 Mausoleum of 'Arab Ata (977-978) Tim (Uzbekistan) showing the

first known use of star-and-polygon pattern in non-window settings...........113

5.6 Refinement of the Samarra style, incorporating polygonal elements

at the Madrasa Complex at Nishapur (900) Nishapur (Iran).

5.7 Early use of the muqarnas at Mausoleum of 'Arab Ata (977-978)

Tim, Uzbekistan..................................................... 114

6.1 Timeline for the eleventh century ....................................117

6.2 Eleventh century density overlay map, showing three centuries of

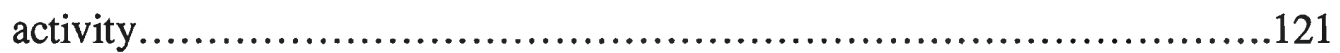

6.3 Regions of high-density pattern complexity move steadily west.............125

$6.4 \quad$ Western portion of eleventh century activity..............................128

6.5 Interlocking Figures, showing mathematically correct constructions

of repeat units in geometric patterns for use in architectural decoration......131

6.6 Left: Reconstruction of original proof. Right: One method of

constructing Khayyam's triangle in Interlocking Figures. 
6.7 Detail of Figure 6.2 showing region of high pattern complexity around Isfahan. 134

6.8 Star-and-polygon decoration from Kharraqan (1067).......................136

6.9 Star-and-polygon pattern at the Palace at Lashkari Bazaar, Bust, Afghanistan (1075)

6.10 Chart presents comparison of the percentage of monuments of Sunni and Shia ruling groups whose monuments exhibit muqarnas and starand-polygon patterns

6.11 Interior of muqarnas dome at the Mausoleum of Imam Dur, Samarra, Iraq (1085) .143

6.12 Exterior of muqarnas dome at the Mausoleum of Imam Dur,

Samarra, Iraq (1085) .144

7.1 Timeline for twelfth century, showing the many emerging dynasties. 148

7.2 Dynastic change leading up to the twelfth century. 149

7.3 Density overlay map of eastern portion of twelfth century. .152

7.4 Density overlay map of western portion of twelfth century .153

7.5 Salah al-Din's territories at the end of the twelfth century....................157

7.6 The regions of highest pattern complexity move west as time goes on.......164

7.7 Simplified detail of twelfth century overlay map highlighting where high pattern complexity coincides spatially with later, not earlier cultural activity 
7.8 Examples of the geometric mode in northwestern Iran in the twelfth century: 1: Gunbad-I Qabud; 2: Round Tower of Maragheh; 3 and 4: Gunbad-I Alawiyan. 168

7.9 Diagrams by al-Tusi, referencing the circle and polygons: 1-3 diagrams of planetary motion; 4 diagram from final page of al-Tusi's commentary on the Elements of Euclid. .171

7.10 Diagrams by al-Shirazi: 1,2 from a treatise on music and harmonics; 3 from an astronomy text .172

7.11 Muqarnas and star-and-polygon patterns in twelfth century

Damascus: 1-3: Bimaristan al-Nuri; 4: Madrasa al-Nuriyya. .174

7.12 Diagram of the Mystical Cosmos by Ibn al-Arabi. 177

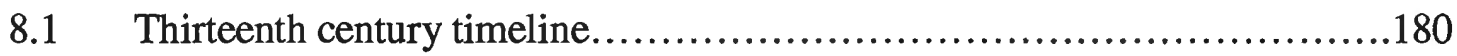

8.2 Density overlay map of the thirteenth century.............................181

8.3 Anatolia in the middle of the thirteenth century ............................183

8.4 Examples of Rum Seljuq architecture ................................... 184

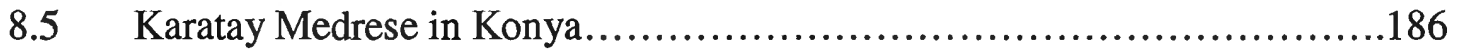

8.6 Pages from al-Jazari's Book of Knowledge of Ingenious Mechanical

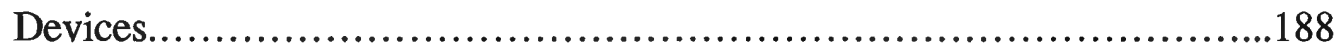

8.7 Detail of thirteenth century high-density pattern complexity region...........193

8.8 The western Islamic lands in the first part of the thirteenth centuryrelatively stable, no major movement. 196 
8.9 The eastern Islamic lands at the middle of the thirteenth century-

chaotic, rulers and boundaries volatile, unstable.

8.10 Floral arabesques and medallions incorporating the influences from

China brought by the Mongols, in tile decoration at the Shah Mosque

of Isfahan, 1611 and later......

8.11 As time goes on, the activities in science and philosophy decrease

while use of geometric pattern in architecture increases.....................201

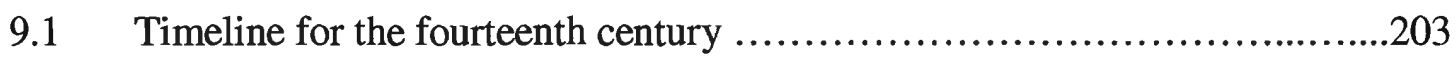

$9.2 \quad$ Fourteenth century density overlay map...............................204

9.3 Exceptional muqarnas decoration at the Shrine of Ahmad Yasavi ...........206

9.4 Other monuments from the Timurid period in this region exhibit a

variety of star-and-polygon patterns in dome interiors, in contrast to

the Shrine of Ahmad Yasavi; exteriors are similar to that used at the

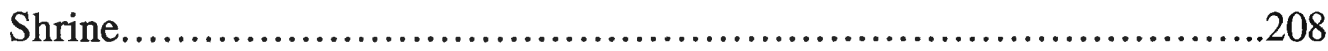

10.1 Detail of tenth century density overlay map............................217

10.2 Simplified detail of twelfth century density overlay map.....................219

10.3 Detail of eleventh century density overlay map...........................221 


\section{GLOSSARY}

Anatolia Region of central Turkey (illustrated in map below).

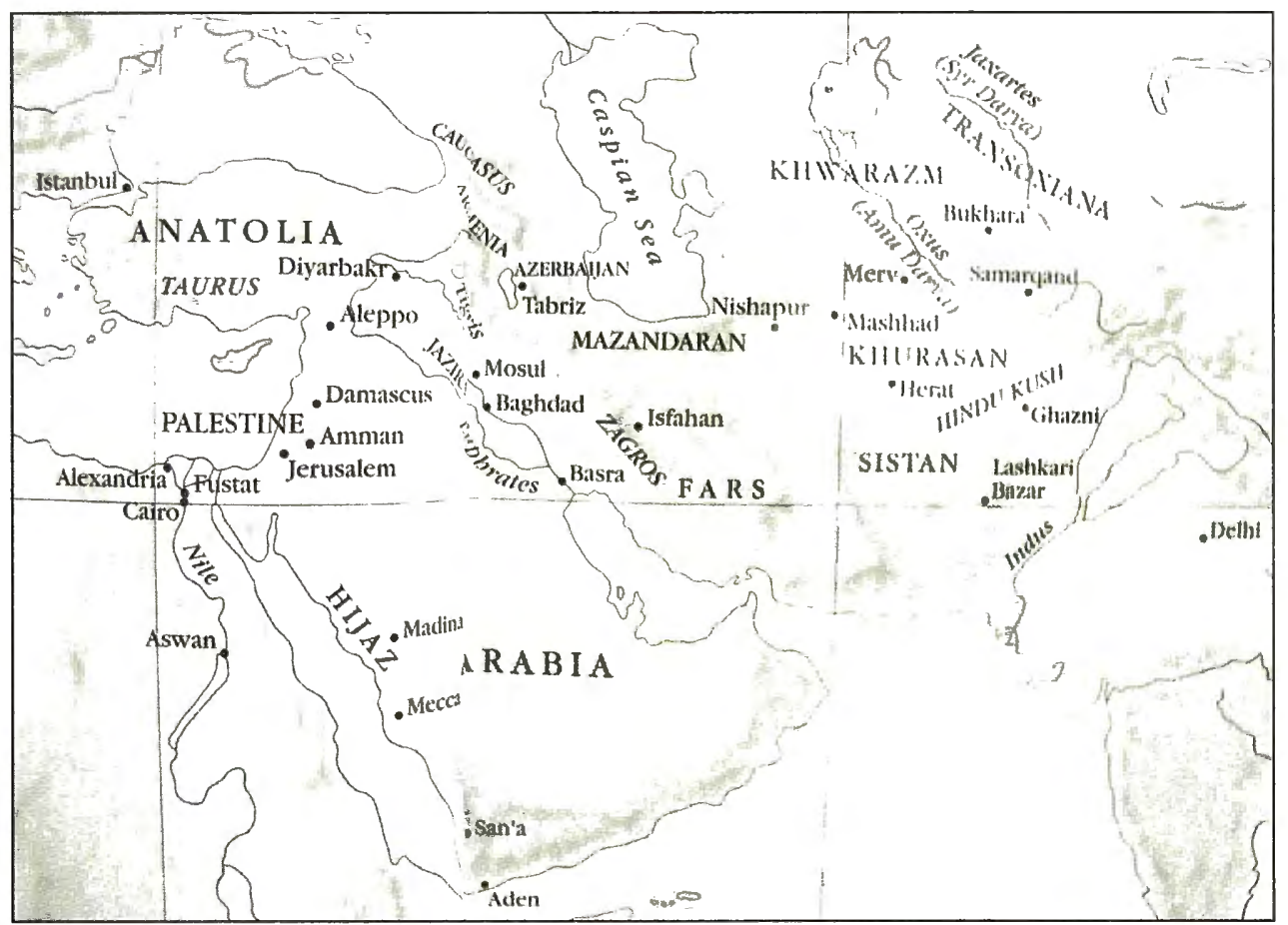

Reference map showing regions named in the text: Anatolia, Transoxiana, Khwarazm, and Khurasan (Ettinghausen 2001, xii).

Arabesque Decorative style derived from plant imagery, used in many milieus, including textiles, ceramics, metalwork, and architecture.

Caliph Political leader of the peoples of Islam, in Arabic khalifa, literally successor or deputy of the Prophet Muhammad.

Dar al-ilm Literally means 'land of science' but refers to a series of schools set up by Fatimid rulers beginning in the tenth century.

Falsafah Tradition of scientific, Neoplatonic metaphysics in Islamic philosophy.

Falasifah Practitioners of Falsafah.

Gnosis Personal, subjective, or experiential knowledge of the Divine.

Hegira Literally means 'emigration'; Muhammad's emigration from Mecca to Medina in 622 , the date from which the beginning of the Muslim lunar calendar is calculated. 

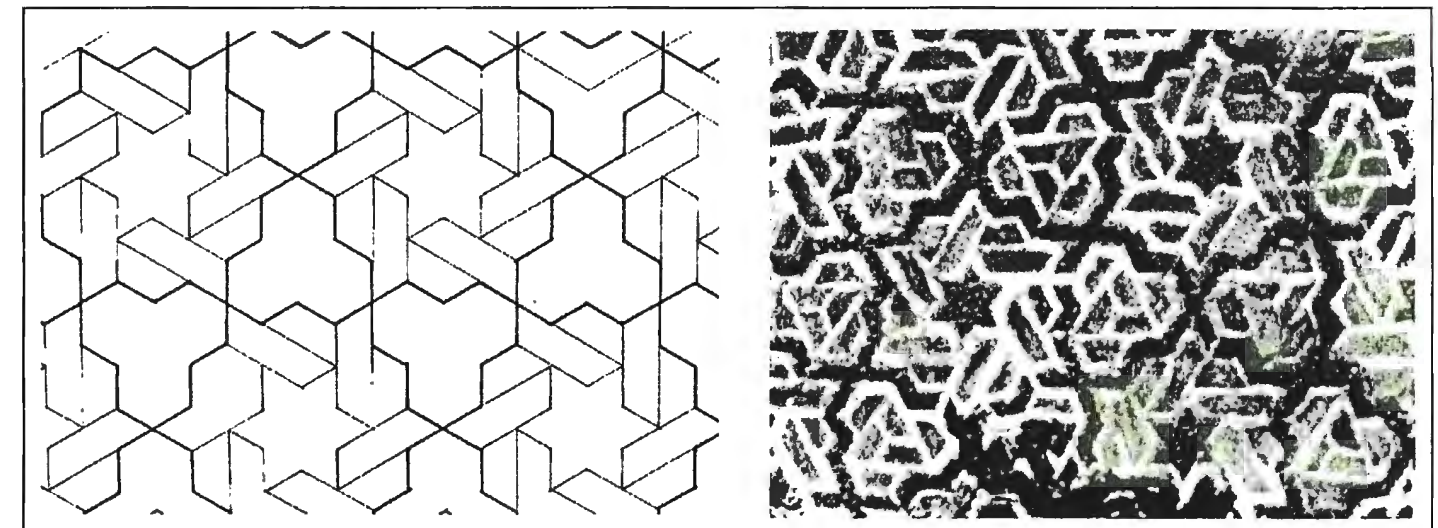

Madrasa al-Mustansirya, Baghdad, Irae, 1233
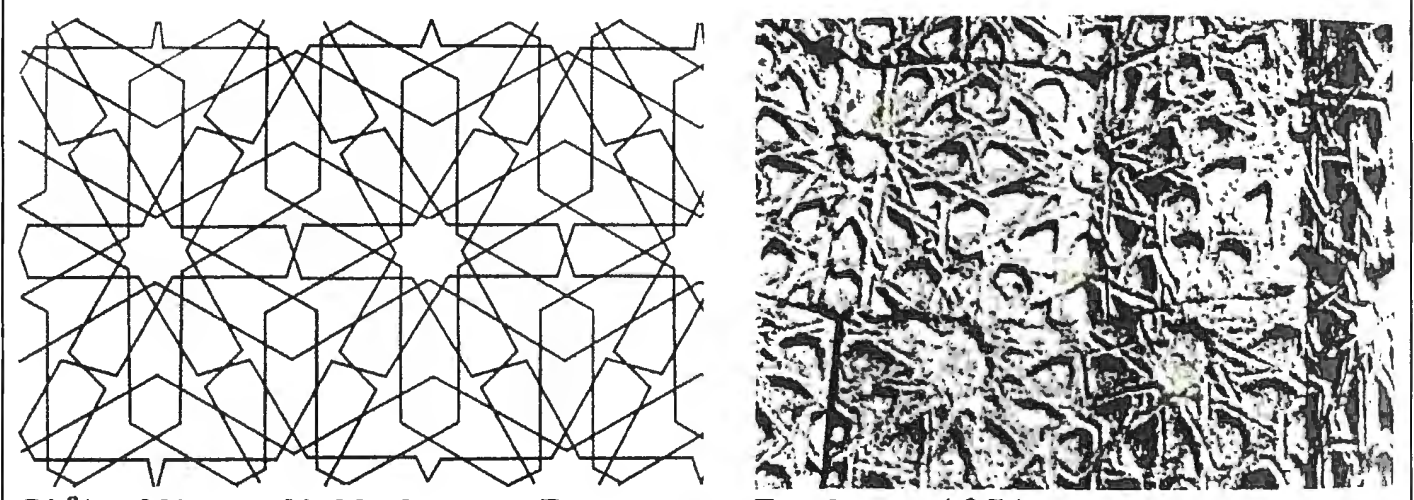

Cifte Minareli Medrese, Erzerum, Turkey 1271
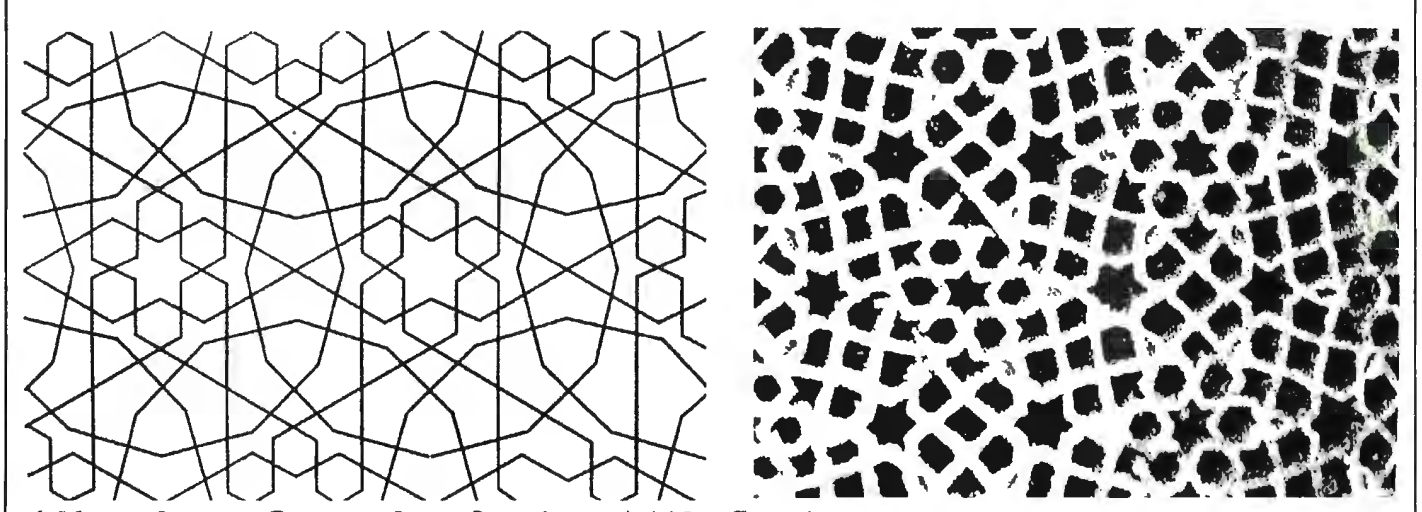

Alhambra, Granada, Spain 14th Century

Figure 1.1 Illustrations of geometric pattern, in schematic form and as found in Islamic architecture (image source: Demiriz 2000, 62, 156, 68). 
geography provides a natural framework for this project, as it is a dynamic subfield, increasingly inclusive of ideas, subject matter, and theories from other disciplines.

Here I review the applicable theories used by cultural geographers; specifically note how more inclusive analytical strategies assist in understanding complicated phenomena; review the current hypotheses regarding the geometric mode; discuss how mapping reveals patterns previously unseen; and provide context for the importance of projects like this one.

\section{Theories in Cultural Geography}

Influenced by postmodern and poststructural theory, cultural geographers have moved toward more subjective definitions of some terms-in particular, "culture" and "landscape," two of the most complicated terms that geographers work with.

Geographers now recognize (and often state explicitly) the benefits of realizing that words and concepts cannot be considered transcendent elements of language or culture but rather have definitions, indeed histories, that depend on context. Peter Jackson's approach to the use of these terms inspires my own:

The conception of cultural geography advanced here [in Maps of Meaning] focuses on the way cultures are produced and reproduced through actual social practices that take place in historically contingent and geographically specific contexts. It is in the specification of context in its fullest sense that geography can make its most immediate contribution to cultural studies, rather than through a unique interest in the geographical distribution of 'cultural traits'. Geographers can no longer take the definition of culture as given; it is a contested term the meaning of which must now be considered problematic. $(1994,28)$ 
Further, I agree with Denis Cosgrove's statement in Social Formation and Symbolic Landscape that the use of the term landscape implies agreement with more subjective approaches: "in recent years [the term landscape] has been employed as a geographic concept by writers seeking to challenge the orthodoxy of scientific method in geography, to incorporate into the discipline an open acceptance of subjective modes of study" $(1984,28)$. I employ the term landscape in this way. Tuan advocates perceiving the totality of landscape through using multiple views at once, referencing the role of cartography: "landscape is an ordering of reality from different angles...the vertical view is objective and calculating...the side view, in contrast, is personal, moral, and aesthetic" $(1979,90)$. Crang emphasizes the inextricability of the ideas of landscape and culture: "[landscapes] are always bound up in particular cultures. We have then a geography on two levels, the way cultures use geography, investing meanings in certain spaces, and then (but not only) the geographical distribution of these cultures" $(1998,31)$. My project follows the work of these cultural geographers in privileging historically contingent contexts, multiple viewpoints, and the subjective. Major reappraisals and textbooks of the field of cultural geography (Foote et al 1994, Mitchell 2000, Crang 1998) deal with the unstable nature of terms like landscape and culture by drawing on concepts from postmodern and poststructural theory. They rely on authors such as Jean Baudrillard, Terry Eagleton, Roland Barthes, Paul Ricoeur, Terence Hawkes, Raymond Williams, and Ferdinand de Saussure. These authors, writing in the fields of critical theory, literary theory, and semiotics have all provided useful concepts for cultural geographers; chief among 
them are the notions that landscapes can be read as texts, and that other texts, such as art, literature, and the popular press, are available for geographers to use in their analyses. Hence we get "Axioms for Reading the Landscape" in 1979 from Peirce Lewis which includes ideas such as "the axiom of landscape as clue to culture, the axiom of common things with the corollary of non-academic literature, and the axiom of landscape obscurity [which states that the messages that the landscape conveys are not obvious]" (15; emphases mine).

Barnes and Duncan rely on the work of Ricoeur to prove that the world is like a text: "meaning in written discourse is concretized when it is inscribed or textualized. Similarly, in social life, institutional objectification, recurrent patterns of behavior and monuments in the built environment take on the same type of fixity" $(1992,6)$. The theory behind this is the gap between the signifier and the signified (in post-structural semiotics). Relationships between the two are not preordained and meanings are not fixed or "true," such that one cannot describe the one "right" or "correct" landscape. This allows cultural geographers to investigate how meanings are shaped, how elements of the landscape come to mean what they do within various contexts. As Crang notes, "it is in the juxtapositions, mutations and connections of different cultural spaces, in the overlaying of contradictory cultural landscapes over each other that creativity and vitality may emerge" $(1998,175)$. In the context of my project, the different cultural spaces are the ideological realms of religion, philosophy, and science. The contradictory cultural landscapes are those of the aesthetic/religious (distribution of mosques, etc.) and the scholarly/scientific (distribution of centers of 
power/learning). Showing the "juxtapositions, mutations and connections" via "overlaying" is effectively my methodology; finding examples of "creativity and vitality" is my goal.

\section{Inclusiveness as a Strategy}

In order to show these juxtapositions, mutations, and connections, I will rely on information from fields such as the histories of art, science, philosophy, and Islam. Many geographers advocate this sort of inclusive approach (Tuan 1974, 1979, 1995, 1999; Scott and Simpson-Housley 1991; Light and Smith 1988; Duncan and Duncan 1988; Barnes and Duncan 1992; Meinig 1983; Barnes 1996; Cosgrove 1984, 1988, 1999). Referring to cultural geographers working currently, Mathewson notes, "receptivity to ideas originating from other disciplines is perhaps greater than that of their predecessors" $(1994,167)$. Mandoki (1998) provides a novel synthesis of ideas by invoking the theory of relativity in assessing the symbolic "densities" of Mexico City's Zócalo Square. Cosgrove is a major proponent of working with other areas of interest and connecting them via the theories of the cultural geographer. In Social Formation and Symbolic Landscape, he provides an excellent model for my work (1984). He links the transformation of feudalism to capitalism in Europe with a shift in the Europeans' artistic use of linear perspective as shown in landscape paintings; similarly, I argue that the uses of geometric patterns (in specific places in the Islamic world) can be linked to shifts in doctrine and scientific enquiry. I will not be looking at representations of the landscape (such as paintings by J.M.W. Turner) as Cosgrove did, but instead at how people decorated their landscapes, (specifically their religious 
landscapes) and how that decoration carries with it the subtlety of difference that exists in the web of science, religion, and power of the time. While Cosgrove's model provides insight into the aesthetic/political intersection, Livingstone offers a useful take on the science/religion dynamic (1994). He weaves together the histories of science and religion within a localized spatial framework in Ireland and in so doing examines how two religious groups responded to the publication of Darwin's Origin of Species.

My project will draw on the texts of Islamic mathematicians, artisans, and theologians, as well as the idea that the complex geometric patterns manifested in the landscape act as text to be read and interpreted. Many cultural geographers draw upon art and literature to enrich and extend tangencies of inquiry and analysis. To this end, these geographers use an expanded concept of "text" that includes "other cultural productions such as paintings, maps and landscapes, as well as social, economic and political institutions" (Barnes and Duncan 1992, 5). Thus a variety of texts can be used to study geography, and the landscape itself is a text to be read as any other (Meinig 1979). More specifically, Meinig, in "Geography as an Art" calls for geographers to actively seek out work from the humanities in cultural geographic research as well as for geographers themselves to be more artful, subjective, and emotional (1983). Phillip Wagner, in Re-Reading Cultural Geography, discusses the issue of reading material evidence of culture as a text:

[Viewing landscape] as communication stresses the power of symbols in social life. Studies premised on iconographical and semiotic theories have stressed both the implicit and explicit symbolism that lies behind many landscape features. The idea is that landscape symbols can embody relationships of 
power and authority among social groups but also that such symbols influence human attitudes and behavior. In this view, cultural traits and material artifacts must be taken at more than face value in registering the movement of people and the transformation of ideas. Such traits and artifacts must also be read as a record of human perceptions, values, fears, and aspirations. $(1994,29)$

Wagner's use of the phrase "landscape symbols" indicates that "symbolism" is yet another shifty concept, but it is one with which cultural geographers have found resonance. Meinig presages Wagner's statement by fifteen years when he says: "We regard all landscapes as symbolic, as expressions of cultural values, social behavior, and individual actions worked upon particular localities over a span of time...And every landscape is a code, and its study may be undertaken as a deciphering of meaning, of the cultural and social significance of ordinary but diagnostic features" $(1979,6$; emphases mine). Often, the landscape itself or a representation of the landscape is the symbol, but sometimes elements in the landscape are the symbols. For example, geographers have examined a range of vernacular symbols, from garages (Jackson 1997) and house types (Lewis 1994) to eating establishments (Bell and Valentine 1997).

\section{$\underline{\text { Symbolism and Art History }}$}

Geometric decorations are symbols embedded in the landscape of the Islamic world; while they are clearly construed as symbols, their meanings continue to be contested (Bloom and Blair 1997, Necipoglu 1995, Ettinghausen 2001, Gonzalez 2001, Tabbaa 2001). Their meanings are not at all transparent to observers from either within or without Islamic culture. Golombek writes, "[geometric ornament] is the least understood [mode of decoration] in terms of its manner of production as well as 
its significance" $(1997,137)$. Some art historians are largely dismissive of any meaning in the geometric patterns-Ernst Gombrich, a noted historian of decorative art, states simply "Islamic designers...knew how to keep the mind busy without allowing variety to turn into confusion" $(1979,146)$. Contrary to Gombrich's simplistic evaluation, Oleg Grabar, one of the foremost scholars of Islamic art, writes that Islamic decorative programs (specifically in religious contexts), since they are not based on images, "[are] extremely difficult to approach, because the West-centered universal culture of today finds it difficult to understand anything without a system of [figurative] representations" $(1998,56)$. Grabar suggests direction for future study: "Regardless of how much pressure is put on us singly or collectively to generalize about Islamic architecture, we cannot do so without a clearer understanding of the meaning of any one monument in its time, in the fullness of its historical circumstances...today's world can only be true to itself if it is aware of the immense complexity of its time past" $(1998,58)$. He further states that geometry, as a carrier of systems of communication and of social relations, is still incompletely understood. It is thus in light of an art historian's appeal that assessing geometric decoration with an explicitly cultural geographic lens begins to make sense across disciplines.

Many present-day scholars, both Islamic and Western, have attempted to extract meaning from the decorative geometric patterns in Islamic art. There is a quantity of books that supplied the notion that the complex geometric patterns found in Islamic art were all held to the same set of meanings related to Sufi esoterics. Nader Ardalan and Laleh Bakhtiar's The Sense of Unity: The Sufi Tradition in Persian 
Architecture reached a wide audience in 1973, when it was published for the World Festival of Islam. This festival included a series of events and publications that celebrated the $1400^{\text {th }}$ anniversary of Islamic culture. Other books published for the festival relating to art and architecture included Burckhardt's Art of Islam: Language and Meaning (1976), Nasr's Islamic Science (1976) which has just been reprinted, and el-Said and Parmans' Geometric Concepts in Islamic Art (1976). The overriding principle in all of these books is that Islamic art is to be taken as a whole, and that the geometric mode is associated with a loosely defined religious mentality (Necipoglu 1995). Because of this tendency to reduce Islamic art to its essentials, subsequent art historians have called these authors 'essentialists', and I adopt this terminology.

The legacy of these books persisted with the publication (and subsequent reprinting) of other books on the geometric mode in Islamic art. For example, Critchlow's Islamic Patterns: An Analytical and Cosmological Approach, published later in 1976, concretized the overarching meanings assigned to geometric pattern in Islamic art. In the preface, Nasr writes "thanks to the efforts of a small number of authorities, among them...Titus Burckhardt, Islamic art is gradually coming to be understood for what it is, namely a means of relating multiplicity to Unity by means of mathematical forms which are seen, not as mental abstractions, but as reflections of the celestial archetypes within both the cosmos and the minds and souls of men" $(1976,6)$. Critchlow's work connects all Islamic geometric pattern to a metaphysics of number, irrespective of where or when the pattern in question was used; he echoed Ardalan and Bakhtiar when they wrote, "these shapes, as the personality of numbers, 
are understood by traditional man as aspects of the multiplicity of the Creator" (1976, 40). In contrast, Grabar, in Mediation of Ornament says, "There does not exist, to my knowledge, a single instance justifying the views that the Muslim community... as opposed to individual thinkers, understood mathematical forms as symbolizing or illustrating a Muslim cosmology" (1992, 151). Gulru Necipoglu, historian of Islamic art, graciously offers a middle position:

Although this [the geometric mode representing Sufi or esoteric cosmology] may have been true in some cases, the [essentialist] authors showed no attempt to contextualize their arguments or to demonstrate through primary sources the ways in which geometry was interpreted in specific historical settings. Their universalizing generalizations were based on conceptual categories freely borrowed from a wide variety of Sufi texts without regard to time and place, or to the cultural mechanisms that informed the assumed connection between visual aesthetics and Sufism. $(1995,79)$

Thus while the association between these complex decorative geometric patterns and the Sufi concept of tawhid, or divine unity may exist in some places, the way the essentialists blanketed the entire region and time period with this meaning masks a wealth of diversity. It is this diversity, both spatially and culturally, that I seek to elucidate.

Necipoglu's own massive study of geometry and ornament, The Topkapi Palace Scroll: Geometry and Ornament in Islamic Architecture involves historical as well as semiotic analyses (1995). She uses the recent discovery of an architectural scroll, essentially a workshop patternbook containing instructions on how to create geometric patterns, as a point of departure. To her, the patternbook, produced in the late fifteenth/early sixteenth century, represents the culmination of a tradition of mathematicians working with artisans to develop and codify complex patterns for use 
in architecture. One theme that emerges from her discussion is the patronage of mathematics in courts where the geometric mode flourished. She states that the geometric mode spread when "its basic repertory became elaborated in different ways in various local courts that had acquired a taste for geometry" (1995, 132, emphases mine).

Alpay Özdural, another historian of Islamic art, following Necipoglu, has written on the relationship between mathematics and the geometric mode (1995, 1996). Özdural also states that artists needed to have advanced skills in geometry to execute these patterns, pointing out that:

approximation methods would have been accurate enough had the pattern been used as a single ornamental motif... however, when the task was to execute compositions of numerous interlocking patterns on large surfaces-which was usually the case in the ornamental arts related to architecture-the accumulation of inherent inaccuracies using approximation methods would have been intolerable. Under such circumstances, the correct [mathematical] solution would answer the need" (1996, 201).

The crucial position then seems to be that the accumulation of evidence, in the form of sparse existing textual material and anecdotal evidence, leads to the assumption that activity in mathematics (and the related exact sciences, which includes astronomy) preceded the use of the geometric mode in architecture in time and place. Causation is implied by these positions, therefore leading to the real question: did the one need to be present and established for the employment of the other? Without consideration of the spatial context, a case can be made to support these hypotheses, as shown in figure 1.2. In the figure, the use of the various types of complex decorative geometric patterns in architecture spike after the greatest occurrences of activity in mathematics 
and astronomy, two closely allied disciplines, in the eleventh century. This would support the notion that activity in mathematics precedes the use of the geometric mode. But another set of associations emerges after a comprehensive examination of the spatial relationships between scientific activity and use of the geometric mode. I explore these varied associations in the discussion section.

Necipoglu, in addition to discussing associations with math and science, develops possible meanings of geometric pattern with respect to political and theological influences (1995). One of her most important hypotheses, that Sunni ruling groups in Syria in the eleventh and twelfth centuries used the geometric mode to reinforce a specific doctrinal position, has been reinforced and elaborated on by Tabbaa (2001).

In the discussion I examine this hypothesis in great detail, via a thorough spatial analysis. Crang, a cultural geographer, states the ultimate difference of the geographic perspective: “"culture', however defined, can only be approached as embedded in real-life situations, in temporally and spatially specific ways...this is the contribution of geography-insisting on looking at cultures (plural) as locatable, specific phenomena" $(1998,1)$. While Necipoglu and Tabbaa try to manage this textually, the nature of my spatial data allow for a scale of analysis they did not attempt. They produced no maps, which I do in abundance, and which allow for a complex type of overlay analysis. Only this spatial analysis shows that the hypotheses produced by others may not provide all the answers, nor even ask all the right questions. 


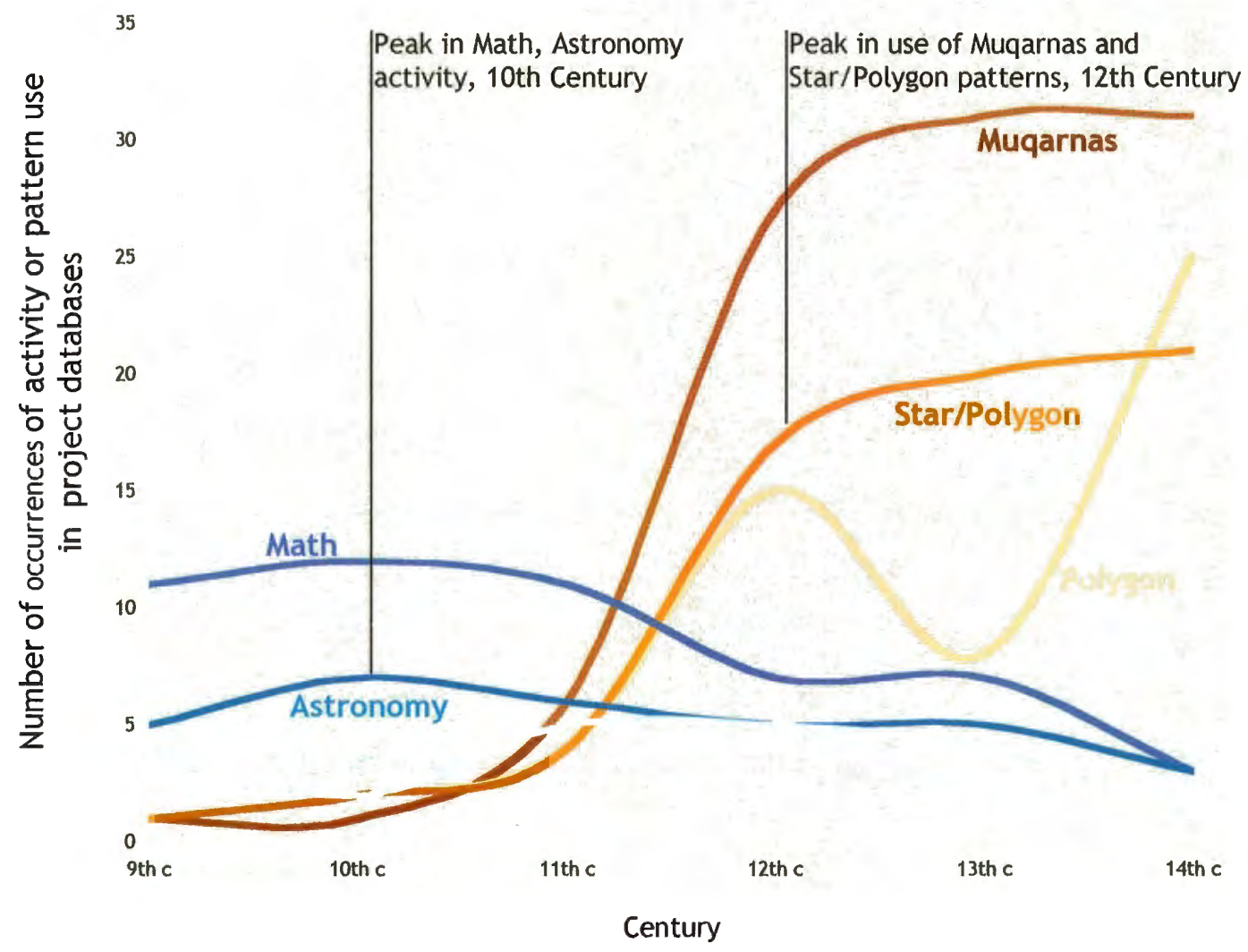

Figure 1.2 The chart shows use of the different forms of the geometric mode compared to other types of cultural activity - math, astronomy, and philosophy. The height of the use of geometric styles in architectural decoration follows that of math and astronomy. 


\section{Importance and Role of Cartography}

Many cultures, ideas, and processes are relevant to this discussion; thus I need a device to organize the many elements. Fortunately, cartography is perfectly suited to this task. Robinson states "the combination of the reduction of reality and the construction of an analogical space is an attainment in abstract thinking of a very high order indeed, for it enables one to discover structures that would remain unknown if not mapped" $(1982,1)$. Accordingly, the outcome of this project is not text alone; I have produced a series of complex maps used in analyzing the relationships between the geometric mode and other cultural phenomena.

For communicating difficult, multi-faceted concepts with spatial parameters (albeit shifting ones), maps are unparalleled; many variables can be examined simultaneously within the map structure, and images reveal things not often apparent in prose. "The map is perhaps the most sophisticated form yet devised for recording, generating, and transmitting knowledge" (Cosgrove 1999, 12). Maps lend legitimacy to the subject at hand through their visual sophistication, speak with authority, and reflect the cultural circumstances of their making (Wood 1992). Indeed, maps often serve as the basis for metaphors involving disparate topics like language, frameworks, minds, theories, culture, and knowledge (Turnbull 1993); that I will use them is especially apt, as this project requires the synthesis of ideas and information from many fields. 
The maps I created for this project developed out of the belief that maps are unique in their ability to reveal relationships that lay hidden within a great complexity of data. Norman Thrower, a cartographic historian, says it best:

In the modern world the map performs a number of significant functions as a necessary tool in the comprehension of spatial phenomena; a most effective device for the storage of information... and a fundamental research tool permitting an understanding of distributions and relationships not otherwise known or imperfectly understood." (1996, 1; emphasis mine)

The great expanse of space and time covered by this project necessitates a

cartographic approach, which ultimately enables an analysis of these data that has heretofore not been undertaken.

\section{Justification}

The desire to elucidate cultural issues both for their own sake and in order to place belief systems into a richer and more nuanced context lies at the heart of this project. While cultural geographers are calling for more humanism and more synthetic research, they are also stressing the importance of the geography of religion. Park, in 1994, in the first survey of the subfield of geography of religion since the 1970s, characterizes it as "embryonic...and has great potential" (286). Marvin Mikesell, a huge figure in cultural geography, states:

Unlike language, religion may have a prominent, visible manifestation in landscapes, but this is not the only reason why religion is important to us. Religion, like language, is a system of communication and a mechanism that promotes integration when it is not promoting conflict. The distribution of any faith poses questions about its origin, propagation, and frontiers. Religion is a value system that fosters and inhibits human activity and so should be a major concern of human geographers" $(1994,439)$. 
Islam and its many local variants form a complex distribution, and one cannot really extricate the religious aspects of Islamic culture from non-religious ones. Therefore my project, while not explicitly about the geography of religion, will by necessity illuminate similar concerns.

My project is clearly focused on an Islamic world located long ago. In order to cement the relevance of such an inquiry, it is important to connect the past to the present. Don Mitchell states that studying culture history has valuable ramifications for understanding contemporary culture, such that "it is essential...to try to understand the construction of culture historically—or better, historical geographically—for it is only by understanding how these battles over culture have been determined over time by the material geographical conditions within which they occur, that we can begin to understand the contemporary shape of the cultural world" $(2000,12)$. Barnes and Duncan also provide grounds for my investigation: "[the landscape] also becomes detached from the intentions of its original authors, and in terms of social and psychological impact and material consequences the various readings of landscapes matter more than any authorial intentions. In addition, the landscape has an importance beyond the initial situation for which it was constructed, addressing a potentially wide range of readers" $(1992,6)$. The "initial situation" in this case cannot have anticipated that Islam would become the fastest growing religion in the world, nor that the "wide range of readers" would come to include a geopolitically polarized East and West. 
The particularity of popular and academic Western perceptions of Islam today forms an important backdrop for this project. Characterizing this perception, Powell, an art historian, states that we are in a time when "Islam is increasingly perceived as an alien and often hostile culture and the study of Islamic art is relegated to specialist museums and libraries" $(1998,135)$. It is thus important to bring work focused on the Islamic world into other contexts, like that of cultural geography, in order to provide more opportunities for positive exposure.

Orientalism, the seminal book by Edward Said, provides the historical background for much of the way the West conceives of, and in part creates, the Islamic world, both past and present; it has been examined by cultural geographers and anthropologists (Duncan and Duncan 1998, Jackson 1994, Mitchell,1989). An important (unstated) objective of the Orientalists was the creation and cultivation of an Orient populated by inferior, opposite, and cohesive (i.e., they are all the same) "others." The Orientalist agenda, knowingly or not, helped ease colonialists into power in the nineteenth century. The Orientalists "created" and perpetuated this "place," this "culture" to suit various agendas: "as a cultural apparatus, Orientalism is all aggression, activity, judgment, will-to-truth, and knowledge" (Said 1979, 204). One main Orientalist strategy was to conceive of the land and more importantly the culture of Orientals as one big unit, a block, such that all Muslims are Arabs and all Arabs are Muslims. Said elaborates on the mechanics of this process:

On the one hand, Orientalism acquired the Orient as literally and as widely as possible; on the other, it domesticated this knowledge to the West, filtering it through regulatory codes, classifications, specimen cases, periodical reviews, dictionaries, grammars, commentaries, editions, translations, all of which 
together formed a simulacrum of the Orient and reproduced it materially in the West, for the West. The Orient, in short, would be converted from the personal, sometimes garbled testimony of intrepid voyagers and residents into impersonal definition by a whole array of scientific workers. It would be converted from the consecutive experience of individual research into a sort of imaginary museum without walls, where everything gathered from the huge distances and varieties of Oriental culture became categorically Oriental. It would be reconverted, restructured from the bundle of fragments brought back piecemeal by explorers, expeditions, armies, and merchants into lexicographical, bibliographical, departmentalized, and textualized Orientalist sense. (1979, 166; emphasis mine)

In this way it is easier to digest, dismiss, or to appropriate the Orient for one's own purposes, because the massive generalization blurs all regional/cultural diversity, and robs the region/culture of its power of distinctiveness (something ostensibly reserved for the West). Said's work provides ample justification, indeed, shows that there is still a pressing need to embark on projects that seek to approach the Islamic world from synthetic, holistic perspectives. By focusing on a small facet of the complicated political/historical/religious structures of the region, I hope to encourage ways of understanding the Islamic world that are based on careful investigation rather than didacticism or stereotyping. 


\section{REGIONAL AND ARCHITECTURAL HISTORY}

In this chapter I describe the major changes in the geographic boundaries of the Islamic world, and which ruling groups helped change these boundaries. Examples from the history of Islamic architecture anchor the discussion. I describe the foundations of the Islamic empire and its architecture, the fragmentation of the Caliphate, the efflorescence of architectural types and decorative modes, and the end of an extraordinarily complex era.

\section{Foundations}

The story begins with Muhammad, the Prophet of Islam. The final installment of the Abrahamic prophetic tradition came to Muhammad via the Archangel Gabriel over the course of twenty-three years, resulting in the body of revelation that would come to be codified as the Holy Qur' an. The year $622 \mathrm{AD}$ (or year one in the Muslim calendar, AH, after the Hegira), marked the flight of his small community from Mecca to Medina, where he built a house with a large courtyard and palm trees for shading the faithful at prayer. This arrangement became the basis for the Arabian (the central Islamic lands) style of mosque, and is called the congregational style.

After the Prophet's death, the leaders of the faith focused on geographic expansion. By 711 AD Muslim armies had reached Tashkent in the east, and in 732 AD were beaten by the Franks at Poitiers in the west, but had taken North Africa and Spain. Thus by the middle of the $8^{\text {th }}$ century, ruling from Damascus, the Umayyad caliphate stretched from the Indus valley and central Uzbekistan in the east to the Atlas and Pyrenees mountains in the west, as shown in figure 2.1. 


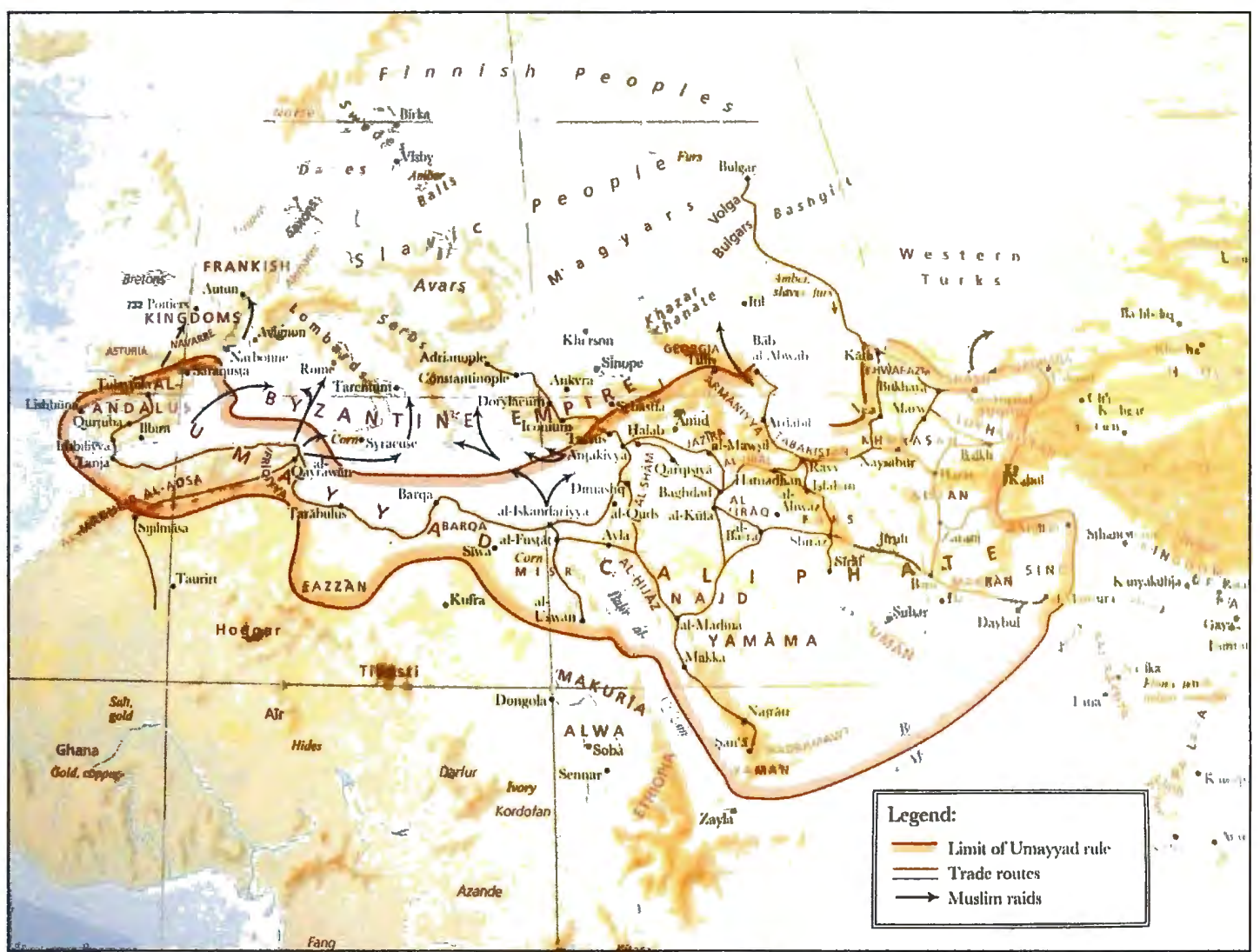

Figure 2.1 Extent of the Islamic empire in the mid-eighth century (Kennedy 2002, 8). 
The Umayyads, the first political rulers of the Islamic world, built mosques at Basra (665) and Kufa (670) in Iraq where they had garrisons, and the Umayyad Mosque of Damascus (715) at their capital. These mosques were built in the congregational style, which was suited to house the newly converted populations, who required large structures in which to gather and pray. Figure 2.2 compares a reconstruction drawing of the Prophet Muhammad's house and the Umayyad Mosque of Damascus and shows the prominence of the large courtyard in both. The Dome of the Rock in Jerusalem (691), also built by the Ummayads, was an exception from the first style of mosque; its architect used Byzantine buildings as models. Thus the first Islamic architects' repertoire consisted of the Arabian congregational style and a coopted regional style.

During this period, critical divisions formed in the political and religious foundations of the empire and the faith. The Shi'ites (Shi'a means party or faction) thought the caliphate should be determined by blood relationship to the prophet; they believed that Ali, the cousin and son-in-law of Muhammad, should have been granted leadership after Muhammad's death in 632. In this they went against the mainstream of Muslim political thought, represented by the Sunnis, who established the Caliphate as an elected office. The Umayyads, an aristocratic Meccan clan, managed to achieve dynastic possession. The massacre of Ali's son Hussein, his family, and his small force at Kerbala in 680 generated a surge of Shia resistance to Umayyad rule and transformed an initially political division into a religious one. In 750, descendants of 


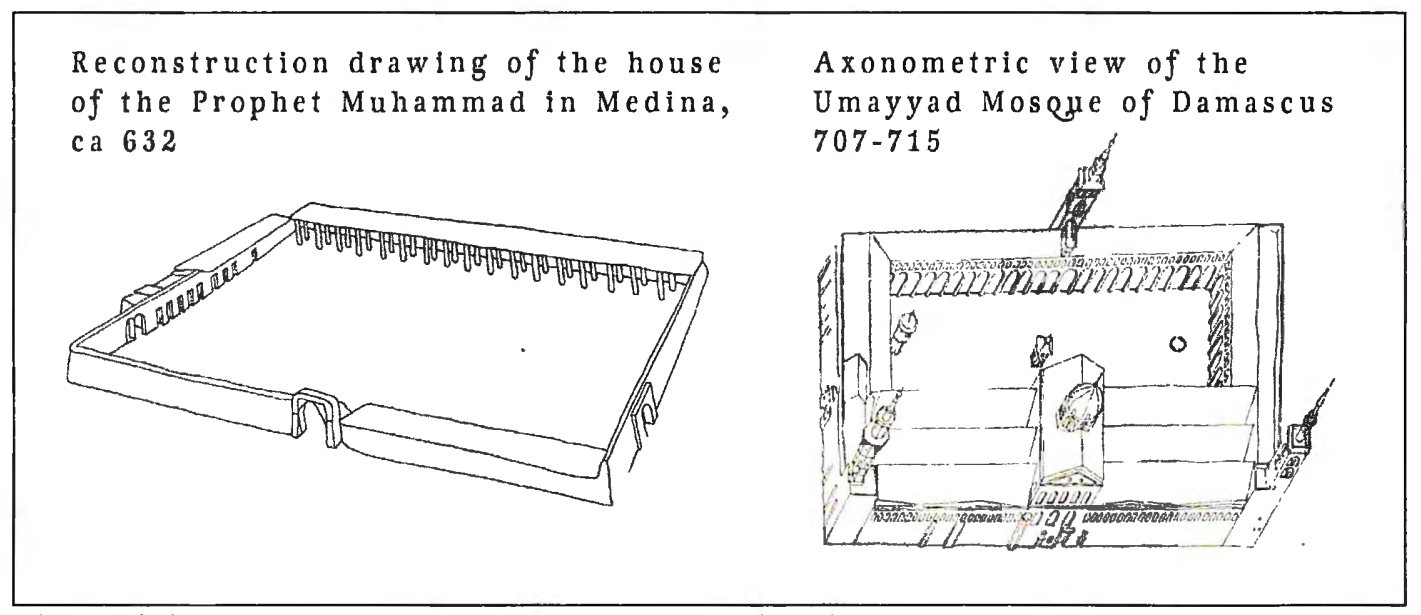

Figure 2.2 The origins of the congregational style mosque, as seen in the home of the Prophet Muhammad and the Umayyad Mosque of Damascus (Bloom and Blair 1997, $24,32)$. 
the Prophet's uncle, al-'Abbas, established the 'Abbasid Caliphate. Because of this relationship to the Prophet, the Shia supported the 'Abbasids in toppling the Umayyads but as time went on, withdrew their support. The power struggles between Sunni and Shia arise numerous times in the history of Islam, and take many forms.

The 'Abbasid Caliphate heralded a new era for the Islamic world, as "the conquered peoples...met and mingled as never before in the great Pax Islamica carved out by Arab arms, and a brilliant civilization was created" (Robinson 1982, 32). This phase was marked by consolidation and internal, rather than external, growth. Figure 2.3 portrays the extent of 'Abbasid influence in the early ninth century.

The shift in leadership from Umayyad to 'Abbasid was reflected geographically as well— the capital moved from Damascus to the newly built city of Baghdad (est. 762). The congregational style mosque was refined and exported from Baghdad to cities throughout 'Abbasid empire. The biggest of the early mosques were: the Great Mosque of Samarra (Iraq, 848-852), the Great Mosque of Qairawan (Tunisia, 836) and the Great Mosque of Ibn Tulun (Cairo, Egypt, 876-879), illustrated in figure 2.4. These mosques provided large urban populations of Muslims with places of worship that doubled as assertions of the power and confidence of the burgeoning Islamic leadership. As such, these mosques were all of the distinctly Islamic congregational style, as refined by the 'Abbasids, exhibiting no structural imprint of Byzantine or other influence. 


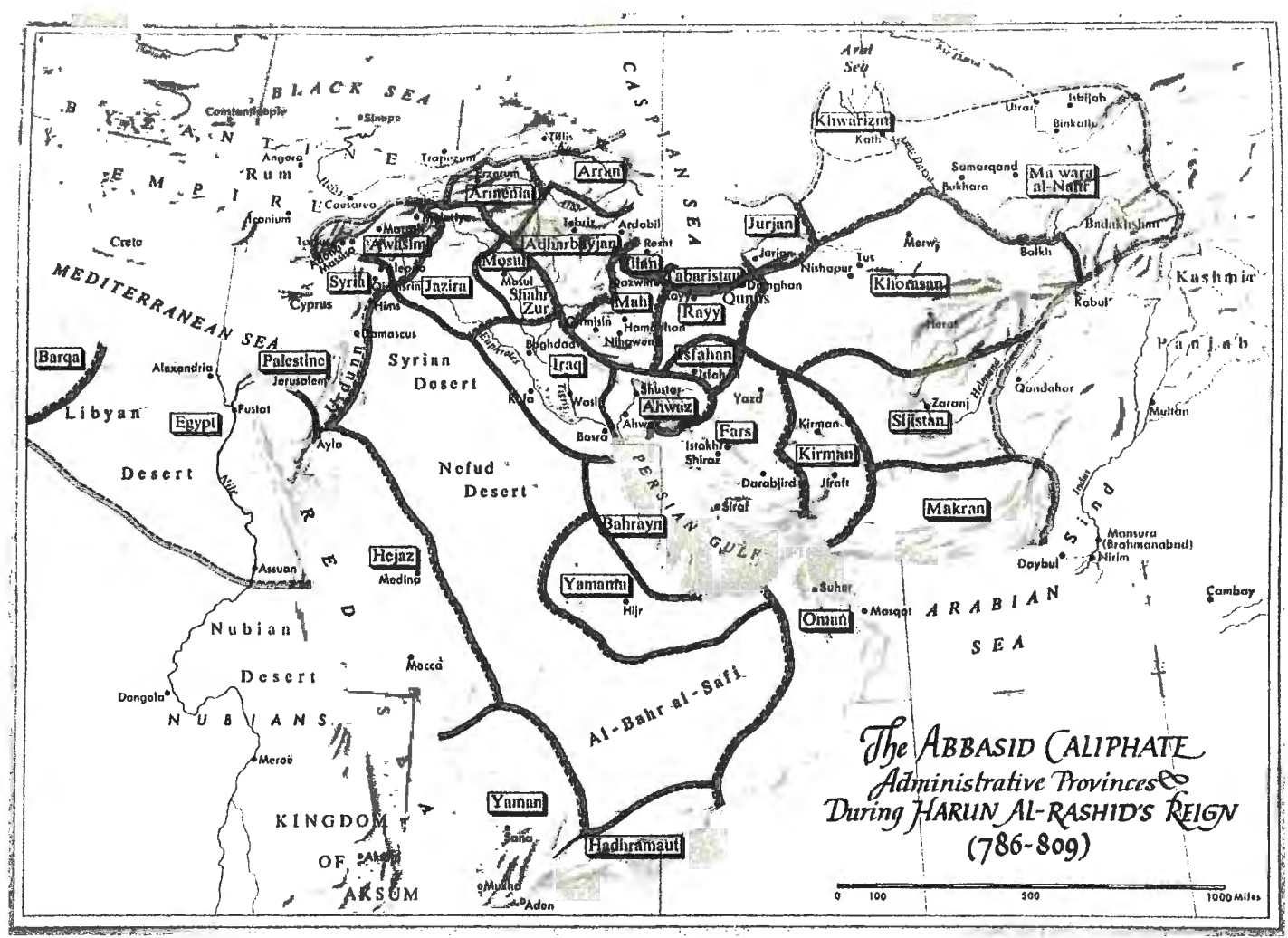

Figure 2.3 Extent of 'Abbasid Caliphate in the early ninth century (Roolvink 1957, 7). 

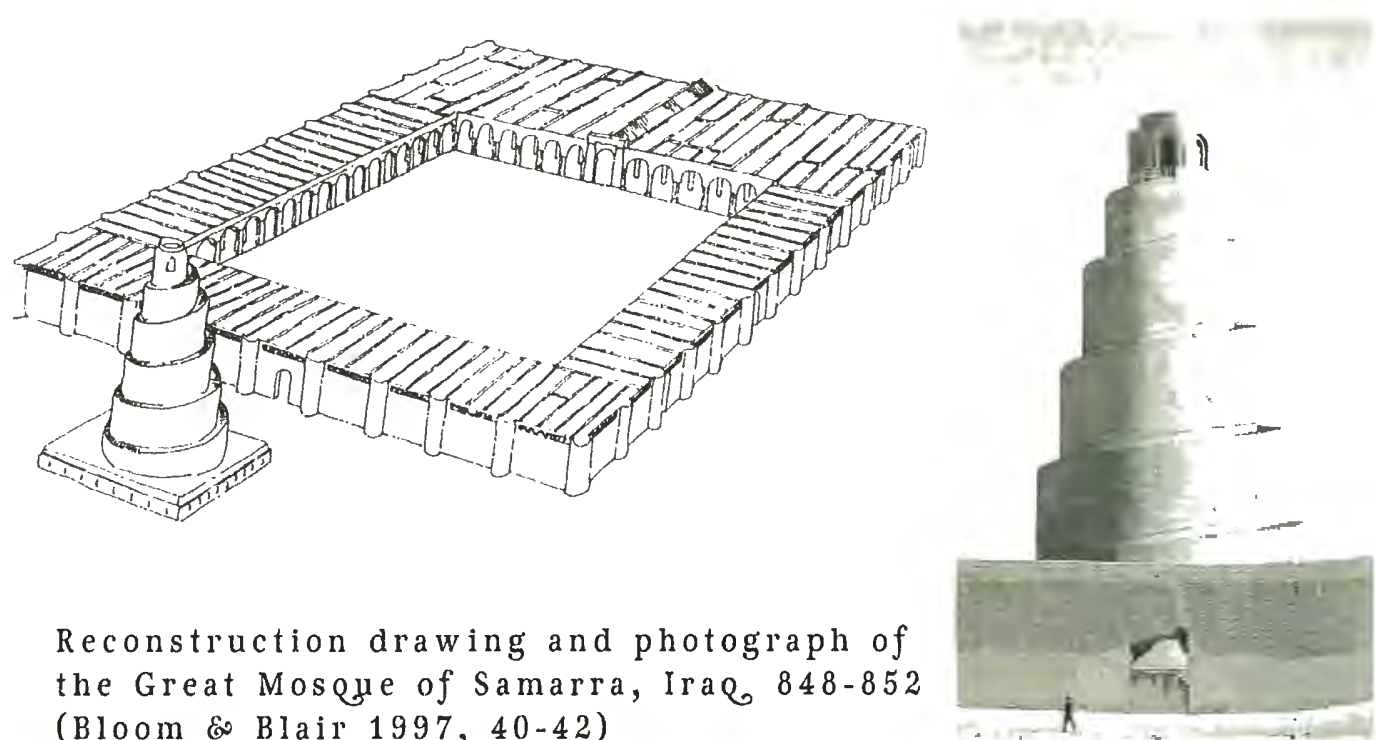

Reconstruction drawing and photograph of the Great Mosque of Samarra, Irab 848-852 (Bloom \& Blair 1997,40-42)

Views of the Great Moseje of Qairawan, Tunisia $836-875$

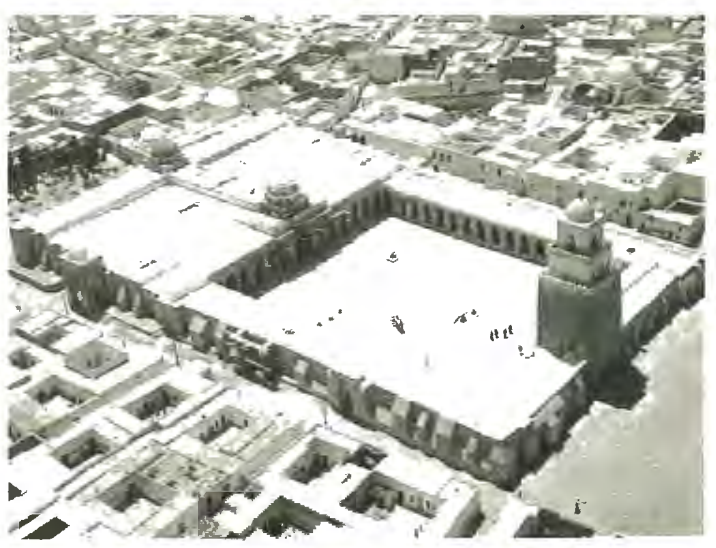

(Bloom E Blair 1997, 45-46)
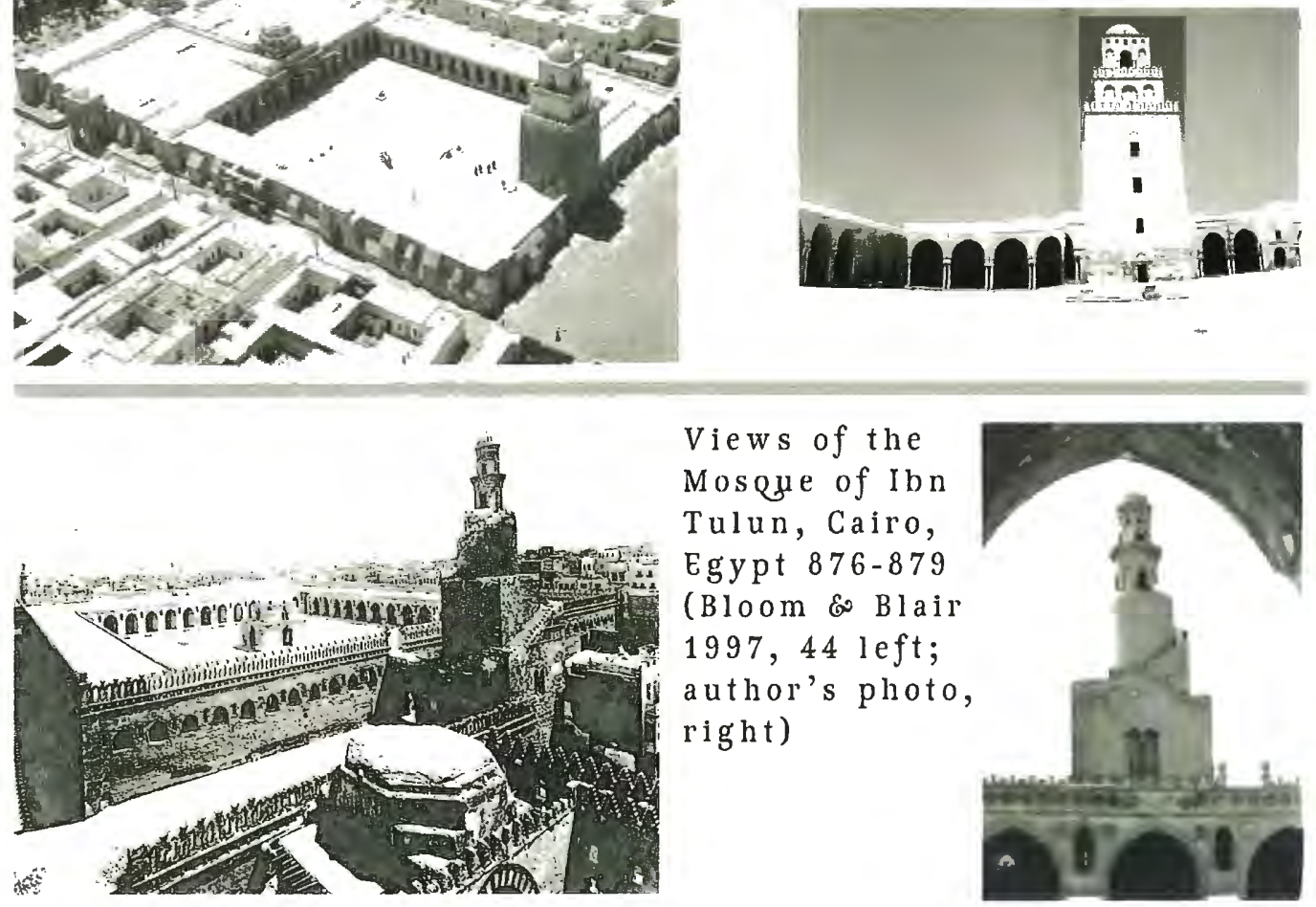

Figure 2.4 Congregational style mosques found throughout the 'Abbasid empire in the ninth century. 
This era in Islamic history saw the emergence not only of imposing mosques but institutions of learning, the pathways of international trade, and the mechanisms of sustained scientific inquiry.

\section{Fragmentation: Beginning of Period Covered by this Project}

In the late ninth and early tenth century, Islamic architecture came into its own, as the empire's power dispersed from Baghdad to many other regions where new architectural styles and decorative modes thrived. This moment in the history of the Islamic world - as the ninth century gave way to the tenth, as consolidation gave way to fragmentation - forms the earlier temporal boundary of my project.

In the ninth and tenth centuries, regional dynasties, such as the Idrisids and Aghlabids in North Africa, exerted local influence and gathered local support, but still recognized the authority of the 'Abbasid Caliphate. Similarly, in Persia, the Samanid

and Buyid dynasties (Sunni and Shia, respectively) established themselves. Figure 2.5 depicts the diminishing area under direct 'Abbasid rule. Figure 2.6 encapsulates the many ruling groups discussed in this section.

The tradition of tomb architecture began in this period, and the earliest surviving example is from the Samanids, a Persian dynasty that controlled Khurasan and Transoxiana (northern Iran and Uzbekistan) between 819-1005 (figure 2.7). The Persian dynasties wielded a great deal of power, and helped make Persian the second language of the Islamic world by heavily patronizing the arts and literature. In contrast to the congregational style of the central Islamic lands, they developed 


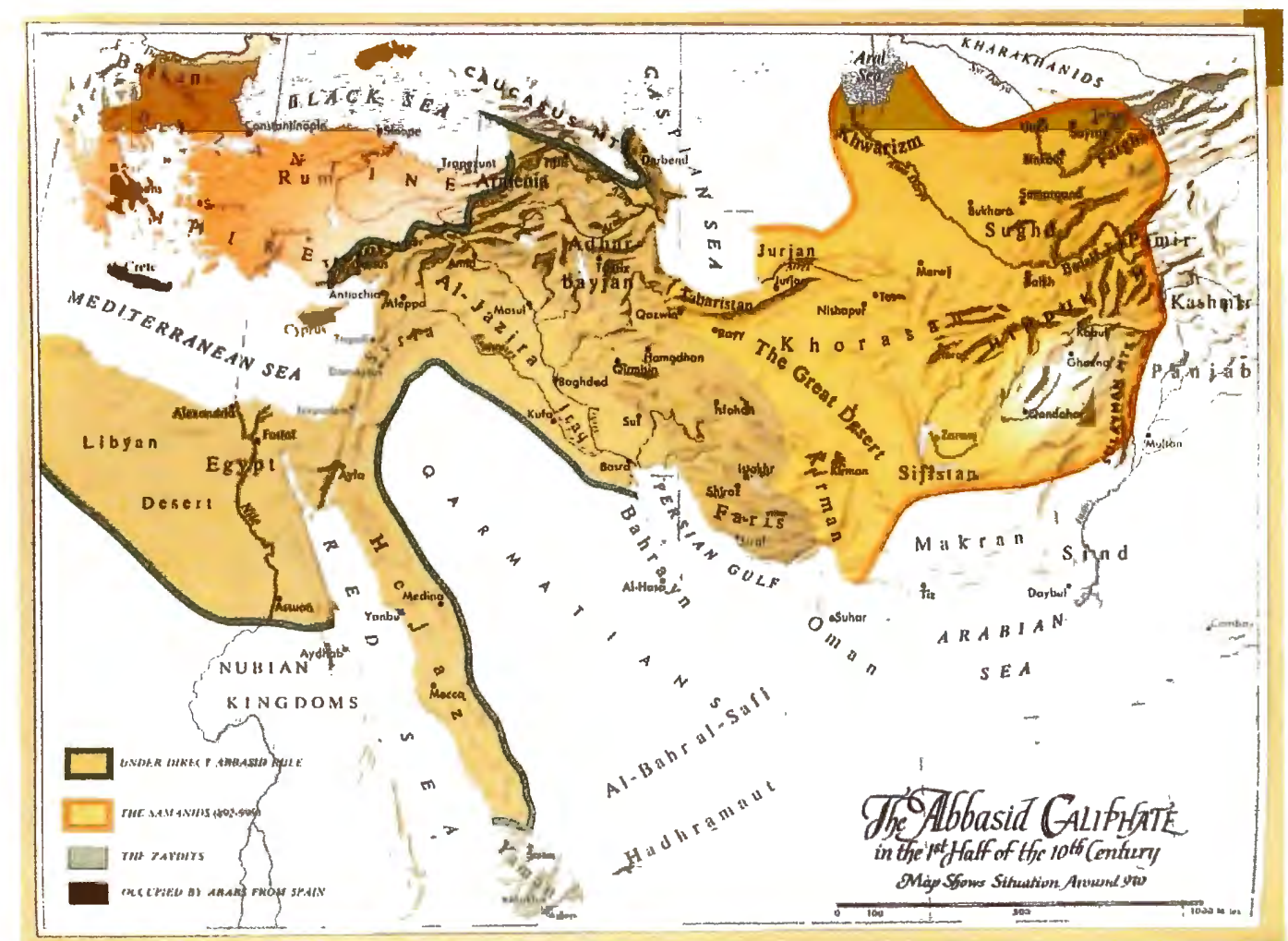

Figure 2.5 'Abbasid Caliphate and emerging dynasties (Roolvink 1957, 10). 


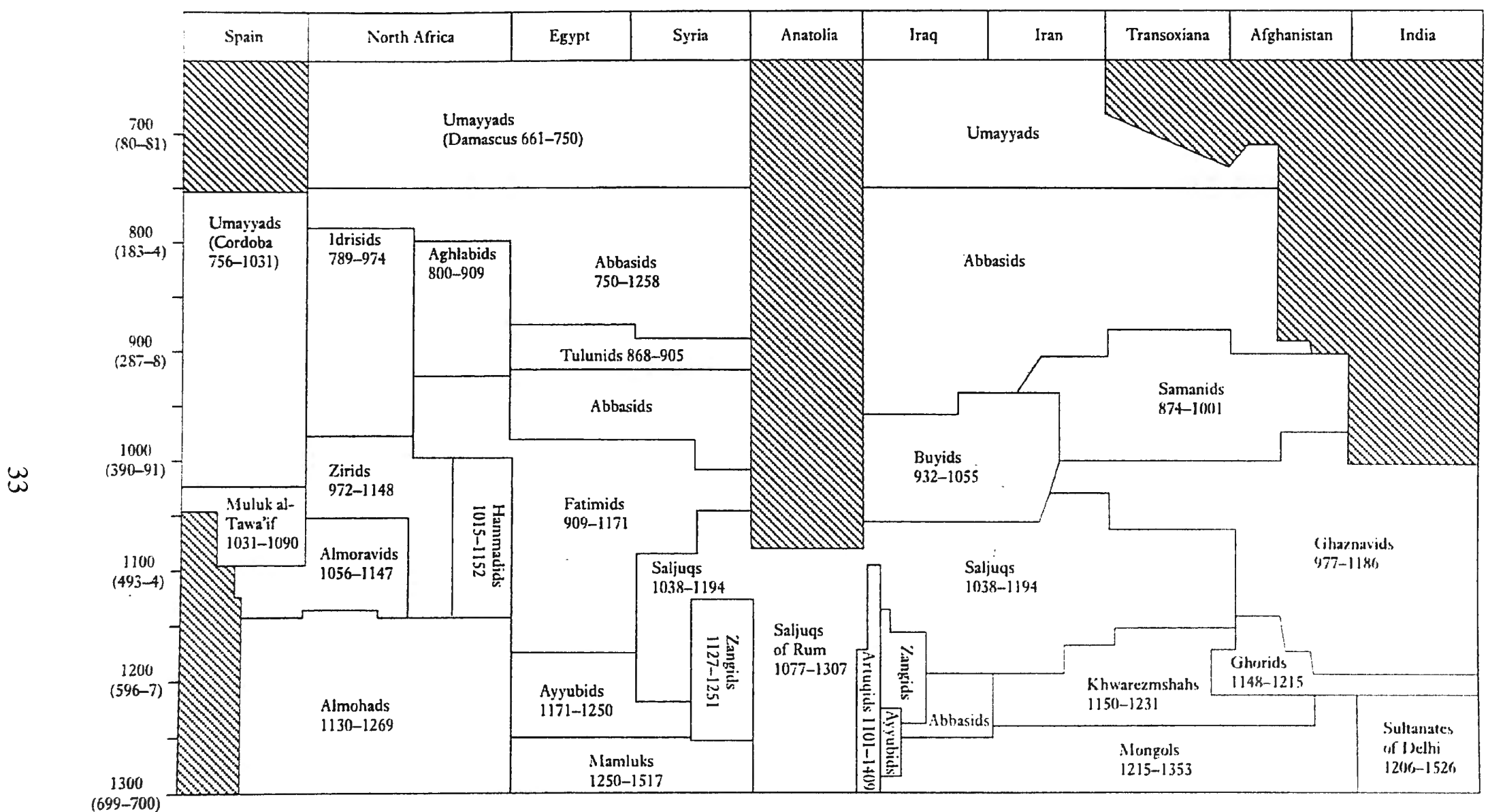

Figure 2.6 Chronological chart of the principal Islamic dynasties, 661-1300 AD (Ettinghausen 2001, xi). 


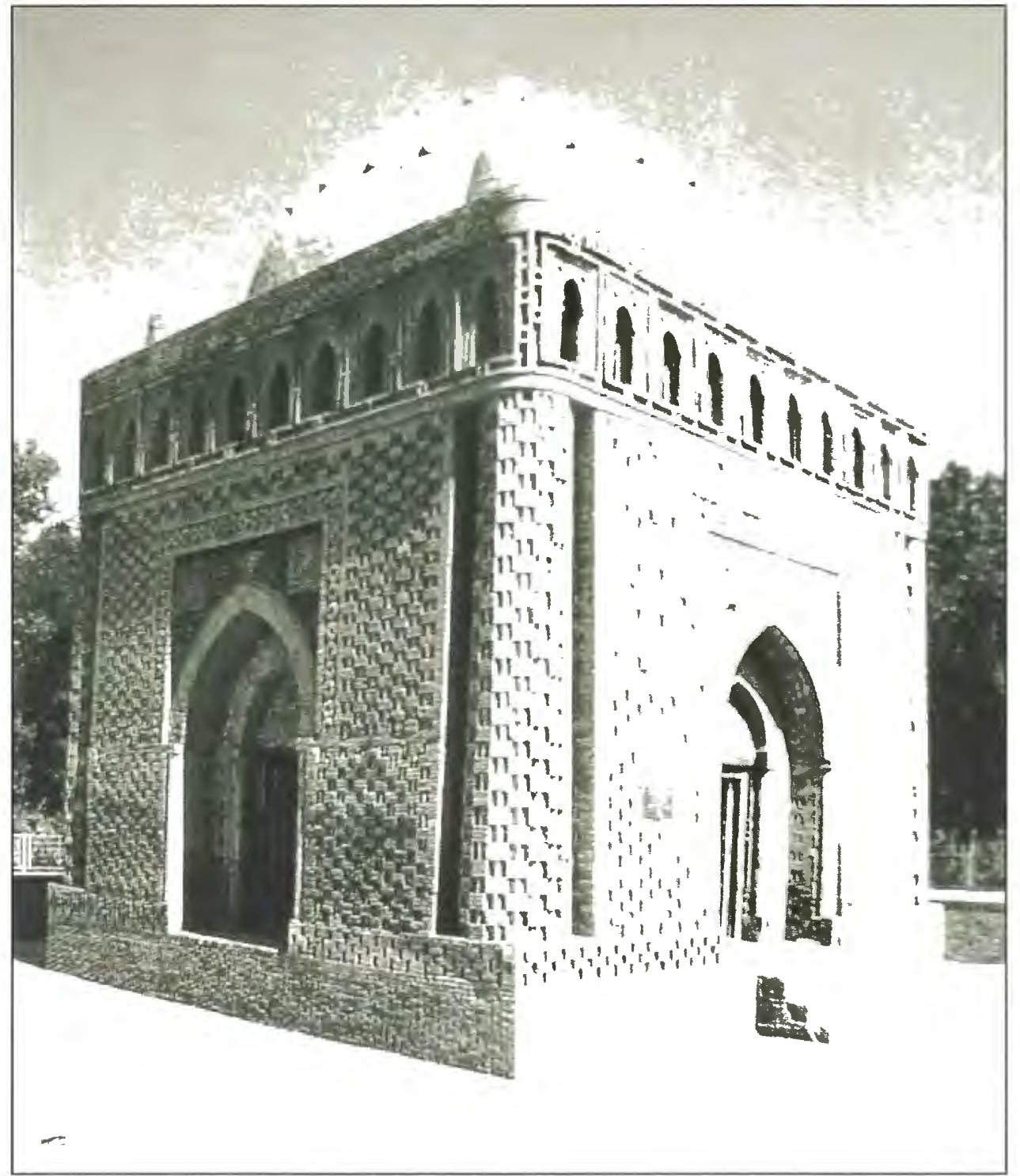

Figure 2.7 The Tomb of the Samanids (Bukhara, 920), the earliest example of Islamic tomb architecture to survive (Clevenot 2000, 91). 
another style of mosque, called the four-iwan type, based on the older regional architecture, employed for audience halls of the Persian kings (figure 2.8).

In addition to the influence of many regional dynasties, there were other forces at work that contributed to this period of division. In the $10^{\text {th }}$ century, the Fatimidswho were Shia and controlled North Africa, Syria, and south and west Arabiaestablished their own caliphate, as did the Spanish Umayyads in Cordoba (figure 2.9). These groups claimed descent from the Prophet and asserted their legitimacy over the 'Abbasids, challenging them openly. This massive breakup of the empire heralded changes in many aspects of the Islamic world, which I will examine in detail in the discussion section.

\section{Efflorescence: Focus of the Project}

A great many dynasties ruled contemporaneously to the three rival caliphates. The resulting diversity of rulers and geographic areas being ruled helped encourage the establishment of a variety of architectural styles and decorative modes. "The proliferation of centers meant that no single style of art or architecture predominated as the "Abbasid style had in the early period. Regional styles became more important" (Bloom and Blair 1997, 137). The nomadic invasions of the Turkic peoples in the late tenth and eleventh centuries partially account for the variety of regions under control of different leaders, in that they greatly affected the internal boundaries of the Islamic empire. Figure 2.10 portrays the later Fatimid Caliphate as well as regional dynasties that ruled in 1100; this map is but a snapshot of the great shifts in this period. 


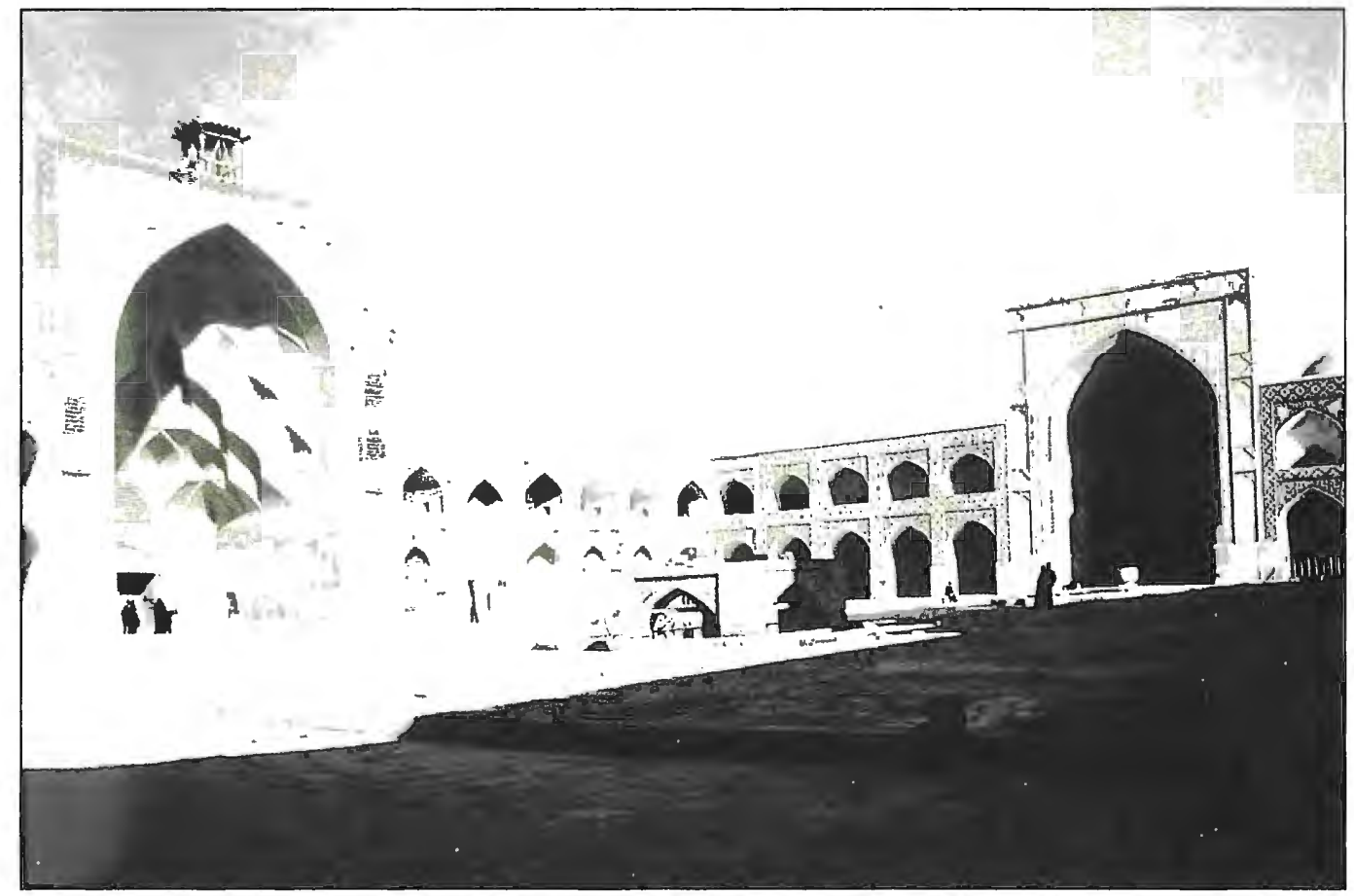

Figure 2.8 Courtyard of the Great Mosque of Isfahan, (twelfth century and later), showing north and west iwans (Bloom and Blair 1997, 155). 


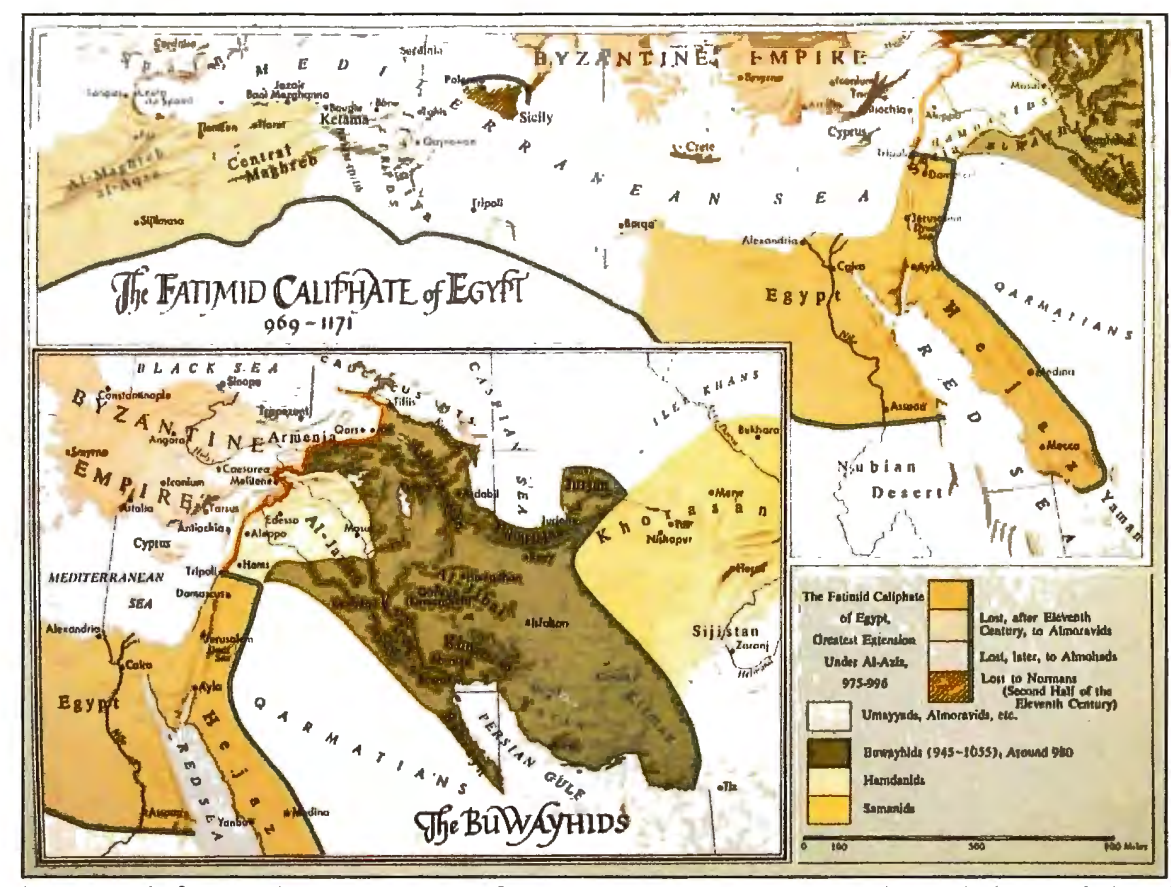

Figure 2.9 Ruling entities of the late tenth century (Roolvink 1957, 13).

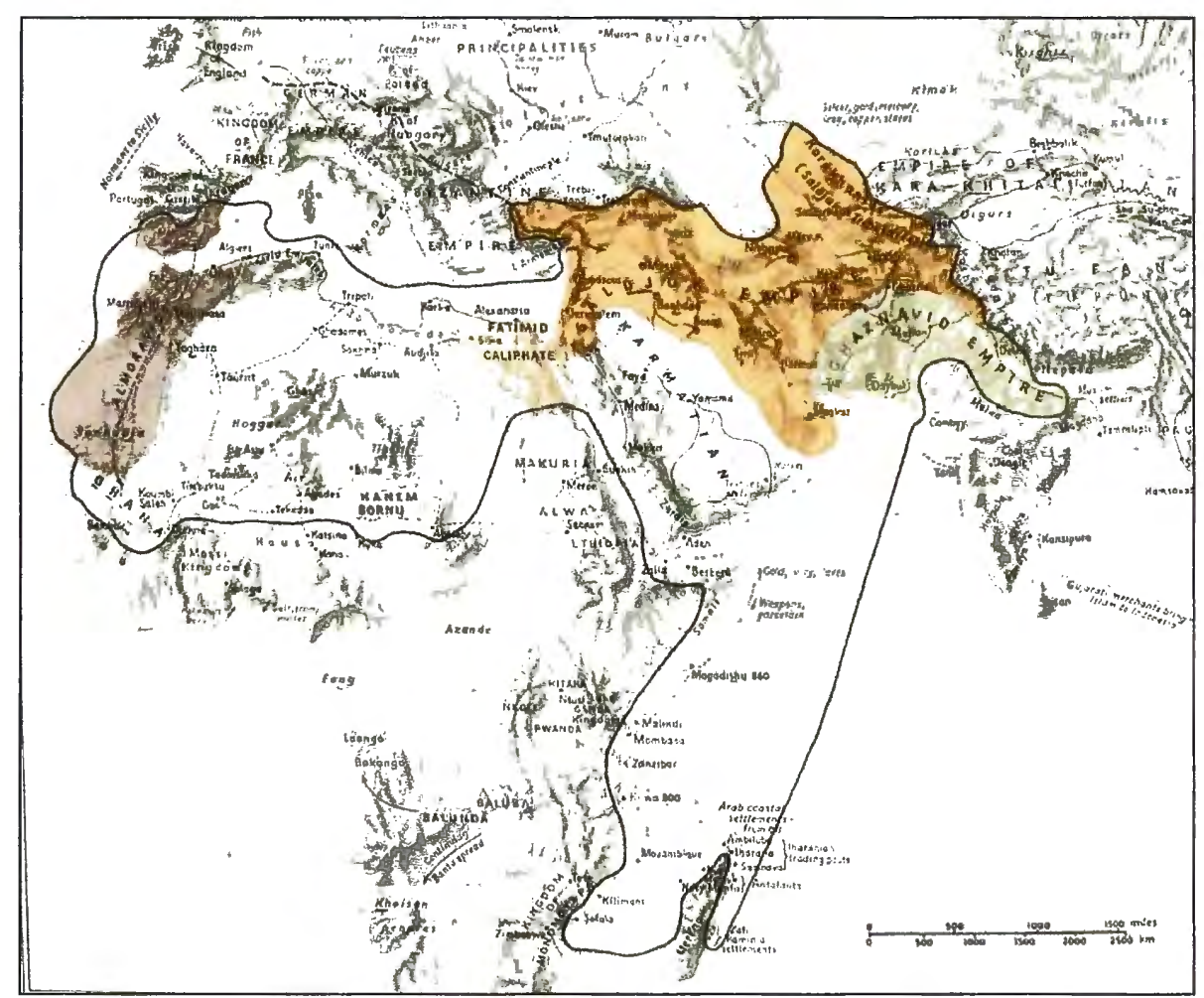

Figure 2.10 Almoravid, Fatimid, Seljuq, and Ghaznavid empires in 1100 (Adapted from Brice 1981, 9). 
Turkic tribesmen from Central Asia had begun to move into the Islamic heartlands, coming often as mercenaries, captured slaves, or even royalty. The Seljuqs were a Turkish princely family who came to rule over wide territories in Central Asia and the Near East from the early eleventh to the late thirteenth centuries. The Seljuqs were even powerful enough to establish multiple dynasties: the Great Seljuqs of Iraq, Persia, Syria, and Kirman, and the Rum Seljuqs of Anatolia. They were Sunni, and their ascendance meant decline for the Shi'ite Fatimids and Buyids (sometimes spelled Buwayhids). All three of these groups—the Buyids, Fatimids, and Seljuqs—created impressive monuments and used different types of decorative styles, illustrated in figures 2.11-2.13.

In this time period, the early $11^{\text {th }}$ to the mid thirteenth, the Ayyubid and Zangid dynasties in Syria and the Almoravid and Almohad dynasties in Spain and the Maghrib were developing significant regional power bases. They, too, built magnificent mosques, mausolea, and madrasas in distinctive styles as shown in figures 2.14-2.17.

The Mongol invasion, however, was even more influential than that of the Turks. Genghis Khan swept the eastern portions of the Islamic empire (Transoxania, Khurasan, and the Caucasus) under Mongol control in 1220-1225. Hulegu, his grandson, founded the Ilkhanid dynasty (also called the Ilkhanate). He controlled Central Asia by 1255, and in 1258 killed the last of the 'Abbasid caliphs. Figure 2.18 depicts the various 


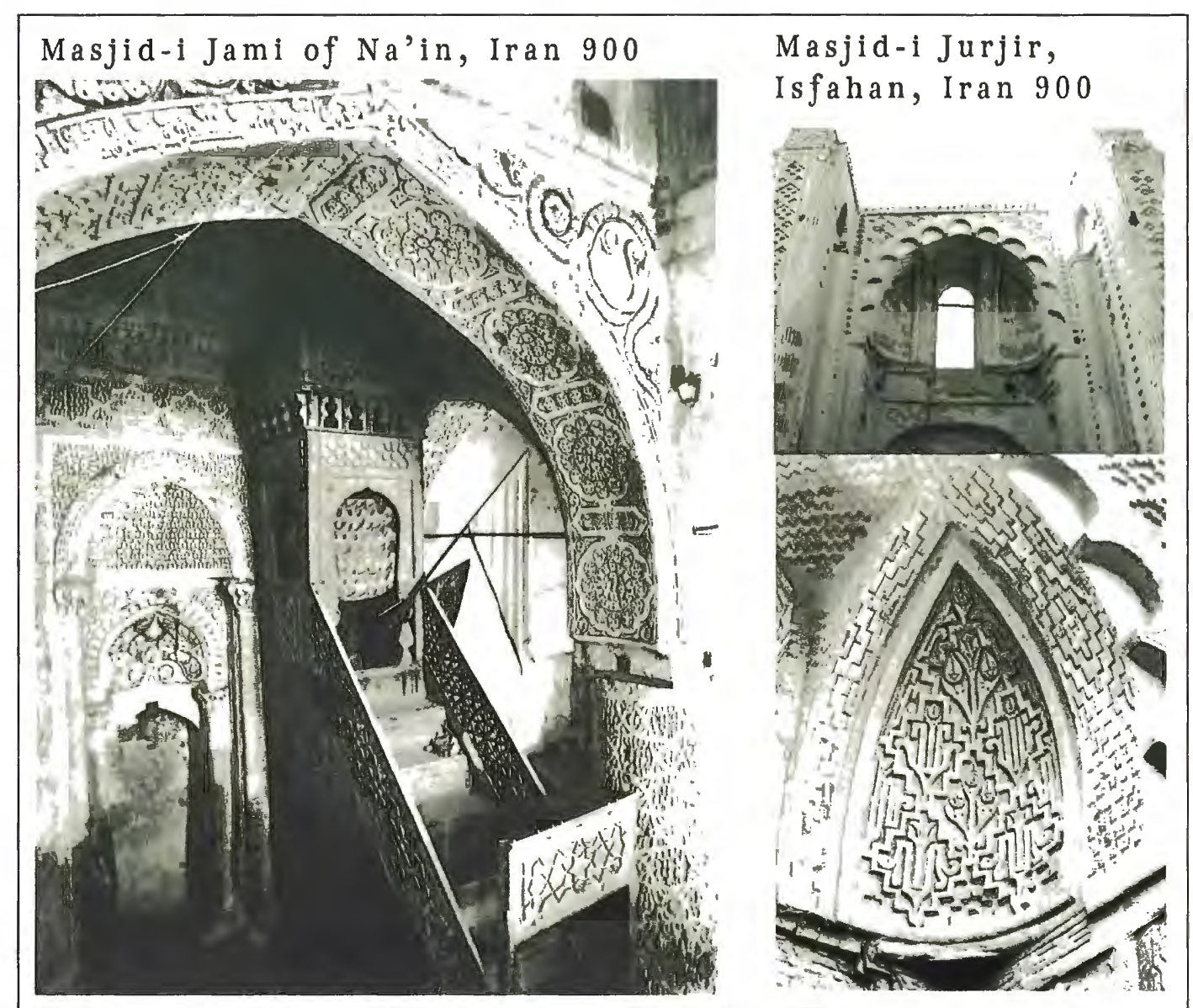

Figure 2.11 Examples of carved stucco (left) and stone decoration (right) in Buyid architecture (Ettinghausen 104,166, and archnet.org). 


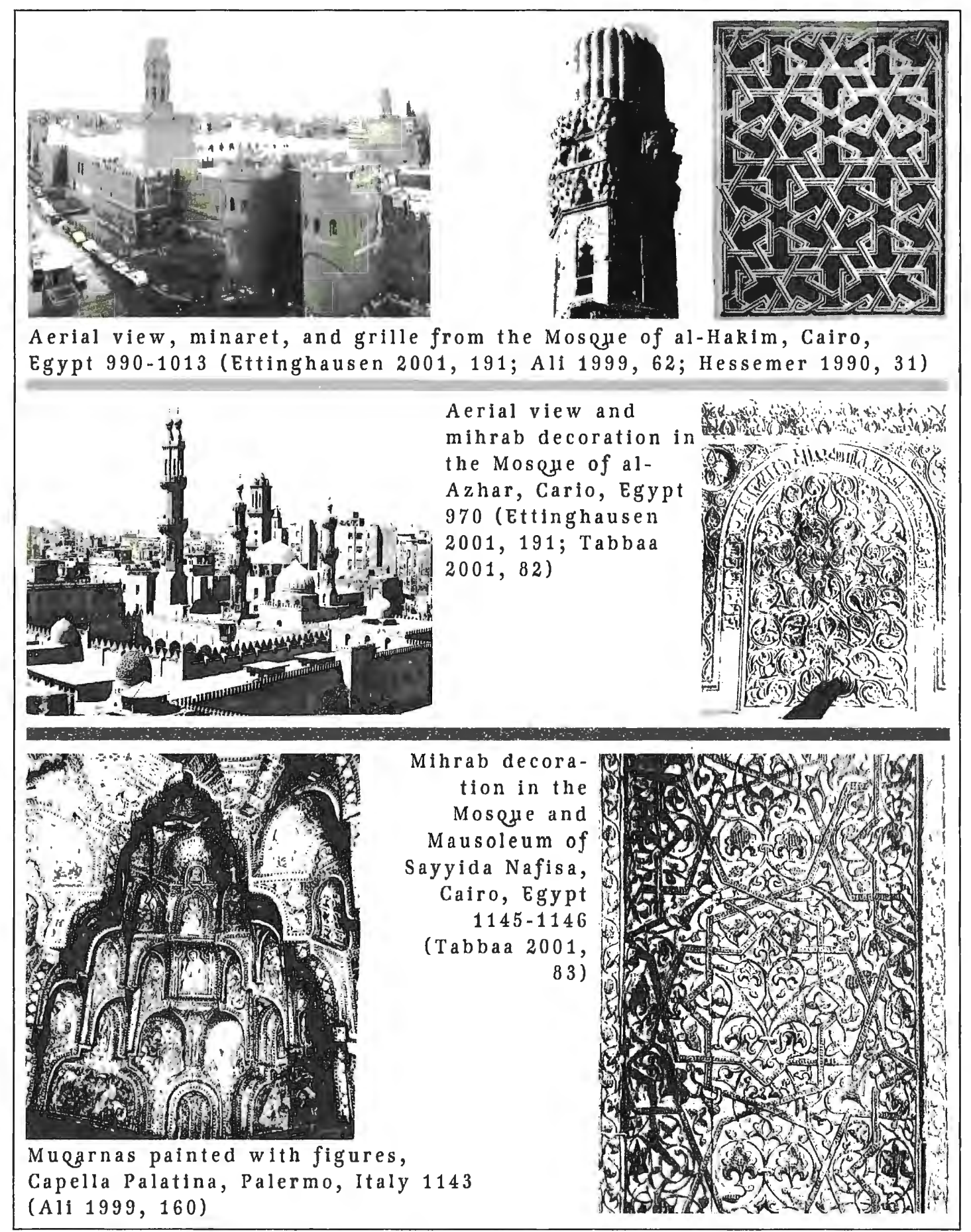

Figure 2.12 Examples of Fatimid architecture show the variety of decorative styles used. 


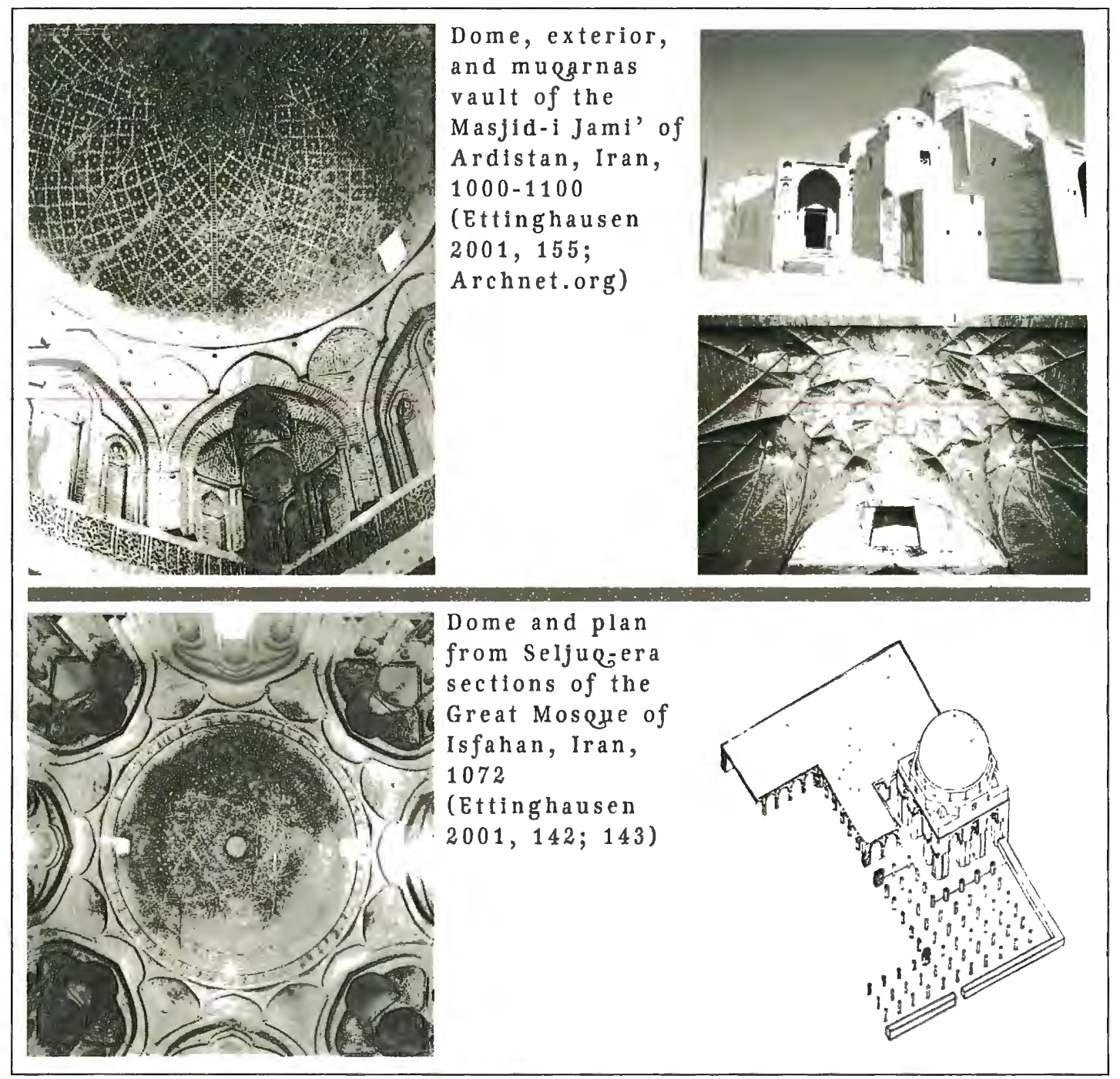

Figure 2.13 Examples of Seljuq architecture from Isfahan and Ardistan, Iran. 


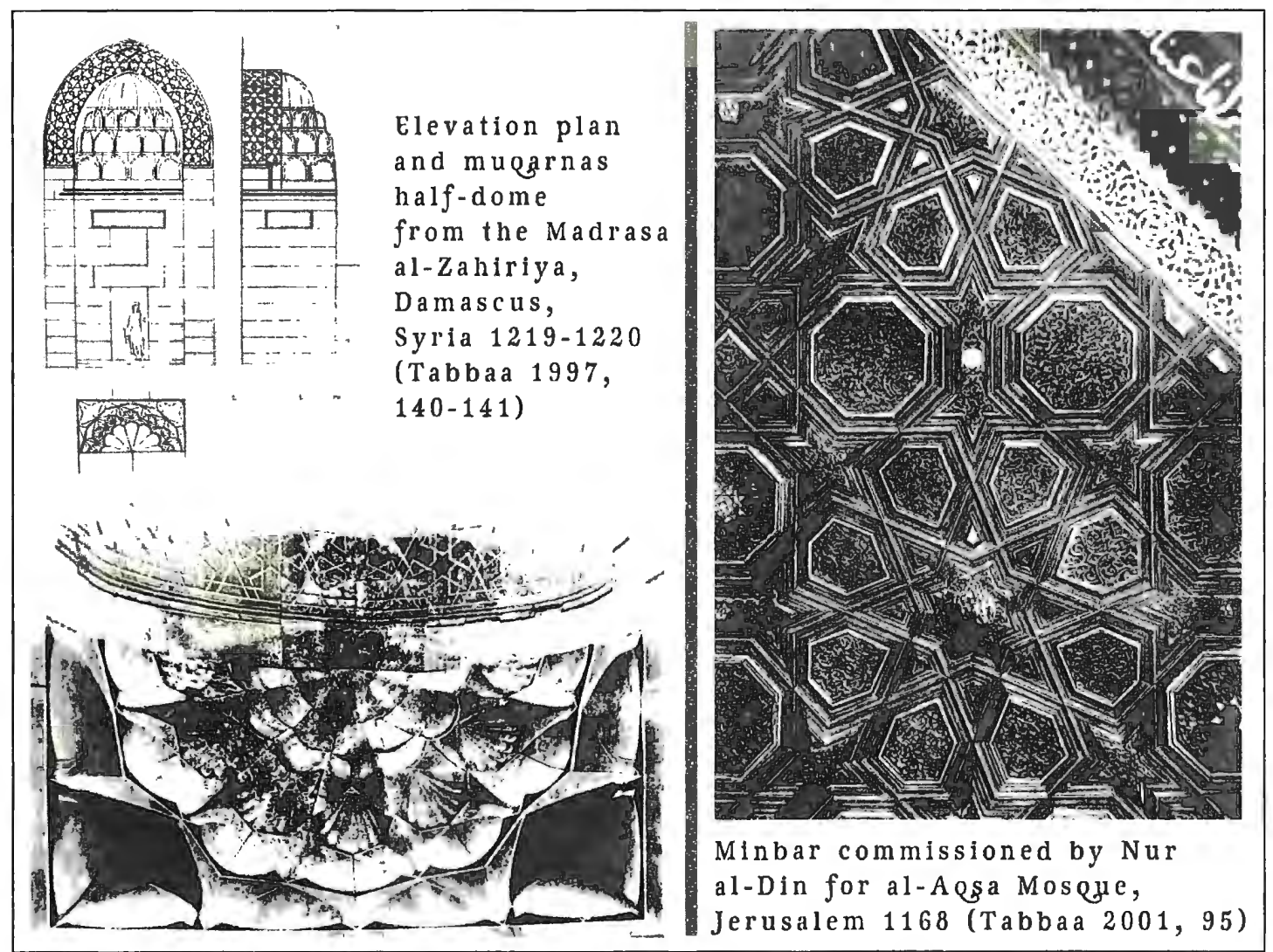

Figure 2.14 Examples from the height of Ayyubid architecture. 


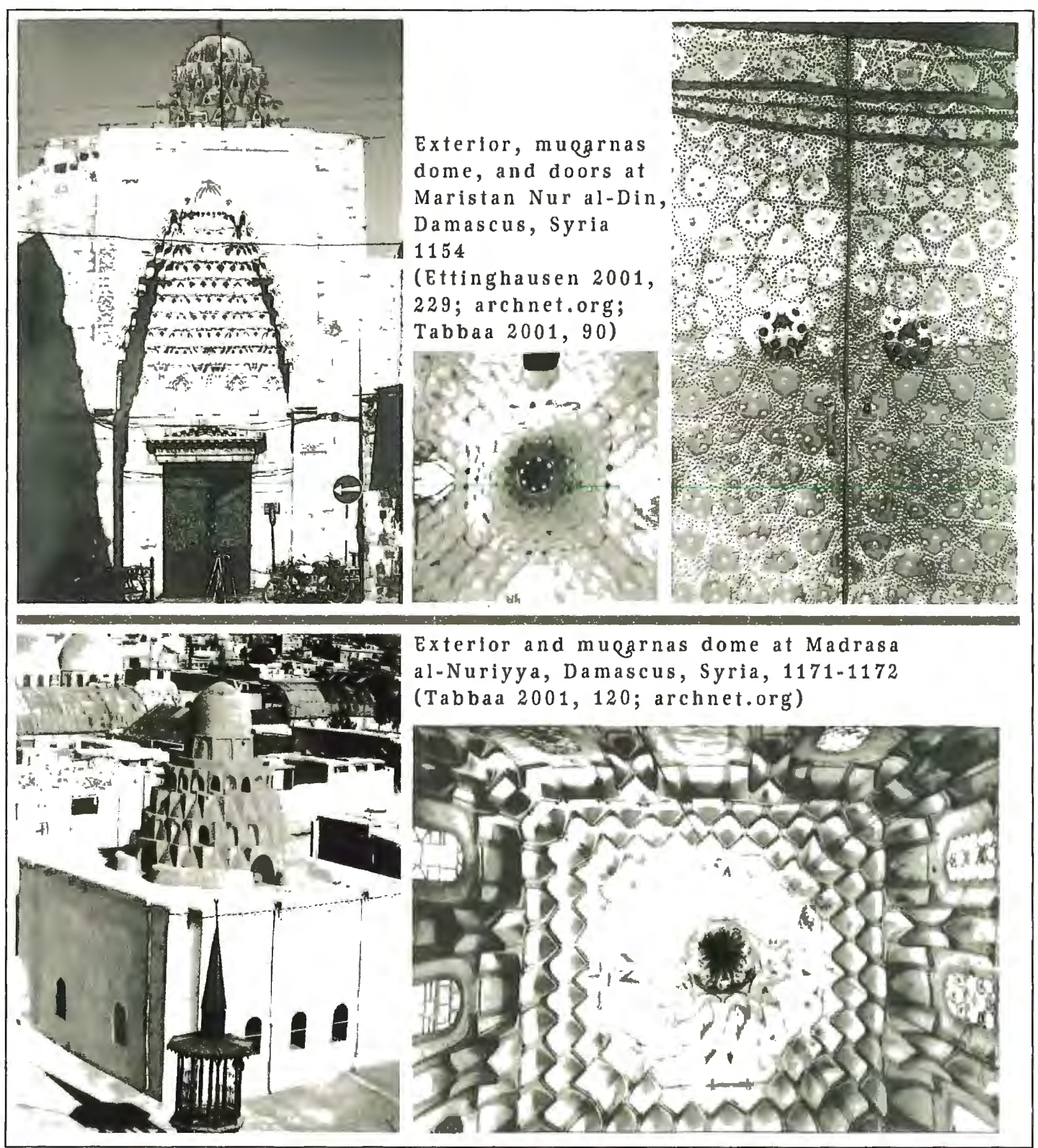

Figure 2.15 Distinctive interior and exterior muqarnas decoration as used in Zangid architecture. 


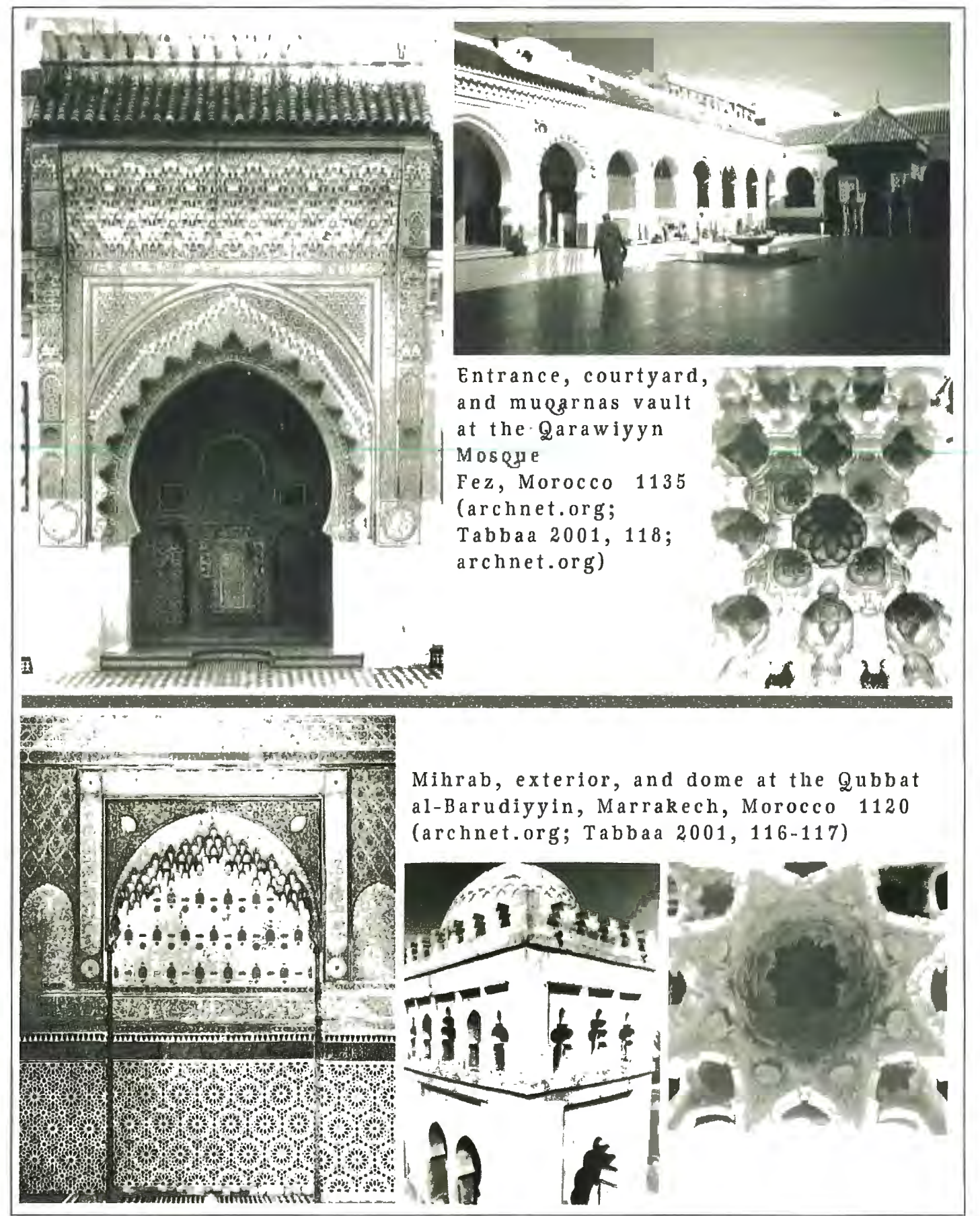

Figure 2.16 Examples of Almoravid architecture. 


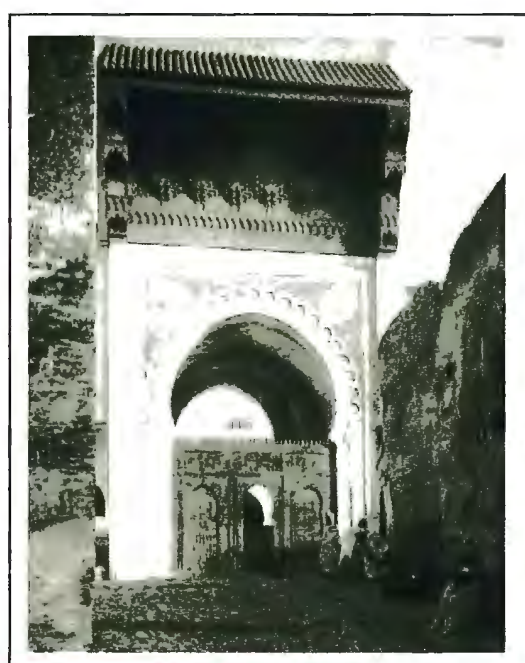

Mosque of al-Andalusiyyin Fez, Morocco, 1203-1207 (archnet.org)

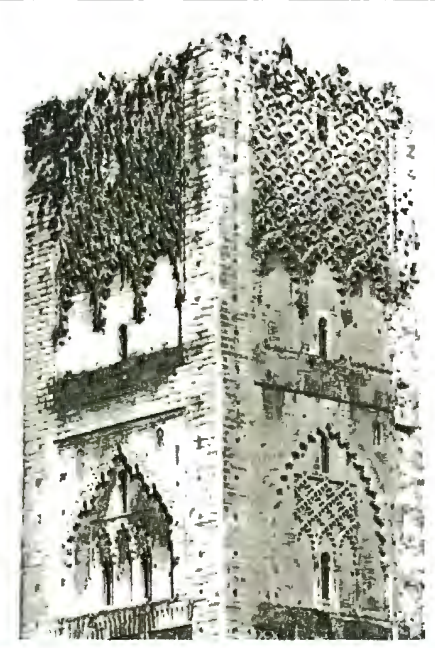

Mosefue of Hasan, Rabat, Morocco, 1191 (archnet.org)

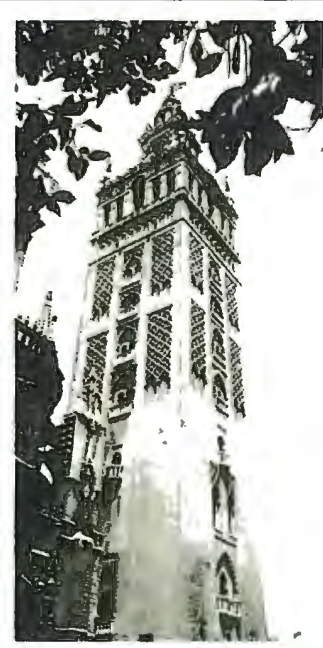

Great Mosque of Seville, Spain,.11721198 (archnet.org)
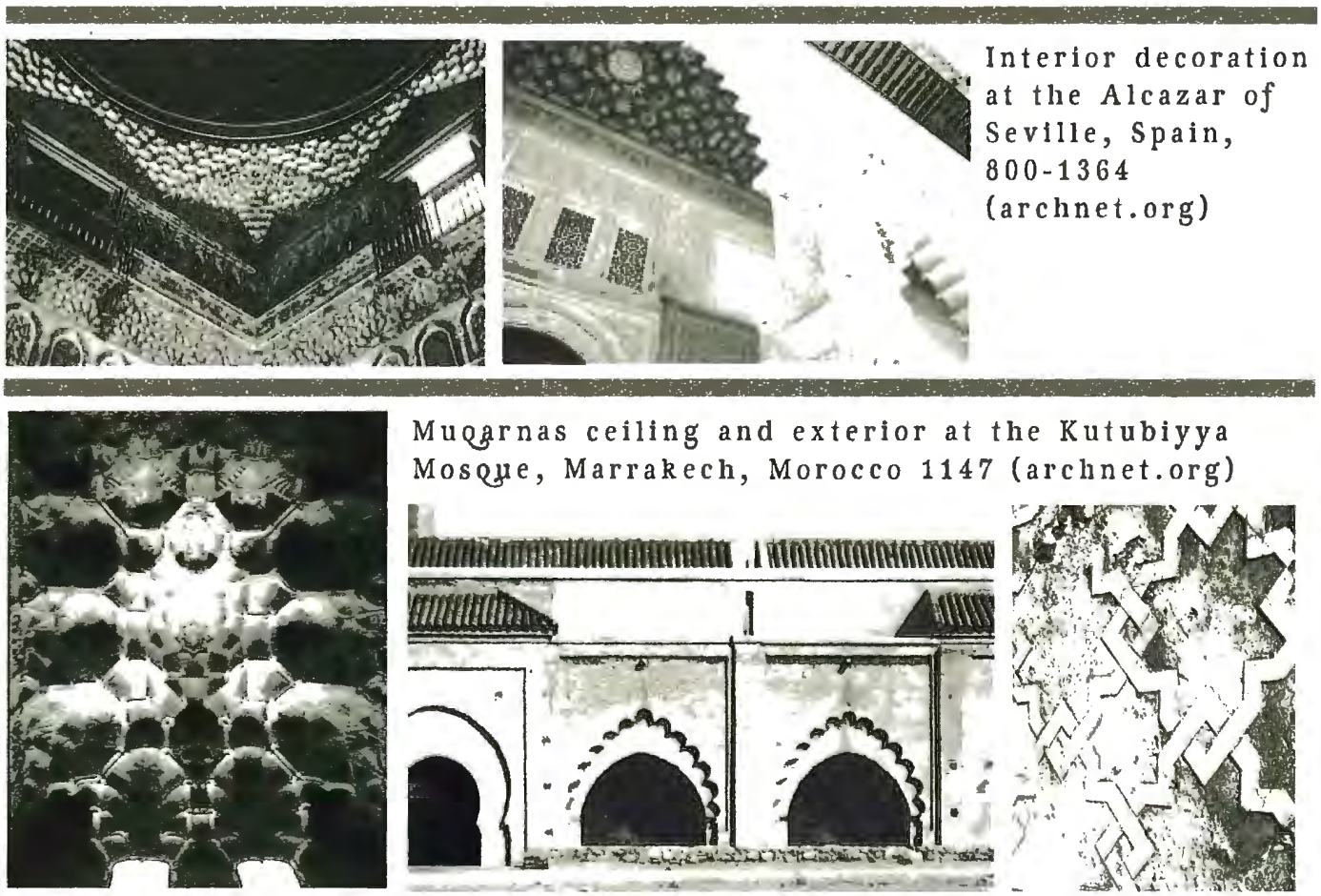

Mugarnas ceiling and exterior at the Kutubiyya Moseue, Marrakech, Morocco 1147 (archnet.org)

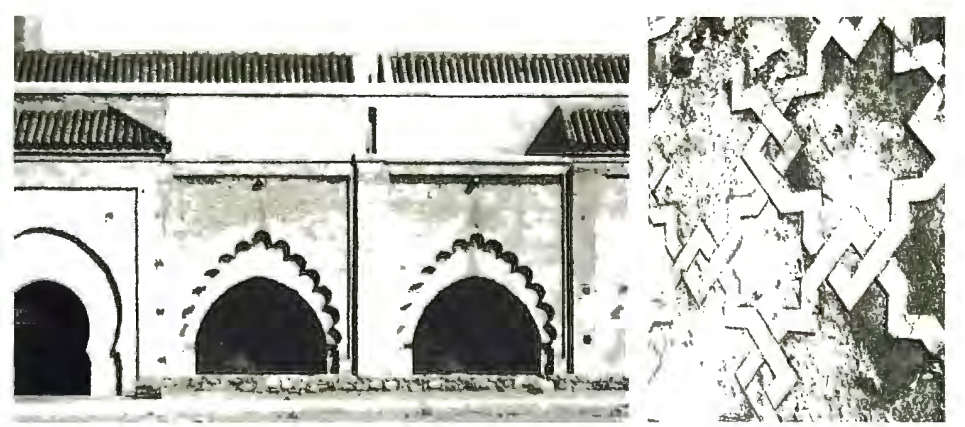

Figure 2.17 Examples from Almohad architecture. 


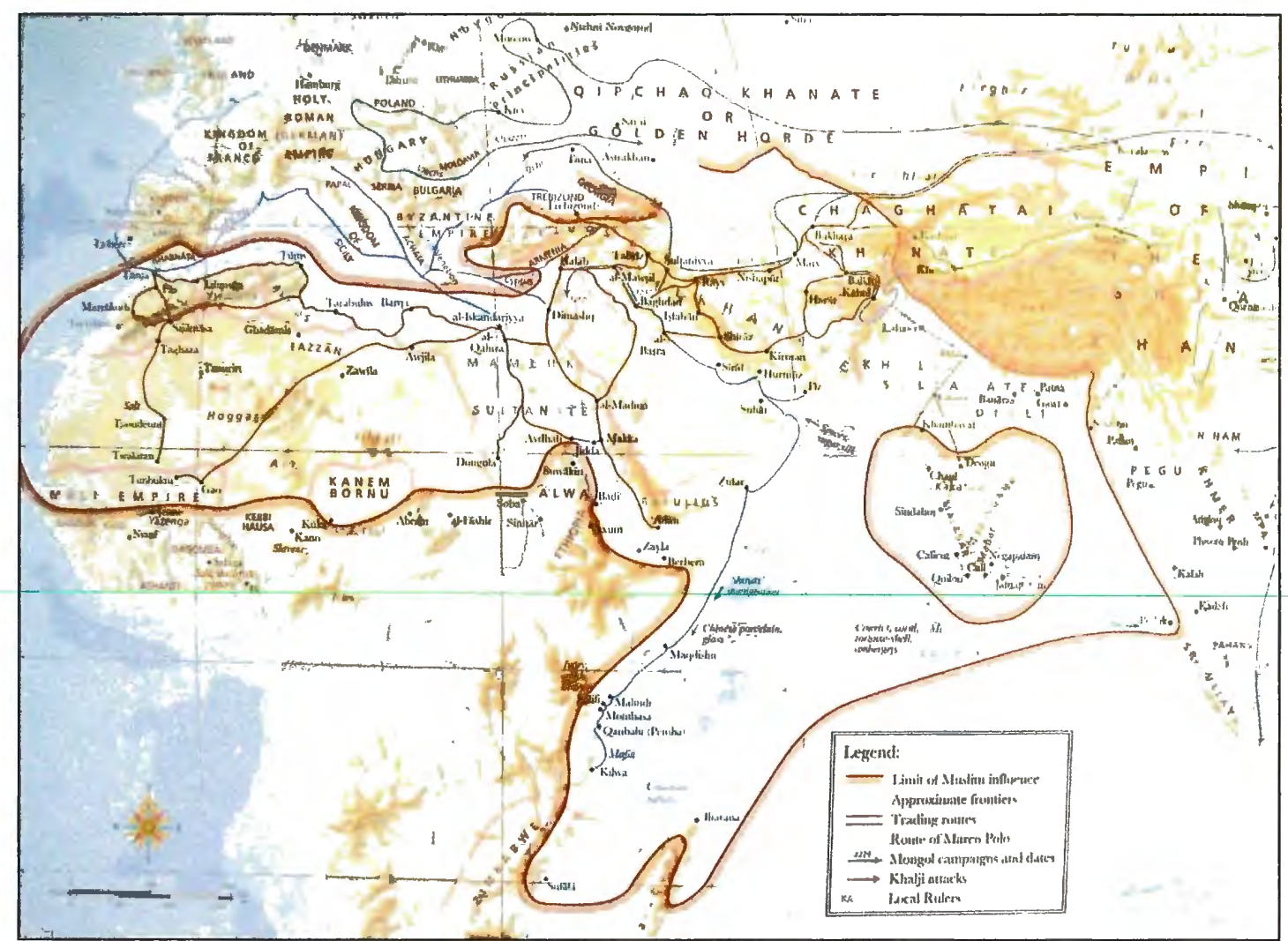

Figure 2.18 Extent of Muslim world in 1300, showing the borders within the empire (Kennedy 2002, 11). Note the Il-Khanate (in Iraq/Iran), the Chagatai (in Uzbekistan), and Qipchaq Khanates (around the Caspian Sea), as these were the Mongol Khanates controlling a significant part of the Islamic world. 
Khanates and how they straddled the Islamic world in this time period. Hulegu was defeated at 'Ayn Jalut in Syria in 1260 by the Mamluks of Egypt, thereby keeping the western half of the empire free from Mongol rule. Mongol suzerainty meant that nonMuslims ruled huge Muslim populations, however, as time went on, Mongol rulers in the southern portions of the Mongol territory converted to Islam and began patronizing the arts and architecture. Of these converts, Sultan Oljeitu (Uljaytu) (d. 1317), second ruler of the Il-khanid dynasty (r. 1256-1353) had built for himself a tomb that is now considered the height of Il-khanid architecture (Sims 1988) (figure 2.19).

The western Islamic world was still under the control of an 'Abbasid "shadowcaliphate", established in Cairo by the Mamluk sultan Baybars I. The Mamluks (r.1254-1517) built impressive mosque complexes that housed not only places of worship but schools and hospitals as well (figure 2.20). The Marinids and the Nasrids in the Maghrib and Spain, respectively, constructed some of the most recognized structures in the entire Islamic repertoire (figures 2.21-2.2).

All of these examples of decoration fall within the time period from the early tenth to the late fourteenth century. These monuments, along with the rest of the structures catalogued for this project, form the basis for the spatial analysis I undertake. These structures were built as centers of activity in the Islamic world multiplied, creating new opportunities for expression through architecture. 


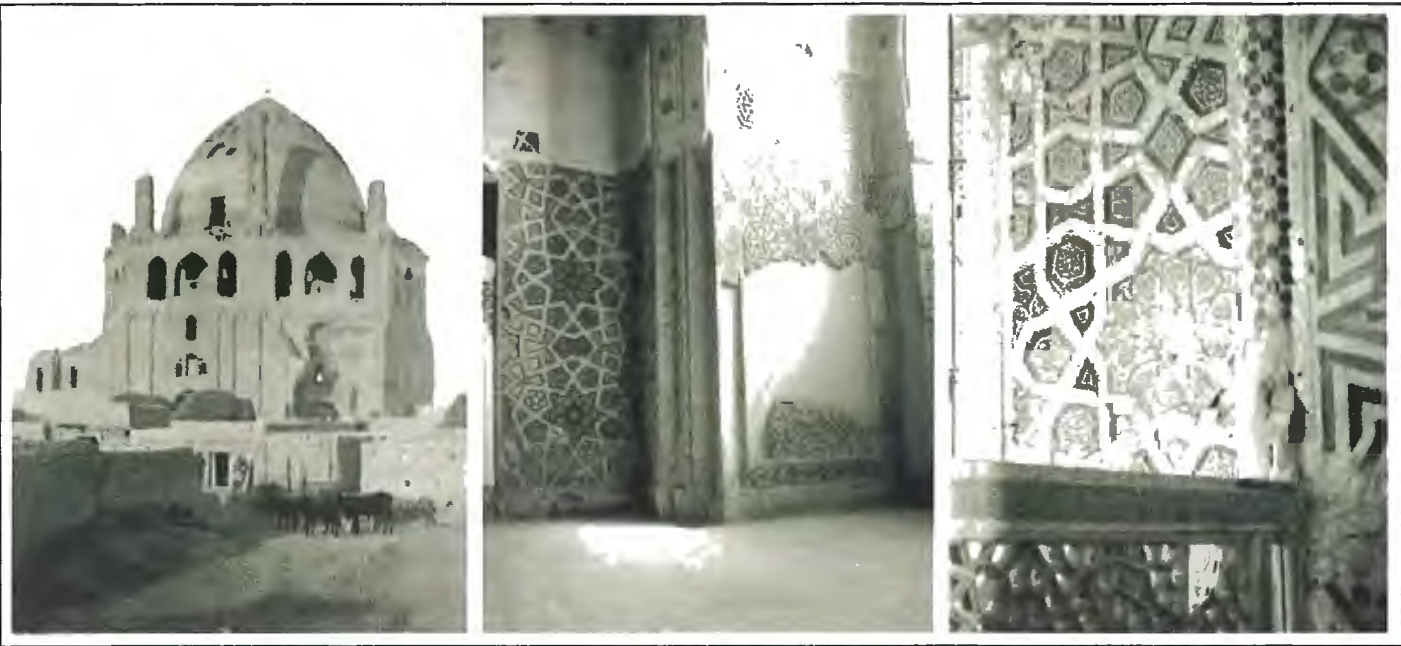

Figure 2.19 The Mausoleum of Sultan Muhammad Oljeitu Khudabanda, at Sultaniyya, Iran (1307-1313), represents the pinnacle of Il-khanid architectural achievement (images from Archnet). 


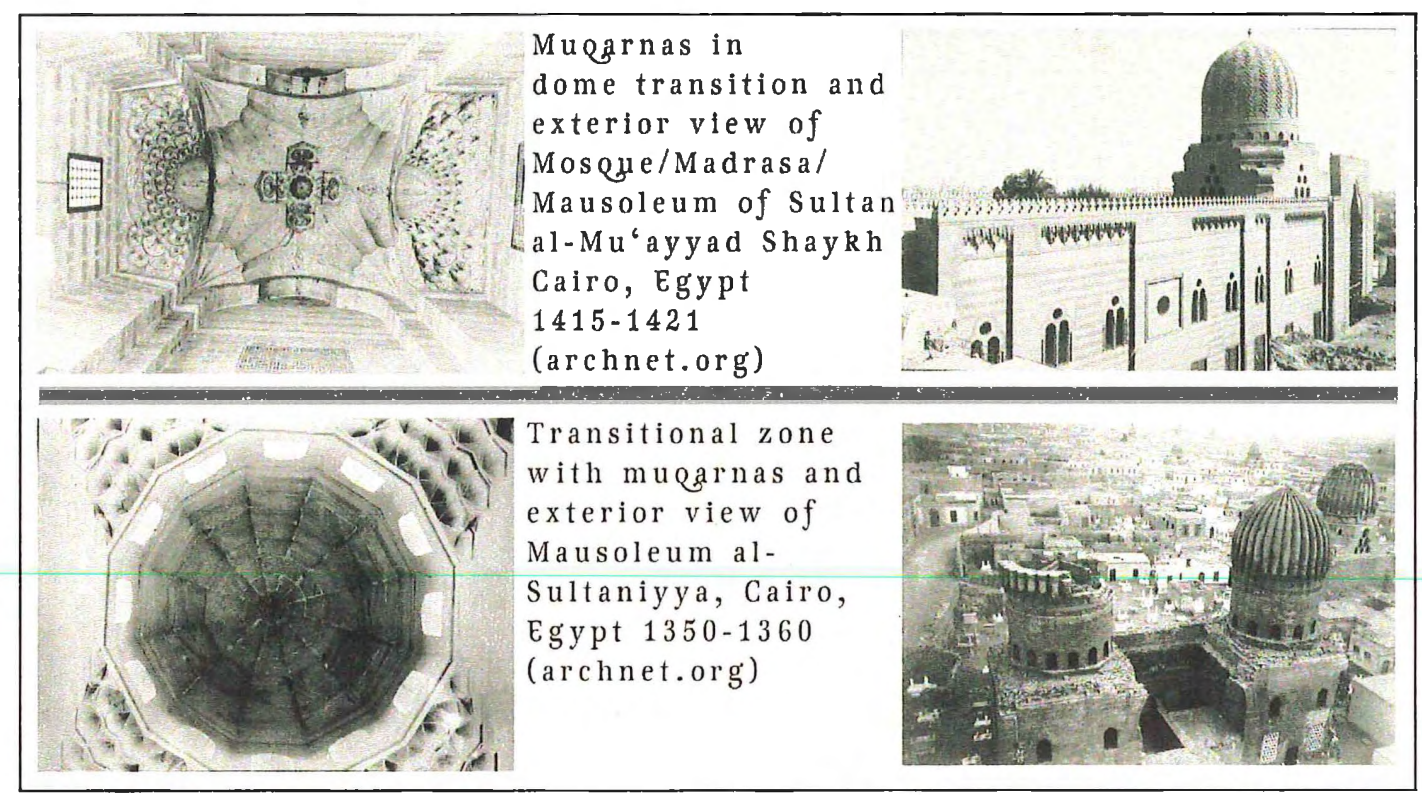

Figure 2.20 Mamluk mosque complexes. 


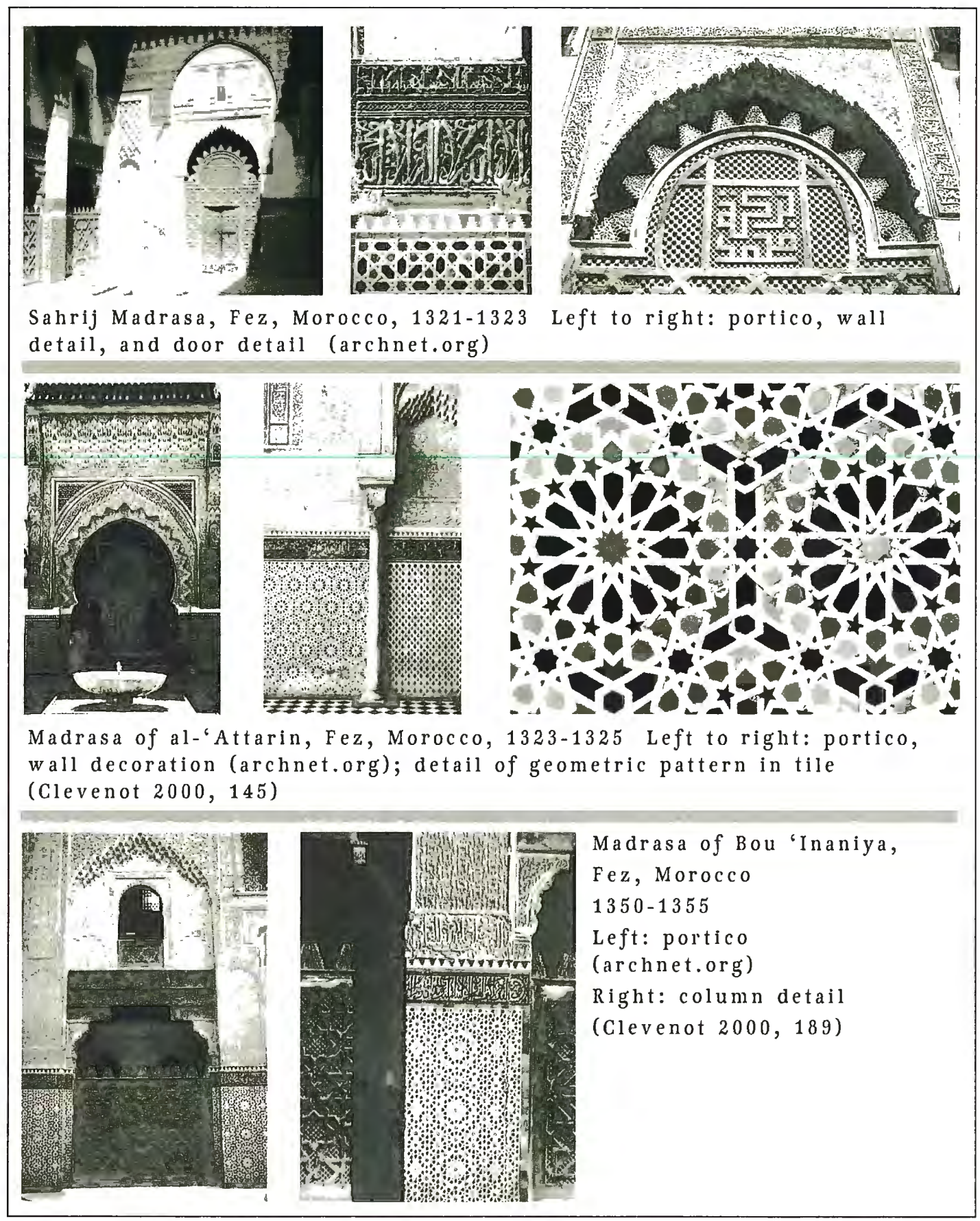

Figure 2.21 Examples of Marninid architectural decoration. 


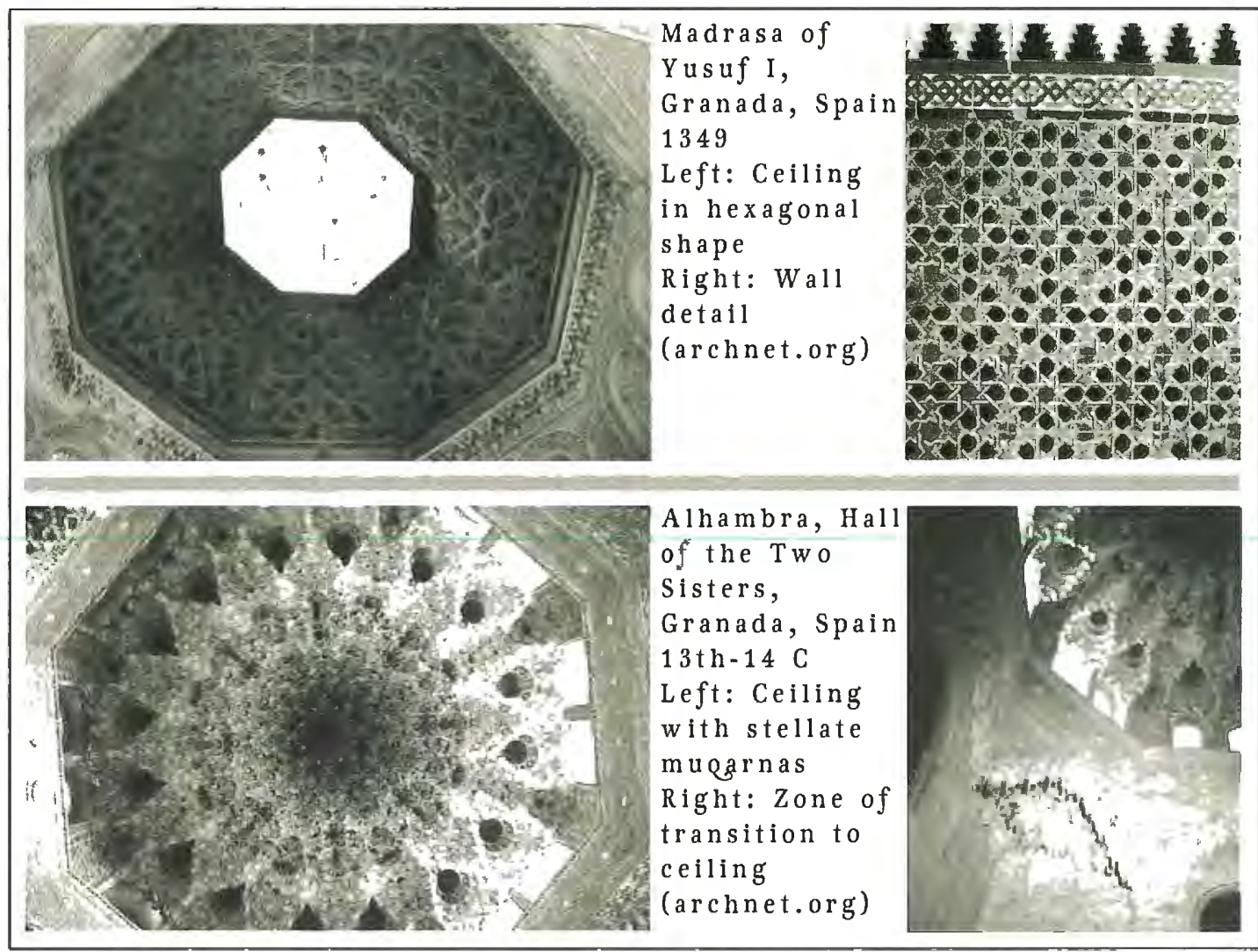

Figure 2.22 Spectacular muqarnas and ceiling decoration in Nasrid architecture. 


\section{Re-consolidation, or the Beginning of the End}

After the fourteenth century, other forces began to consolidate power, drawing influence back to more concentrated centers. The fragmented powers began to coalesce in the fifteenth century, culminating in the Ottoman, Safavid, and Mughal empires. While these empires spent great sums on architecture, the established forms underwent more refinement than change. The decorative programs changed from the strict geometric forms to grandiose floral/arabesque styles, signaling an end to the use of the geometric idiom, marking the aesthetic boundary of the project. It is at this phase of development where my project's timeline ends.

After the fifteenth century, the geometric idiom was too widespread, too common. The geometric style evolved, resulting in "increasingly ubiquitous forms and elaborate techniques [which] came to convey only a generalized Islamic meaning" (Tabbaa 2001, 166). The later ruling groups, such as the Ottomans and Safavids, employed these elaborate techniques. The Ottomans found expression with Sinan, their greatest architect, who built their most iconic mosque complexes (figure 2.23). Shah Ismail established a Shia state in Iran in 1501, and the Safavids ruled until 1786, building many extraordinarily tiled mosques (figure 2.24). Babur cemented the Mughals' rule in India in 1526, which lasted until 1858. These ruling groups' styles fully incorporated the influence of the Far East, which had come with the Mongols and insinuated themselves in the form of extreme floriated styles that came to supplant the geometric patterns of interest in this project. 


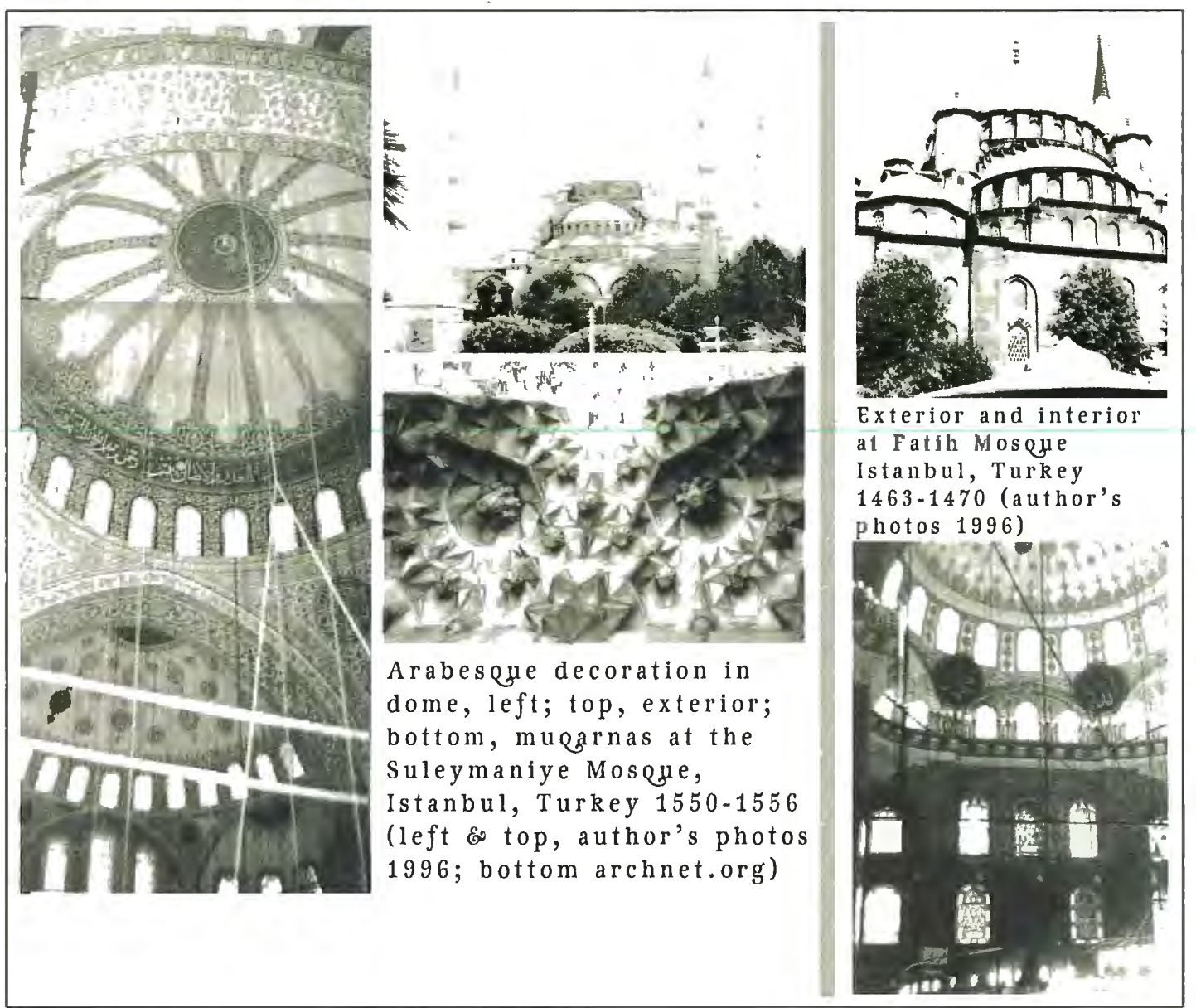

Figure 2.23 Ottoman architecture, characterized by multiple domes and floral arabesque decoration, as seen in the interior of the domes. 


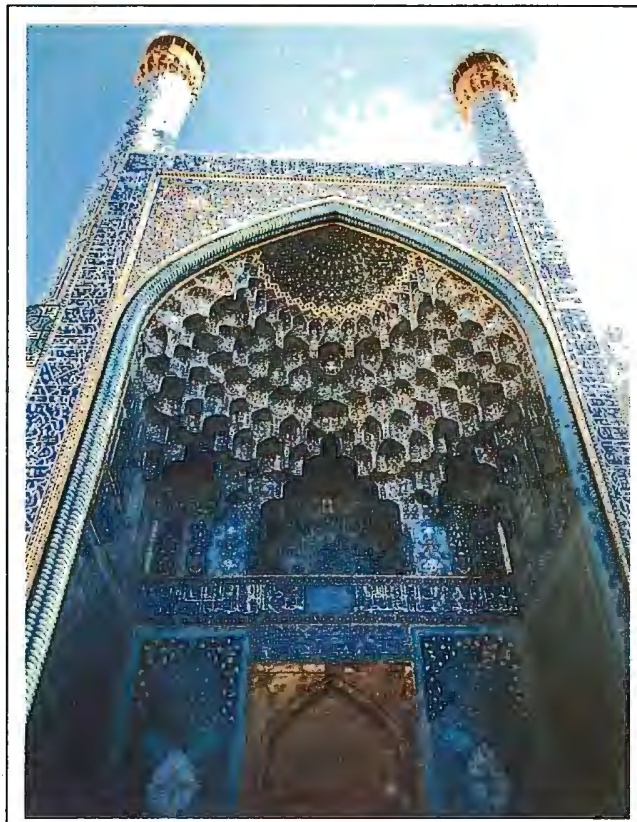

Tiled muearnas iwan and tiled dome exterior at the Masjid-i Shah, Isfahan, Iran 1612-1637 (Bloom and Blair 1997,294;

Clevenot 2000,39 )

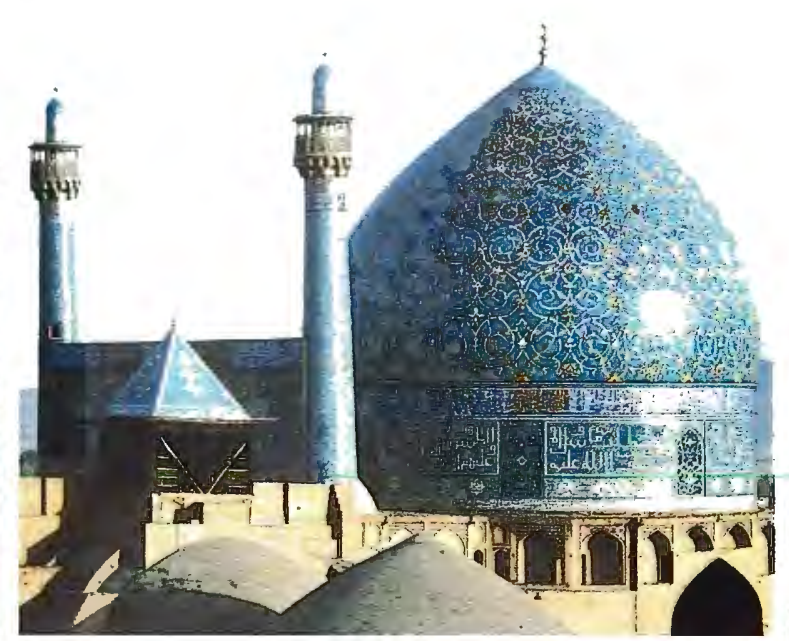

Figure 2.24 Examples of extensive use of multicolored decorative tiling found in Safavid architecture; floral arabesque patterns dominate. 
Indeed, "the Ottomans, Safavids, and Mughals...no longer assigned geometry the privileged role it had enjoyed" (Necipoglu 1995, 116). Because the geometric idiom first emerged in the early tenth century and was supplanted by other forms after the late fourteenth century, my project focuses on the period from the early tenth to the late fourteenth centuries.

As for the geographic extent of this project, it is determined by where the geometric mode was employed during the period of interest. The area covered thus spans the area from India west to Spain, and from Yemen north to the Caspian Sea. Although Africans, Indians, southwestern Europeans, and Southeast Asians converted to Islam, they often relied on their pre-existing forms of cultural expression, thus drawing less heavily on Arab, Persian, or Turkic traditions in the arts and architecture. The architecture produced by these peoples tended not to include the decorative types of interest here, and thus have not been included in the project. 


\section{METHODS}

In this section I demonstrate how I used a geographic information system (GIS) to create analytical maps of complex temporal and spatial data. These maps show the spatio-temporal relationship between locations of buildings exhibiting decorative geometric pattern and scientific and philosophical activities spanning over five hundred years and nearly four thousand miles.

Spatial analysis necessitates spatial databases. GIS data for basic contemporary political, social and physical parameters of the Middle East and the broader Islamic world are readily available. Some environmental data are available, as pertains to water rights, resource extraction, soils, hydrology, and other physiographic parameters. However, specialized information associated with cultural and historical geographic concerns is largely lacking. Indeed, studies in the fields of art history and the history of science in the Islamic context contain few maps, and even fewer spatial analyses. Therefore my initial task involved developing two databases to consolidate the available textual information, then building a GIS model to process and analyze these databases spatially. Here I address the development of the two databases used in mapping these phenomena, provide the rationale for the information I produced (specifically the categorization of geometric pattern types), and I describe my mapping strategies and final cartographic products.

The Pattern Database, or The Monuments

The first database I created contains the information on the geometric patterns that adorn religious and funerary structures. To build this database, I looked to the 
Aga Khan Program for Islamic Architecture, a joint academic venture between the Massachusetts Institute of Technology (MIT) and Harvard University that provides resources for the study of Islamic architecture both past and present. In 1994 this organization produced a report of 2,072 important monuments spanning the earliest days of Islam to the early modern period, from which 777 are designated "core" monuments in the Islamic world, which geographically covers everything from Africa to Indonesia (Spurr, Riedlmayer, and Sabri, 1994). The core list includes many of the oldest (and especially those monuments from the period of interest), as well as monuments that have retained some portion of their original structure and decorative programs. The thinking of those who created this list provides the theoretical background for my pattern database, and informs my approach to the material:

The choice of monuments encompasses those erected under the patronage of individuals or states adhering to or under the influence of the Islamic faith and culture, in both urban and rural settings, which meet the basic criteria of being important or exemplary representatives of the built environment...These buildings exhibit architectonic, stylistic or institutional features which best illustrate the characteristics or development of the architecture in a particular time and place by exemplifying them most clearly and often by providing models for later structures...the list includes ... significant architectural features, the articulation of facades, decorative vocabulary and iconography (Spurr, Riedlmayer, and Sabri, 1994, iii).

From the Aga Khan Program's core list, augmented with other sources (see Appendices 1 and 2 for full databases and sources) I was able to compile a list of 221 monuments that fell within the spatio-temporal boundaries of this project. Each of these 221 monuments has a verifiable visual record of at least one example of decorative geometric pattern. If I could not find a visual record for the monument, I did not include it in my database. 
The records in my pattern database span a large portion of geographical and temporal extent of the historical Islamic world-they fall in the area stretching from Spain to India, from approximately $950-1400 \mathrm{CE}$, as shown in figure 3.1. Included in this database of monuments exhibiting decorative pattern are records both prior to and after this period, to provide a kind of temporal buffer for the true period of interest. Each record in the database contains:

- Name of the structure

- City

- Date

- Region

- Pattern type(s)

- Pattern complexity ranking (described below)

- Location of the pattern in the structure (such as exterior, dome, minbar, etc)

- Building material used to create the pattern (tile, stucco, stone, etc)

- Caliphate or dynastic period

- Capital of that dynasty

- Source of image(s)

- Latitude and longitude in decimal degrees (see Appendix 1 for full table). I have made every effort to construct a database that encompasses as many monuments as possible, but the nature of the end product is necessarily incomplete. For example, I found ninety-nine additional monuments (and there are undoubtedly many more) that most likely exhibit geometric patterns, based on their spatial and 


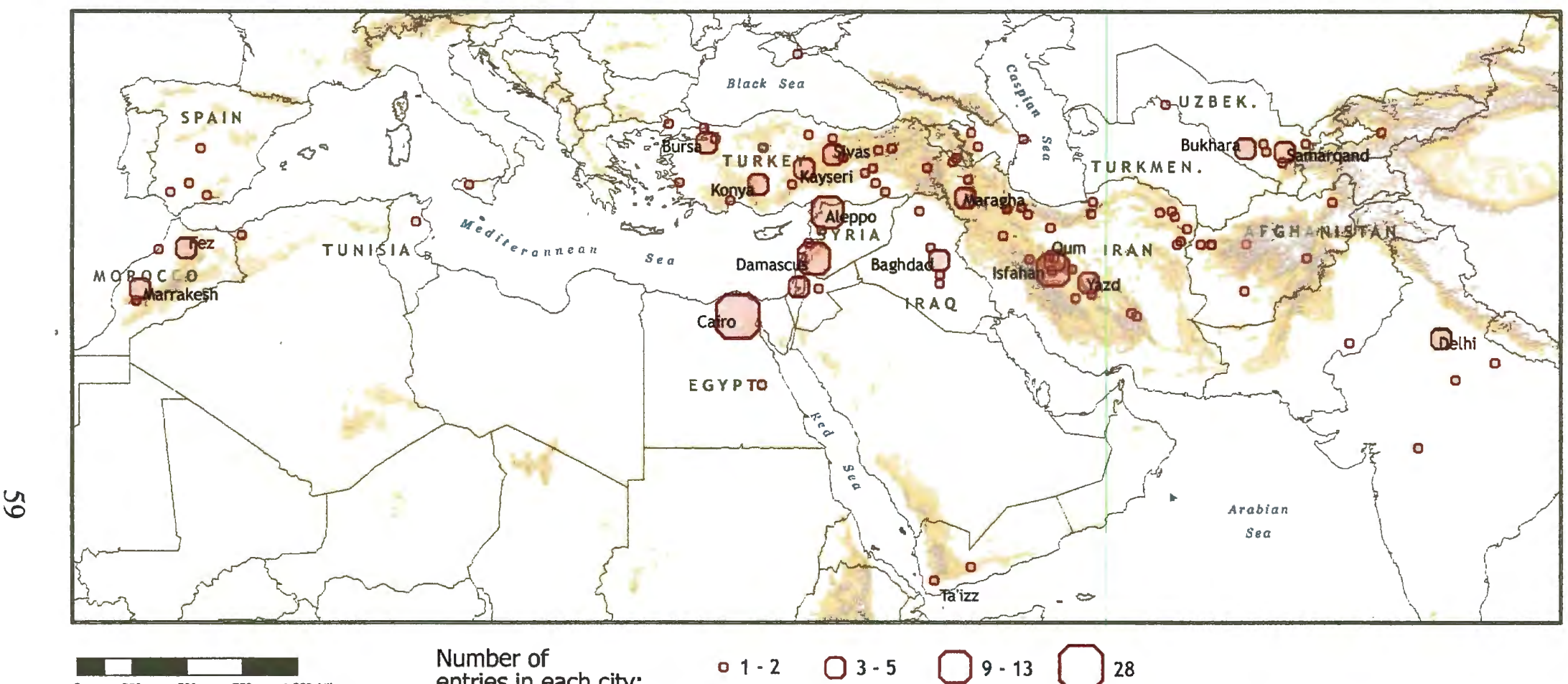

Figure 3.1 Map of cities in pattern database, showing number of monuments in each location. Cities with more than three monuments have been labeled. 
temporal circumstances-but with no visual records available, I cannot include them in my database. But not only are existing structures left out for lack of documentation. Countless structures have been destroyed and altered in the intervening centuries due to war, power shifts, natural disaster, and changes in style and taste-sometimes because of colonial impositions, as in the case of nineteenth century Cairo (Bierman 2003), but also because subsequent rulers added more elaborate and costly elements to buildings to enhance their own reputation, as in the case of Salah al-Din (r. 11381193) adding the minbar in al-Aqsa Mosque. Indeed, my reliance on secondary and tertiary sources for documentation speaks to the difficulty of not only travel to many parts of the region but also of the current and historical scarcity (in the West) of resources for studying Islamic culture. What is important here is that the database's incompleteness reflects erasures, destruction and rifts in the landscape. In life on the ground just as in life in the map, we have to navigate around those gaps and understand beyond them.

The Culture Database: The People \& the Schools-the Sciences \& the Philosophy

To answer the questions related to scholars' hypotheses about the geometric mode, I gathered and formatted other textual data for use in the GIS. This "culture" database includes 103 entries derived from many sources, and has no model as the pattern database does (see Appendix B for full table including sources). The distribution of this database is shown in figure 3.2 . 


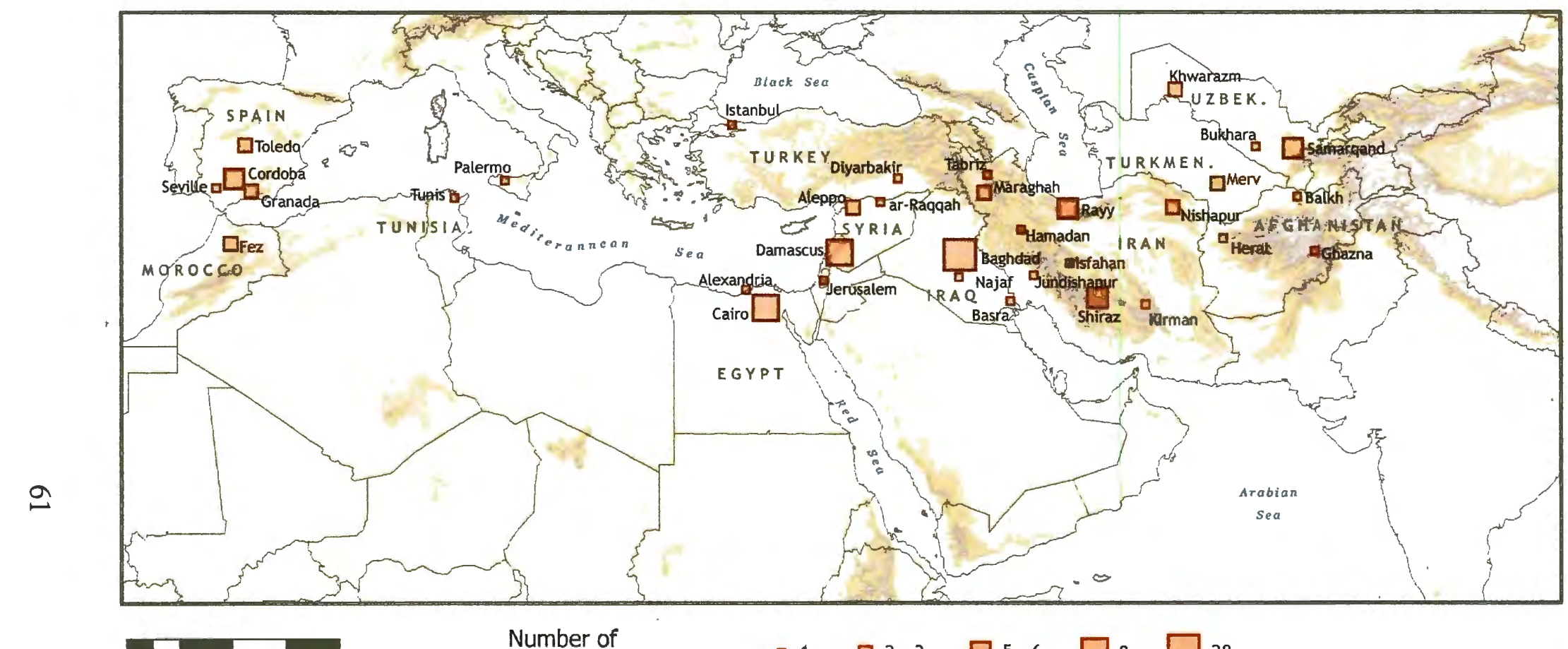

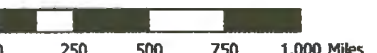

entries in each city:

- $1 \square 2-3$

$\square 5-6 \square 8 \square 28$

Figure 3.2 Map of cities in culture database, showing number of entries in each location. 
The fields in this database are:

- City where caliph, school, or scholar was active

- Caliph

- Schools of thought

- Patronage type or institution

- Notable scholars

- Scholar description/classification

- Important texts by those scholars

- Era for the scholars

- Era for the caliph

- Source for the entry

- Lat/long in decimal degrees

As the pattern database classifies the types of decorative pattern, the culture database classifies the types of activities pursued by institutions and individuals. My classification is derived from Ibn Khaldun's (1332-1406) Muqaddimah (Introduction to History), which contains a classification of the sciences of the Islamic world (1968). He distinguished between the transmitted sciences - theology, exegesis, law, jurisprudence, and linguistics (all based on the Qur'an), and the philosophical sciences, which include logic, the natural sciences or physics (and medicine), the sciences of nature/metaphysics (such as alchemy), and sciences dealing with quantity, often called the exact sciences-astronomy, mathematics, optics, geography, music (Montgomery 2000, 94; Nasr 1968, 62). Thus the secondary literature employs these 
classifications to describe most individuals' activities. My culture database does not include individuals who were strictly jurists, poets, historians, or experts in medicine, as these activities have not been part of the academic discussion surrounding the development of geometric patterns. However, a fundamental aspect of Islamic scholarship is the integration of many disciplines; for example, most important astronomers were also noted geometers, and some were historians and philosophers as well.

Noteworthy events and achievements incorporated in the culture database include records related to the translation movement which continued on for a century in Baghdad (est. $762 \mathrm{CE}$ ) begun by al-Mansur, first Caliph of the "Abbasid dynasty. Other important records include the observatories at Maragha, Samarqand, and arRaqqah, as well as particular schools such as al-Azhar in Cairo, the Zaytuna in Tunis, and the Qarawiyyin in Fez. Major individuals from specific disciplines include alTusi and al-Kashi in astronomy; al-Khwarzimi, Khayyam, and al-Karaji in mathematics which includes geometry, trigonometry, and algebra; al-Idrisi in geography; al-Haytham optics; al-Razi in physics; and al-Arabi, al Ghazali, and alKindi in philosophy/theology.

\section{Pattern Type}

Here I must elaborate on some elements of the pattern database. The variety of pattern types found on Islamic monuments required separating them into categories. As a decorated space becomes packed with tessellating (fit together without leaving spaces) polygons, a pattern develops. Below are examples of the types of geometric 
patterns that decorate the monuments in the pattern database. I have broken down the patterns into six categories:

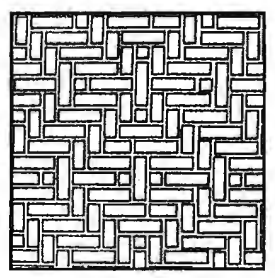

Brick geometry is the type of pattern found most often on earlier monuments; the patterns are formed using the shape of the brick itself (image from Demiriz 2000, 227).

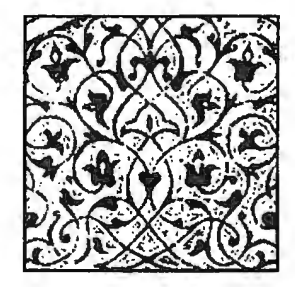

Arabesque refers to patterns of a floriated nature (image from archnet.org). These patterns are Byzantine in origin, and derived from plant imagery; the arabesque is ubiquitous, found in architecture, textiles, metalwork, ceramics, etc. This type of pattern is included because of its frequent use in architecture even though it does not represent a "true" geometric pattern, as it is not comprised of tessellating polygons. It appears on many monuments, alongside the other types of patterns.

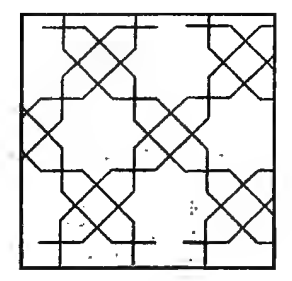

Polygon patterns are comprised of simple, repeated multi-sided shapes - these patterns are nearly as pervasive as the arabesque (image from Demiriz 2000, 110). 
Polygon containing arabesque refers to simple polygon patterns filled with arabesques (image from Demiriz 2000, 83).

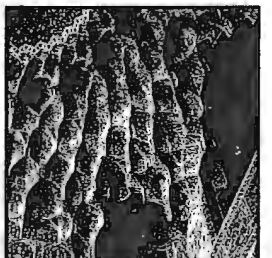

Muqarnas are three-dimensional architectural elements built from planimetric geometric designs (image from archnet.org).

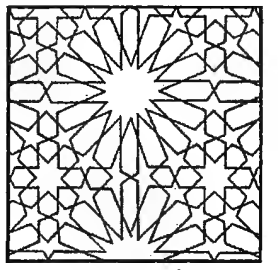

Star-and-polygon patterns represent a unique type of design

(image from Demiriz 2000, 157).

There are many variations of each type of pattern, and within a given monument, one may find examples of every type of pattern. Others have attempted to categorize the variety of decorative Islamic patterns (Demiriz 2000; Abas and Salman 1995).

Demiriz's categorizations are too fine and do not provide enough distinction to use directly. Abas and Salman developed a categorization strategy based on the type of symmetry used in each pattern. They categorized pattern using all seventeen of the possible types of symmetry-were I to use that many distinctions, the project would become too cumbersome. Therefore my classifications are partially based on these studies, with attention paid to other art historians' terminologies and typologies (Bloom and Blair 1997, Ettinghausen 2001). 


\section{Not all Patterns are Created Equal: A Complexity Ranking}

Classification alone does not go far enough in describing the visual properties of these geometric patterns. The way a polygon twists and moves its way across a surface must be regulated by some mechanism or another, or else the pattern falls apart and loses its coherence. The mechanisms used to regulate these patterns are actually different types of grid systems and are unseen in the final execution of the design. I relied on these underlying grid systems to further categorize the different types of pattern.

Use of certain grid systems results in certain types of patterns, which have clear visual differences. These differences coincide with the categories I have described above and they form the basis of my pattern complexity ranking. Each type of pattern was evaluated and assigned a rank based on its visual relationship to a type of grid system. Bourgoin's Arabic Geometrical Pattern and Design, which illustrates grid systems for 190 different patterns, provided the basis for determining what grid system each pattern was based on (1973, originally published in 1879). For example, figure 3.3 shows the differences between triangular and radial grid systems; these underlying grids are denoted by the dotted lines. I also relied on Abas' and Salman's diagrams as aids in assigning my complexity values, as their work shows underlying grid systems as well. Another example of the radial grid under examples of star-and polygon pattern is shown in Figure 3.4. It is visually clear that the non-radial grids result in simpler patterns. Necipoglu agrees, and writes that as time went on, geometric patterns developed "dynamic radial grid systems whose rotational 


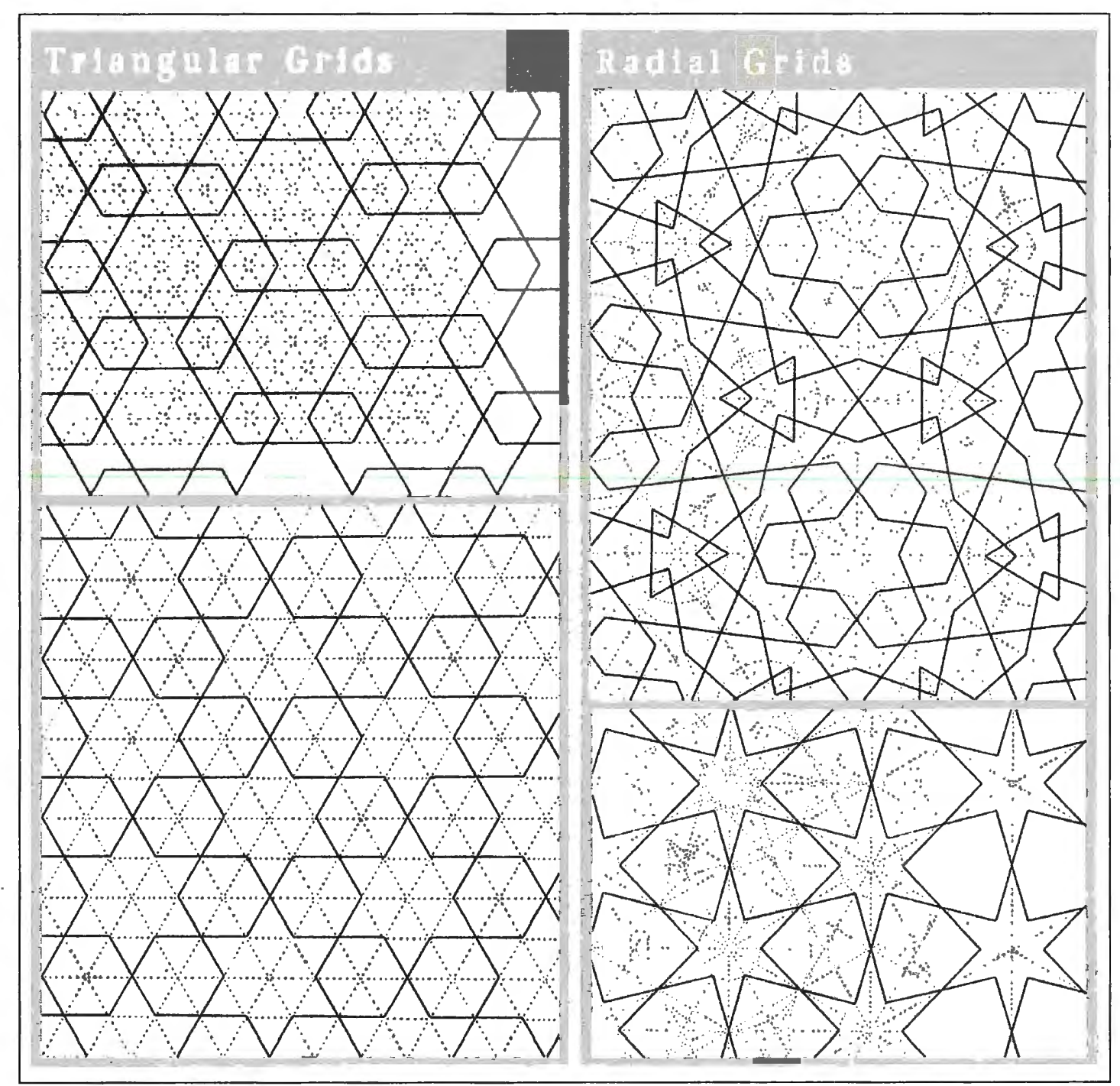

Figure 3.3: Triangular and radial grid systems (shown by dotted lines) underlying polygon and star-and-polygon patterns. (Images from Bourgoin, 1973). 


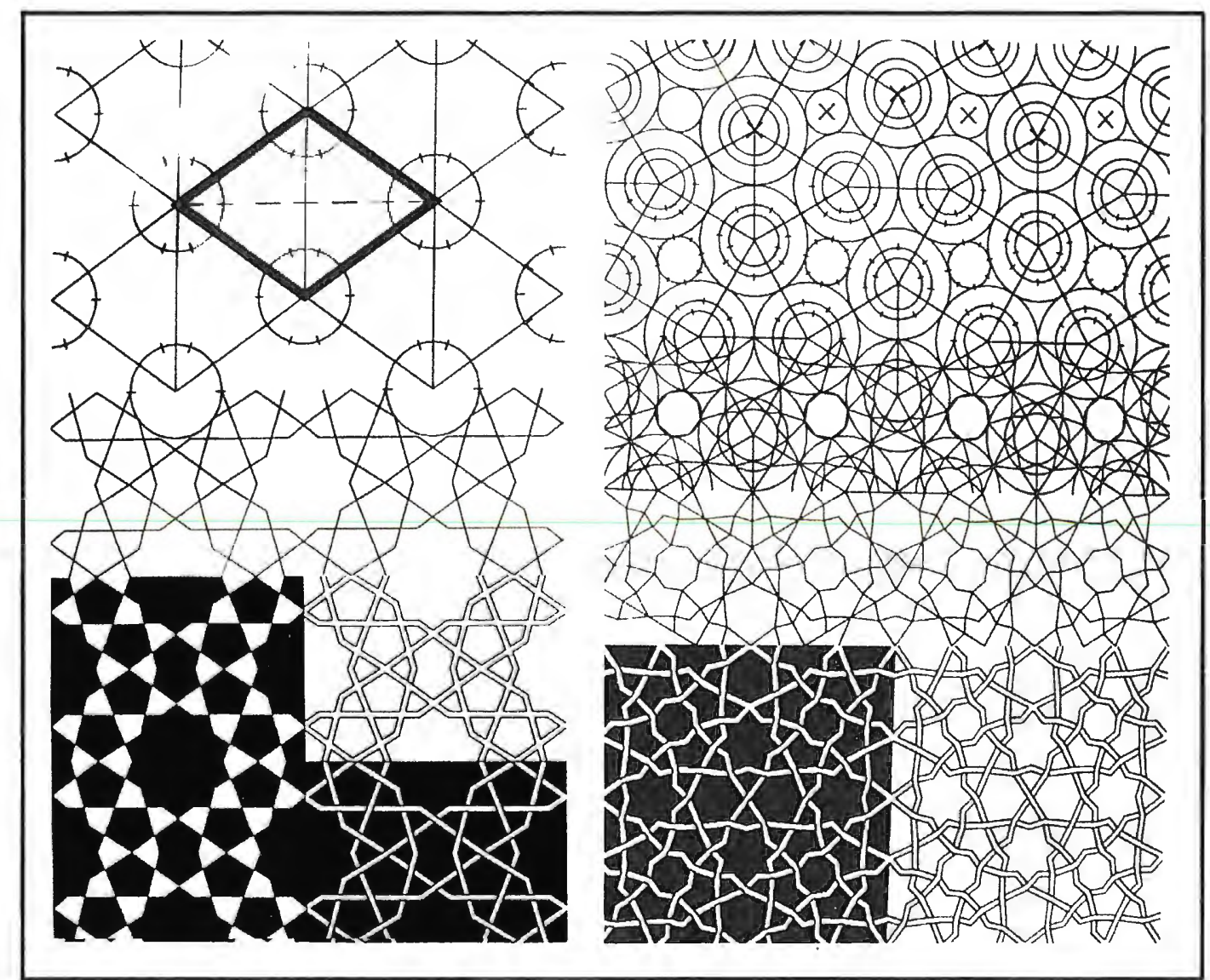

Figure 3.4: Radial grid systems underlying star-and-polygon patterns (Abas and Salman 1995, 47, 23). 
symmetries were far more complex than their late antique and early Islamic counterparts, which were based on simpler rectilinear grids with diagonal coordinates" (1995, 103, emphases mine). She places the grid types in a continuum from simple to complex, and I have followed her example.

The simplest rank in my group of patterns falls to the brick geometry, which is based on plain rectilinear grids. The middle ranks fall to the triangular grids, and finally the muqarnas and star-and-polygon patterns receive the highest ranks, as they are based on the radial grids. Necipoglu further describes the grids of these most complex patterns, as "based on the harmonic properties of circles approximately divided into equal arcs and composed in quadrangular repeat units proportionally cut into congruent parts by dynamic axes of symmetry around which elements rotate or through which mirror axes pass" $(1995,139)$. Figure 3.5 shows schematic drawings and in situ examples of each level of pattern complexity. The values in figure 3.5 were used only at an ordinal scale, meaning simply that they were ranks, used to compare to each other. A value of "three" means only that it is less complex than a "six" and more complex than a "one", not one-half the complexity of a "six," et cetera.

Classifying and analyzing patterns in terms of their structure has scholarly precedents. In Symmetries of Culture, Washburne and Crowe develop a method for studying cultures based on the types of symmetry found on their artifacts (1988). Working from an anthropological perspective, they assert that symmetry is a culturally meaningful property and that "symmetry, then, is a cognitive perceptual universal, basic to the processing of all shape information. A culture's symmetries are part of 


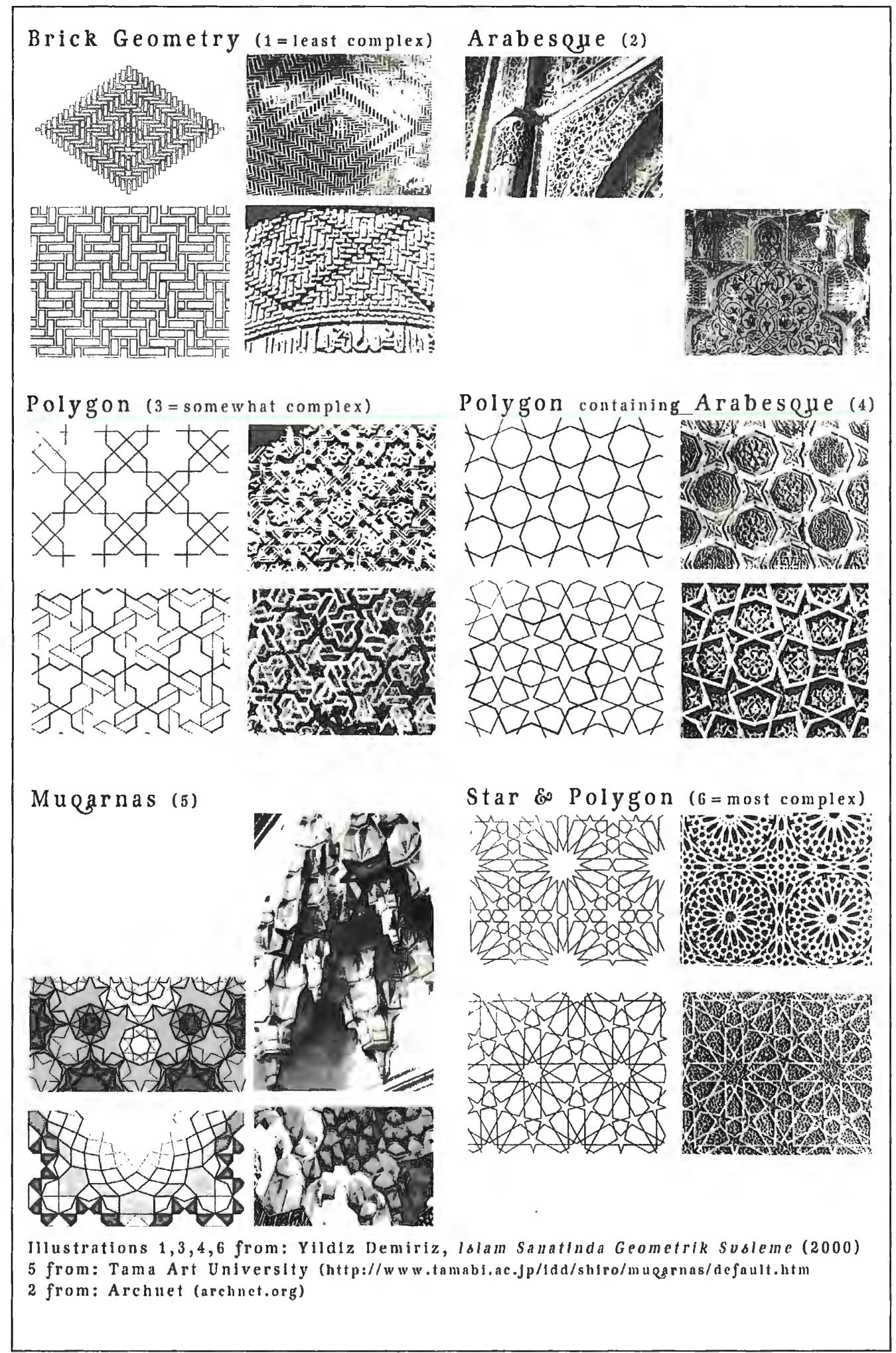

Figure 3.5: Pattern types and complexity ranking. 
that culture's cognitive organization map, and the classification of symmetries is a meaningful measure of the way members of a particular culture perceive their world" $(1988,24)$. While I am not analyzing the types of symmetries in these patterns, my classification and ranking reflect an ordering of shape information that is comparable to ordering by symmetry type.

\section{Mapping}

The pattern complexity ranking effectively forms an index. In spatial analyses, we often use indices of one (or more) attributes to determine the viability, availability, or condition of another (or other set of) attribute(s). There is a wealth of wellestablished spatial analysis that employs indices; there are the Normalized Difference Vegetation Index (NDVI), earthquake and hazard indices, and environmental sensitivity indices, just to name a few. Ultimately, this pattern complexity index, based on the pattern types and grid systems described above, is the "variable" to which factors in the culture database (science, philosophy) are compared. I will describe the iterative process I used to create maps that provide the basis for a deep discussion of the cultural frameworks surrounding these phenomena.

The cartographic model (Appendix C) graphically describes the process I developed and details all values and operations I used. The first step, a visual analysis of the first maps of simple point distributions yielded what one might expect from 300 data points - a tangled set of points obscuring any detail. Further breakout maps of the point data provided a limited basis that was too general for further cartographic and spatial analysis. 
These locations needed to make the transition away from simple points in order to undergo more dynamic spatial analysis-in mapping, points can be converted to surfaces, or rasters. Each known point contains an $x-, y$-value which locates it in flat coordinate space, and a z-value containing another numeric attribute. The output is a continuous raster dataset, with the quantity or magnitude of the $\mathrm{z}$-value distributed over a defined unit of area. The density operation creates manageable regions to work with, to compare to each other-because this project's study area and time frame are so broad, densities provide an optimal method for analyzing so much data.

Additionally, using a density surface makes sense for these data because they are representative samples - the data points are not all of the monuments, science, or philosophy activity that existed. There was 'culture' elsewhere, and the use of surfaces recognizes that. These data are not continuous (such as elevation data); they are discrete (such as population data, which are often mapped as densities). For specific values and parameters in the density calculations and classifications, see cartographic model (Appendix C).

\section{Density Map Series:}

Since each location in the two databases represents an activity or monument of importance, determining the densest regions of monuments and activities is a good way to draw out general spatial patterns in each database. Each point in a density operation has a $\mathrm{z}$-value in addition to the $\mathrm{x}$ - and $\mathrm{y}$-values. In this case, the $\mathrm{z}$-values in the first density maps represent simple 'counts'. Each location (in both databases) has a certain number of records associated with it, for example, Cairo, with twenty-eight, 
has the most records in the pattern database, representing twenty-eight monuments there with verifiable decorative pattern. (One possible reason why Cairo has more records than any other city can be traced to the Mongol invasions in the mid-13th century. They destroyed many structures in Iran, Iraq, and Transoxiania; but the Mongols were defeated at 'Ayn Jalut (Syria) in 1260 by the Mamluks and never made it to Egypt). Baghdad has the highest count in the culture database, also with a total of twenty-eight records. Thus the resulting density maps of these "counts" simply show the range of importance of regions that dominate each database, clearly visible in figures 3.6 and 3.7. But both of these density maps obscure the temporal diversity of pattern use and complexity and other cultural activity.

To gain a sense of the temporal diversity, I broke the pattern database down by century into separate GIS coverages. Each of these new coverages then had a smaller number of data points-a more manageable range of pattern types and complexity values. To understand where the most complex patterns, the ones of most interest were concentrated, I made a density map based on the pattern complexity ranking for each century. In other words, the pattern complexity ranking was the $z$-value for this series of densities.

I then made century breakouts of the cities in the culture database to be overlaid on the pattern complexity density maps as point themes as shown in figure 3.8. This depicted the general spatial relationship between pattern complexity and cultural activity in one century but was not yet detailed enough for use in a systematic discussion. 


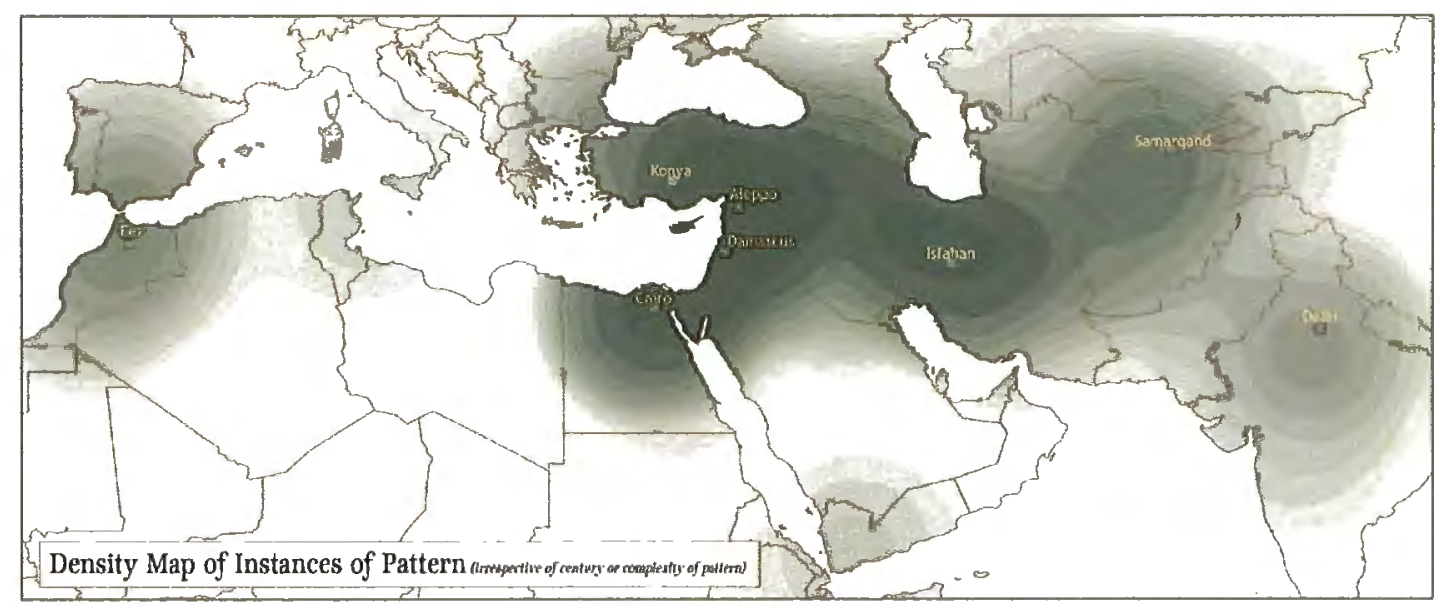

Figure 3.6: Pattern Database "Count" Density with major cities included for reference.

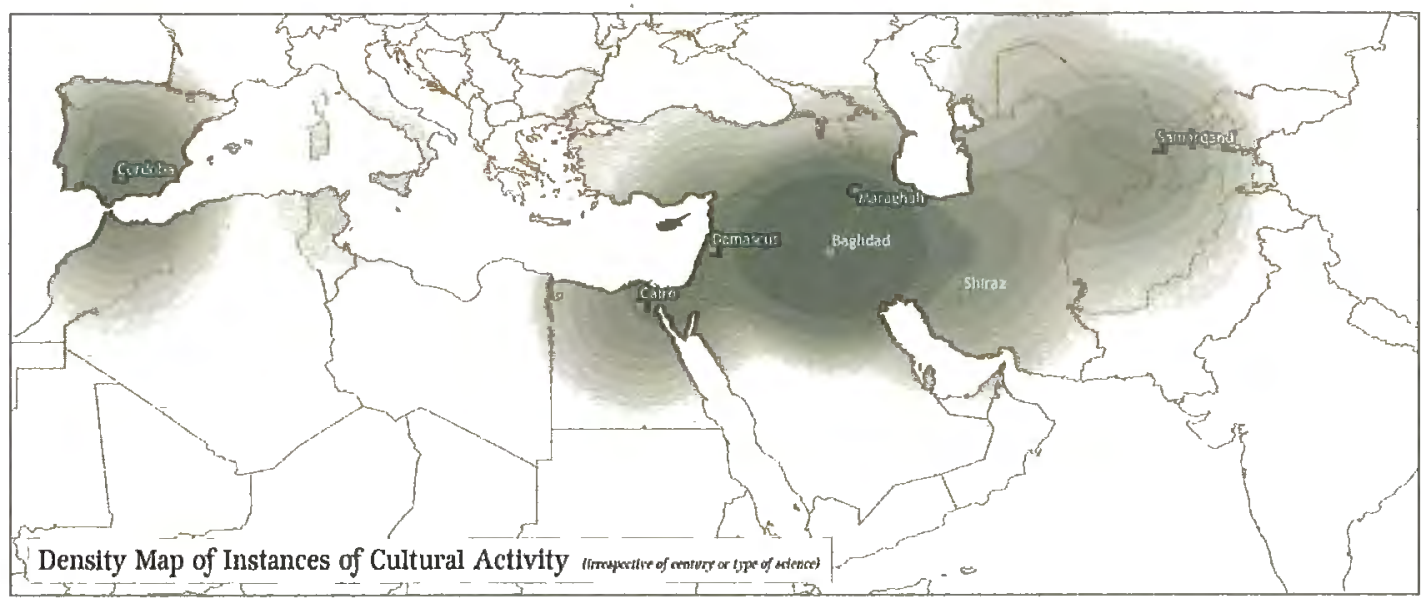

Figure 3.7: Culture Database "Count" Density, with major cities included for reference. 


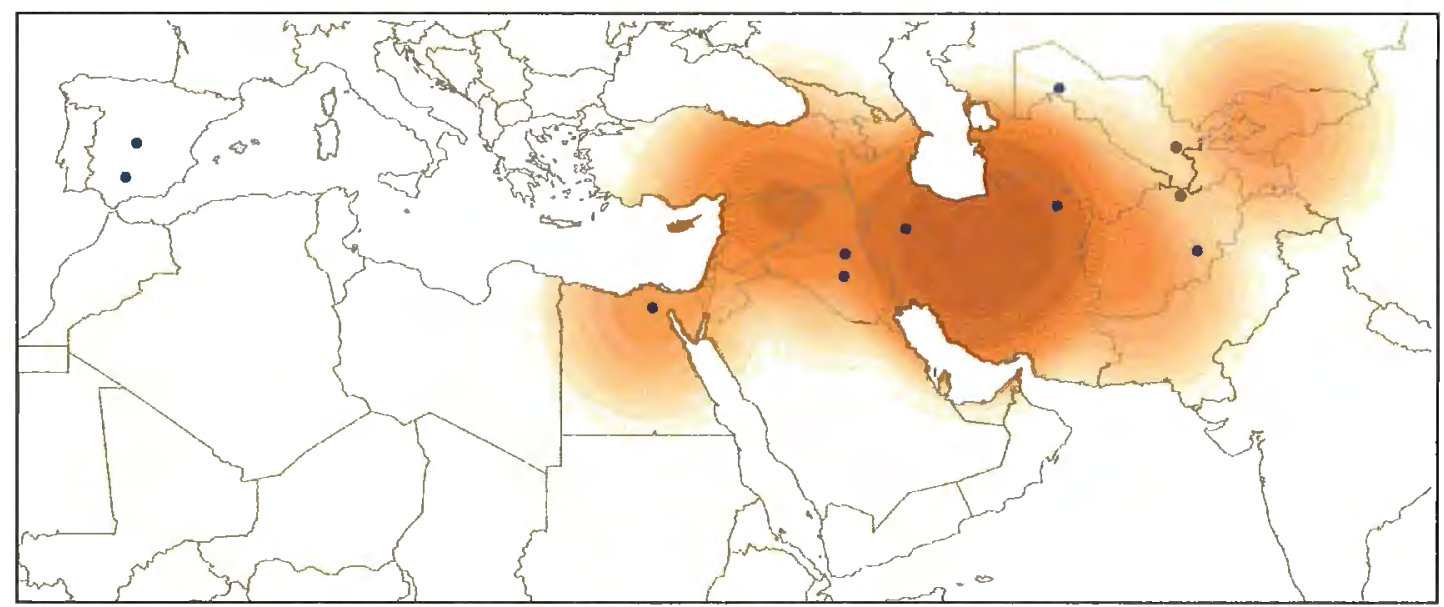

Figure 3.8: Eleventh Century Pattern Complexity Density shown with cities in the Eleventh Century Culture Database. 
Therefore I looked at, for example, a density map of pattern complexity for the eleventh century overlaid with tenth, eleventh, and twelfth century point themes of cities in the culture database because I wanted to see how places of scientific and philosophical activity coincided, spatially and temporally, with regions of highest pattern complexity in more than one time period. Further, the types of activity in question needed to be distinguished from one another. This necessitated two new density series: a mathematics/astronomy density series and a philosophy density series. One set ranked math/astronomy activity highest, and the other ranked philosophy (including theology) highest. The goal of these new density series was to tease out which types of activities were related spatially to the regions of highest pattern complexity.

To render these multiple density series visually comprehensible, I digitized the regions of highest density in each century into a single coverage. For example, the eleventh-century coverage contains the following: the region of highest pattern complexity for the eleventh century; the regions of highest astronomy/math activity for the tenth, eleventh, and twelfth centuries; and regions of highest philosophy activity for the tenth, eleventh, and twelfth centuries, as shown in figure 3.9. This method of overlay enables, in a single map, a comparison of 300 years of major regional activity. From these overlay maps, a focused and detailed discussion of the relationships between cultural phenomena results. 


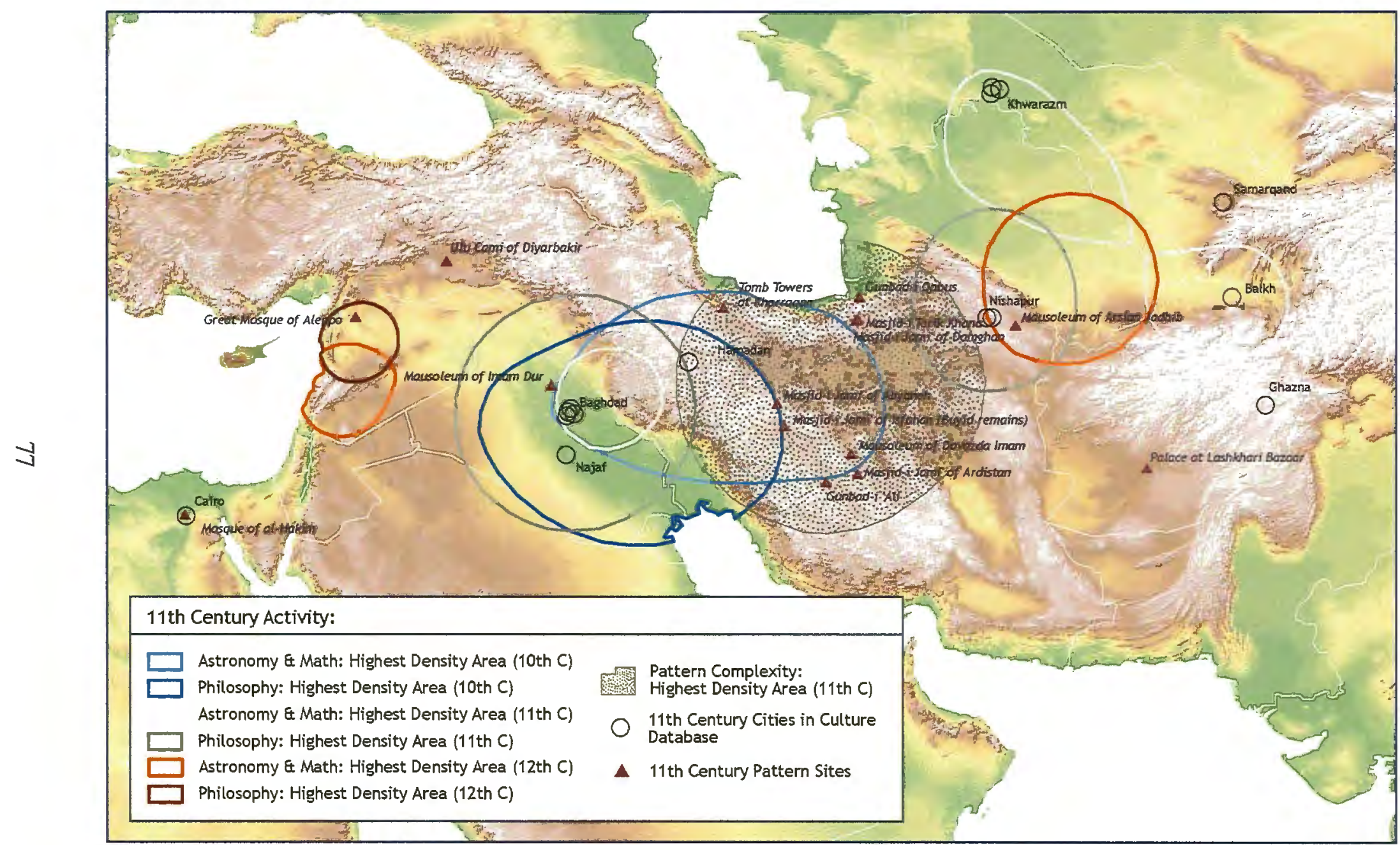

Figure 3.9 Eleventh century density overlay map. 
What I have done is create a model. There are elements that can be adjusted according to the level of detail and line of questioning one desires. The "knobs" that can be tweaked in effect are: pattern ranking-for example, if one's hypothesis involved a connection between the brick geometry pattern and some other variable, a density series could be developed with that ranked highest. Other data could be added to the culture database, such as the different Sufi turuq (schools), or another type of scientific activity, such as alchemy. The time step could also change-densities could be created for fifty-year intervals, ten-year intervals, et cetera to show better detail in regions of very dense activity. The highest densities of each activity or pattern could be pulled out, just as I have done, and compared for any number of time intervals, to see if there are areas that correspond to each other at smaller or larger time steps. The point is that the foundation and process is here, and there are many further questions to be asked and answered using this process. 


\section{DISCUSSION: NINTH CENTURY}

The maps I have created provide the basis for a closer examination of cultural and artistic activity in the medieval Islamic world. I provide historical contexts for the ninth through fourteenth centuries, and bring the broad view into focus by analyzing specific events, movements, persons, and monuments that are summarized on the maps. The density overlay map created for each century anchors my discussion of these activities' histories, contexts, and connections.

The cultural activity of this period sets precedents followed by the rest of the Islamic empire in the succeeding centuries, therefore I examine it even though it is technically outside of the period of interest with regard to the employment of decorative geometric pattern in architecture. I discuss this century in some detail because the institutions and traditions developed in the ninth century were massively influential, both geographically and temporally. The major themes I cover are: the rise of the "Abbasids, the translation movement, developments in Islamic philosophy, influential thinkers, and the establishment of early regional architecture. I describe these events and persons because they form the intellectual foundations for the spatial patterning on the density overlay map for this century. I have developed a timeline for each century that collects the events, ruling groups, and persons mentioned in the text (figure 4.1). 


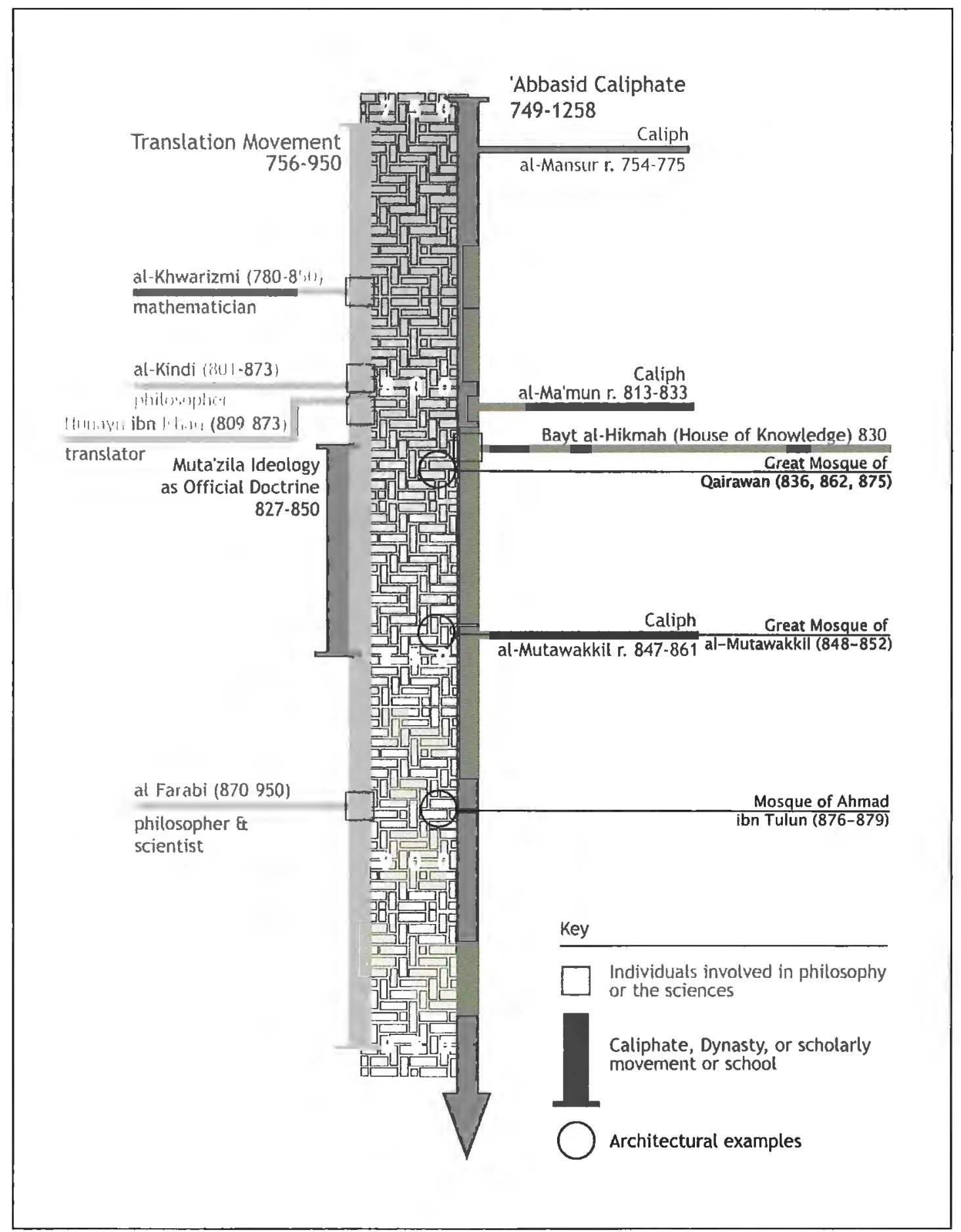

Figure 4.1 Timeline for ninth century. 


\section{The Rise of the 'Abbasids}

The transfer of the capital of the empire from Umayyad Damascus to "Abbasid Baghdad in 762 signaled major changes in the interests of those in power. The political climate that gave rise to the 'Abbasids ascent to power was in part created by the Umayyads' privileging tribal or clan affiliations (remember that the expanding Islamic world was now encompassing more than just an Arab population); the oppressive and ethnocentric nature of the Umayyad regime resulted in unrest and ultimately civil war. To defeat the Umayyads, the 'Abbasids claimed legitimacy as being related to al-'Abbas, the Prophet's uncle, which garnered nascent Shi'a support, and they relied for assistance on the Sassanian Persian and Near Eastern populations (non-Arabs, including Aramaic-speaking Christians and Jews, Persians, Kurds, and Baluchis). This involvement from existing populations in the eastern portion of the empire extended to their inclusion in the "Abbasid administrative structure. For example, the Barmakids (Barmecids), a Persian family from Balkh, became a vizier (political advisor) dynasty, serving under the first four 'Abbasid Caliphs. On a higher level, the organization and presentation of 'Abbasid statehood relied upon the institutions of their predecessors in the region-the Sassanian Empire.

The 'Abbasids explicitly and publicly connected with Sassanian tradition in as many ways as possible to appease the groups that had helped them achieve power and over whom they now ruled. Indeed, the policy of integration with pre-existing traditions and cultures is apparent at many levels. Al-Mansur, the second 'Abbasid caliph, (r. 754-775) was the son of a Persian mother. The "political astrology" used as 
the rationale for the siting of Baghdad (both where and when), reflected 'Abbasid rule as an extension of and natural successor to the astrological practices of the Sassanian and Near Eastern empires (Gutas 1998, 45). However, the most important and influential way the 'Abbasids connected to the cultures and traditions of the extant populations was through the systematic translation of Greek texts and by the development of an intellectual elite.

\section{The Translation Movement}

The translation movement lasted from approximately 756 to $950 \mathrm{CE}$, and was the basis for an incredible arc of intellectual development. As we have seen by their inclusion of non-Arabs and pre-existing eastern culture, it was the 'Abbasids who took the first steps toward creating a multi-cultural, inquisitive, and creative society. Under these caliphs, "the genius of the Persians fused with Arab-Islamic civilization to reach a first high point" (Glasse 2002, 11). Figure 4.2, the first in the series of density overlay maps, illustrates the role of Baghdad as spatially dominant in terms of cultural activity; eighth, ninth, and tenth century astronomy/mathematics and philosophy activity all circle around Baghdad, clearly defining a highly localized sphere of influence. Empire-building under the Umayyads had meant consolidation of power to the exclusion of most other concerns, but the "Abbasids put massive resources behind intellectual endeavors:

The translation movement involved more than two centuries of planned and unplanned effort, hundreds of individual works, at least four major source languages (Syriac, Greek, Pahlavi, Sanskrit), efforts of manuscript collection, the setting up of translation 'workshops,' the building of libraries and observatories, all under the immediate and committed sponsorship of existing rulers and a variety of other patrons. The secular knowledge introduced in this 


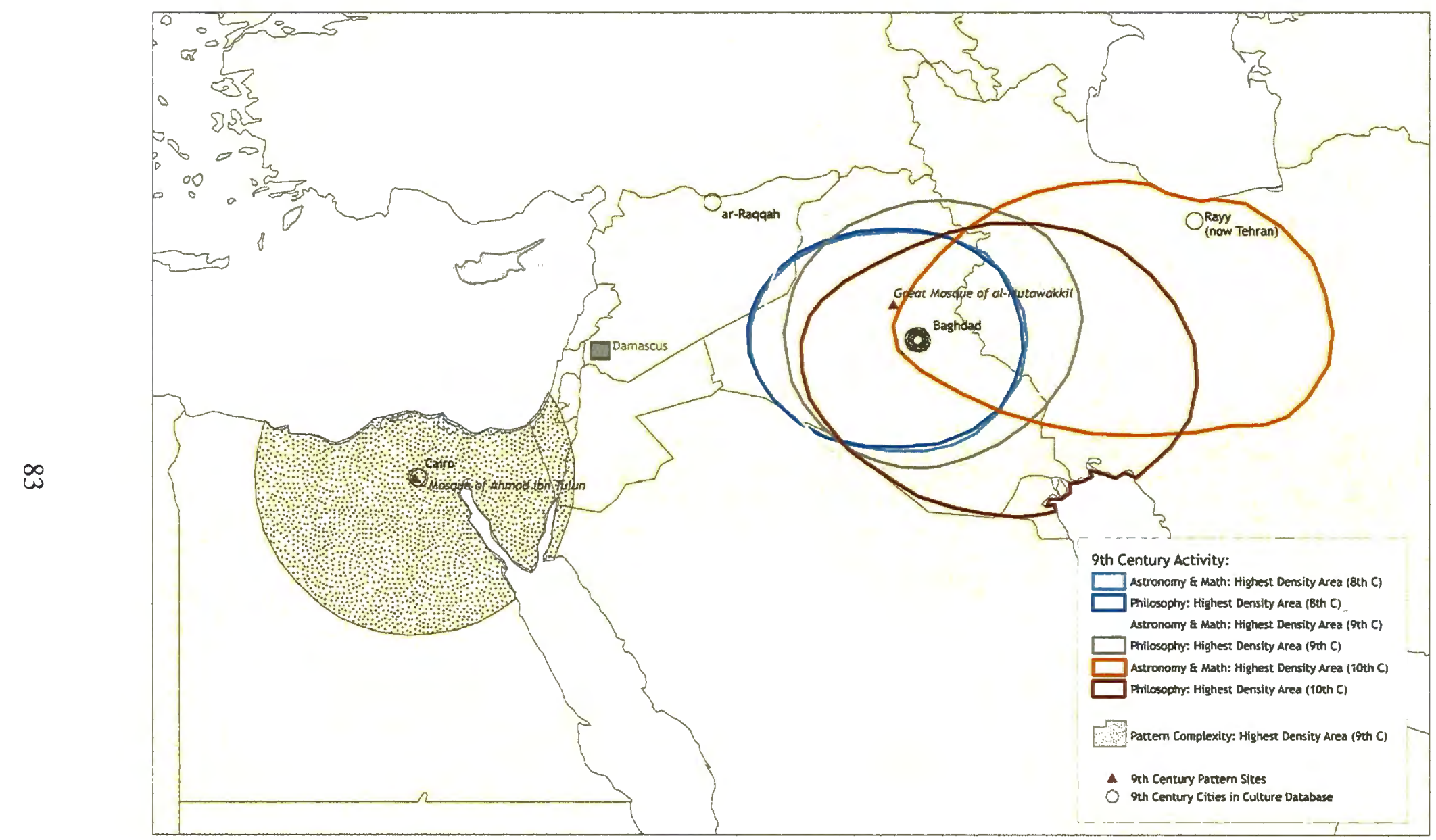

Figure 4.2 Ninth Century density overlay map, showing three centuries of activity. (Damascus shown for reference only). 
manner eventually came to affect writing and thought in almost every conceivable discipline and was instrumental in making Islam into a 'world civilization' of the highest order... (Montgomery 2000, 93)

Thus the seemingly localized phenomenon (as seen in figure 4.2) fostered by the translation movement in Baghdad would eventually spread out, affecting the whole spatial and temporal fabric of the Islamic empire. Without the translation movement, the advances in the sciences, philosophy, and theology could not have occurred as they did.

The translation movement owes part of its success to the spatial distribution of different intellectual traditions. The tradition of Greek learning existed in some of the pre-Islamic cities in the area: Dayr Qunna near the Tigris River, al-Hira on the Euphrates, Harran, Edessa, Nisibis, and Marv contributed to this success (Gutas 1998, 14; O'Leary 1979, 72). A.I. Sabra, historian of Islamic science, notes that the groups occupying these locations were Christian physicians and theologians "who continued to pursue their interest in Greek logic and philosophy in scattered monastic schools; the other [group] was the pagan Sabians of Harran, in northern Mesopotamia, an ancient Semitic group whose astral religion connected them to Hellenistic astrology and astronomy and to Hermeticism" $(1996,658)$. The earliest translators of astronomical and mathematical works came from the region of Khurasan, and most especially its capital Marv, where the Barmakid viziers (ministers in the 'Abbasid court) were from (O’Leary 1979,156).

The ideological differences between the Umayyads and the 'Abbasids parallels the important differences between Byzantine and Hellenistic Greeks. The Umayyads 
in Damascus relied on Byzantine administrative models and pursued an intellectually conservative agenda; the Greeks there followed Christian Orthodoxy, and did not look back favorably upon Hellenistic thought. The Greeks in the region around the new capital at Baghdad, however, felt the opposite - they valued and continued the pursuits of the Hellenistic Greeks. This means that the translation movement could never have occurred in Damascus; the spatial framework of locations of unbroken intellectual activity in the East supported the movement early on, providing a unique and ideal foundation (Gutas 1998). The importance of the spatial context in this early period provides the underpinning for the distributions of later developments in the sciences and philosophy.

Although many translations had been commissioned as early as the reign of alMansur (r 754-775), Al Ma'mun (r 813-833) is most often associated with the translation movement. He founded the Bayt al-Hikmah (House of Knowledge) in Baghdad in 830 . It was an academy as well as a library, an ideal setup that facilitated translation and interpretation, and it attracted many scholars; thus translation activity and development of new texts occurred overwhelmingly in Baghdad. The great variety of translated texts also speaks to the magnitude of the translation movement. There are hundreds of important texts (originally written in Greek but usually translated from Pahlavi or Syriac versions) translated into Arabic that pertained to mathematics and astronomy. From Indian sources come the Siddhantas of Brahmagupta and Aryabhata, and from Persian sources many Zijs, or astronomical tables (Nasr 1968 169). 
Works in the fields of philosophy and logic by Plato, Socrates, Plotinus, and Porphyry made their way into Arabic. Hunayn Ibn Ishaq (809-873), one of the most prolific of the earliest translators, produced translations of Aristotle's Categoriae, Hermeneutica, De Anima, Metaphysica L., De Generatione et Corruptione, and parts of the Analytica Priora and Posteriora. Indeed, as early as al-Mahdi's reign (775785), scholars translated Aristotle's Topics for guidance on methods of disputation for use in religious debates, and they translated Aristotle's Physics for use as "ammunition" in these debates. Court records from the period report theologians formally refuting Aristotle in writing, showing that his works were not just copied but assimilated and disputed (Gutas 1998, 72). As Fakhry writes in A History of Islamic Philosophy, the introduction of Greek ideas

generated a bipolar reaction of the utmost importance for the understanding of Islam. The most radical division caused [by this introduction] was between the progressive element, which sought earnestly to subject the data of revelation to the scrutiny of philosophical thought, and the conservative element, which disassociated itself altogether from philosophy on the grounds that it was either impious or suspiciously foreign. This division continued to reappear throughout Islamic history as a kind of geological fault, sundering the whole of Islam. (1983, xix)

Thus the translation and disputation of Aristotle occasioned significant debate in the intellectual communities of Islam. These debates changed the nature of how intellectuals thought about their world and their religion, resulting in manifestations of these different ideas over time and space, as the density overlay maps will show. The Philosophical Hinge

Court culture, especially that of al-Ma'mun ( $\mathrm{r}$ 813-833), encouraged debate and discussion by continuing to fund the translation of scientific and philosophical 
works into Arabic. The frenzy of all this translation resulted in the introduction and application of Greek modes of thought to Islamic ideology, as noted above. Islamic scholars faced reconciling topics as various as astronomic theories and free will with Qur'anic principles. The court culture, representative of the extant Persian population of the region, also facilitated the attempts at synthesis of the translated material with Islamic ideas: "...the higher administration of the ['Abbasid] court itself was in the hands of cultivated Persians...whose intellectual interests inclined them to various forms of secular learning and to a rationalizing approach for understanding matters of religious belief" (Sabra 1996, 657). It comes as no surprise that these attempts at synthesis resulted in deep divisions whose legacy was the development of distinct schools of philosophy and theology.

The translation of Aristotle's works and the appearance of original commentaries in Arabic marks one of these divisions in the intellectual history of Islam. Two major strands in Islamic thought, Aristotelianism and atomism, hinge at this point. Briefly, Aristotelianism, in the hands of Islamic scholars, represented the application of logic, deductive reason, and empiricism to the problems of Qur'anic exegesis. These philosophers held that "philosophy could be developed in a way that was both in accordance with its own nature and also compatible with revelation" (Watt $1985,40)$.

The works of Aristotle raised important issues for the understanding of the nature of the universe, in particular its origination. For example, Aristotle suggested that the world is eternal, which appears to contradict the inference in the Qur'an that 
God created the world out of nothing. One Islamic scholar, al-Farabi (870-950), following Aristotle, "used as his principle of creation the process of emanation, the idea that reality continually flows out of the source of perfection, so that the world was not created at a particular time" (Leaman 1998, 57). These types of conciliatory theories came to comprise the body of Aristotelian thought in the Islamic world. However important the original works of Aristotle, most of the Islamic philosophers were of the Neoplatonic position- "this was mainly the result of the form taken by the later Greek philosophic tradition when the Muslims came into contact with it. Though Aristotle was studied carefully, he was seen through Neoplatonic eyes" (Watt 1985, 40). Plotinus, the founder of Neoplatonism in ancient Greece, incorporated into its corpus the notion that "reality was an ordered hierarchical whole with two movements, one of descent and the other of ascent...the first is a movement from unity to multiplicity, while the second is a movement from multiplicity to unity...the theory which most influenced Islamic thought is that of emanation which aims at explaining the creation of the universe" (Qadir 1988, 38).

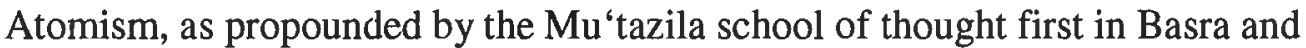
then in Baghdad, was a philosophy indigenous to Islam (O'Leary 1979, 145). Their Atomistic cosmology was:

based on the dualism of essence (atom) and existence (accident). This atomistic view of matter, space, and time... explained all phenomena in the physical world through the inherence of accidents in the atoms that composed matter. This was an ephemeral and perishable material world in perpetual flux where anything visible remained only accidentally bound to its apparent form" (Necipoglu 1995, 95). 
As for the force behind this perpetual flux, they held that "atoms come into existence out of nothing and disappear after losing their existence...[this depends] upon the will of Allah, Who is the final and the ultimate cause...it was Allah Who was responsible for the harmony among the atoms" (Qadir 1988, 67).

The Mu'tazila constituted the first real Islamic school of theology in that they applied reason to their questions and used argument and dialectic as methods (Glasse 2002, 248). The Mu'tazilites, also called rationalists, seem to have created a need for the translation and study of additional texts. The ideas propounded by the Atomist Mu'tazila raised questions; therefore, intellectuals sought answers in the newly translated material and embraced Aristotelianism and Neoplatonism in response. The resulting schism came to play an enormous role in academic and theological debates, and as Gutas maintains, "dominated Arabic intellectual history for centuries" (1998, 73).

If the significant division between atomism and Aristotelianism is a hinge, then the concepts of kalam and falsafah are on opposite sides of the door. Mu'tazila atomist cosmology is part of the larger tradition of kalam, which literally means "speech" or "dialectic," but generally refers to Islamic scholastic theology. Falsafah and its practitioners, called falasifah, lie on the other side of the door. "[Falsafah] is a tradition which postdates kalam... [and] received its fundamental inspiration from the translated Greek works, remained committed to Aristotelian logic, operated in the framework of Neoplatonic metaphysics, and held the mutakallimun [practitioners of kalam] in intellectual contempt" (Haq 1998, 59). Al-Kindi (801-873), deemed the first 
Muslim philosopher, al-Farabi (870-950), and Ibn Sina (Latin Avicenna, 980-1037) all belong to this tradition, and are examples of individuals included in the culture database whose activities affect the development of the regions of high-density activities on the density overlay maps. I will discuss their distinctive achievements in greater detail in succeeding sections. Neoplatonism, as practiced by these and other scholars, became the prevailing school of thought and it followed the Greek (Peripatetic) philosophical schema. All of these traditions-Aristotelianism, Neoplatonism, atomism—shaped the methods and approaches of philosophers, astronomers, mathematicians, geographers, and more-all those individuals who engaged in scholarship worked within one world-view or another.

But depending on the orthodoxy of the caliph and resulting culture in which these people worked, there were certain conceptual limitations. The role of the $\mathrm{Mu}$ 'tazilites is especially important because in 827 al Ma'mun officially adopted the Muta'zilite (Atomist) philosophy as the position of the state. He so vigorously supported their doctrines that he even instituted the mihnah, or inquisition into religious scholars' beliefs. Eventually, the pendulum swung the other way when the extremely orthodox Caliph al-Mutawakkil (r. 847-861) removed the Mu'tazilites from the 'Abbasid court because some of their ideas were deemed heretical (Qadir 1998, 52-53). As a result of their exclusion, the Mu'tazilites' themes and lines of inquiry changed (Dhanani 1994).

Shifts in caliphal support resulted in differences in the topics being discussed and considered, as well as the pursuits of the various groups. These different 
philosophical groups gathered in different places over the course of time, depending on who would support them, thereby contributing to the rich spatial diversity of beliefs and practices making up the vast Islamic world.

Influential Thinkers

There were many important scholars in the ninth century, most of whom worked in Baghdad, as evidenced by the accumulation of points there as shown on figure 4.2. But the achievements of some individuals affected the development of Islamic philosophy and science more significantly than the rest. Two of these scholars, al-Kindi (801-873), already mentioned above, and al-Khwarizmi (780-850), a towering figure in the Islamic exact sciences, stand out.

Al-Kindi worked in Baghdad and represents the Aristotelian camp, in opposition to the Mu'tazila; he sought to "elaborate an encyclopedic system of Greek philosophy... [and his] treatises encompass the whole Classical encyclopedia of sciences: philosophy, logic, arithmetic, spherics, music, astronomy, geometry, cosmology, medicine, astrology, etc..." (Klein-Franke 1996, 165). Within this purview, scholars made progress in the fields listed above. Yet once again, caliphal support or censure played a critical role. Al-Mutawakkil (r 847-861), the same caliph who expelled the $\mathrm{Mu}$ 'tazila from court, still reacting against the intellectual tendencies of the time, seized al-Kindi's library, and many of al-Kindi's original treatises (fewer than ten percent of which are estimated to have reached the twenty-first century) were lost (Klein-Franke 1996, 166). Despite this, al-Kindi set the foundation for the acceptance of Greek Classical, and especially Neoplatonic learning, in his treatises On 
Definitions and Descriptions of Things, On First Philosophy, and That Philosophy

Cannot be Acquired except with a Knowledge of Mathematics.

Al-Khwarizmi served al-Ma'mun at the Bayt al-Hikma (House of Wisdom) in Baghdad. He produced pivotal works in algebra, arithmetic, geography, and astronomy. His Kitab al-jabr wa l-muqabala (The Book of Restoring and Balancing), gave rise to the term algebra, and was the first Muslim work on the subject. A Latin corruption of his name produced the term algorithm (Berggren 1986,7). AlKhwarizmi produced "[t]he most important contribution of the Muslims in arithmetic ...the introduction of the Indian system of reckoning, using the nine Arabic numerals, with a point for zero" (al-Hassan and Hill 1994, 24). Figure 4.3 shows the graphic elegance of his astronomical tables. He assisted in the creation of the famous Map of Ma'mun and corrected some of Ptolemy's calculations in his geographical work, The Image of the Earth. Nasr, historian of Islamic science, represents many scholars' estimation of al-Khwarizmi when he notes, "[t]he writings of al-Khwarizmi...had an immense influence, more than that of any other single mathematician" $(1968,45)$.

Both al-Kindi and al-Khwarizmi wrote treatises that spanned categories of learning, such as philosophy and mathematics, and they both represented the Aristotelian and Neoplatonic tradition. As with the larger structures making their activity possible, their innovations produced ripples that would travel to the edges of the Islamic empire and would be felt for centuries. Therefore it was within this framework of traditions of learning built upon a distinct and unique spatial foundation that the trajectory of Islamic science and philosophy developed. 


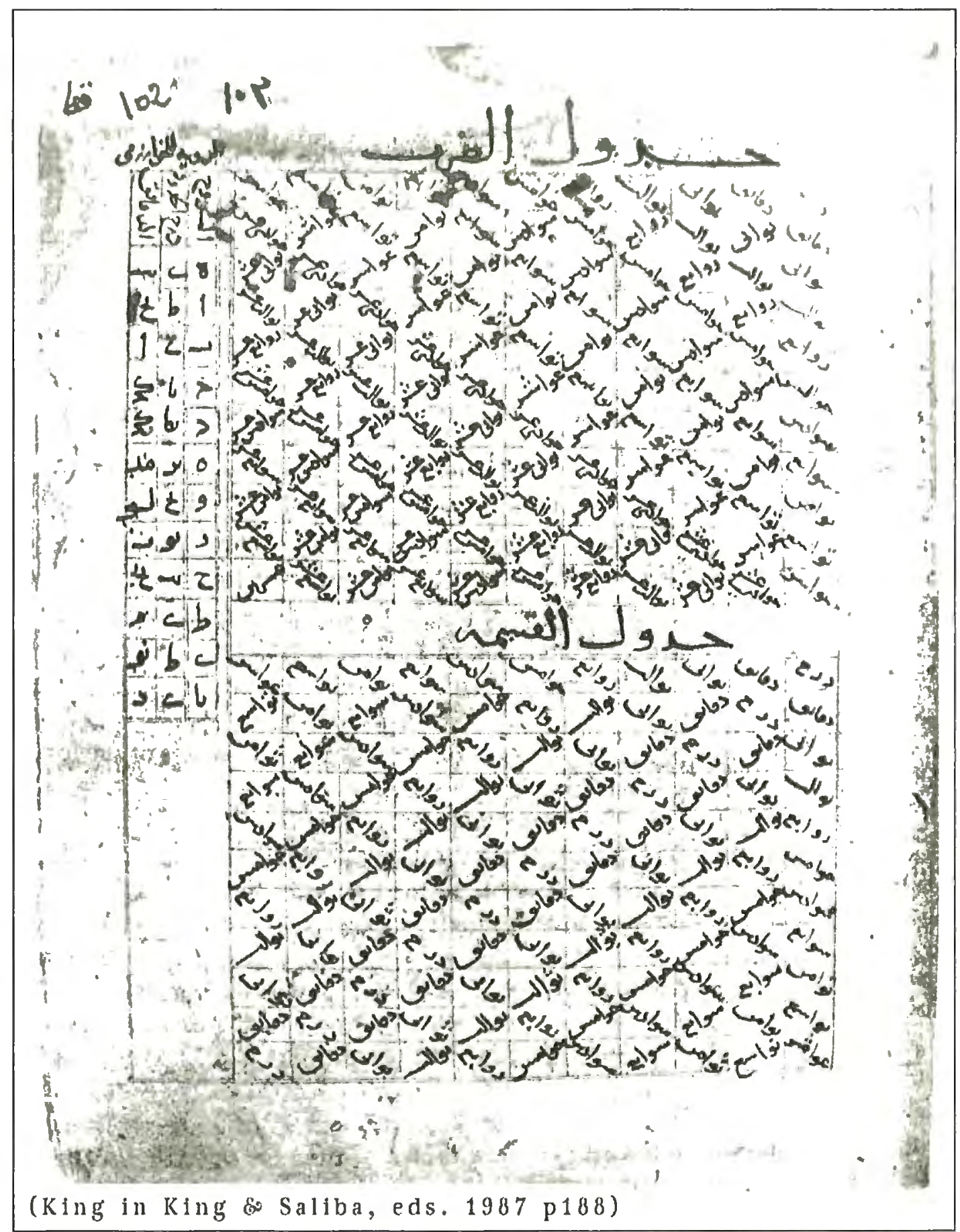

Figure 4.3 Page from a book of astronomical tables by al-Khwarizmi (780-850). 


\section{$\underline{\text { Early Regional Architecture }}$}

As we have seen, the 'Abbasid rise to power related to the spatial distribution of various culture groups; the same distributions of cultures made the translation movement and therefore developments in science and philosophy possible. The density overlay map for the ninth century (figure 4.2) graphically represents Baghdad's influence in science and philosophy. Curiously, although all of this activity surrounds Baghdad, the city does not fall within the region of highest pattern complexity.

This represents a departure from what we would expect, given the notion that advances in mathematics and astronomy, and/or philosophy and theology relate spatially to occurrences of complex decorative geometric pattern; but perhaps this is because there is a problem with the data itself. Only three mosques were built in Baghdad proper in the ninth century, but none have survived, therefore I have no record of their decorative style. The existing 'Abbasid monuments in Iraq that date from the ninth century are at Samarra, where al-Mu'tasim moved the capital in 836 (the capital later moved back to Baghdad). The Great Mosque of al-Mutawakkil, built in 848-852, and Abu Dulaf, built somewhat later, embody 'Abbasid grandeur in their size and display austerity in their decoration. The secular architectural remains at Samarra reveal an opposite tendency - the type of stucco decoration employed there, dubbed the Samarra style, covers many architectural surfaces (figure 4.4). An important aspect of this style is its repeatability-each shape forms the boundary of 


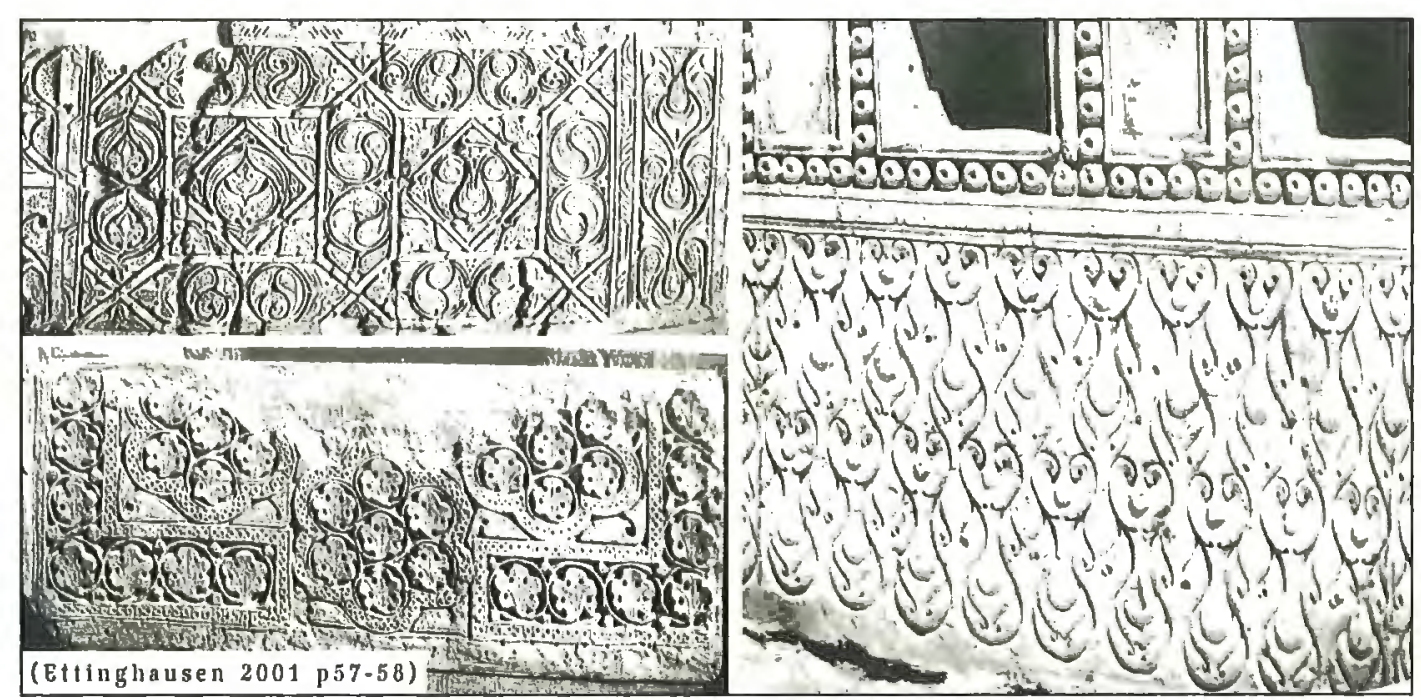

Figure 4.4 'Samarra style' decoration found in ninth century, Samarra, Iraq. 
the next, and can repeat across a surface. This kind of decorative mechanism, the repeated form covering a surface, became much more widespread (in the form of geometric pattern) than the style itself in succeeding centuries. While the Samarra style represents a turning point in decorative modes, it does not constitute a complex geometric pattern, thus it does not result in a region of high pattern complexity on the map.

Yet the artistic authority of Baghdad was still considerable. 'Abbasid influence traveled to the Great Mosque of Qairawan (built 836-875) in Tunisia, which houses a Baghdadi mihrab and minbar decorated with tiles crafted in Baghdad. 'Abbasid influence also appears at the Mosque of Ibn Tulun in Cairo in the use of the Samarra style. Ibn Tulun, a powerful governor who maintained a semi-independent court in the service of the 'Abbasids, built this mosque between 876 and 879 . Hillenbrand, an historian of Islamic art, summarizes the importance of 'Abbasid culture to artistic development across the Islamic world of the ninth century:

[t]he shift in the centre of gravity from Damascus to Baghdad involved not merely a geographical adjustment of five hundred miles. It had potent repercussions in politics, culture and art. Baghdad became, in a way that Damascus had not, an Islamic Rome. It absorbed ideas, artifacts, and influences from the East-from the Iranian world, India, China, and the Eurasian steppe, and then exported them, transformed, throughout the Islamic world, stamped with its own unique cachet and glamour. $(1999,40)$

Alongside elements of the Samarra style at Ibn Tulun, one also finds limited examples of star-and-polygon geometric pattern (figure 4.5). These star-and-polygon patterns are what drive the region of pattern complexity on the figure 4.2. Necipoglu notes that the star-and-polygon patterns such as those employed in window grilles at 


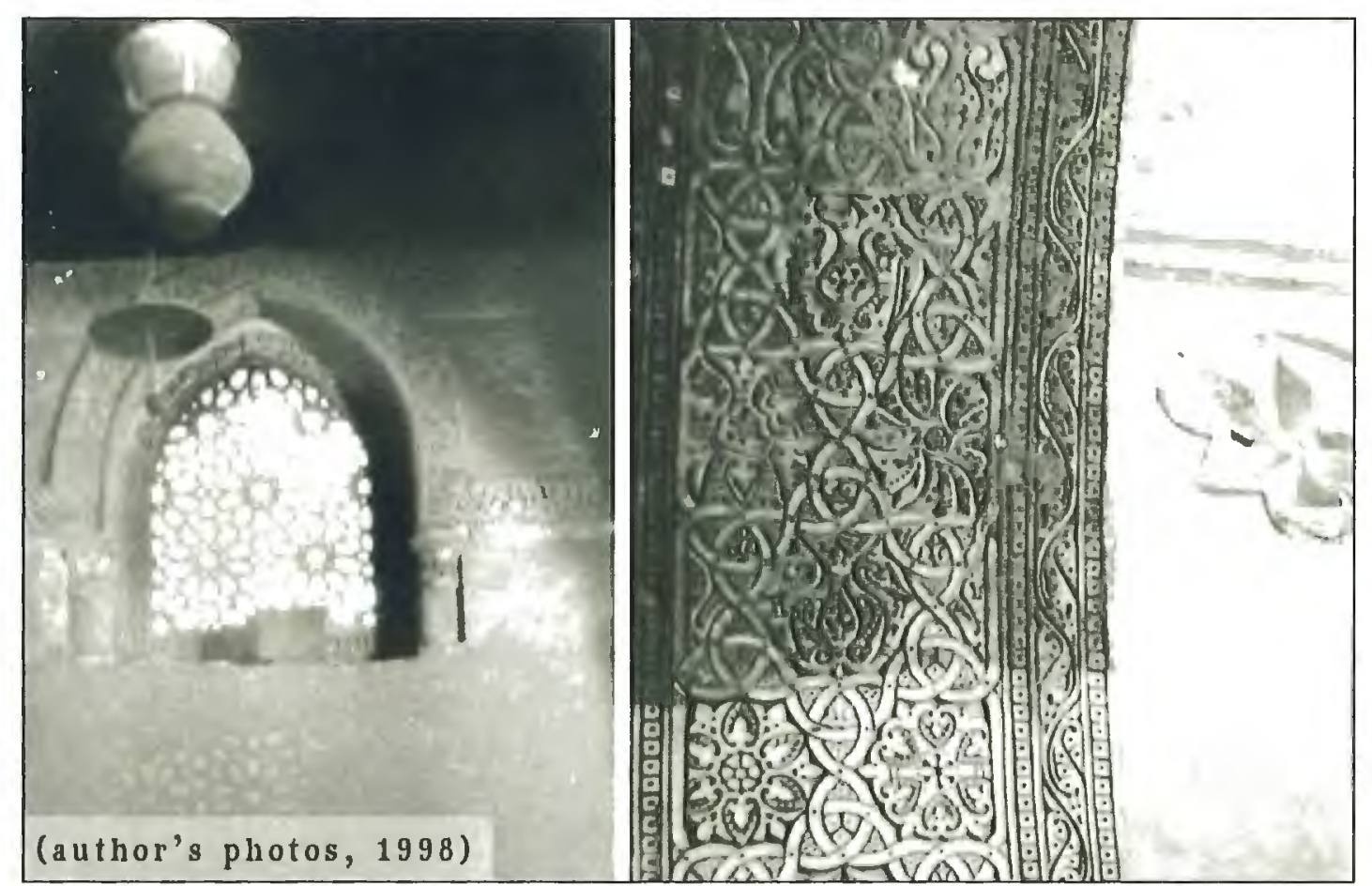

Figure 4.5 Two kinds of decoration at the Mosque of Ibn Tulun (876-879, Cairo): star-and-polygon window grille, left, and Samarra style, right. 
Ibn Tulun had not found widespread use by the ninth century, indicating their use was unique and severely limited $(1995,93)$. Certainly, evidence from this early in Islamic architectural history is incomplete, but my database reflects the scarcity of star-andpolygon decoration in this period.

Ultimately, the map for the ninth century does not show the kind of spatial arrangement consistent with the hypothesis that activity in the sciences and mathematics is a precursor to the existence of these patterns. There may be examples from this period that have not survived which would alter the map, but with the information available, we see that the austerity of decoration in the remaining 'Abbasid mosques of this period and earlier lies in stark contrast to the great number of individuals and institutions at work in the fields of science and philosophy in the ninth century. 


\section{DISCUSSION: TENTH CENTURY}

The map of tenth century activity (figure 5.1) indicates an outward trend in activity, with expansion to the east, to a lesser degree the west, and a general dispersal of activity away from Baghdad. This century witnessed the dissolution of the 'Abbasids political power, although they maintained nominal control of the caliphate for three hundred more years. The establishment of regional (multiple) power bases in the Islamic empire contributes to the patterning of activities on the map; Baghdad retains some centrality but the furthest extents east and west represent regions that achieve great importance in the ensuing centuries. In this section I discuss the new power bases, these regions' relationship to ongoing developments in science and philosophy, one especially important group of scholars (the Ikhwan al-Safa), and the development of new architectural decorative modes. The following timeline summarizes the events discussed in this section (figure 5.2).

A Multiplicity of Caliphates-the New Power Bases:

Although Baghdad remained a center of culture and learning in the tenth century, political and economic disturbances contributed to the devolution of 'Abbasid political power. Their authority bled out to groups in Cairo, Cordoba, Samarqand, and Shiraz (O'Leary 1979, 4).

The Fatimid dynasty, based in Egypt, claimed descent from Fatima, daughter of the Prophet Muhammad. In 909, they used this legitimacy to call themselves Caliphs, in direct challenge to the 'Abbasids. The Fatimids were Isma'ilis, which is but one strand of Shi'ism. They set up their capital in Cairo in 969 and founded al 


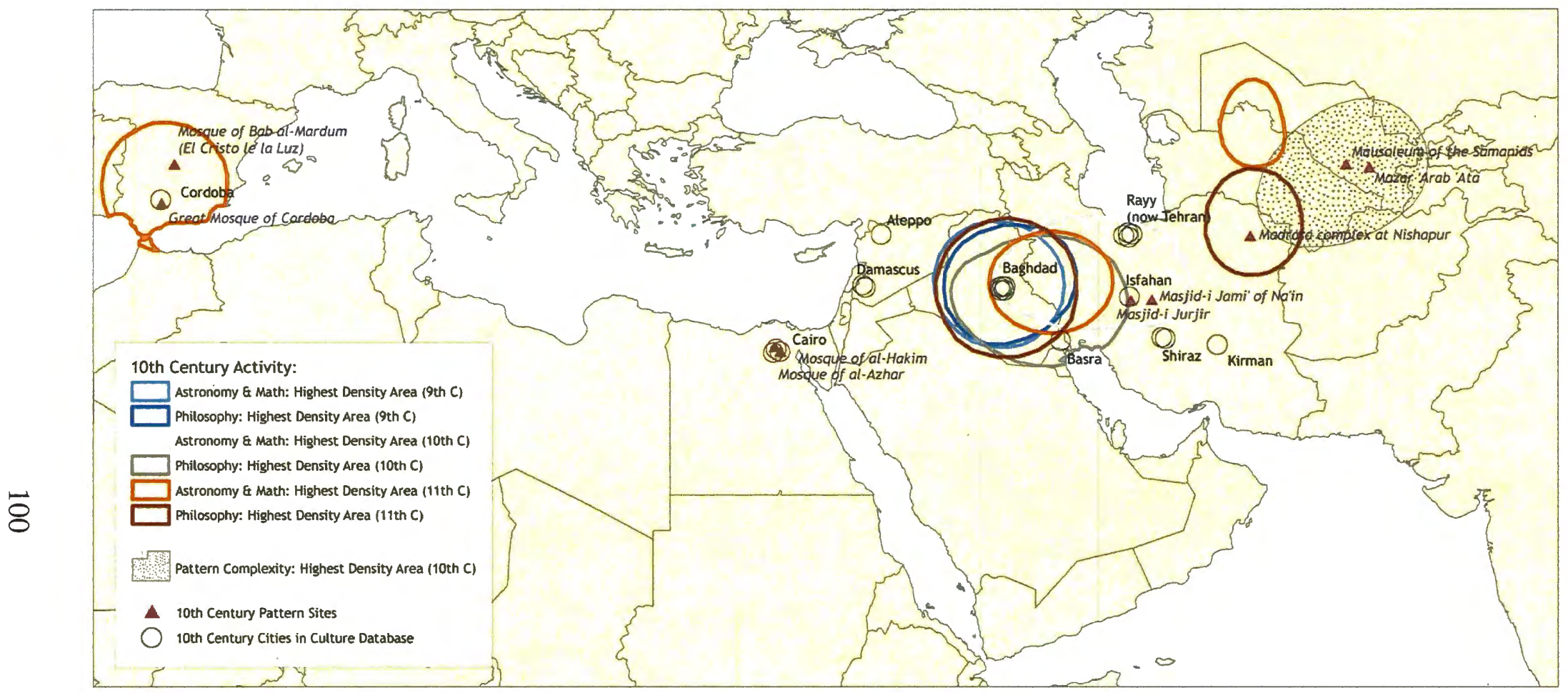

Figure 5.1 Tenth century density overlay map, showing three centuries of activity. 


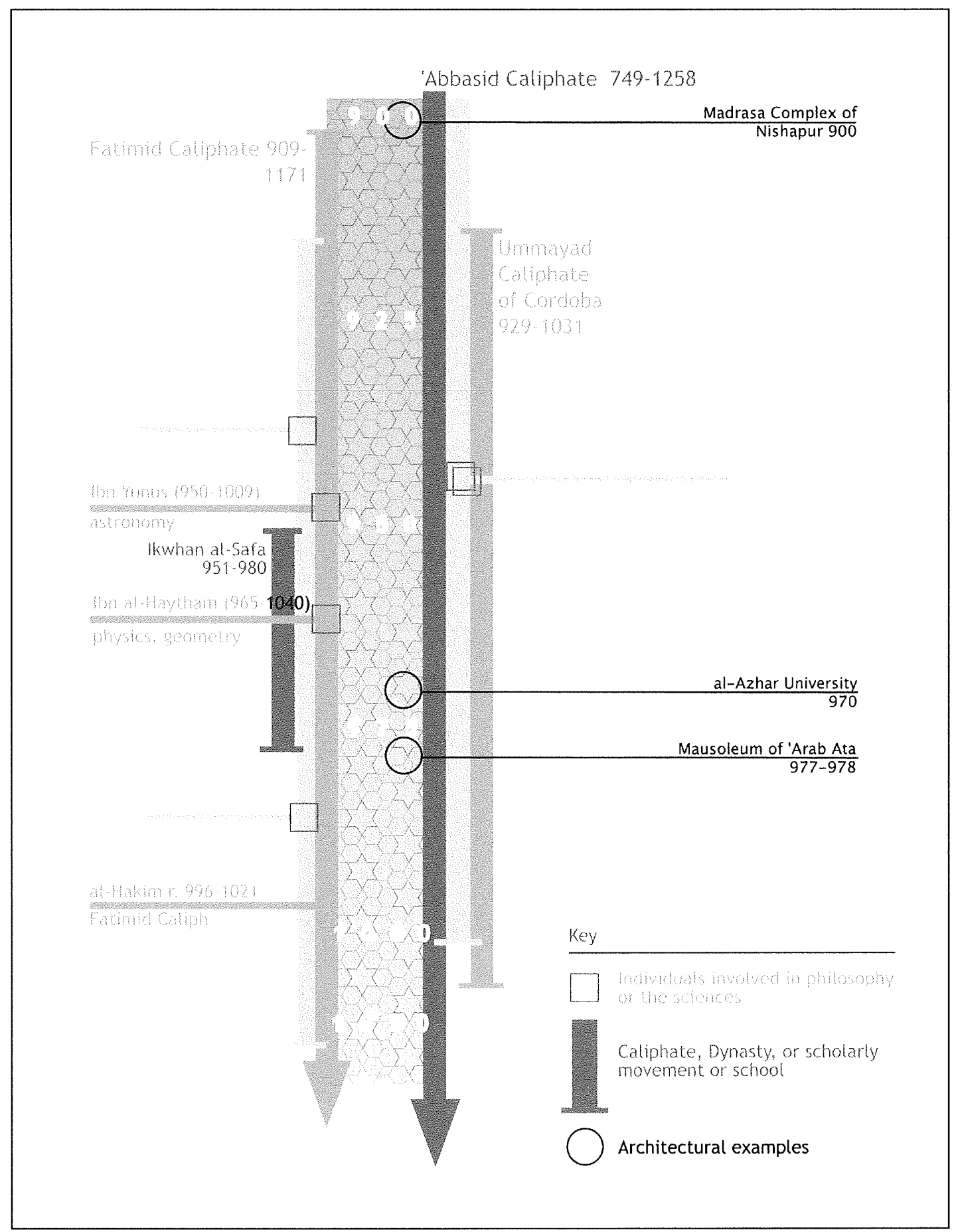

Figure 5.2 Timeline for tenth century. 
Azhar University shortly thereafter. This school taught Isma 'ili doctrine and in doing so threatened the dynasties in other regions. In reaction, early in the next (eleventh) century, the Saljugs, who were Sunni, set up a series of madrasas (religious schools) to propagate their own doctrines. These institutions became important conduits of more than just theological teachings, and the divisiveness between the Sunni Saljuqs and the various Shi' a dynasties grew exponentially as time went on (Sabra 1987). The Sunni/Shia contest, while emerging in the tenth century, does not have any spatial referents on the density overlay map from this period; the division will play out in spatial form in the ensuing centuries.

Despite this unrest, the Fatimids managed to rule over the area from Palestine to Tunisia until 1171 . Indeed, Cairo displays slightly more activity in the map of the tenth century than the ninth, but the accomplishments associated with these activities do not relate spatially to high-density regions of significant scientific, philosophical, theological, or artistic activity.

As noted earlier, in Cordoba, an offshoot of the Umayyad dynasty established itself. 'Abd ar-Rahman III, claiming legitimacy through his Umayyad lineage, also took the title of Caliph in 929. The Umayyads had ruled in Spain since 756, and by ar-Rahman's reign, "the Islamic realm in Spain attained an unprecedented prosperity and cultivation. The arts and sciences flourished...the court and capital of Cordoba were the most brilliant in Europe" (Glassé 2002, 463). Figure 5.1 shows evidence of this work in astronomy in the following (eleventh) century, as shown by the orange line around Cordoba. 
The Samanids, a Persian dynasty ruling in Central Asia, made Samarqand their capital. They ruled from 819-1005 as vassals of the "Abbasids in the regions of Khurasan and Transoxiana. The Samanids did not have pretensions to the Caliphate, but their courts in Samarqand and Bukhara achieved wealth at the crossroads of Asian trade, and became important locations for disseminating and patronizing Persian culture. Ettinghausen states, "it is reasonable to argue that northeastern Iran did rival Baghdad and central Iraq in brilliance and originality" (2001, 130). It is here, at the easternmost extent of the Islamic world of the tenth century that the region of highest pattern complexity falls (figure 5.1).

Lastly, Mu'iz al-Dawlah established Buyid (also called Buwayhid) rule in the east in 932, in effect making the 'Abbasid Caliph a figurehead in his own region. The Buyids established themselves at Rayy (now Tehran), a center of commerce, and made their capital at Shiraz. The Buyids were Shia, but did not practice the same version as the Fatimids in Cairo. However, these manifestations of Shia influence made Sunni groups nervous, so they went on the offensive, and by 1062 the Buyid dynasty gave way to two Sunni dynasties-the Saljuqs in the western part of Persia and the Ghaznavids in the east-both of which play an important role in the following (eleventh) century. Ultimately, this was a very bad time for the "Abbasid empire. New Regional Scientific and Philosophical Centers

In the tenth century map (figure 5.1), scholarly activity has spread from Baghdad west to Cairo and Cordoba and east to Persia. Further east, in Transoxiana, there is no evidence of any mathematical, astronomical, or philosophical activity 
predating the high pattern complexity found there. Thus the changes wrought by the shifts in regional power had not appeared there yet, but show up in Khwarazm (modern-day Uzbekistan) in the following (eleventh) century. This spatial arrangement of tenth century high pattern complexity and the overlapping of eleventh century philosophy runs contrary to the expected outcome, the notion that mathematical (or other cultural activity) precedes use of the geometric mode. Nowhere in the literature surrounding these patterns does anyone suggest that the presence of the geometric mode spurred or otherwise inspired activity in any other discipline. Figure 5.3 presents a detail of this area.

The city in this region of unique overlap is Merv, but in the culture database, there is no science or philosophy activity there until the twelfth century (in the persons of 'Umar Khayyam and al-Khazini). However, the city that is generating the overlapping zone is Nishapur, whose philosophy activity in the eleventh century was dominated by al-Ghazali (1058-1111, discussed in the following section). There may yet be a relationship between al-Ghazali and the region of high pattern complexity, as Nishapur is only 225 miles from Merv. Because al-Ghazali was such an important figure in the intellectual history of Islam, any possible connection to the region of high pattern complexity is worth exploring, even though the overlap in this case does not correspond exactly. Further research, outside the scope of this paper, should look more closely at the architectural and intellectual activities in Nishapur and Merv, and the mausoleums in Afghanistan of the late tenth/early eleventh centuries, with special 


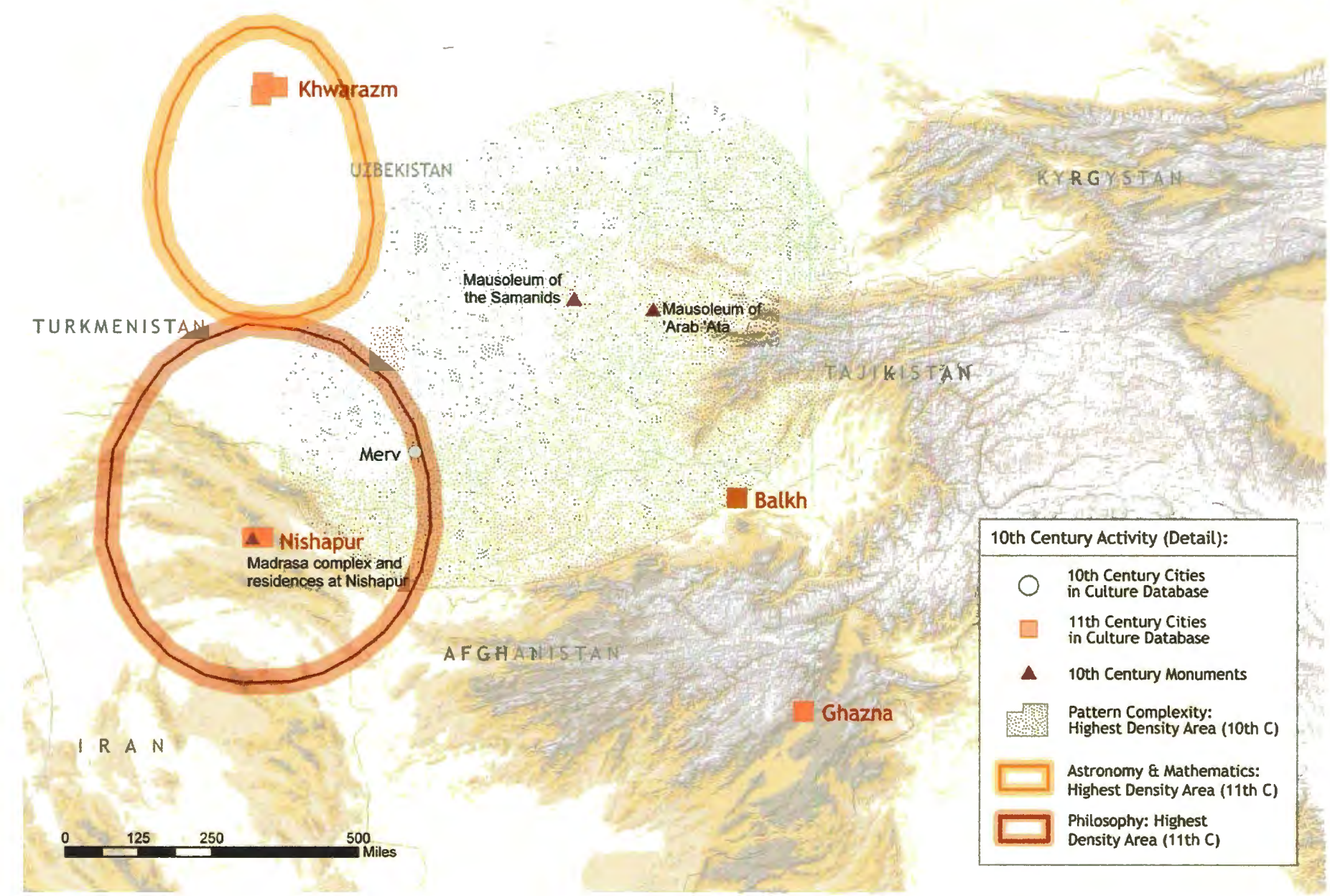

Figure 5.3 Detail of tenth century density overlay map. 
focus on the movements of al-Ghazali. As we will see in succeeding maps, this kind of spatio-temporal arrangement is not an isolated occurrence.

Moving back to the rest of the tenth century density overlay map (figure 5.1), I discuss here the developments in Cairo, Persia, and the continued activity in the region surrounding Baghdad in the tenth century. In the tenth century, scholars Ibn alHaytham (965-1040, Latin Alhazen) and Ibn Yunus (950-1009) made their home at Cairo. Al-Haytham rebuilt the field of optics from the ground up, and contributed to astronomical models and physics. Ibn Yunus had an astronomical observatory on the outskirts of Cairo and produced al-Zij al-Hakimi al-Kabir (Large book of astronomical tables dedicated to Caliph al-Hakim); he also contributed to the field of spherical trigonometry. That the city attracted these important scholars says something about how Cairo developed into a stronger power, with more patrons and opportunities for scholars than had existed there before the rule of al-Hakim (r 996-1021). Indeed, alHakim established the Dar al-ilm (House of Knowledge); mathematics and physics were taught, and as many as one million books are said to have been collected there. Other Shi'ite institutions using the same name sprang up, adding more fuel to the Sunni/Shi'a intellectual antagonism.

Isfahan, Rayy, and Shiraz all gained importance in the tenth century. On figure 5.1 the light grey line indicates a region of high astronomy/math density there for the tenth century. Buyids ruling in Isfahan, Shiraz, and Kirman supported the work of high caliber mathematicians like al-Sijzi and ibn Sahl who "worked in a century that was one of the most active periods of geometrical research in medieval 
Islam" (Berggren 2003, 177, emphasis mine). A great many astronomers and mathematicians in this region corresponded with each other and developed works on conic sections, quadratic and cubic equations, comprehensive astronomical tables, and the improvement of astrolabes. Scholars at Rayy, such as al-Kuhi, under Samanid (thus 'Abbasid) patronage worked on these same themes; indeed, the roles of correspondence in this period and the cooperation of the Buyids are credited with the advancements in these topics (Berggren 2003,181).

One scholar in particular at Rayy produced an important link between mathematics and artistic practice. Muslim mathematicians knew the many practical applications of geometry, and to this end, Abu'l-Wafa al-Buzjani (940-998) wrote Fi ma yahtaj ilayhi al-sani min a'mal al-hindisah (What the Artisan Needs of Geometric Operations) in the late tenth century (figure 5.4). The book reduces complex problems like conic sections into very simple mechanical methods for "constructing, proportionally subdividing, and symmetrically multiplying geometric figures" (Necipoglu 1995, 138). This is one of few tangible and explicit links between mathematics and art of the time. Necipoglu notes that the interdisciplinary nature of arithmetic, geometry, and astronomy implied a link already, "especially since most mathematicians in the medieval Islamic world were to some degree involved with astronomy, the predominant use of orbitlike radial grids in generating [polygonal geometric patterns] may partly have been inspired by a mentality that assigned the most privileged place among geometric figures to the circle" $(1995,133)$. So does the relationship implied here play out in figure 5.1? The region showing high-density 


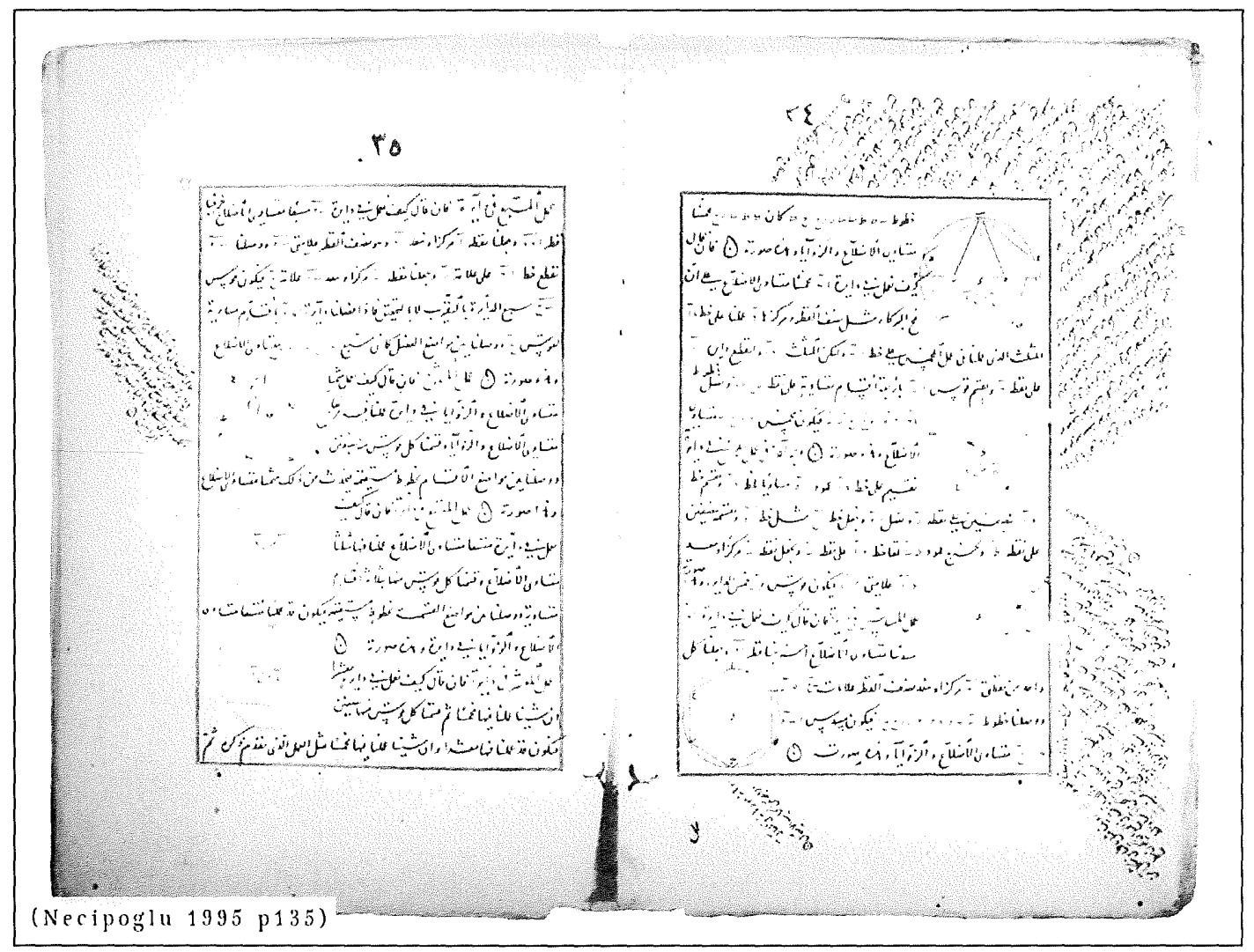

Figure 5.4 Pages from al-Buzjani's What the Artisan Needs of Geometric Operations, written in the late tenth century in Rayy, Iran. 
pattern complexity lies far to the east of Rayy, and is centered on Tim, Uzbekistan. The zone is based on the decorative pattern used at the Mausoleum of 'Arab 'Ata, built in 977-978. Since al-Buzjani's book was written in the late tenth century, the book may or may not have had any connection to the use of star-and-polygon pattern there. In the next century, the eleventh, the region of high-density pattern complexity is centered in Persia; thus the book most likely relates to structures built in the following century. The connection between al-Buzjani's book and the use of the geometric mode in Persia in the eleventh century thus appears to be an example of where Necipoglu's ideas hold up under spatial analysis.

\section{The Ikhwan al-Safa}

Significant advancements in the sciences and philosophy still occurred in Baghdad and Basra, despite the 'Abbasids' waning political influence. Their continued patronage drives the high-density regions surrounding Baghdad on figure 5.1. To be sure, if the ninth century saw the development of the Muta'zila's atomist theories, then the tenth saw the Neoplatonist Ikhwan al-Safa (Brotherhood of Purity) delve into cosmological reflections that synthesized other philosophies.

From 951-980 the Ikhwan al-Safa compiled their encyclopedia of philosophy and science in Basra. They completed 52 essays: numbers 1-14 were on math and logic, 15-31 on natural science, 32-41 on metaphysics, and the rest were on mystic theology, astrology, and magic. Nasr says of their world-view:

the sympathies of the Brethren of Purity were definitely with the PythagoreanHermetic aspect of the Greek heritage, as is especially evident in their mathematical theories, which exercised a great influence during later centuries, 
particularly among Shiite circles. Like the Pythagoreans they emphasized the symbolic and metaphysical aspect of arithmetic and geometry. (1968, 153, emphasis mine)

They developed their ideas "at a time when the recent accession to power of the Buyid dictators produced a temporary experience of toleration and free thought" (O'Leary 1979, 179). With Buyid (Shi'a) influence, the Ikhwan al-Safa, who themselves practiced a form of Shi' ism, managed to develop stunningly intricate (and sometimes obscure) metaphysical works that synthesized their theological and metaphysical concerns with their interests in the exact sciences.

Both the essentialist authors and Necipoglu have written about the relationship between the Ikhwan al-Safa and the use of the geometric mode. From the essentialist camp, Nasr dubbed the Ikhwan's particular synthesis "Abrahamic Pythagoreanism" and defines this as "a way of seeing numbers and figures as keys to the structure of the cosmos and as symbols of the archetypal world...[it] enabled the creation of a sacred art of an essentially geometric nature", thereby connecting their ideology to Islamic artistic practice (Nasr in Critchlow 1976, 6). Ardalan and Bakhtiar use examples from the Rasa'il (Epistles) of the Ikhwan al-Safa to support their theory that the theological concept of tawhid (unity) underlies the use of Islamic decorative geometric pattern (1973). They state "an artist does not necessarily have to know the entire metaphysics of the tradition in order to practice his art. Tradition transmits models and working rules, thereby guaranteeing the spiritual validity of forms for the artist" $(1973,10)$.

These connections between the Ikhwan and a monolithic Islamic artistic practice have been roundly criticized by Necipoglu: "whatever conclusions they reach, 
studies emphasizing the religiospiritual and cosmological dimension of Islamic art are characterized by sweeping generalizations unsubstantiated by concrete data" (1995, 80). However, she does link the popularization of mathematical concepts to the Rasa'il of the Ikhwan al-Safa, acknowledging that they explored theoretical links between mathematics and various crafts (1995). Therefore she posits a more unique relationship rather than an all-encompassing one.

Figure 5.1 spatially supports Necipoglu's criticisms of the essentialists but also does not seem to support her own ideas, in that even at a moderately fine temporal and geographic scale, the use of complex geometric pattern in architecture did not occur proximate to the region where Abrahamic Pythagoreanism developed and was studied; not even in the next century, either. This may, however, be partly due to the destruction of monuments there that could possibly have shed more light on the relationship between the $I$ khwan and the geometric mode.

\section{Advances in the Art of Architecture}

"Rulers with diverse artistic attitudes and tastes" exerted their own influence on the Islamic artistic tradition (Ettinghausen 1976, 57). On figure 5.1, the high pattern complexity region has moved east from Cairo to Transoxiana, an area encompassing Tim and Bukhara (modern-day Uzbekistan). At Cairo in this period one finds star-and-polygon patterns again only in window grilles at the Mosque of alHakim. However, this one instance of star-and-polygon pattern is not enough to generate a region of high pattern complexity at Cairo, given the rest of the examples in the tenth century. In the east, at Tim, Uzbekistan, star-and-polygon patterns begin to 
appear in non-window settings (figure 5.5) on the façade of the structure, and at Nishapur, in northeastern Iran, polygons start to overtake the amorphic shapes of the Samarra style and begin to be used in all-over decoration (figure 5.6).

Most importantly, this period witnesses the initial occurrence for the muqarnas as a decorative strategy. While the muqarnas' origins and routes of transmission are unclear and as yet contested by art historians, Ettinghausen asserts that the earliest extant example is at the mausoleum of 'Arab Ata in Tim $(2001,157)$. This example of a 'proto-muqarnas' is closer to being an articulated squinch (an arch placed at the corner of a square structure to accommodate a dome), visible in figure 5.7. The point of using the muqarnas was to disguise areas of transitions between supports and domes or niches, and "to make the dome appear insubstantial, as the play of light on its intricate surfaces dissolves its mass. This visual display...is one of the most important features of muqarnas vaults" (Tabbaa 1985, 61). As use of the muqarnas increased with time, so did their complexity, resulting in the desired visual 'dissolving' effect, which we will see in the following centuries.

The muqarnas did not appear in the built environment out of nowhere, but the architectural record is lacking some of the pivotal earliest examples. Tabbaa (1985) posits that Baghdad (although there are no extant examples there) saw the initial use of the muqarnas and from there its use traveled to other locations in Iraq, like Samarra, Mosul, Basra, and Raqqa in Syria. Ettinghausen, however, points to an eastern origin, looking to architects in either central or eastern Iran as the originators: "the muqarnas squinch seems to have been a transformation of an originally northeastern decorative 


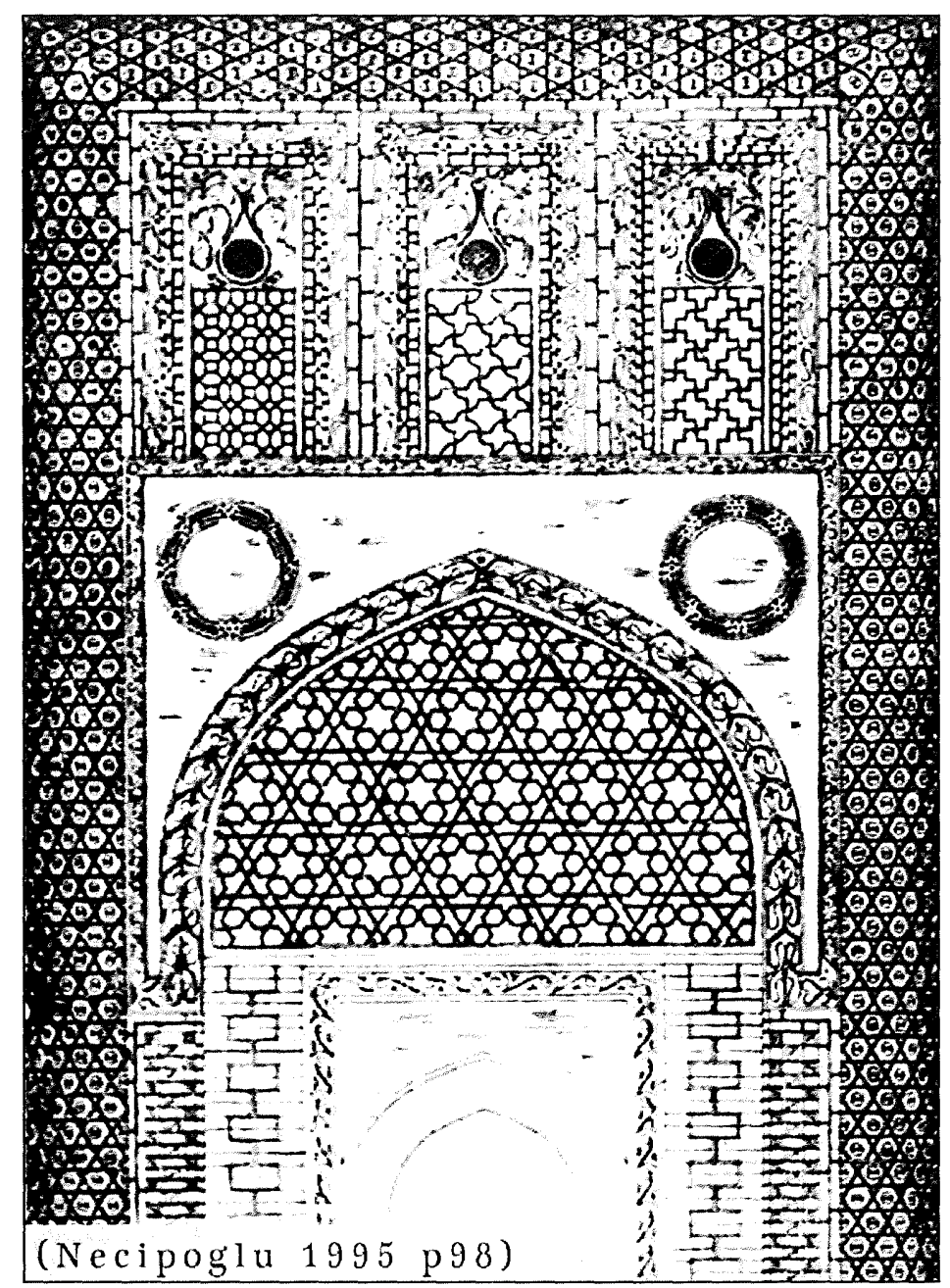

Figure 5.5 Mausoleum of 'Arab Ata (977-978) Tim (Uzbekistan) showing the first known use of star-and-polygon pattern in non-window settings.

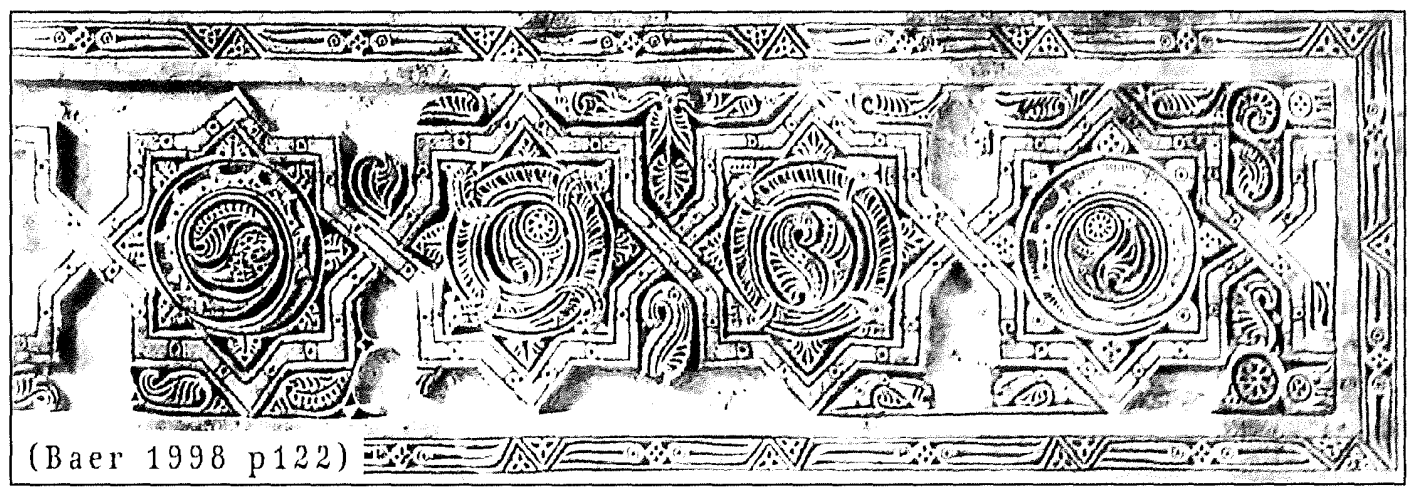

Figure 5.6 Refinement of the Samarra style, incorporating polygonal elements at the Madrasa Complex at Nishapur (900) Nishapur (Iran). 


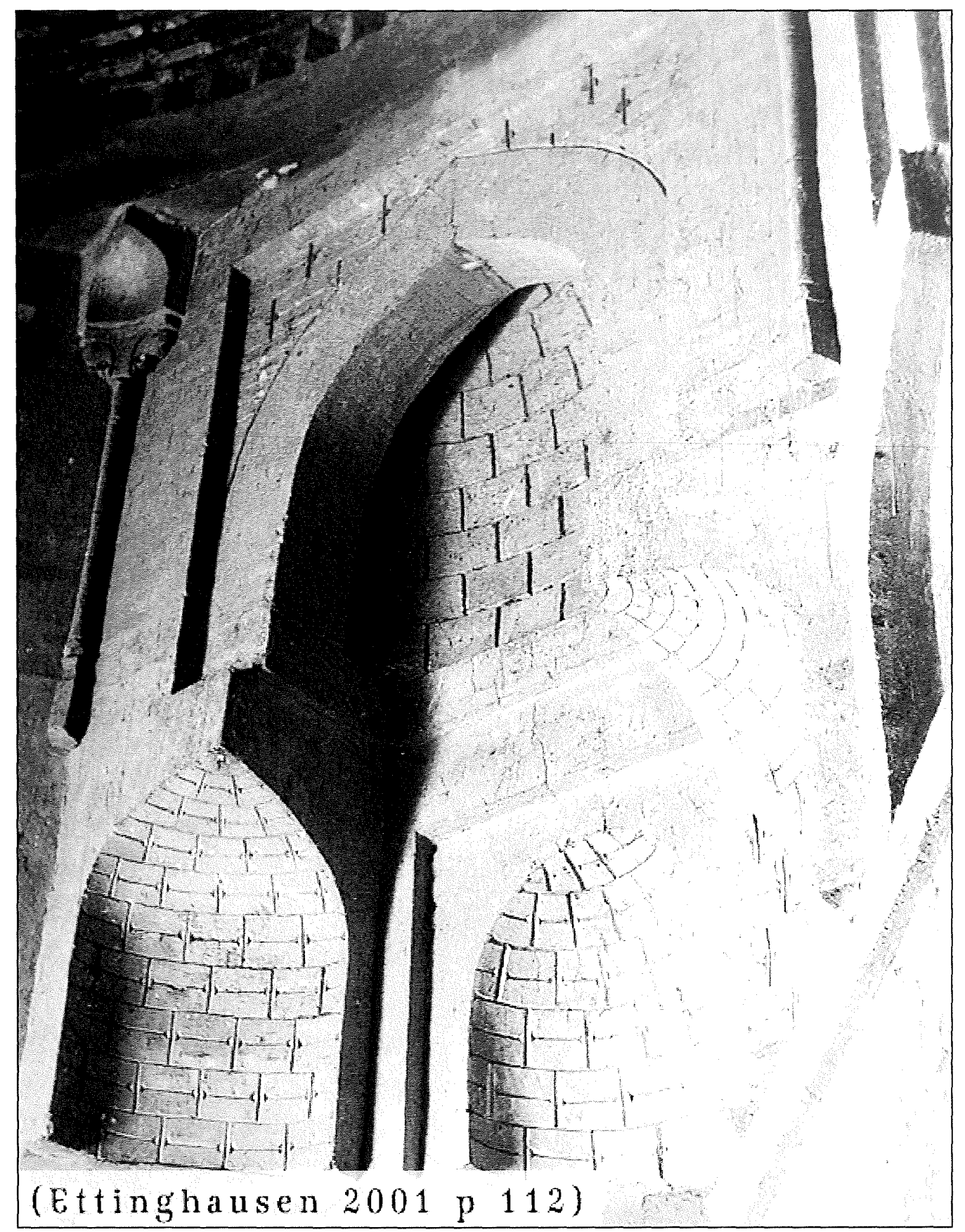

Figure 5.7 Early use of the muqarnas at Mausoleum of 'Arab Ata (977-978) Tim, Uzbekistan. 
development which became popular in western Iran" (2001, 157). Either way, just at the turn of the tenth into the eleventh century, muqarnas came into widespread use, appearing in North Africa, greater Syria, Anatolia, Iran and further east, and even showing up in Palermo, Italy by the twelfth century.

In the tenth century, the different regional groups, representing variant ideologies and backgrounds, asserted themselves politically by claiming legitimacy to the Caliphate and setting up regional capitals. This resulted in the fragmentation of 'Abbasid power but also gave rise to the development of new courts with different ideological frameworks and various regional artistic styles, which in the following centuries mature further. 


\section{DISCUSSION: ELEVENTH CENTURY}

The eleventh century witnessed the evolution of the ideological and political fragmentation that began in the previous century. The two major rifts, those between Sunni and Shia and between theologians and philosophers, became more firmly institutionalized in the eleventh century. The intellectual and artistic activities in each region also underwent a kind of maturing and found patronage in the emerging Sunni dynasties. In this section I discuss the Great Saljuqs and the Ghaznavids, the major forces in Sunni political advancement, and their relationship to the Shia Fatimid Caliphate; al-Ghazali and Ibn Sina, who embody the rift between theologians and philosophers; 'Umar Khayyam, who through his works, forms a bridge between mathematics and decorative geometric pattern; and the artistic elements in each region, either as reflections of evolving ideologies or as possible inspirations to other, new ones.

The Great Saljuqs and the Ghaznavids:

The Great Saljuqs, a dynasty founded by Turks in 'Abbasid military service, established their dynasty in 1038. Instead of abolishing the "Abbasid Caliphate, they (in theory) cooperated with the 'Abbasids, using them as figureheads of moral legitimacy (since they were descended from the Prophet), while they, the Saljuqs wielded the real power. The timeline shows the elements discussed in this period (figure 6.1). 


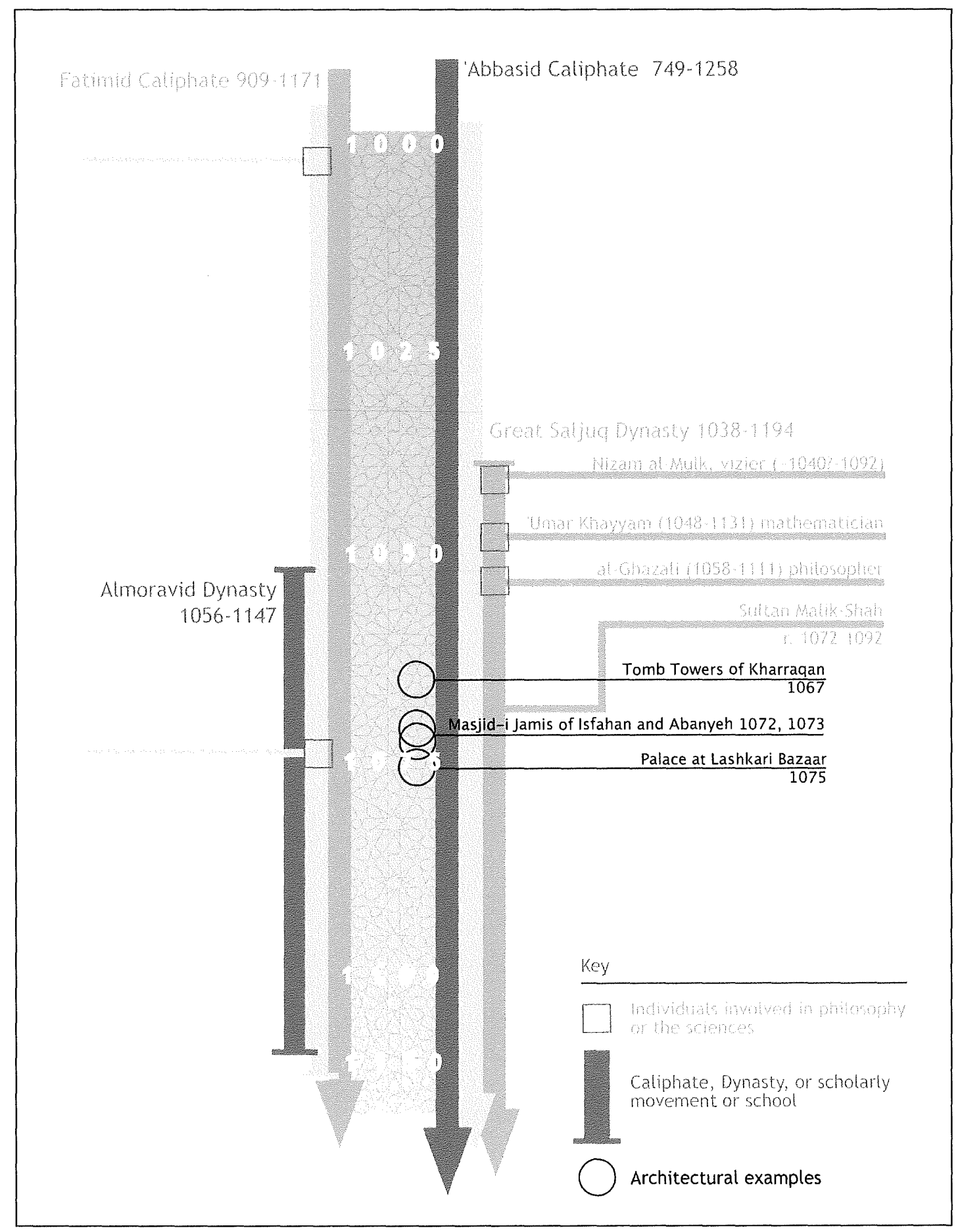

Figure 6.1 Timeline for the eleventh century. 
By 1055 the Saljuqs displaced the Shia Buyids from positions of power in Baghdad, thereby controlling the eastern portion of the 'Abbasid empire. The spatial element of this relationship is telling; the real political power (with no legitimacy) was exerted by the Saljuqs to the frontiers of the "Abbasid lands, while the moral entity, wielding no real power, was in the center of 'Abbasid territory, in Baghdad. With Isfahan as their capital, the Saljuqs entrenched the core of the Islamic empire further east, all the while controlling lands further west. The third leader in the Saljuq dynasty, Malik Shah (r. 1072-1092) expanded their rule beyond Iraq to Syria, thus assuring eventual Sunni control of major cities such as Aleppo and Damascus. Throughout the Saljuqs' rise, the Shi'ite Buyid dynasty and Fatimid Caliphs lost influence and power. Further manifestation of their ongoing contest was the establishment of many Sunni madrasas to combat Shia doctrine emanating from the dar al-ilm institutions begun in Cairo in the tenth century.

The great vizier Nizam al-Mulk (d. 1092) directed Saljuq policy and is credited with assisting in the revival of Sunni Islam, especially via the many madrasas he established in Iraq and Khurasan. Conveniently called the Nizamiyya madrasas, these institutions were created to combat Shia (most particularly Ismaili) ideology. Sabra (1987) notes that

[i]t may be debated whether the Nizamiyya madrasas were originally conceived as rivals or emulators of the dur al-ilm [plural], the library-cumteaching institutions which, like the original Dar al-Ilm in Fatimid Cairo, had made room for the philosophical sciences. It remains true in any case that [the 
Nizamiyya madrasas] quickly replaced the dur al-ilm...I am inclined to the view of [other scholars] who detect a theologico-political motivation behind the establishment of the Nizamiyya system of madrasas. (233)

The swift growth of the Nizamiyya madrasas reflects a stunning defensiveness on the part of the Saljuqs, especially in light of the ascendancy of the Sunni Almoravid dynasty that ruled North Africa from Algeria to southern Spain in 1056-1147. But Fakhry notes that the Fatimids "had so successfully wielded the double weapon of propaganda and political assassination...[the] Saljqus felt compelled to reply in kind" (1983, 217). Thus the Fatimid dur al-ilm were apparently threatening enough to mobilize significant non-military resources for the construction of new schools and mosques in Sunni territory, and threatening enough to occasion the renewed patronage of certain theological principles.

To this end, the Saljuqs additionally shored up their theological position by rehabilitating a school of thought called Ash'arism. Al-Ash‘ari, (d 944) originally aligned himself with the Mu'tazila but then created a separate school by modifying his ideas and synthesizing them with others. The Saljuqs made Ash'ari theologians the spokesmen of their dynasty. Patronized by the Saljuqs, al-Ghazali (1058-1111), whom I discuss further below, embodied the synthesizing process as well; an Ash'arite and a Sufi, he impacted the path of Islamic theological and philosophical debate and Islamic intellectualism as a whole for centuries to come.

Theologically aligned with the Saljuqs, the Ghaznavids promoted Sunni 
doctrine in Khurasan and Khwarazm-from eastern Iran into Afghanistan and Uzbekistan. The Ghaznavids, who were ethnic Turks, supported the 'Abbasid caliphate and fought against the Shia Buyids. In adopting Sunni doctrine, their military expansion reverberated with theological legitimacy.

Yet Dominique Sourdel, historian of medieval Islam, questions the motivations of the Saljuqs and notes that the Ghaznavids' motives are yet unclear to us (1983). She implies that the Saljuq adoption of Sunni doctrine developed out of political expediency, not theological fervor. Sourdel characterizes the Saljuqs as invaders who proclaimed themselves champions of Sunnism, but she also suggests that "[n]o one can tell how sincere their Sunnism was, but what is important is that they could not claim to dominate such a vast empire without taking up a stance on religious questions" $(1983,182)$.

In fact, because of the intellectual and political climate of the time, neither the Saljuqs nor the Ghaznavids could control regions of any size without foregrounding their doctrinal position. The Saljuq's response to Shi' ism took form in intellectual realms, manifesting in madrasas and other schools, and as we will see, their response may have come in the form of decorative art as well. Thus figure 6.2 shows a preponderance of activity in the regions controlled by the Saljuqs and Ghaznavids, mainly in Iraq and Iran. 


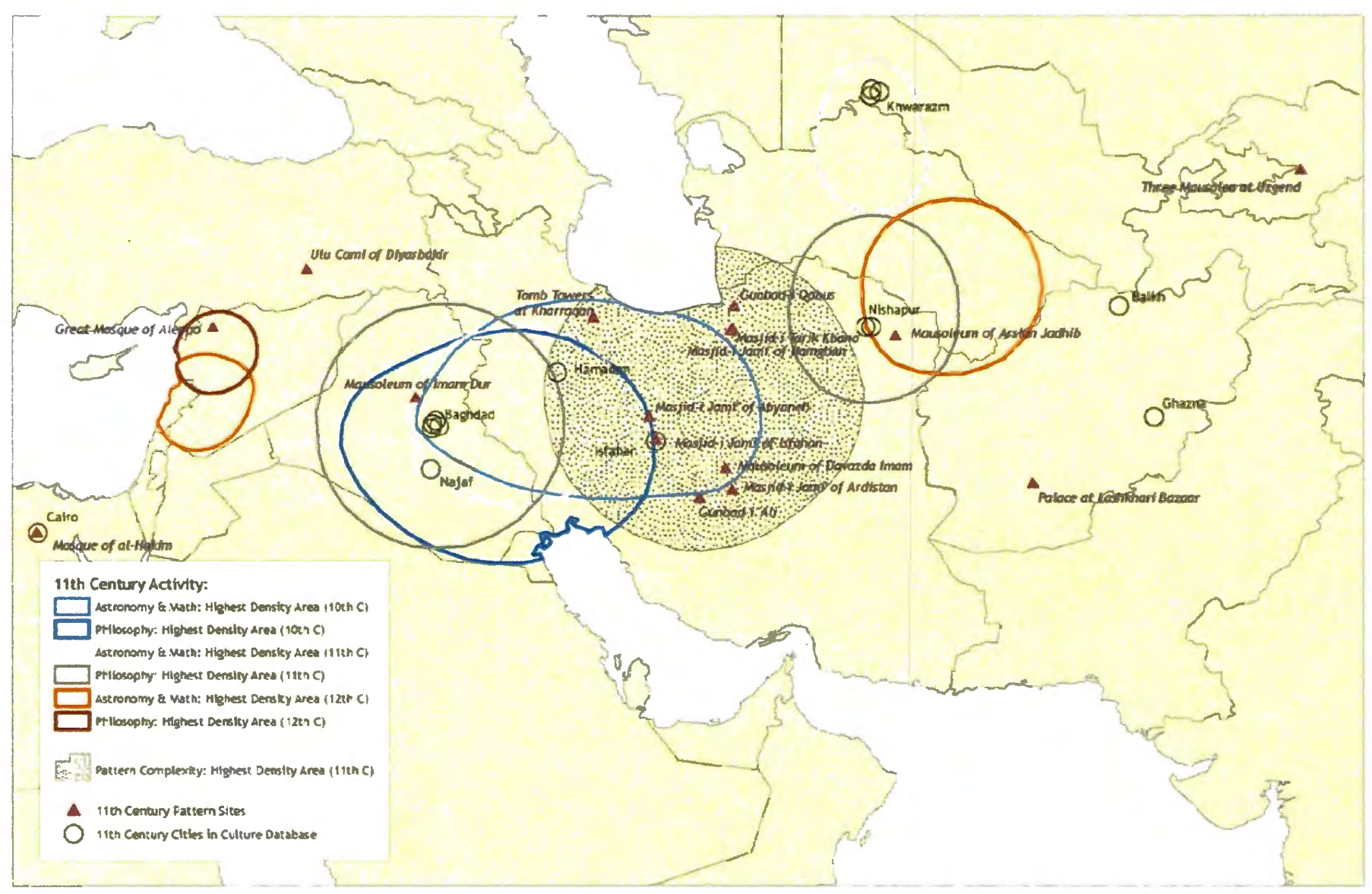

Figure 6.2 Eleventh century density overlay map, showing three centuries of activity. 
Ibn Sina \& al-Ghazali, a Great Debate

Ibn Sina (Latin Avicenna, 980-1037) was born near Bukhara, and by age seventeen he was a physician at the Samanid court and later served as vizier for the Buyid ruler Shams al-Dawlah in Hamadan, in west central Iran (al-Andalusi 1991, 89). His philosophical writings brought together the best of the earlier Neoplatonic works by Muslim philosophers. Topics in his major philosophical treatise, Kitab al-Shifa' (Book of Healing, or The Cure [from ignorance]) range from logic to mathematics, forming an encyclopedia of Islamic-Greek learning of the eleventh century. Under Buyid patronage, he wrote some 270 works on a variety of subjects, and represents the epitome of Neoplatonic thought for his time.

The work of al-Ghazali (1058-1111) represents a major turning point in Islamic theology. Working first in the Nizamiyya madrasa in Baghdad, he eventually settled in Nishapur in Persia. The dark grey line around Nishapur in figure 6.2 represents the philosophical activity spearheaded there by al-Ghazali. He ultimately came to the belief that Sufi mysticism, within a framework of exoteric theology and law, was the best way to achieve what can be described as enlightenment, or "perfection" of the spirit. His unique synthesis of Sufi mysticism with the more outward, or exoteric, expressions of Islamic doctrine secured his work a place of lasting influence. He held "not only that religious knowledge is higher in rank and more worthy of pursuit than all other forms of knowledge, but also that all other forms of knowledge must be subordinated to it...the final result of all this is an 
instrumentalist and religiously oriented view of all secular and permitted knowledge" (Sabra 1987, 239-240).

His criticism of philosophy, especially of ibn Sina and the Neoplatonists, appeared in his book Tahafut al-Falasifa (Collapse [sometimes translated as Incoherence or Downfall] of the Philosophers), which was mainly aimed at Ibn Sina, although ibn Sina had died twenty years before al-Ghazali's birth—a fact that speaks to the power and longevity of ibn Sina's argument. Al-Ghazali levels his attack via a series of propositions and even a mathematical argument related to the eternity of the world and the infinity of the heavens' revolutions (Fakhry 1983, 224). Indeed, the debates between al-Ghazali and the Neoplatonists involved theology and philosophy, but also contained threads of physics and the nature of causality (Nasr 1976,137). AlGhazali's refutations also produced a positive effect for the ideology he disapproved of-his pointed and considered critiques actually aided the development of Muslim philosophers and scientists by prompting them to consider new questions and thus new, refined answers.

Most importantly, after the widely published refutations of al-Ghazali and the subsequent rebuttals by Ibn Rushd in Cordoba in the following (twelfth) century, philosophical works eventually started to accept a synthesis of the ideas of kalam (Islamic scholastic theology, as discussed previously) and Neoplatonism. Hourani describes the nature of this synthesis:

works on kalam began with the explanations of logic and the nature of being, and proceeded from there to a rational articulation of the idea of God; in this way a logical structure was erected to defend and explain the revelations of the 
Qur'an, and it was only after this that such works dealt with matters which should be accepted entirely on the basis of revelation. $(1991,175)$

Al-Ghazali's opponents (the philosophers and philosophically-committed scientists) wanted to achieve the same state of being al-Ghazali did. But the way to get there was how they differed. The philosophers thought one could achieve this state of perfection via the improvement of one's "philosophical or scientific knowledge and the way to...salvation was none other than the way of science" (Sabra 1987, 240). The opposing position held by al-Ghazali and the theologians found support in the Sunni institutions of the Saljuqs. With the support of political-religious establishments, the ongoing dialectic between these points of view resulted in refinement of both ideologies, as exemplified by al-Ghazali and Ibn Sina.

Not surprisingly, with the Shia Buyids supporting Ibn Sina and the Sunni Saljuqs supporting al-Ghazali, the opposing camps of theology and philosophy were part and parcel of the political machinations of the time. This ideological rivalry parallels the larger institutional ideological antagonism represented by the different learning institutions being established in North Africa by the Shia (Ismaili) Fatimids and in Iraq/Iran by the Saljuq vizier Nizam al-Mulk. The culture of dialectic fostered by the probing critiques of al-Ghazali resulted in debate, both published and not, that lasted into the following centuries.

Generally paralleling the debate that followed al-Ghazali in eleventh-century Nishapur westward to Ibn Rushd in twelfth-century Cordoba, the use of the most complex decorative mechanisms - muqarnas and star-and-polygon patterns-also moved west, away from Persia (figure 6.3). 


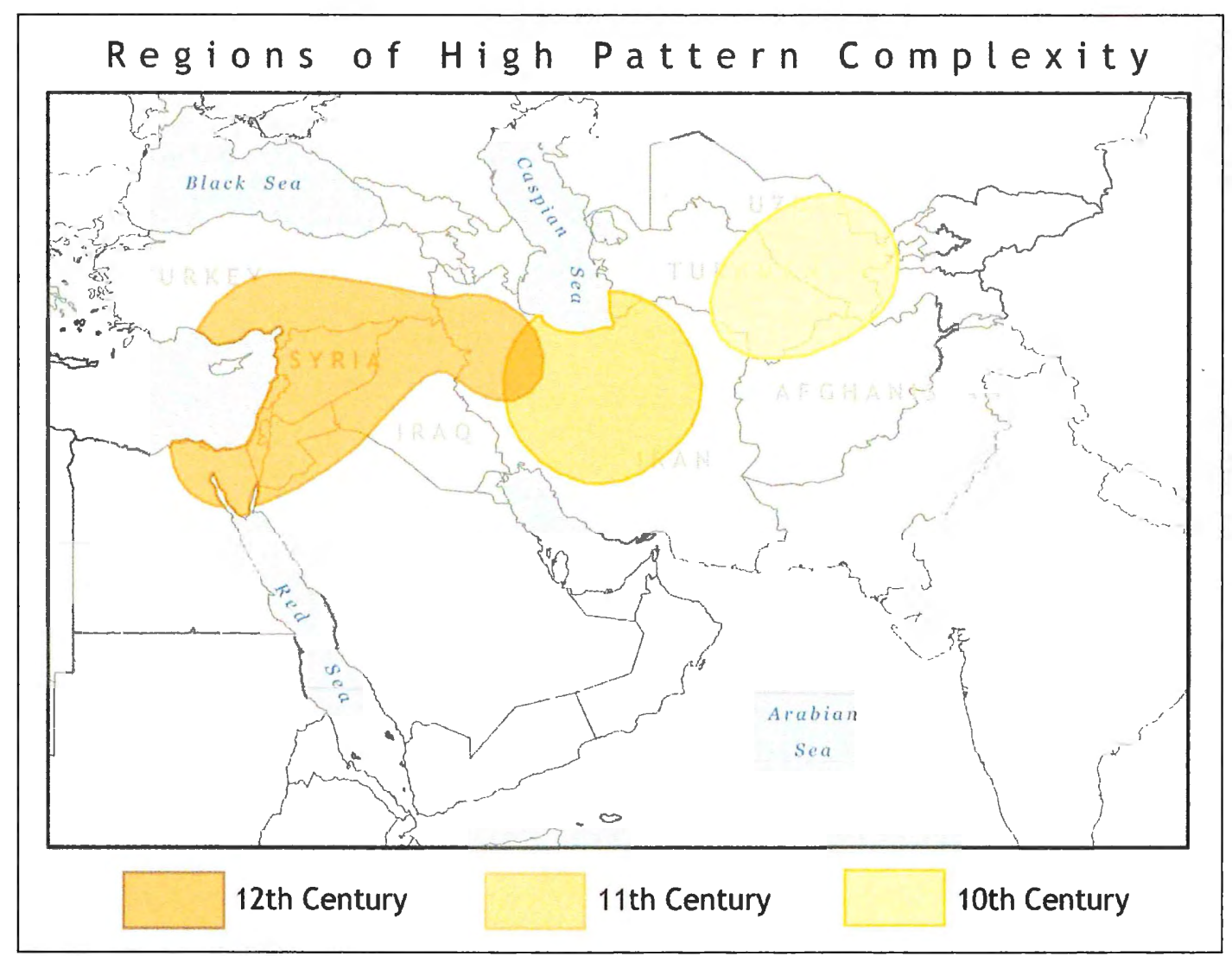

Figure 6.3 Regions of high-density pattern complexity move steadily west. 
The point is that in the two centuries following al-Ghazali's comprehensive refutations of Ibn Sina's lucid consolidations of Aristotelian thought, and Ibn Rushd's responses to al-Ghazali, there was an explosion of the use of muqarnas and star-and-polygon decoration in Islamic architecture in regions proximate to the major figures in the debate.

This general atmosphere of dialectic pervaded the centers of learning throughout the capitals of the Islamic world, and in these cities, complex geometric patterns decorated architecture more and more frequently. Indeed, there are fifteen records for monuments in the eleventh century, with $66 \%$ exhibiting muqarnas or starand-polygon patterns. This is a small number compared with the fifty-one records in the following (twelfth) century, with $70 \%$ exhibiting muqarnas or star-and-polygon patterns. There is a tantalizing possible relationship between this debate culture and artistic activity, as outlined by Tabbaa (2001). He says complex decorative geometric patterns were "engendered in a period of intense political and sectarian conflict," and that "conflict, challenge, and controversy, long abhorred by Islamist scholars and dismissed by positivist writers, were at the very foundation of change in medieval Islamic architecture" (167). While general, these comments, coupled with a promising spatial relationship between a specific debate and the distribution of areas of high densities of complex geometric pattern, may provide a new avenue of research. 


\section{The West: Andalusia, a Case in Point}

Here we must return to other hypotheses regarding the geometric mode. Up to this point, the western-most areas of the Islamic empire have not shown high-density regions of any type of activity. But the map of the western portion of the eleventh century finally depicts scientific and philosophical activity in Andalusia (figure 6.4). The case of Andalusia in this time-frame is an example of where others' theories break down. The light grey circle around Cordoba and Toledo reflects the activity of a number of individuals working in the fields of mathematics and astronomy. Indeed, al-Majriti, working in Cordoba, was the first to introduce advanced mathematics and alchemy to western Islamic world, and he spread the Ikhwan al-Safa's epistles to Andalusia (Nasr 1968, 51). But there are no corresponding monuments exhibiting geometric pattern here in this, the eleventh century, and in the next (twelfth) century there is only one, with artistic activity appearing instead in North African cities, where there is no mathematics, astronomy, or philosophy activity. These distributions do not support Necipoglu's assertion relating scientific activity to the use of complex decorative geometric pattern. She states:

[b]y the eleventh century the mathematical sciences had become so widespread and achieved so much prestige that even some rulers boasted expertise in them. For example the Ghaznavid ruler Mas 'ud I was not only skilled in geometry but could also draw architectural plans with his own hands...It was in this receptive setting that [the geometric mode] initially spread during the eleventh century when its basic repertory became elaborated in different ways in various local courts that had acquired a taste for geometry. (1995, 132, emphases mine) 


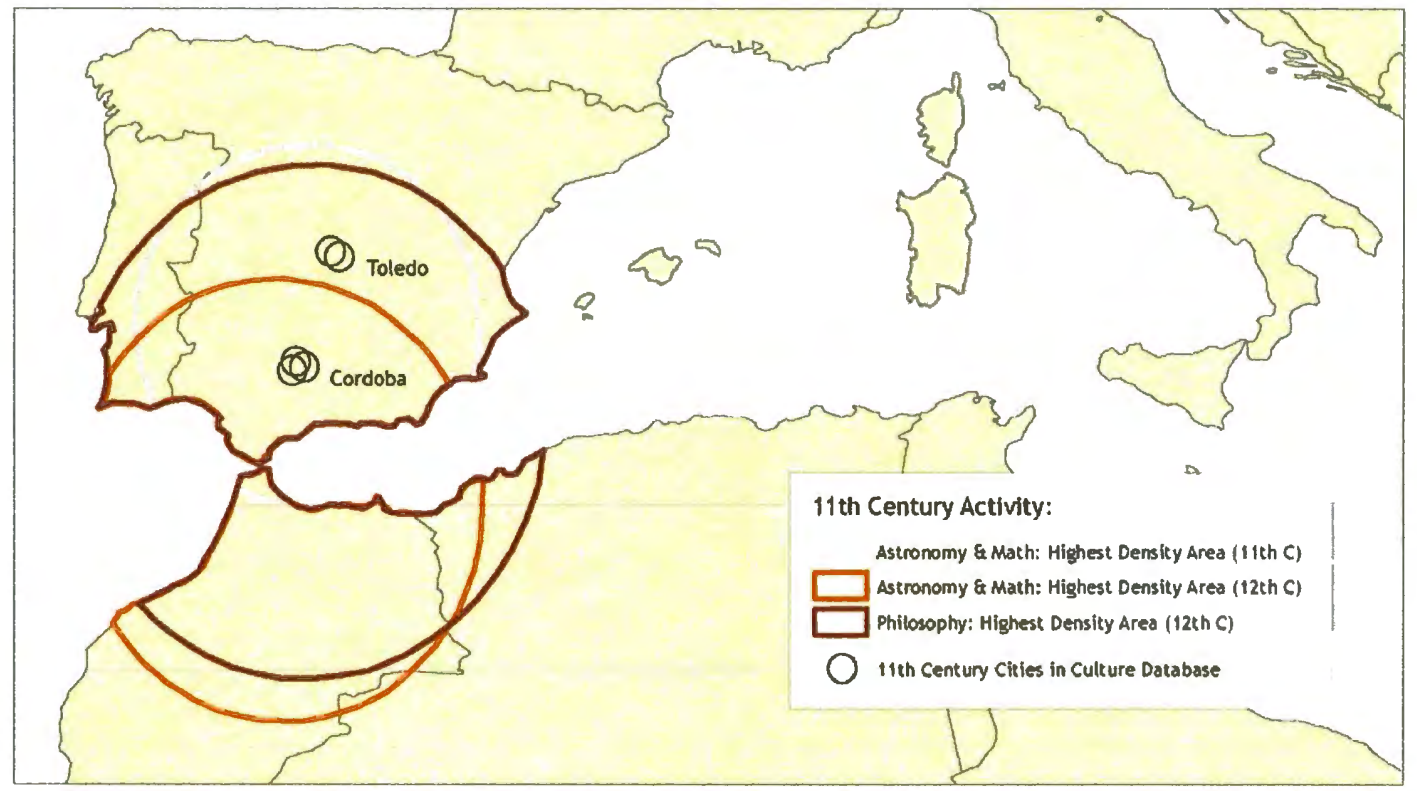

Figure 6.4 Western portion of eleventh century activity. 
She is in effect saying that mathematical activity is a prerequisite for the use of pattern-that in a situation like we see in Andalusia, since there was indeed a "taste" for geometry, as indicated by the light grey and orange lines, the decorative patterns should therefore start to appear in monuments, but this is not the case. The example of eleventh century Andalusia provided here is not unique; glances at the rest of the density overlay maps show similar inconsistencies. The relationship between mathematics and decorative geometric pattern is, quite simply, not that simple, when viewed spatially.

\section{'Umar Khayyam and The Artisans}

In the person of 'Umar Khayyam (1048-1131), we find a person of great capacity for synthesis. Known in the west as a poet and in the east as a mathematician, Khayyam's oeuvre encompasses art as well as science. His contributions to mathematics include his book Risala fi'il-Barahyn 'ala Masa'il alJabr al-Muqabalah (Treatise on the Proofs of the Problems of Algebra and "Balancing"), his use of Euclidean geometry in proofs; he was also the first to solve cubic equations. He wrote a number of philosophical treatises, and of course produced his well-known Rubiyyat, a very long series of quatrains. A true polymath, Khayyam's contributions also extend to astronomy; he headed the observatory at Isfahan, and compiled a zij (book of astronomical tables) for the Saljuq sultan Malikshah. No less than Nizam al-Mulk, who established so many of the earliest madrasas, was Khayyam's patron. 
Khayyam, supported by the Sunnis, worked mainly in the region of central Persia, although he also spent some time in Samarqand and Merv. Details of his life are slim, but much of his work was completed at Isfahan; this is where I have mapped him. Alpay Özdural, historian of Islamic art, claims that at some point Khayyam came across a proof in al-Buzjani's book, What the Artisan Needs of Geometric Operations, which was written in the tenth century (and discussed in the previous section). The proof prompted Khayyam to write a treatise specifically on this proof, of which further constructions are illustrated in a subsequent anonymous treatise On interlocking similar or corresponding figures (known as "Interlocking Figures").

Interlocking Figures, introduced in Persia some time between 1074 and the thirteenth century, contains mathematically correct illustrations of repeat units of geometric patterns (figure 6.5). This text, written in Persian, simplifies the methods of mathematicians for use in a decorative milieu. Ultimately, the implication of the relationship between these texts seems to be that manuals of geometry, written by mathematicians and scientists, were made for artists to use in creating decorative geometric patterns. Therefore we find a documented relationship between art and science. But what are the spatial parameters of this relationship? We must look to where Khayyam was and the architecture that sprang up after his work was made available for the answer.

Khayyam's connection to this continuum of texts is that he was intimately involved in disseminating mathematical information to artisans for specific use in architecture and decoration (Özdural 1995). Part of Khayyam's involvement included 


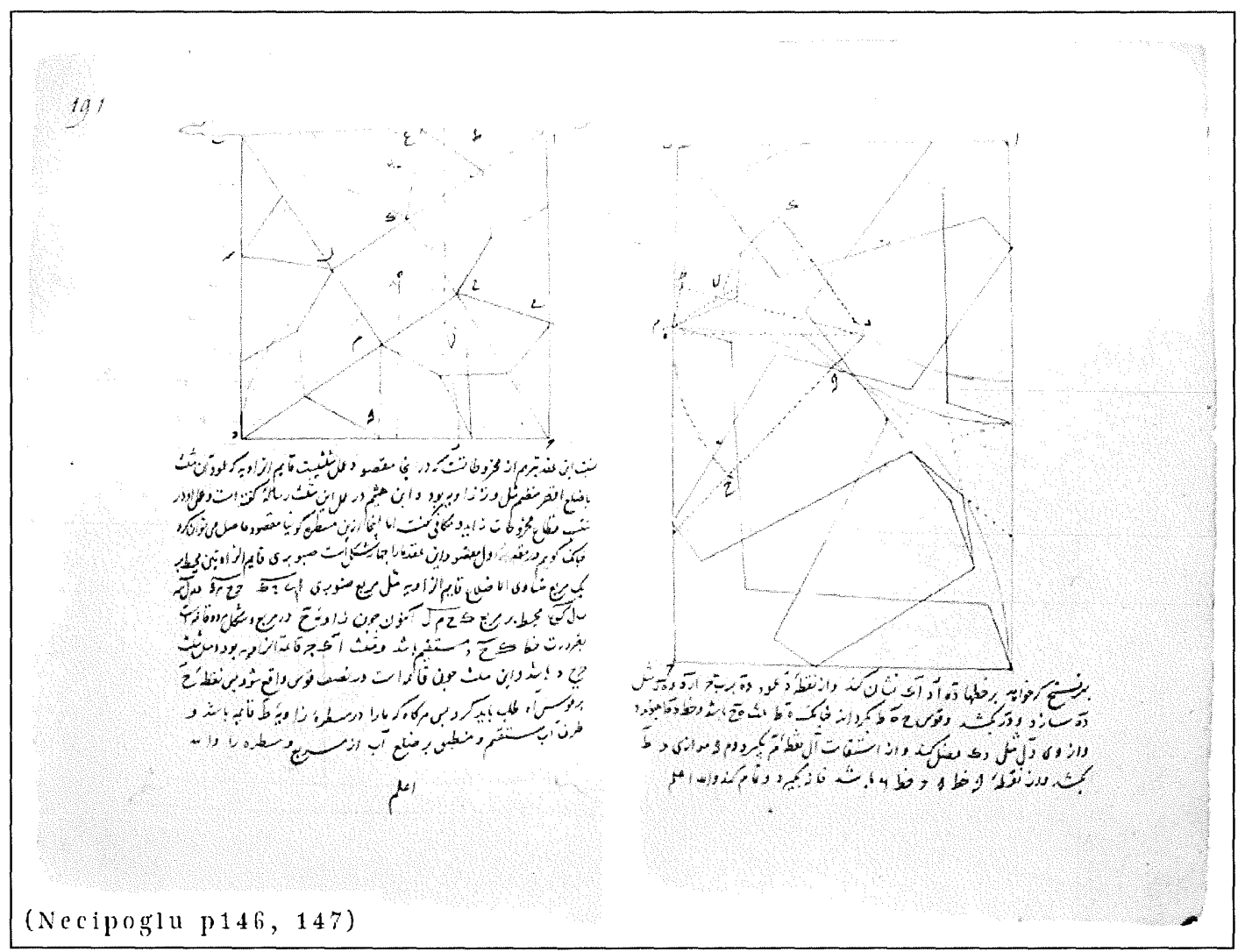

Figure 6.5 Interlocking Figures, showing mathematically correct constructions of repeat units in geometric patterns for use in architectural decoration. 
participation in what Özdural dubs conversazione, or meetings between mathematicians and architects to "discuss the application of geometry to architecture" $(1995,55)$. These meetings ostensibly took place in Isfahan during Khayyam's time there at the observatory. "Thanks to the construction work taking place in Masjid-I Jami' [Great Mosque]...during that period, Isfahan was the hub of architectural activity and certainly an ideal place for conversazione" $(1995,63)$. Özdural reconstructs the chronology of the proof I have already mentioned (which is shown in fig 6.6 below): during one conversazione Khayyam encountered the odd proof from al-Buzjani's book, then considered it and wrote a new proof which was published ca. 1074; he introduced it in another conversazione, from whence it was incorporated into the anonymous Interlocking Figures. Thus in the person of Khayyam, as a mathematician engaged in a textual tradition with artisans and also in dialogue with artists themselves, we find a crucial, tangible link between the discipline of mathematics and decorative geometric pattern in a specific place-Isfahan.

However, the relationships between these texts, the conversaziones, and monuments exhibiting geometric pattern and muqarnas do not manifest themselves in simple spatial arrangements. Since these meetings took place in central Iran, let us look to a detail of the density overlay map for the eleventh century, figure 6.7 , to examine the spatial extent of complex geometric patterns in the eleventh century. 


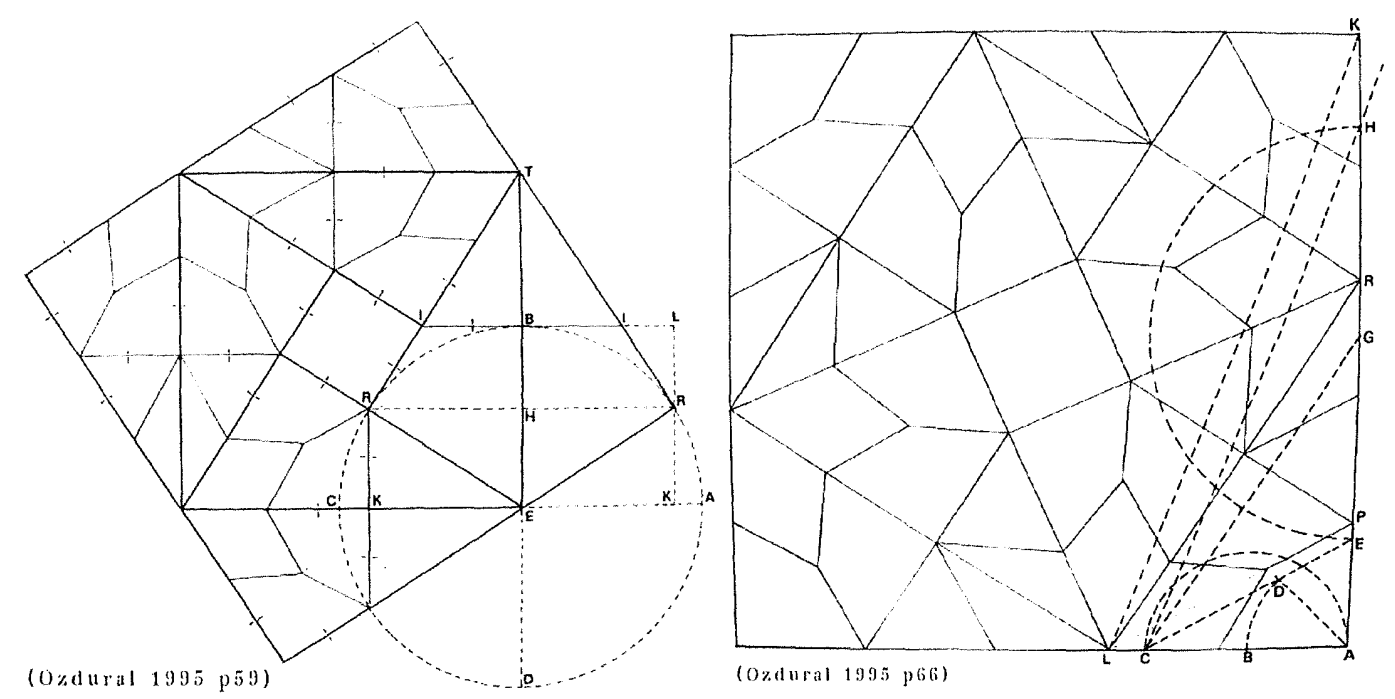

Figure 6.6 Left: Reconstruction of original proof. Right: One method of constructing Khayyam's triangle in Interlocking Figures. 


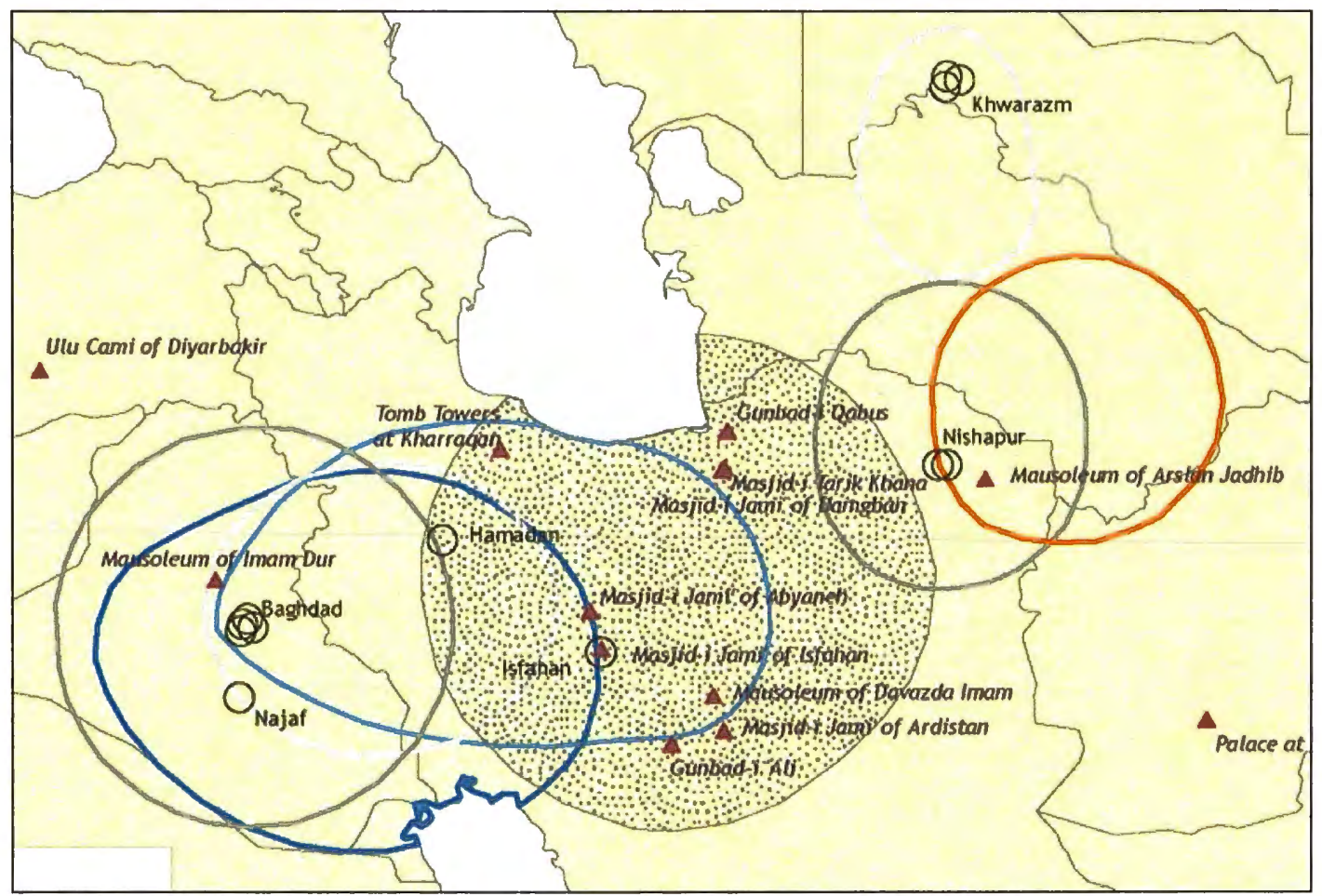

Figure 6.7 Detail of Figure 6.2 showing region of high pattern complexity around Isfahan. 
The high-density pattern complexity region around Isfahan, where these conversaziones took place, generally supports the idea that Khayyam and the other artists' manuals facilitated and thus preceded the use of complex decorative geometric pattern, as the light blue line (tenth century math/astronomy activity) also overlaps that region. However, only the Masjid-i Jami (Great Mosque) of Abyaneh and portions of the Masjid-i Jami of Isfahan were built after the publication of Khayyam's treatise. The other monuments with complex star-and-polygon patterns or muqarnas located in the region around Isfahan were built in decades prior, such as one of the tomb towers of Kharraqan, built in 1067 (fig 6.8). Also, another building much further east, the Three Mausolea at Uzgend (Kyrgystan), built in 1012-1013, makes use of the geometric mode. Similarly, the palace at Lashkari Bazaar in Bust, Afghanistan (built 1075) was decorated with spectacular star-and-polygon repeat patterns (figure 6.9).

Al-Buzjani's book, written in the late tenth century, and even Khayyam's treatise could have reached Bust in time to have affected the monument's decoration, but there is no evidence of conversaziones taking place in the regions further east than Persia in this century, and the full extent of figure 6.2 shows no math/astronomy activity in the tenth century to precede it, as Necipoglu's assertion described earlier would require $(1995,132)$. In the other direction, the Great Mosque of Aleppo (10891094) employed muqarnas extensively, and likewise there, no region of math/astronomy activity precedes their use. 


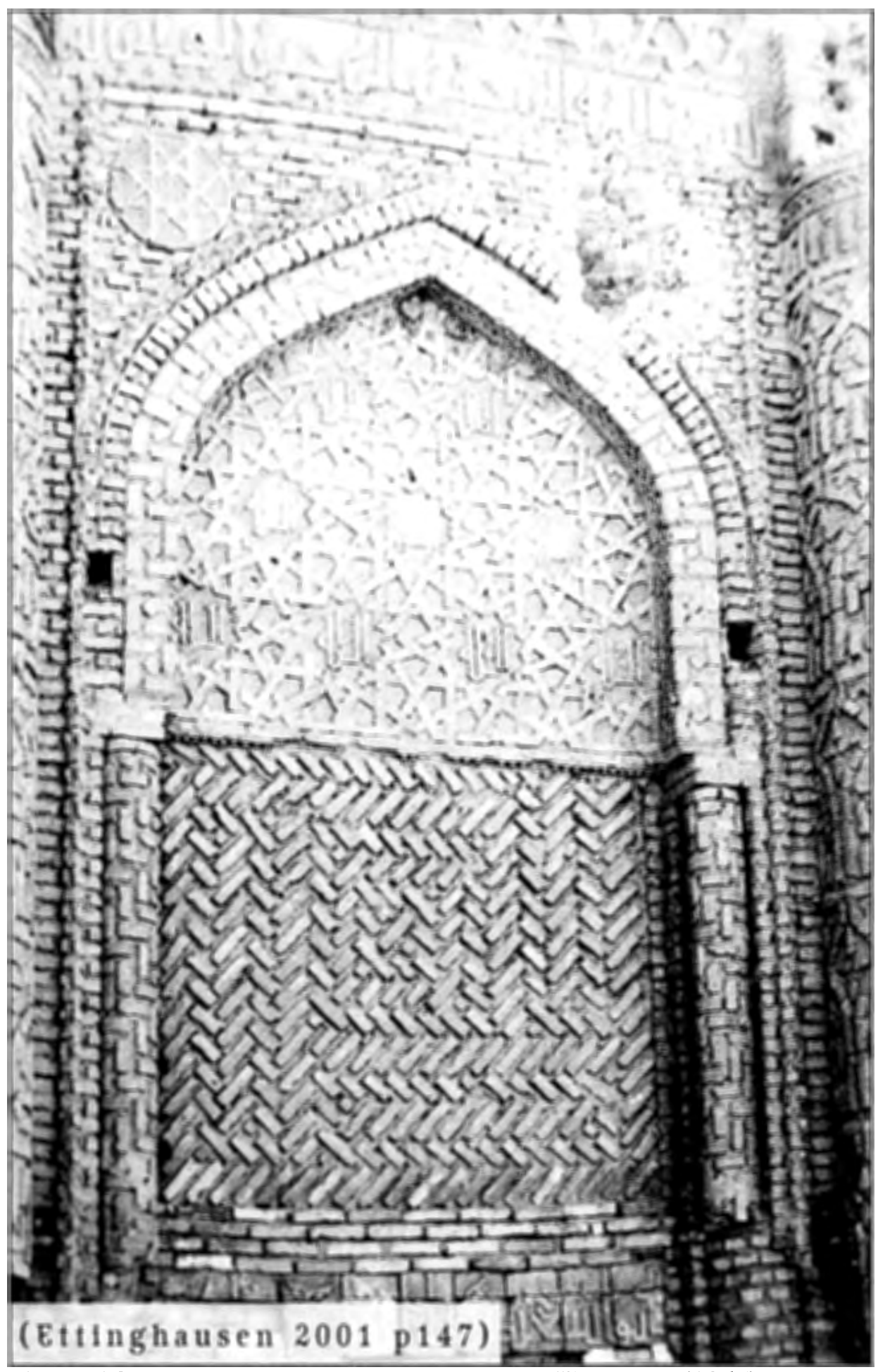

Figure 6.8 Star-and-polygon decoration from Kharraqan (1067). 


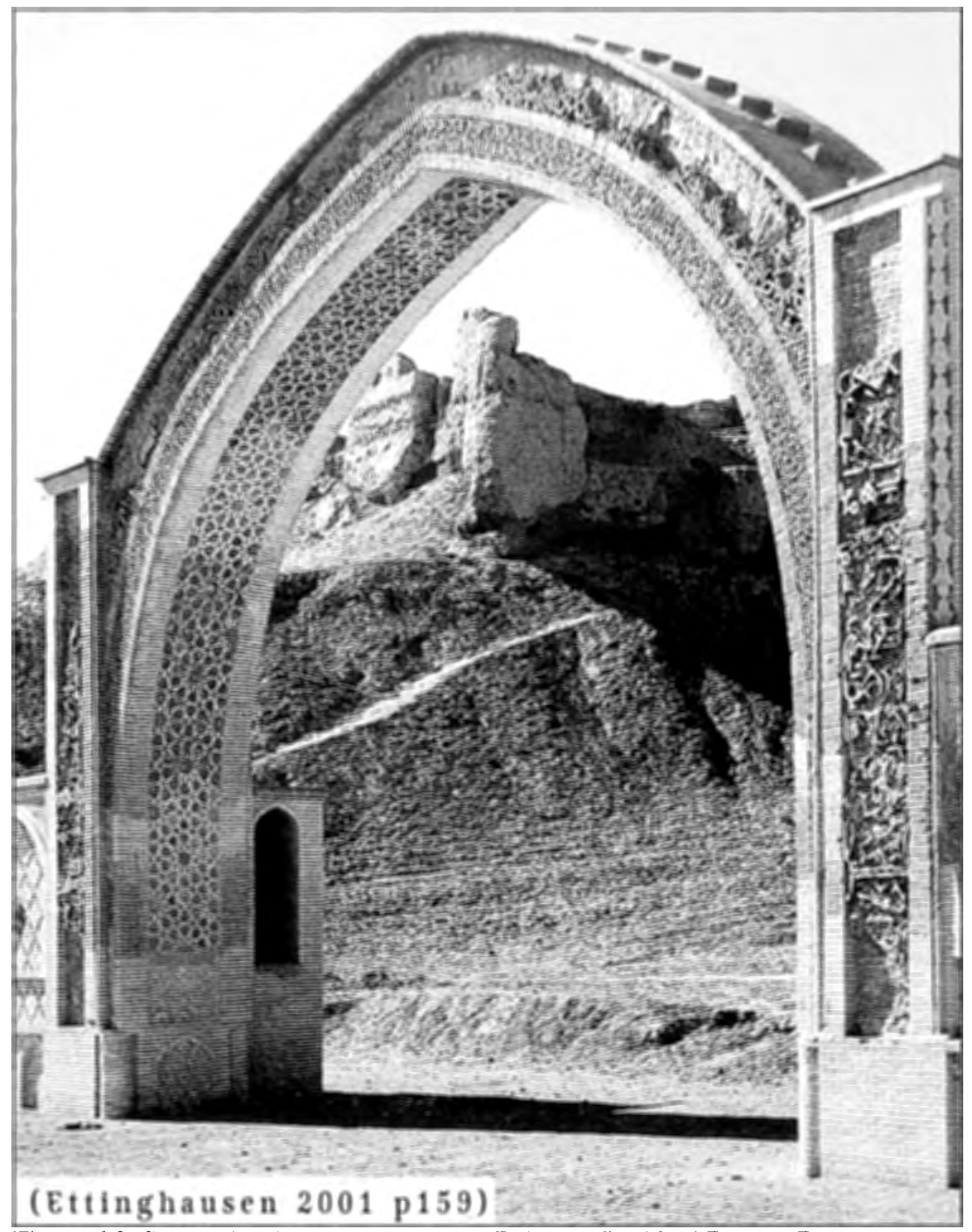

Figure 6.9 Star-and-polygon pattern at the Palace at Lashkari Bazaar, Bust, Afghanistan (1075). 
The inference then is that the most straightforward answers posited to the questions about the why and how of decorative geometric pattern, even such as the documented relationships between mathematicians and artisans, do not, in this instance, help elucidate the broader spatio-temporal distributions of the interactions between these disciplines. The unique connections between Khayyam and the geometric mode, like that of the Ikhwan al-Safa in the previous (tenth) century, do not apply equally_one cannot extrapolate a kind of relationship from them and apply it to the rest of the region or time period.

The problem is that Özdural looks very closely at Khayyam's treatise and conversasione without incorporating broader trends. Necipoglu (1995) looks both broadly and in detail for answers, and supports the notion that courts that patronized mathematics included complex geometric patterns in their architecture. As we have seen, this does not hold up across the board, but her work has led others to develop theories that rely on specific information to describe local as well as regional phenomena. One such example follows.

\section{$\underline{\text { Art and Politics }}$}

One scholar has examined the development of decorative art in light of the larger conflicts playing out in this century. According to Yasser Tabbaa, in his book The Transformation of Islamic Art during the Sunni Revival, the united Saljuq and Ghaznavid policy of Sunni expansion resulted in the development and widespread dissemination of geometric pattern and muqarnas as an explicit expression of Sunni power (2001). He states that the deep conflict between the Sunni and Shia manifested 
itself "on the battlefield as well as in politics, theology, and propaganda. It stands to reason, therefore, that it was also played out in architecture and visual culture and that its dynamic forces of conflict, change, and self-definition, not the prescripts of a static Islam, were behind the transformations in medieval Islamic architecture" $(2001,7)$. Tabbaa relates the intricacies of theology ("Asharism, specifically) and kalam (which is sometimes referred to as occasionalism) to muqarnas and complex geometric patterns: "combining the purity and austerity of geometric principles with the celestial allusions of star-patterns, geometric ornament reflected the ordered universe, whose atomistic and occasionalistic structure was created and sustained by divine intervention, and stimulated passion for the divine creator" $(2001,101)$. Necipoglu concludes similarly: "the new geometric mode [muqarnas and star-and-polygon pattern] seems to have represented a new visual order projecting a shared ethos of unification around the religious authority of the [Sunni] 'Abbasid caliphate" (1995, 109).

The records in my pattern database do show that many of the examples of muqarnas and star-and-polygon patterns in this century were built under Sunni (Saljuq or Ghaznavid) patronage. However, would not the Shia (either the Fatimids or 'Uqaylids) have supplemented their ideological expansions with a differentiated program of visual propaganda to reinforce their ideology? They developed schoolslike al-Azhar in Cairo and the Dur al-'ilm-to propagate their ideologies, and the Saljuqs volleyed with schools of their own. If the Saljuqs went on the offensive by developing a visual symbology for their ideology (or at least co-opting a pre-existing 
or even nascent symbology, like muqarnas and star-and-polygon patterns), the Shia would likely have developed one in response. This logic might be flawed, but no less so than Tabbaa's in positing the relationship in the first place. The two ideologies did not exist in separate vacuums-obviously their proponents were aware of the others' strategies, as evidenced by the madrasa rivalry. It stands to reason that the Shia would have responded in kind to an assault of visual/architectural propaganda. However, there is no evidence that the Fatimids (or other Shia ruling entity, such as the Uqaylids) developed any differentiated visual program.

Also, if we follow Tabbaa's logic, Saljuq and Ghaznavid use of the muqarnas and star-and-polygon patterns should far outweigh Fatimid and Uqaylid use of such decorative devices. However, Fatimid and Saljuq use of muqarnas or star-andpolygon patterns do not support his claims. Figure 6.10 indicates that Shia ruling groups' monuments displayed a higher percentage of use of the geometric mode than did Sunni groups, in the same time period. Tabbaa also claims that the widespread use of muqarnas and star-and-polygon patterns did not enter Cairo until after the Fatimid dynasty ended, but this is untrue; he makes a thin argument for the difference between "major and minor" monuments in Cairo, but if such visual programs were as important as he suggests, one would expect more cohesiveness in expression along the spectrum of patrons, and certainly a lower percentage overall. Tabbaa privileges the muqarnas as especially exemplifying Sunni revivalism, yet near Samarra in Iraq, the mausoleum 


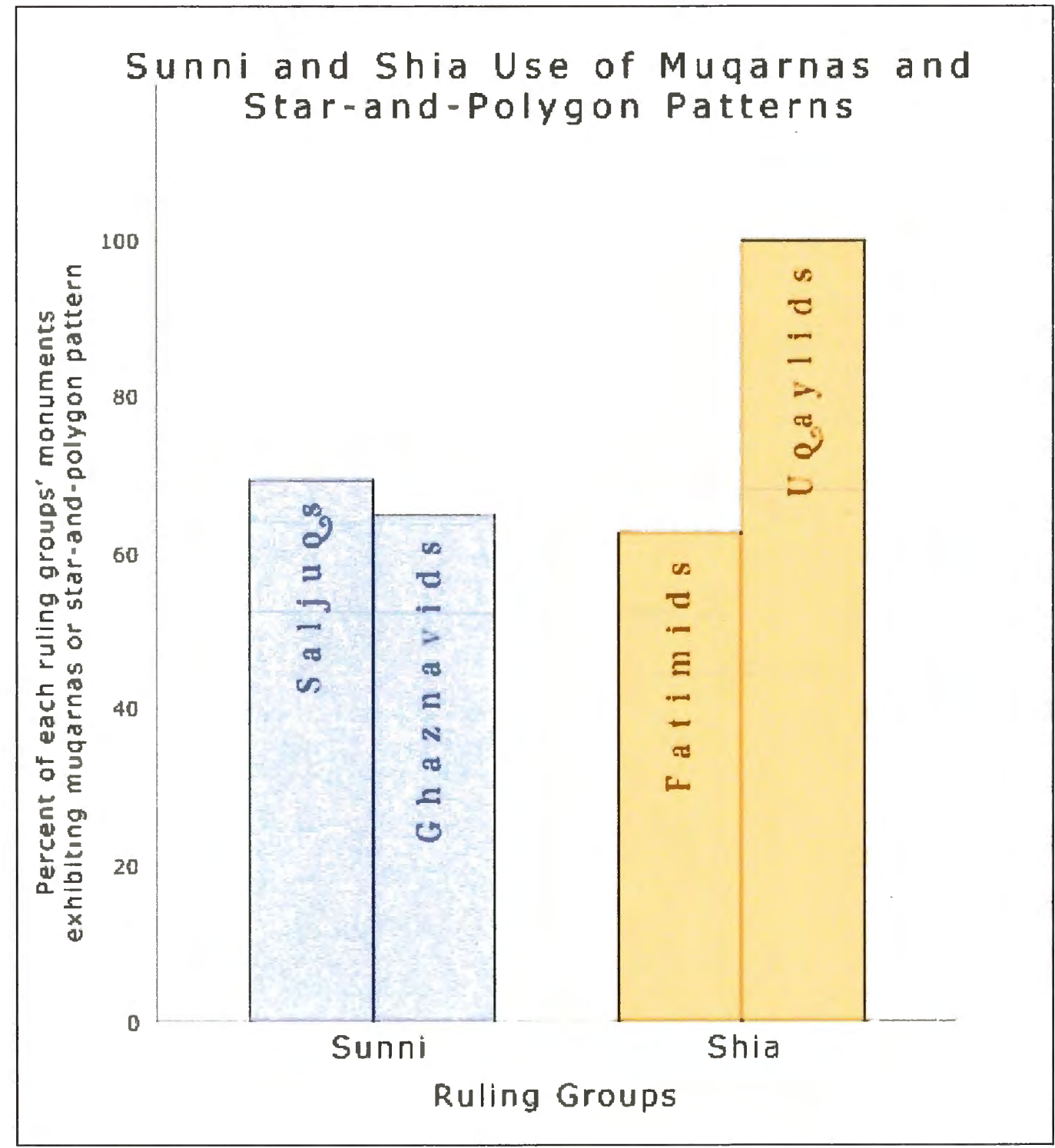

Figure 6.10 Chart presents comparison of the percentage of monuments of Sunni and Shia ruling groups whose monuments exhibit muqarnas and star-and-polygon patterns. 
of Imam Dur was built by Shia 'Uqaylids in 1085 and incorporates a well-developed muqarnas dome (fig 6.11-6.12). Both examples further weaken the argument for these decorative devices being co-opted by Sunnis in a spatially widespread ideological contest.If the Saljuqs used muqarnas and star-and-polygon patterns as signs of Sunni legitimacy to be interpreted as Tabbaa suggests, then the Fatimids should have understood them as such. Since through their own architecture the Fatimids and 'Uqaylids used the same symbols, it appears they did not take these symbols to mean the same thing as Tabbaa alleges of the Sunnis. In "reading" this historical landscape, the conflict playing out most likely had some manifestations in monumental architecture, as evidenced by the building of madrasas themselves, but the decorative elements of the structures seem not to bear the message of Sunni doctrinal propaganda, in light of the spatial and temporal distributions of muqarnas and starand-polygon patterns.

The overall point of my inquiry is to bring this spatial component to bear on others' hypotheses, with the hope of discerning something of the quality of the relationship between the geometric mode and other cultural phenomena. Tabbaa's ideas, while perhaps not valid across the board, incorporate broad and local trends, and include superbly detailed accounts of the regional doctrinal differences of Islam in this period. His ideas are much more nuanced than the all-encompassing theories about decorative geometric pattern provided by the essentialists, to be sure. I agree when he contends that conflict is a major factor in the environment leading to the widespread use of these forms as discussed above. And while I agree that Tabbaa and Necipoglu 


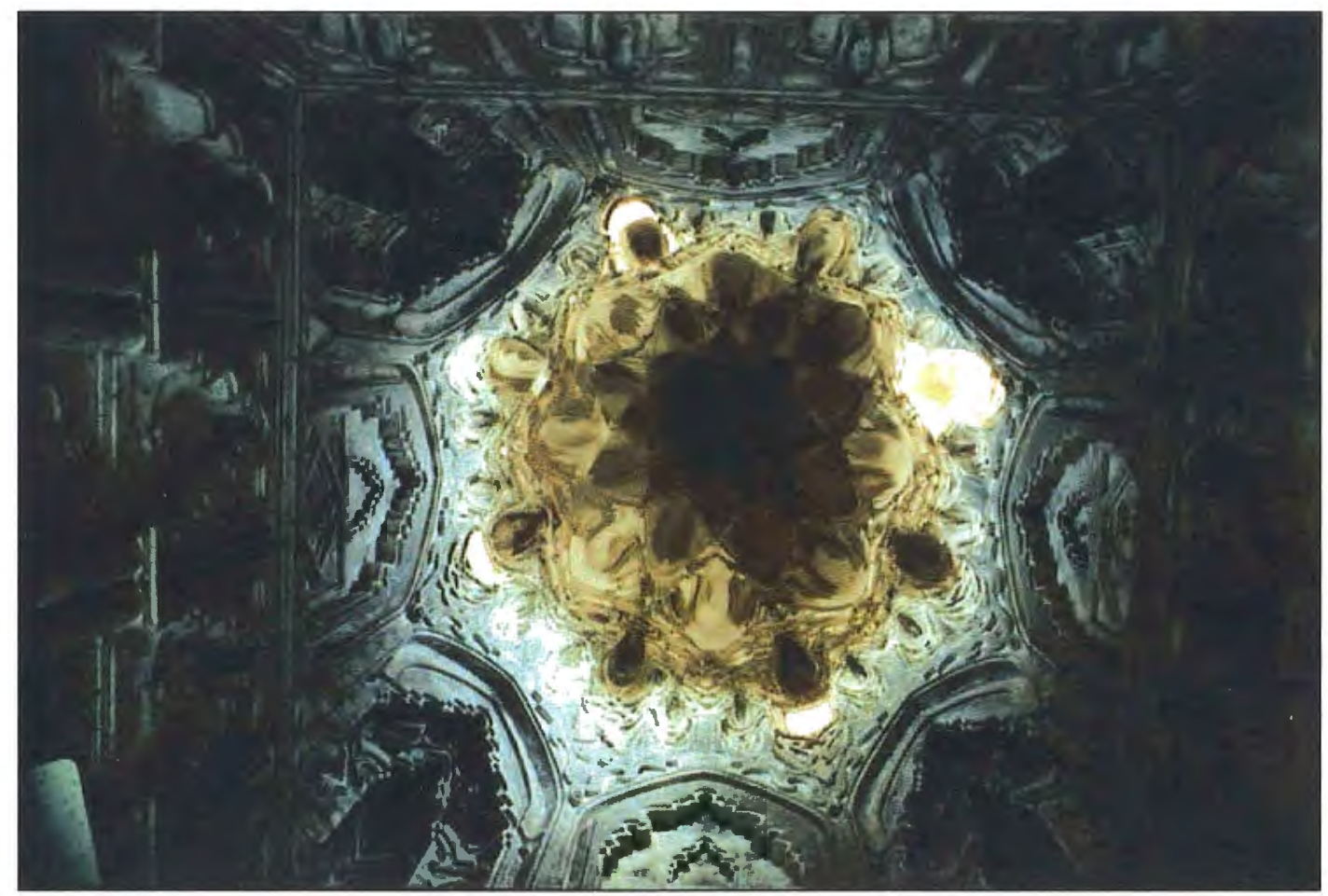

Figure 6.11 Interior of muqarnas dome at the Mausoleum of Imam Dur, Samarra, Iraq (1085) (image from archnet.org). 


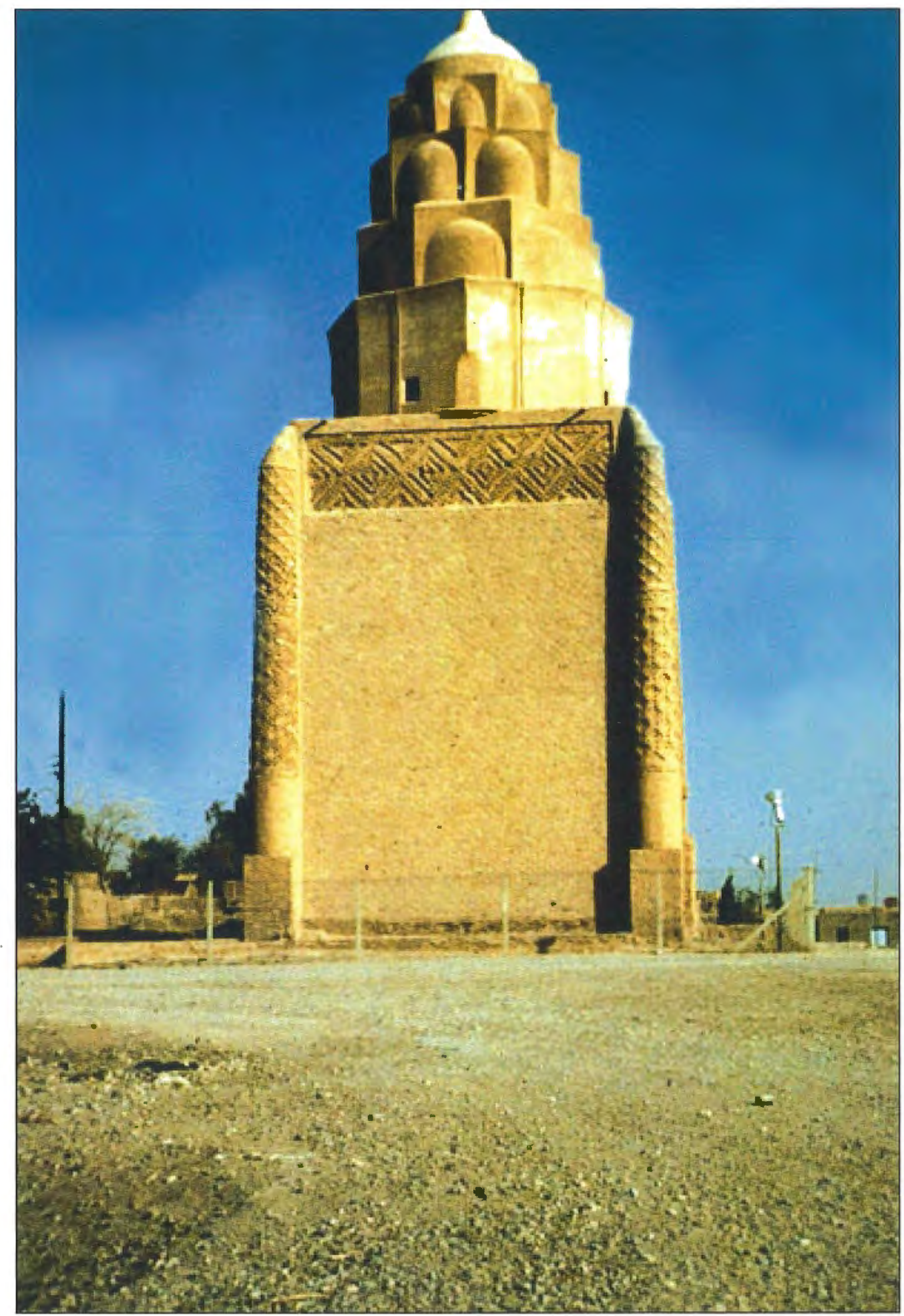

Figure 6.12, Exterior of muqarnas dome at the Mausoleum of Imam Dur, Samarra, Iraq (1085) (image from archnet.org). 
ask the right questions (without which I could not develop my own inquiry), they do not ask all the questions_-indeed, how could they? But most importantly they neglect to ask certain questions that only come up when we examine these factors together spatially, in the twelfth century. 


\section{DISCUSSION: TWELFTH CENTURY}

Following the ideological and philosophical rifts of the eleventh century, spatial fragmentation characterized the twelfth. The major powers ('Abbasid, Fatimid, Saljuq) in the Islamic world completed a long process of disintegration in the twelfth century, leaving room for many other dynasties to take the reins of power. Such broad-scale fragmentation meant that internal borders and the frontiers of the Islamic world in this period shifted constantly, while authority and influence fell into dozens of separate and often independent centers of power. This fragmentation was felt in many aspects of life, and Sufi brotherhoods emerged in this period as important bastions of independent thought in a time of increasing orthodoxy. As the centers of power multiplied, so did the opportunity to build in new places. The number of buildings decorated with geometric pattern exploded, growing from fifteen structures in the eleventh century database to fifty-one in the twelfth.

In this section I examine the political and spatial complexity that developed as the major powers broke down, discussing the importance of Syria separately; the increasing prominence of Sufism; individuals who flourished amid the tumult and how they relate to artistic activity in the increasing number of centers of power, and specific examples of monuments whose spatial distributions relate to other disciplines in the next (thirteenth) century.

\section{Dynasties: The Emergence of New Powers}

As we have seen in a previous section, starting in the tenth century, the Islamic world was comprised of three principal regions, ruled by the three caliphates: the 
Umayyad Caliphate, which ruled from Cordoba and controlled Andalusia and parts of North Africa; the Fatimid Caliphate, whose capital was Cairo, ruled the lands of Egypt and into Syria; and the 'Abbasid Caliphate, whose center was Baghdad and whose nominal influence controlled all of Iraq, Iran, and principalities further east. The three competing caliphates of the tenth century were unable to hold onto their power, and these centralized governing bodies, over the course of two hundred years, fractured into many instances of another type of ruling entity - the dynasty. The timeline shows the many dynasties that emerged in this period (figure 7.1).

The dynasts were not related by blood to the Prophet Muhammad, thus could not claim the title of Caliph-instead they used the term Sultan, which carried great importance, but not the legitimacy of the Faith. However, as we saw with the Saljuqs, alignment with the 'Abbasid Caliphate assured them the authenticity necessary to rule an overwhelmingly Muslim population. The specific economic, political, and social machinations that led to the weakening, corruption, and downfall of each of the major ruling groups are outside the scope of this paper; it will suffice here to enumerate some of the most important of the ensuing ruling groups.

In the central part of the Islamic world, from Persia to Egypt, the Ghaznavid [Ghaznawid], Saljuq [Saldjuk], and Buyid [or Buwaiyhid] dynasties subsumed the power of the "Abbasid caliphate during the eleventh century; figure 7.2 summarizes these dynasties' geographic shifts up to the twelfth century. 


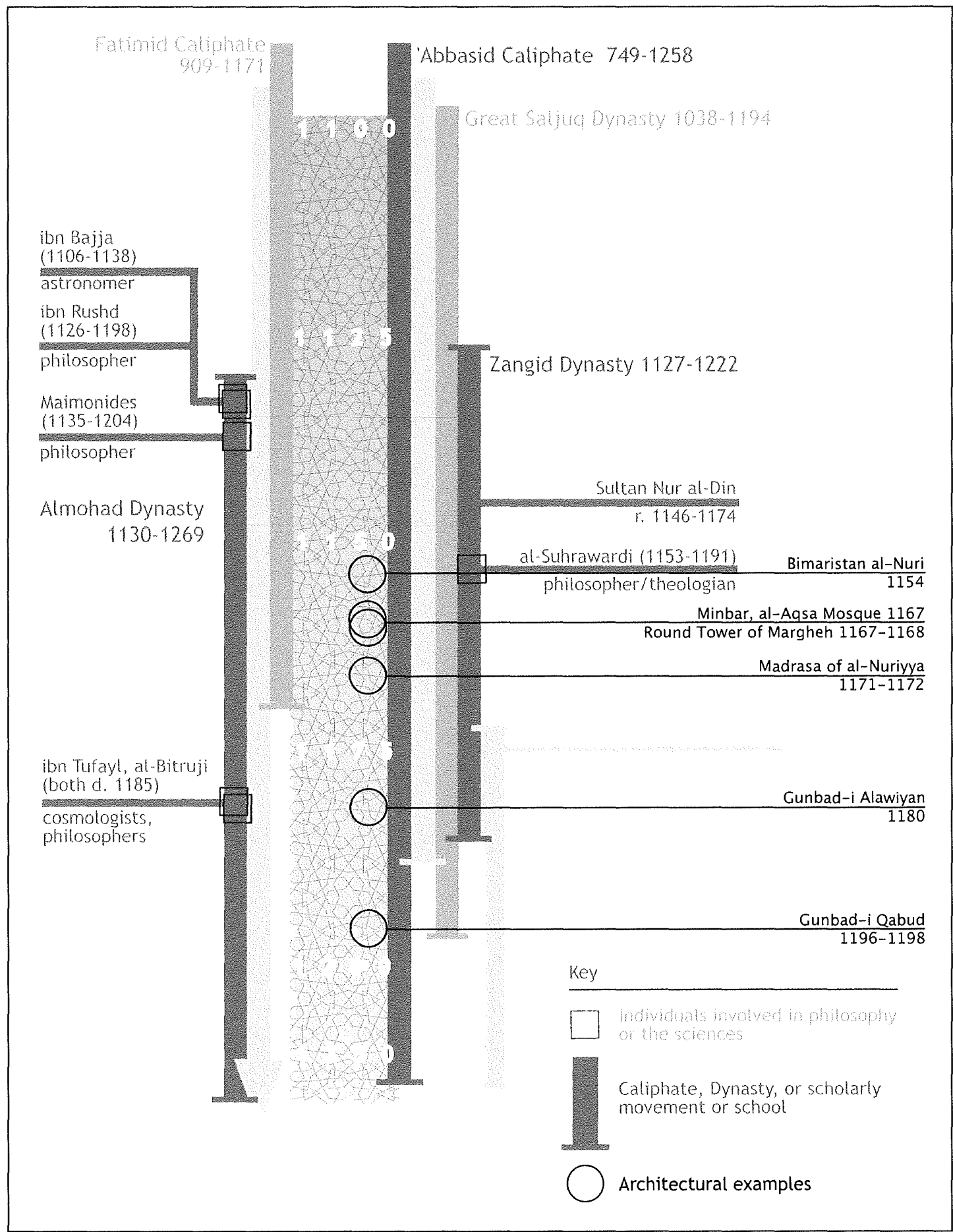

Figure 7.1 Timeline for twelfth century, showing the many emerging dynasties. 
Tenth Century

Samanids \& Buyids

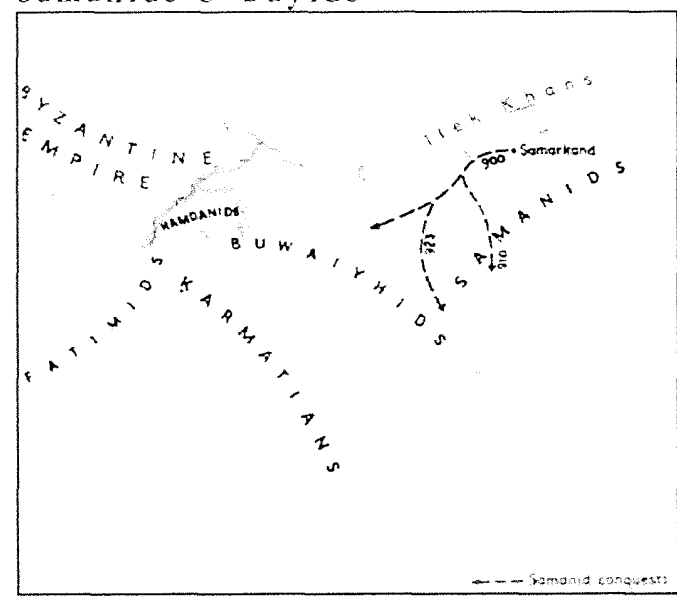

arly Eleventh Century

Ghaznavids

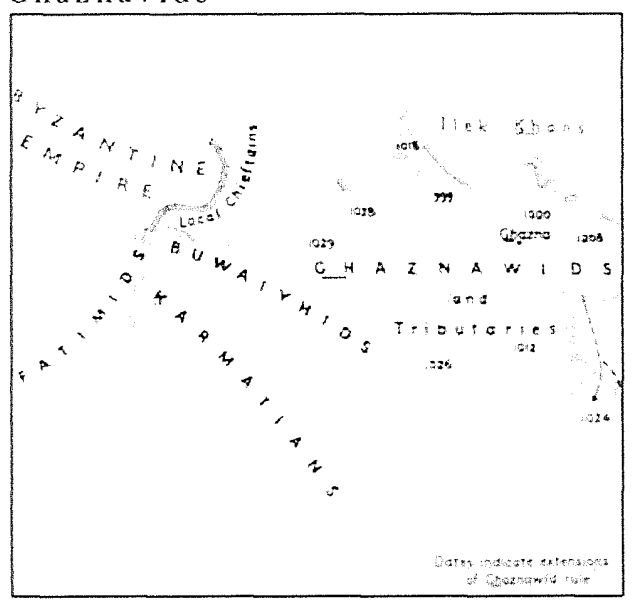

Figure 7.2 Dynastic change leading up to the twelfth century (Brice, 1981, 9).
Eleventh Century

Seljuos

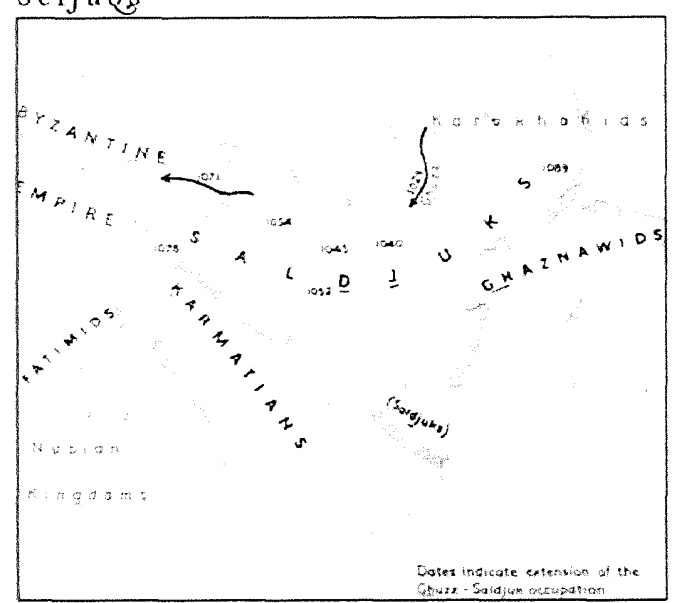


In the twelfth century, these dynasties (shown in the map above) then separated into the Saljuqs of Rum (1077-1307), who moved into Central Anatolia; the Ghurids (1150-1215) who controlled Afghanistan and India; and the Khwarizmshahs (11561231) who established themselves in Iran. The Fatimids also lost control in 1171 to a new dynasty called the Ayyubids, who had in turn been in conflict with the Zangids of Syria. In the west, the Umayyad Caliphate of Cordoba remained stable from 756 until 1031, when it split into smaller, military-based dynasties called reyes de taifas, which in Spanish means 'local kings'. Two especially powerful dynasties emerged in the west in the twelfth century-earlier, the Almoravids (1056-1147), and later, the Almohads (1130-1269).

In the farthest western part of the empire, these two dynasties, both Berber, both from North Africa, sought to control Andalusia and the Maghrib. The Almoravids (1056-1147) brought an army into Spain at the invitation of the Umayyad Caliphate of Cordoba to expel Christian incursions into Spain, but the Almoravids soon captured Andalusia for themselves. The Almohads, whose name means "The Upholders of (Divine) Unity", were motivated by a strident spirituality. Their first leader, Ibn Tumart (1077-1130), a Berber from the Moroccan Atlas mountains, studied Ash'ari theology and the writings of al-Ghazali in Damascus and Baghdad. Upon returning to Morocco, he galvanized other Berber populations, reforming and introducing a stricter and more austere spiritual style to the people there. Thus the Almohads (1130-1269) expanded throughout North Africa, and wrested control of 
Andalusia away from the "the Almoravid dynasty [which] was collapsing through its own decadence" (Glassé 2002, 45). With examples like this in mind, Ibn Khaldun, a renowned fourteenth century North African Muslim historiographer, developed a theory of history whereby tribal invasions from desert or mountain regions break the hold of sedentary and decadent regimes; then they themselves yield to the temptations of sedentary life, having removed the strictures of nomadic existence (Khaldun 1958). This push and pull between nomadic and settled peoples, and the resulting shifts in boundaries between central and frontier lands, is illustrated by the Almoravid/Almohad contest, and indeed resonates throughout Islamic history.

The complexity of this overall fragmentation underlies the dispersal of centers of activity on the twelfth century overlay map (figure 7.3, eastern portion and figure 7.4, western portion). This period of many different dynasties resulted in more capital cities with their own schools, madrasas, libraries, observatories-their own intellectual class. New buildings went up in the form of palaces, mosques, and mausoleums for all these new rulers, their wives, and favorite advisors. Some new cities were settled, and older centers such as Merv, Isfahan, and Damascus underwent a revival as the more localized powers established themselves in centers of manufacturing and trade (Ettinghausen 2001, 133). Tabbaa also comments on this westward revitalizing trend, noting "the geographic shift from Iraq/Iran and Egypt to Syria greatly contributed to the revival and repopulation of its main cities, which began in the twelfth century to reverse several centuries of demographic and cultural stagnation" $(2001,19)$. The dispersal of activity from centers outward during these centuries is clearly visible on 


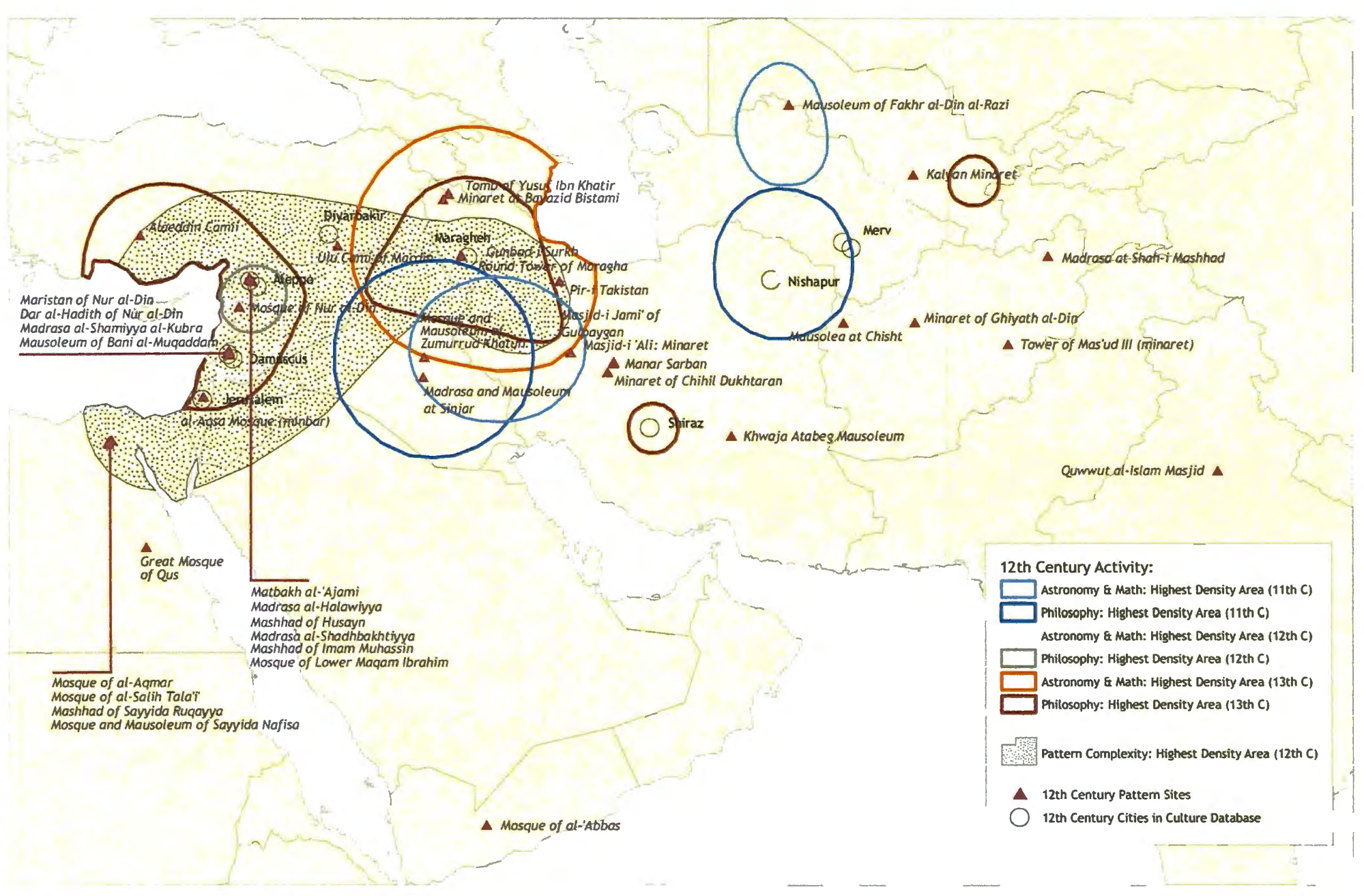

Figure 7.3 Density overlay map of eastern portion of twelfth century. 


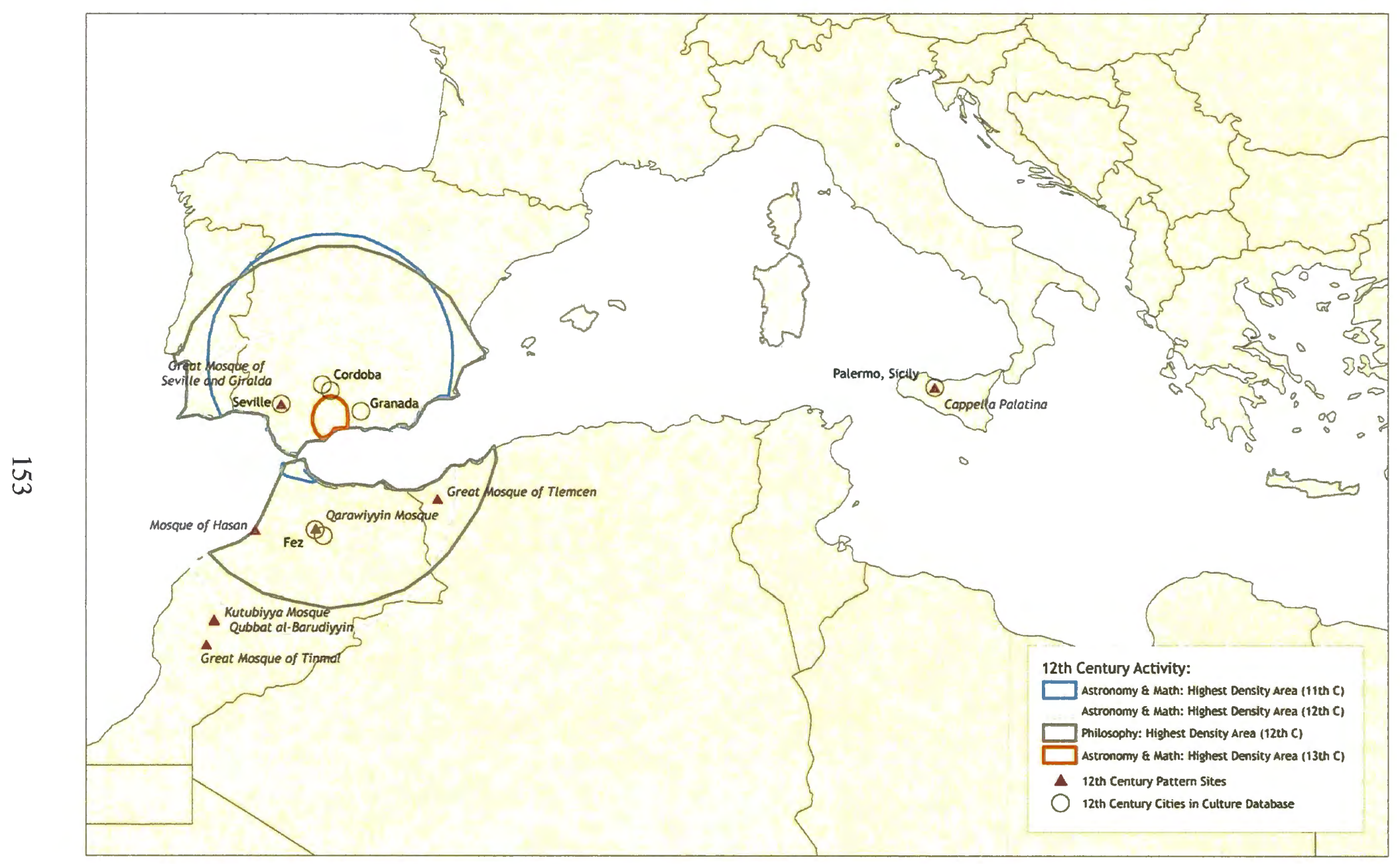

Figure 7.4 Density overlay map of western portion of twelfth century. 
the density overlay maps from the tenth and eleventh centuries. The tight clustering of high-density regions surrounding Baghdad in the tenth century slackened in the eleventh century, and is non-existent in the twelfth. The most prominent cities in the eleventh century-Khwarazm, Cordoba, and Baghdad—gave way to Damascus, Aleppo, Merv, and Cordoba in the twelfth. Damascus and Aleppo especially absorbed much of the power that leaked away from the 'Abbasids and Fatimids, mainly in response to the developing crusader threat.

Most of the dynasties were of different ethnicities than the Arabs who controlled the caliphates. The ethnic makeup of the conquering dynasties further restructured the empire, adding Kurds (Ayyubids), Turks (Seljuqs) and Berbers (Almohads and Almoravids) to the mix. These non-Arab forces that came from the outskirts of the empire took power away from the center, and distributed it at the frontiers (Ettinghausen 2001, 133). The shift from central, caliphal rule to broad-scale dynastic rule resulted in great fragmentation but also in a dispersal and dissemination of the knowledge generated in the caliphal capitals, especially out of Baghdad, the seat of the most powerful and long-lived caliphate. Hourani echoes this when he notes "the political division of the lands of the caliphate brought with it a certain dispersion of energy and talent, but led also to the rise of a number of courts and capital cities to serve as focuses of artistic and intellectual production" (1991, 189, my emphasis). He further establishes a simplified division into three somewhat exclusive regions: "Iraq remained within the sphere of radiation of Iran; Syria and Egypt formed a cultural unit, of which the influence extended to parts of the Arabian peninsula and of the 
Maghrib; and in the far west there developed an Andalusian civilization which was different in some ways from what existed in the east" (1991, 189). From these regions, one emerged in the twelfth century to dominate the rest in terms of artistic, scientific, and philosophical activities.

\section{The Rise of Syria}

The great cities of Syria, Damascus and Aleppo, grew in importance in the twelfth century in response to a growing threat from Christian crusaders, and became military bulwarks for two dynasties, the Zangids and the Ayyubids. However, other conflicts, reflecting both ethnic and religious differences, already existed in Syria:

Damascus and Aleppo became the fiefs and military entrepots for a succession of petty Turkish dynasties...the mutual distrust between Turks and Arabs was fostered by sectarian differences: the Turks were Sunnis, whereas the Muslims of Aleppo were generally Shi'is...Indeed, the numerical and political strength of Shi' is in Aleppo was sufficient to modify or even reverse the general trend of Sunnism throughout the first half of the twelfth century. (Tabbaa 2001,19)

There were also differences in dynastic control and patronage-by the mid-twelfth century, Damascus had nine madrasas, and Aleppo had only one. The two cities had not been united under one ruler for centuries until 1154 when Nur al-Din (r. 11461174), leader of the Zangid dynasty, captured Damascus. Nur al-Din opposed the Frankish crusaders as well as the Shi' a Fatimids, his neighbors to the west-he was a major figure in the continuing struggle for Sunni authority, for the Sunni revival. He built the first madrasa in Aleppo, rebuilt that city's Great Mosque, and sponsored many other structures in both Aleppo and Damascus built in the twelfth century that bear his name. 
Nur al-Din's rule gave way to that of Salah al-Din, (b. 1138, r. 1169-1193, known in the west as Saladin), founder of the Ayyubid dynasty. Under the Kurdish Salah al-Din, the Ayyubids defeated the Fatimids in Cairo, thereby annulling the last mjor Shi'a political power. Salah al-Din also succeeded in capturing Jerusalem from the crusaders in 1187 , and worked his way into Western consciousness via his battles with Richard the Lionheart at Acre in 1189. By the end of his rule, the Shi' a-Sunni contest had been settled, and control of the central Islamic lands, including Egypt, Syria, Yemen, and some of eastern Turkey, was under the control of a single Sunni dynasty, shown in figure 7.5. The great number of Zangid- and Ayyubid-sponsored monuments, in existence partly because of the stability brought to the region by the Ayyubids, is reflected in the density overlay map, in the region of highest pattern complexity, which encompasses the Ayyubids' territory (figure 7.3, above).

\section{The Sufis}

Sufism, the practice of the esoteric or mystical dimension of Islam, emerged as a social and political force during this century. While it is impossible to pinpoint the exact origins of the term or its specific meaning, the word Sufis was already being used to describe a small community of pious individuals in Alexandria, Egypt in the $9^{\text {th }}$ century (Haeri 1998, 4). Sufi practices included all of the normative Islamic activities, but was supplemented by $d h i k r$ (remembrance/invocation), fikr (contemplation/meditation) and other practices, all aimed at the purification of the self and fana (annihilation of the ego) in God. 


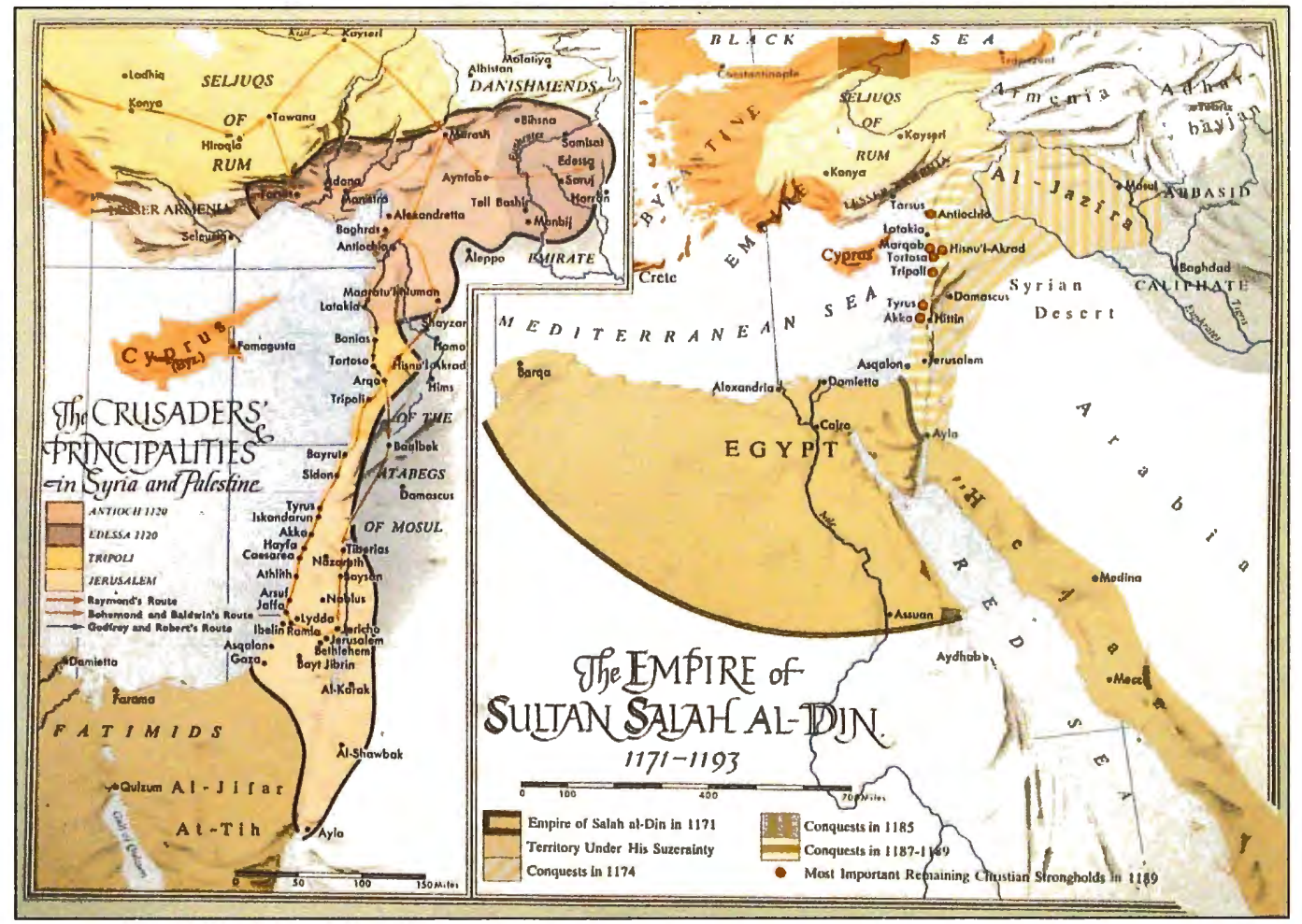

Figure 7.5 Salah al-Din's territories at the end of the twelfth century (Roolvink 1957, 9). 
Though geographically widespread, Sufism remained somewhat underground or 'unofficial' until the eleventh century, when "the intellectual defense of Sufism vis-àvis the jurists, exoteric scholars, and theologians [was] carried out... by the famous Persian theologian and Sufi Abu Hamid Muhammad al-Ghazzali" (Nasr 2003, 83). This rigorous and thoroughgoing explication of Sufi theory and practice allowed the various Sufi orders (turuq) to organize themselves more openly, and to become associated and even patronized by local leaders all the way up to the caliphs themselves. By the end of the twelfth century, officially recognized Sufi orders were being housed in state-sponsored buildings (Bloom \& Blair 1997, 133).

It is important to note that one of the reasons for the emergence of officially patronized and promulgated Sufism in the Sunni world was its ability to compete against Shi' ism for peoples' loyalty. One of the reasons for this ability is that both the Shi'a and Sufis greatly revered Imam Ali (the fourth caliph and cousin and son-in-law of the Prophet Muhammad) as both the paragon of Islamic chivalry, and as the recipient and conduit of the Prophet's more esoteric teachings. Therefore the Sufis, though for the most part outwardly Sunni and prevalent in the Sunni world, practiced an esoteric style of Islam that shared a common root with the Shi'a, and in later times served as "a mediating bridge between those two poles" (Negipoglu 1995, 109).

Because this, the twelfth century, was when Sufism began to be significantly patronized, it is relevant to again bring the spatial analysis to bear on one of the major hypotheses about the origination and meanings of complex decorative geometric patterns. The essentialist discourse, that these patterns held universally similar 
meanings, such as the Sufi concept of divine unity (tawhid) as noted previously, has been thoroughly criticized by Necipoglu (1995) and Tabbaa (2001). Additionally, the spatial parameters of the use of geometric pattern obviously do not seem to have been used only in Sufi contexts, or else we would not have seen them exhibited so widely for so long, among so many different courts and theological sects. Also, al-Ghazali, an important figure in early, organized Sufism:

vehemently defended orthodoxy against Shi'a doctrines and Neoplatonic philosophy, and advocated the Sufi experience as the highest form of knowledge...Quoting statements by the Prophet, he condemned the decoration of mosques because it diverted the worshiper's attention, and because, according to a tradition, the angel Gabriel ordered Muhammad to build a mosque in Medina without decoration" (Behrens-Abouseif 1998, 22, emphasis mine).

Thus both specific spatial and contextual information deny the essentialists' claims. Important Scholarship

As with centuries past, certain individuals stand out as influential; some also provide exceptional links between the disciplines of science and art. With the increased number of cities acting as capitals, more opportunities arose for disciplines and individuals to connect with each other, for their ideas and concerns to come into contact.

During the Almohads' rule in the twelfth century, a group of scholars coalesced around Cordoba: Ibn Tufayl (d. 1185), Ibn Rushd (Latin Averroes, 11261198), Ibn Bajja (1106-1138), al-Bitruji (d. 1185), and Rabbi Moses ben Maimon (Maimonides, 1135-1204). They wrote on topics related to both science and philosophy, and indeed worked together "to replace the Ptolemaic model [of the 
universe] with one more compatible with the physical world" (Djebbar 2003, 316). Such a solution, driven by Aristotelian, or empirical, findings would satisfy theologically and philosophically. Thus these individuals contributed both to the exact and the philosophical sciences. These advancements, this great circle of learning, did not coincide with any monuments exhibiting complex geometric pattern in the cities of Cordoba or Granada, either in the previous century (eleventh), same century (twelfth) or the following century (thirteenth). The mathematics and astronomy activity there did not precede, or "prime the pump" so to speak, for use of complex geometric patterns in architecture. Necipoglu's (1995) assertion that pattern use is predicated on mathematical familiarity is again shown not to hold up to a spatial analysis- the courts in the western part of the empire that 'developed a taste' for either math or astronomy did not pursue a program of building and decorating as intensely as those in regions further east.

Sadly, the group at Cordoba marks the end point of scientific innovation in the western portion of the empire-collectively, they "had little influence beyond alAndalus and the oncoming decline of Western Muslim civilization" (Endress 2003, 157). Individually, however, their works made their way into the Western European canon-Maimonides' philosophical works affected nearly all later Jewish philosophy, and Ibn Rushd's commentaries on Aristotle were translated into Latin as early as the thirteenth century (Broadie 1996, 725).

At the same time, nearly three thousand miles to the east, another kind of philosophy emerged. Both Sufism and Neoplatonism use light and the metaphysics of 
light as a central motif. The source of the deep symbolic nature of light in the different ideologies in Islam comes directly from the Qur'an, from what is aptly called the "light verse":

Allah is the light of heavens and of the earth. A likeness of His Light is a niche in which there is a lamp, the lamp is within a glass, the glass is like a pearly white star lit from the oil of a blessed tree-an olive-tree-neither of the East nor of the West, whose oil all but glows though no fire touches it. Light upon light; Allah guides to His Light whom He chooses. And He sets forth examples for the people, and Allah is the knower of all things $(24: 35)$

As early as the eleventh century, Ibn Sina had made Neoplatonism his own by using illuminationist ideas (Fahkry 1983, 133). The illuminationist tradition was distinct from strict Aristotelianism in that it was related more to Pythagorean-Platonic ideas. What this meant, very simply, is that this tradition delved more into metaphysical and symbolic meanings of the related phenomena of light, vision, and perception with gnosis (direct experience of the Divine) as the goal.

At Aleppo, a man named Shihab al-Din al-Suhrawardi (1153-1191) “ took over the illuminationist ideas of Ibn Sina and developed a philosophy of enlightenment based on the Divine Light as the very substance of the universe," creating a new philosophy, simply (and repetitively) called the Ishraqi (Illuminationist) school (Behrens-Abouseif 1983, 32). He set out the form of the new philosophy in a book called Hikmat al-ishraq (Philosophy of Illumination) written in both Persian and Arabic. Nasr states that because of the metaphysical emphasis in their doctrines and Sufi associations, the Ishraqis grew while the Aristotelians (Peripatetics) weakened during the twelfth century, thereby making Illuminationism the "second major 
philosophical perspective in Islam...[it] became a rival of the earlier Peripatetic school and soon even overshadowed it" (Nasr 1968, 36, 328).

The synthetic element, seen before in the discussion of al-Ghazali, comes up again in Suhrawardi's work. He joined mysticism with philosophy, believing that Sufis and Peripatetic philosophers together made up the model individual who could train the rational mind and purify one's inner being, thereby achieving the position of "theosopher", the ideal of Ishraqi doctrine (Nasr 1996, 369). Suhrawardi also used analogies culled from other disciplines, such as astronomy, to explain his view of knowledge:

he compares physical astronomical observation (irsad jismani) with spiritual astronomical observation (irsad ruhani), and states that the same kind of certitude observed from the world of sense data (al-mahsusat) is obtained from observing or 'seeing' the non-corporeal... his commentators also use it to illustrate the fundamentals of the Illuminationist theory of knowledge. (Ziai 1996, 452)

The philosophy of the Ishraqis has been taught continuously up to this day, and is especially popular in Iran. So not only is it still a vital, living tradition, but it marked the end of the hyper-rationalist Peripatetic philosophy. Despite this legacy, Suhrawardi did not have the contemporary political element on his side. While he was a tutor of Salah al-Din's son, Suhrawardi was accused of heresy, corruption of religion, and corrupting the young prince; as punishment, he was executed. There is debate over the political motivations behind his death, ranging from the jealousies inherent in a member at court rising to popularity as quickly as Suhrawardi had, to the political ramifications of his new philosophy. Ziai contends he was killed because of the latter; Nasr further indicates an anti-Shi' a political motivation, as parts of Syria, 
especially Aleppo, had been vigorously Shi' a up until and even after the Sunni Zangids united Aleppo and Damascus in 1154 (Ziai 1996, 435; Nasr 1996, 459). Suhrawardi's life thus marks a nexus between old and new philosophy, as well as another example of the familiar Sunni-Shi' a antagonism.

Art and Expectation in the Twelfth Century: Examining a New Relationship

The number of examples of complex decorative geometric pattern increased dramatically in the twelfth century. There were only fifteen monuments in the eleventh century database, but in the twelfth that number grew to fifty-one. As the number has increased, the region of high complexity has moved markedly west, as shown below in figure 7.6. As described earlier, many new cities were either founded or re-inhabited, creating new opportunities for architectural expression.

The unique thing about the twelfth century density overlay map is what occurs in northwestern Iran, eastern Turkey, and around Damascus. These places all fall in the region of high pattern complexity in the twelfth century, and they stand out because they are overlaid by thirteenth century regions of high-density astronomy/math and philosophy activity (as depicted by the dark red and orange outlines in figure 7.7). This is the opposite of the spatial relationship supporting the hypothesis that places needed to have certain types of activity occurring in them to be able to employ the geometric mode in architecture-for this relationship we have been looking for the light and dark blue outlines, signifying the previous century, to overlap with the high pattern complexity regions. In the twelfth century, the expected before/after relationship been not just been thrown off, it has reversed, just as we saw 


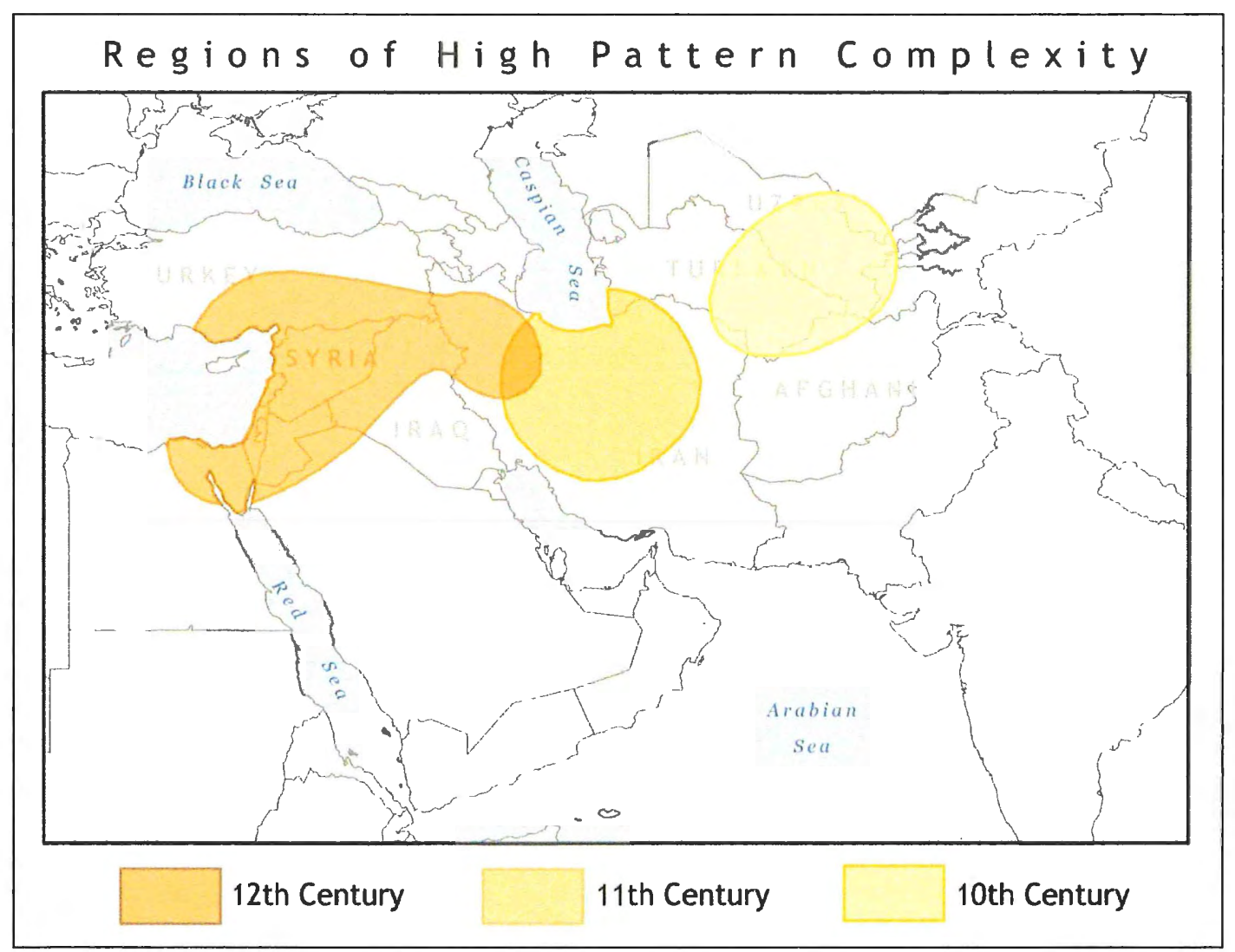

Figure 7.6 The regions of highest pattern complexity move west as time goes on. 


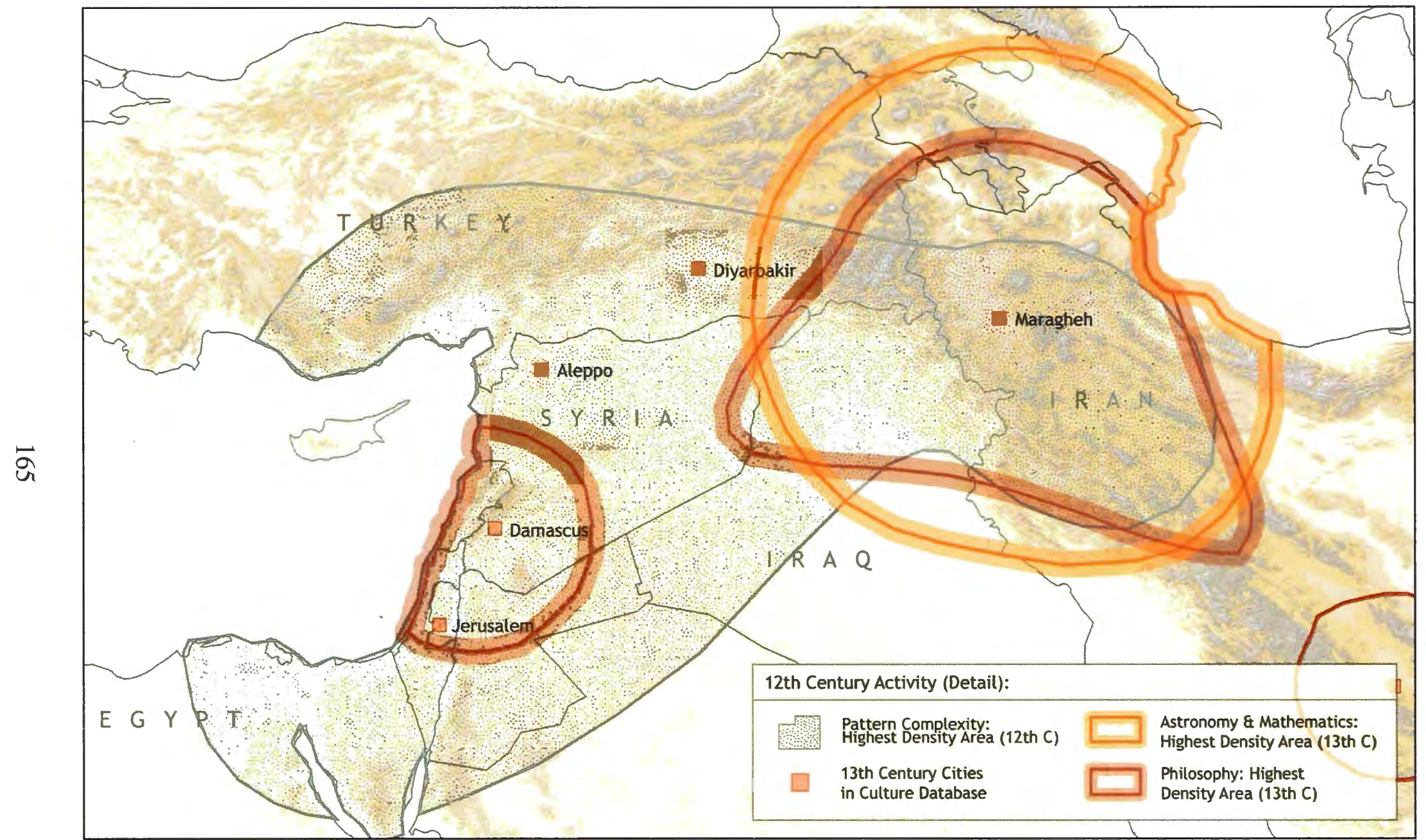

Figure 7.7 Simplified detail of twelfth century overlay map highlighting where high pattern complexity coincides spatially withlater, not earlier cultural activity. 
in the tenth century density overlay map. Instead of proving an existing theory, a new and unexpected line of enquiry unfolds.

This spatial relationship, (while not necessarily proving a causal link), allows us to legitimately ask a fundamentally different question-did this type of art relate to or possibly affect the development of other types of activity? Again, this notion runs contrary to the prevalent hypotheses about the nature and origins of decorative geometric pattern in Islamic art. These existing hypotheses lead to an obvious type of link-advances in mathematics explain the intense use of geometry in art-therefore there has been no effort made to explore the logical and reasonable opposite. But the spatial dynamic set up in the tenth and twelfth century density overlay maps begs the alternate question-rather than "what caused this, what was in place culturally, politically, intellectually, to create or facilitate the use of these patterns" what if instead, based on these spatial arrangements, we ask, "what did these patterns inspire, either culturally, politically, intellectually?" My data show that this is a reasonable line of enquiry, yet no current or past scholars, from within or outside of Islamic culture, seems to have asked this kind of question.

Let us now more closely examine this unexplored spatio-temporal relationship by first looking at the eastern half of the region of overlap from figure 7.7 , then the western half. I link the twelfth century monuments from these regions of overlap to the individuals working in the fields of science and philosophy in those places in the following (thirteenth) century. 
Details in the East:

Figure 7.8 presents examples of the geometric mode from the eastern portion of where twelfth century pattern complexity is overlaid by thirteenth century scientific and philosophical activity-Hamadan and Maragheh. In these cities, the geometric decoration is predominantly on the outside of structures, with muqarnas appearing mainly in arches or passageways. (The western locations in Syria differ in that both interior and exterior surfaces receive geometric decoration, such as in the form of full muqarnas domes in Damascus). The monuments in Hamadan and Maragheh are mausolea, places where patrons, either rulers or wealthy families, paid to have elaborate tombs built for the family or dynasty; as such they are part of an architectural tradition prevalent in northwest and central Iran in that time. These structures played a role in local ideological and political manifestations of powerthey studded the landscape as prominent reminders of both the specific piety and power of the donors.

In the case of the Gunbad-i 'Alawiyan in Hamadan, the patron of the building was a member of the Shi'ite Buyid court who carefully maintained his Shi'ite faith after the Sunni Saljuqs came to rule the region. The calligraphic inscriptions on the building have been characterized as Shi'ite, but are apparently unique in this time period (Shani 1996, 126, 128). The Shi'a-inspired philosophies of Suhrawardi have also been connected to the symbolic architectonics of this structure (Shani 1996, 141). 


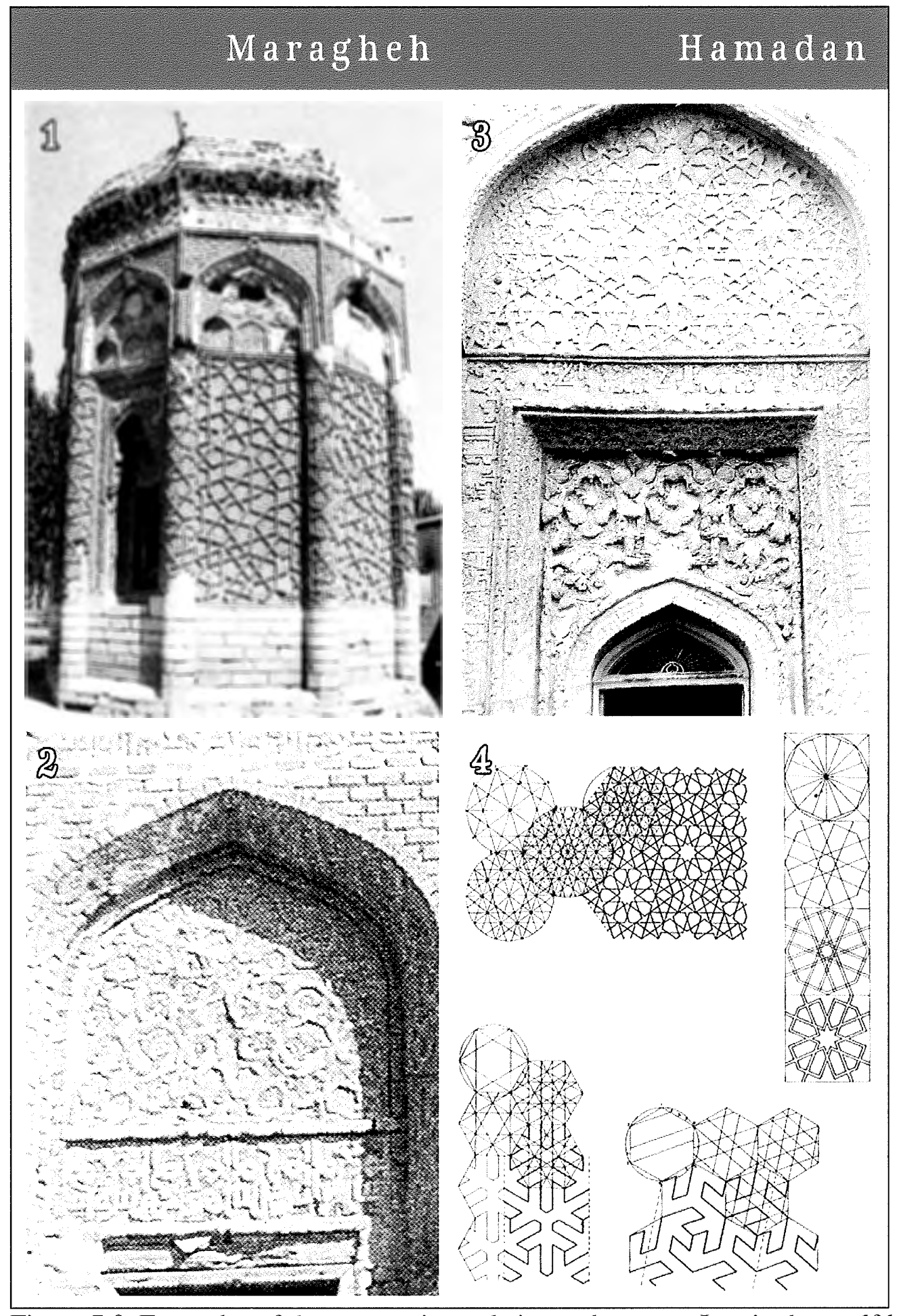

Figure 7.8 Examples of the geometric mode in northwestern Iran in the twelfth century: 1: Gunbad-I Qabud; 2: Round Tower of Maragheh; 3 and 4: Gunbad-I Alawiyan. (Images: 1: Ettinghausen 2001, 2-4: Shani 1996). 
Reflections of the major urban centers of Isfahan and Gulpaigan, both directly southwest of Hamadan and Maragheh, appear in the examples from the eastern cities. The star-and-polygon decoration and calligraphic inscription above the portal of the northern dome chamber of the Masjid-i Jami of Isfahan and the muqarnas transition zones of the Masjid-i Jami of Gulpaigan have been imitated in the Round Tower of Maragheh and the Gunbad-i 'Alawiyan of Hamadan; these stylistic similarities could be an attempt by the patrons to visually recall and thus draw on the political importance of Gulpaigan and Isfahan, the Saljuqs' favorite western capital, as well as to associate these mausolea with places of prayer (Shani 1996). Thus the underlying function of the buildings in the eastern cities seems to have been certain types of communication - that of the power and piety of their patrons, and perhaps the specific ideological viewpoint (Shi'a or Sunni) which they espoused.

In this eastern sector of overlap of twelfth century pattern complexity with thirteenth century scientific and philosophical activity, one individual emerges above all others, proving to be indispensible to the last major epoch of Islamic science. This was Nasr al-Din al-Tusi (1201-1274), "second only to Avicenna, the master of all Muslim philosopher-scientists, in his influence and significance for the Islamic arts and sciences and philosophy" (Nasr 1968, 322). Al-Tusi's father was a prominent jurist of the Twelfth Imam sect of Shi'a Islam (the most prevalent sect of Shi'ism), and he taught al-Tusi their doctrines.

When the Mongols swept through Persia, they captured al-Tusi, who offered his services as an astronomer, which Hulagu Khan, founder of the Il-Khanid Mongol 
dynasty, accepted. The Mongols deeply valued knowledge of the stars and their predictive power and appreciated al-Tusi's abilities in this field. Under al-Tusi's guidance, an observatory and a library of 400,000 volumes were built at Maragheh; he also brought together a great many other scholars and scientists, which resulted in a revival in mathematics and astronomy, and renewed interest in philosophy and theology. A major school thus sprung up around al-Tusi at Maragheh, under the patronage of the Mongols.

Connecting al-Tusi to the monuments at Maragheh is difficult. However, if the mausolea were constructed to convey meanings such as prominence within a community or even an ideological orientation, then their decorative programs would be part of that communication. Al-Tusi's proximity to the star-and-polygon patterns in use in Maragheh and Hamadan may have been important to the development of his ideas and work. Figure 7.9 and 7.10 present examples of diagrams created by al-Tusi and his contemporary in Maragheh, Qutb al-Din al-Shirazi (1236-1311).

Al-Tusi's relationship to these monuments is thus far undocumented, but this may be because the connection has not been relevant until now. Indeed, Necipoglu asserts that astronomers' work affected the development of the geometric mode, noting that their use of orbitlike radial grids, such as those in figure 7.3 and 7.4 , inspired the use of these grids in the decorative arts (1995). However, in this case, spatial analysis shows that the geometric mode preceded the work of these influential astronomers in northwestern Iran in this period. Thus the relationship posited by Necipoglu should not always be fixed in a one-way direction. 


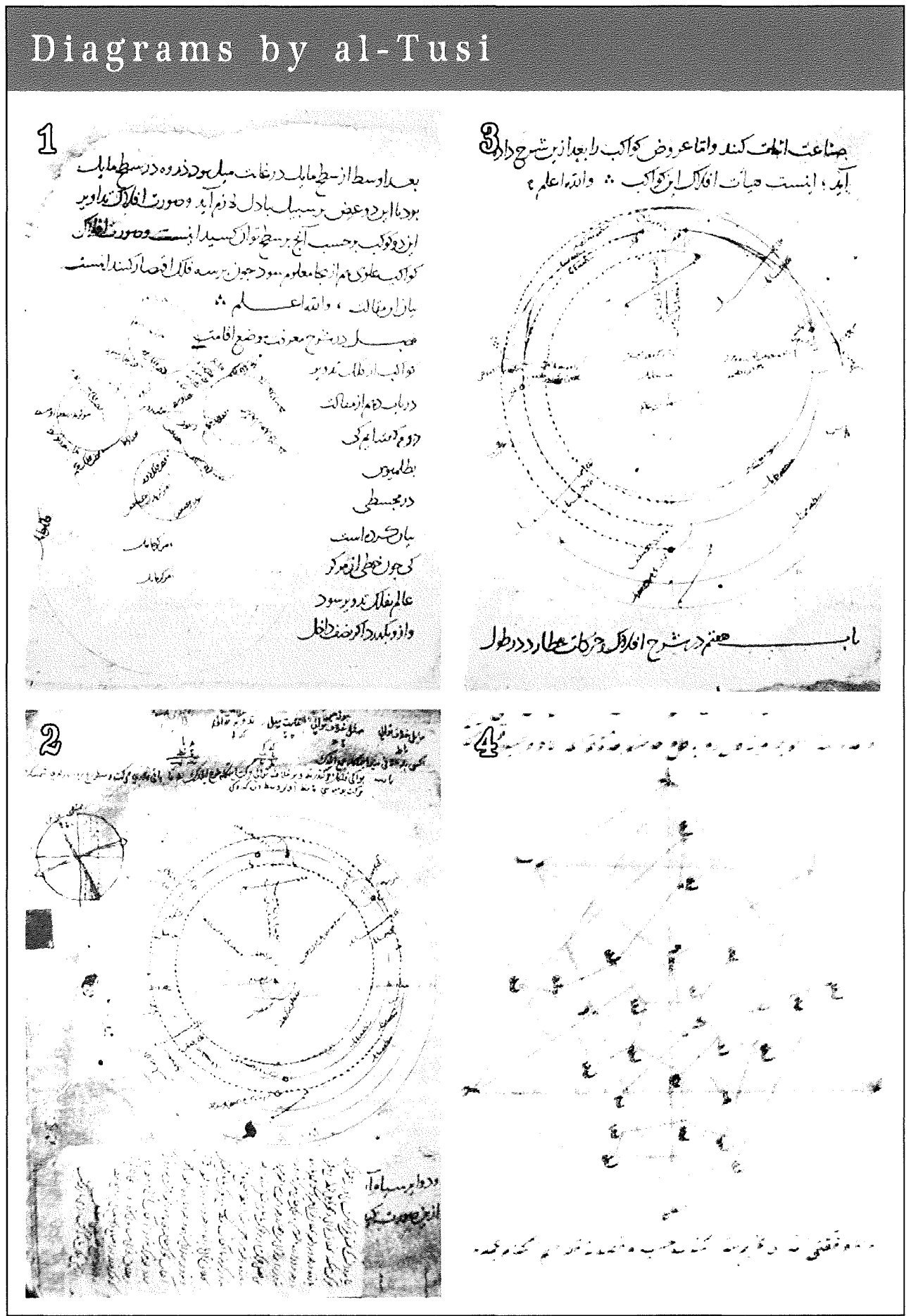

Figure 7.9 Diagrams by al-Tusi, referencing the circle and polygons: 1-3 diagrams of planetary motion; 4 diagram from final page of al-Tusi's commentary on the Elements of Euclid. (Image sources: 1-3: Nasr 1976, 108; 4: Nasr 1976, 83). 


\section{Diagrams by al-Shirazi}

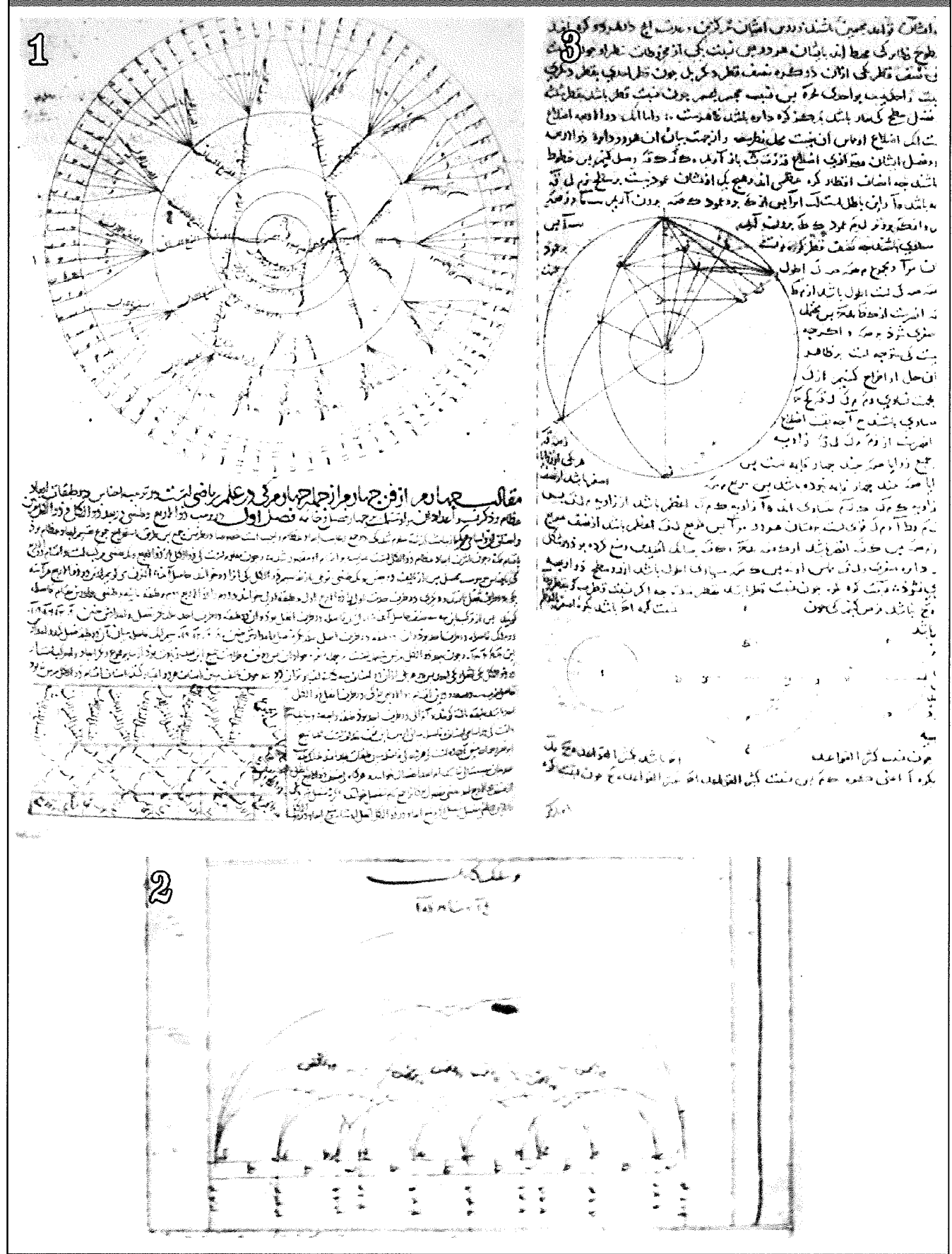

Figure 7.10 Diagrams by al-Shirazi: 1,2 from a treatise on music and harmonics; 3 from an astronomy text. (Image sources: 1,2: Nasr 1976, 87; 3: Nasr 1976, 109). 


\section{Details in the West:}

Among the monuments in the western portion of figure 7.7 (the detail map of the twelfth century) is the Mashhad of Husayn. The Mashhad of Husayn is the most important medieval Shi'a structure in all of Syria (Tabbaa 1997). Decorated with mature examples of muqarnas in its portals and dome, this structure exemplifies the architectural mastery of form and ornament of twelfth century Aleppo. It was built by the Shi'ite community, from individual contributions (as opposed to a Sultan's endowment) as a memorial commemorating the martyrdom of Husayn, the son of Ali, who is revered by the Shi'a. Tabbaa further explains that the Mashhad al-Husayn affected the development of subsequent monuments built under the Sunni Ayyubidstheir leadership perceived the Masshad al-Husayn as a threat to Sunni authority and so the Sunnis expanded the shrine and inscribed their names on it (1997). Thus the structure communicates the authority of the ruling groups, as we saw with the Gunbad-i 'Alawiyan of Hamadan. That these structures communicate anything at all is important if we are to believe that they could have inspired individuals acting in other cultural milieus.

Nearby, in Damascus, Sunni architecture dominated the landscape in the twelfth century. The Bimaristan al-Nuri and the Madrasa al-Nuriyya were both built under the auspices of Sultan Nur al-Din, founder of the Zangid dynasty (figure 7.11). 


\section{Diagrams by al-Shirazi}

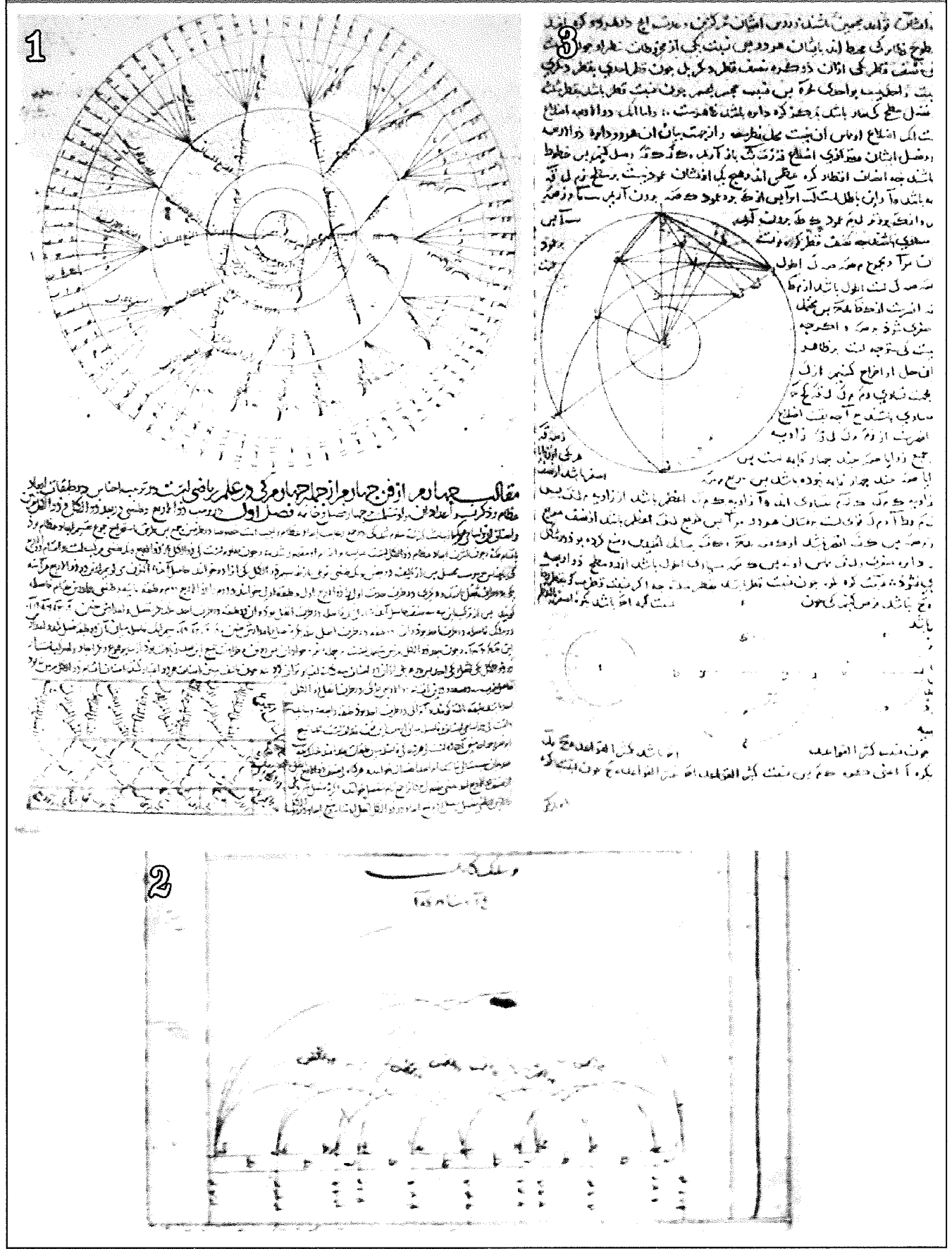

Figure 7.10 Diagrams by al-Shirazi: 1,2 from a treatise on music and harmonics; 3 from an astronomy text. (Image sources: 1,2: Nasr 1976, 87; 3: Nasr 1976, 109). 


\section{Details in the West:}

Among the monuments in the western portion of figure 7.7 (the detail map of the twelfth century) is the Mashhad of Husayn. The Mashhad of Husayn is the most important medieval Shi'a structure in all of Syria (Tabbaa 1997). Decorated with mature examples of muqarnas in its portals and dome, this structure exemplifies the architectural mastery of form and ornament of twelfth century Aleppo. It was built by the Shi'ite community, from individual contributions (as opposed to a Sultan's endowment) as a memorial commemorating the martyrdom of Husayn, the son of Ali, who is revered by the Shi'a. Tabbaa further explains that the Mashhad al-Husayn affected the development of subsequent monuments built under the Sunni Ayyubidstheir leadership perceived the Masshad al-Husayn as a threat to Sunni authority and so the Sunnis expanded the shrine and inscribed their names on it (1997). Thus the structure communicates the authority of the ruling groups, as we saw with the Gunbad-i 'Alawiyan of Hamadan. That these structures communicate anything at all is important if we are to believe that they could have inspired individuals acting in other cultural milieus.

Nearby, in Damascus, Sunni architecture dominated the landscape in the twelfth century. The Bimaristan al-Nuri and the Madrasa al-Nuriyya were both built under the auspices of Sultan Nur al-Din, founder of the Zangid dynasty (figure 7.11). 


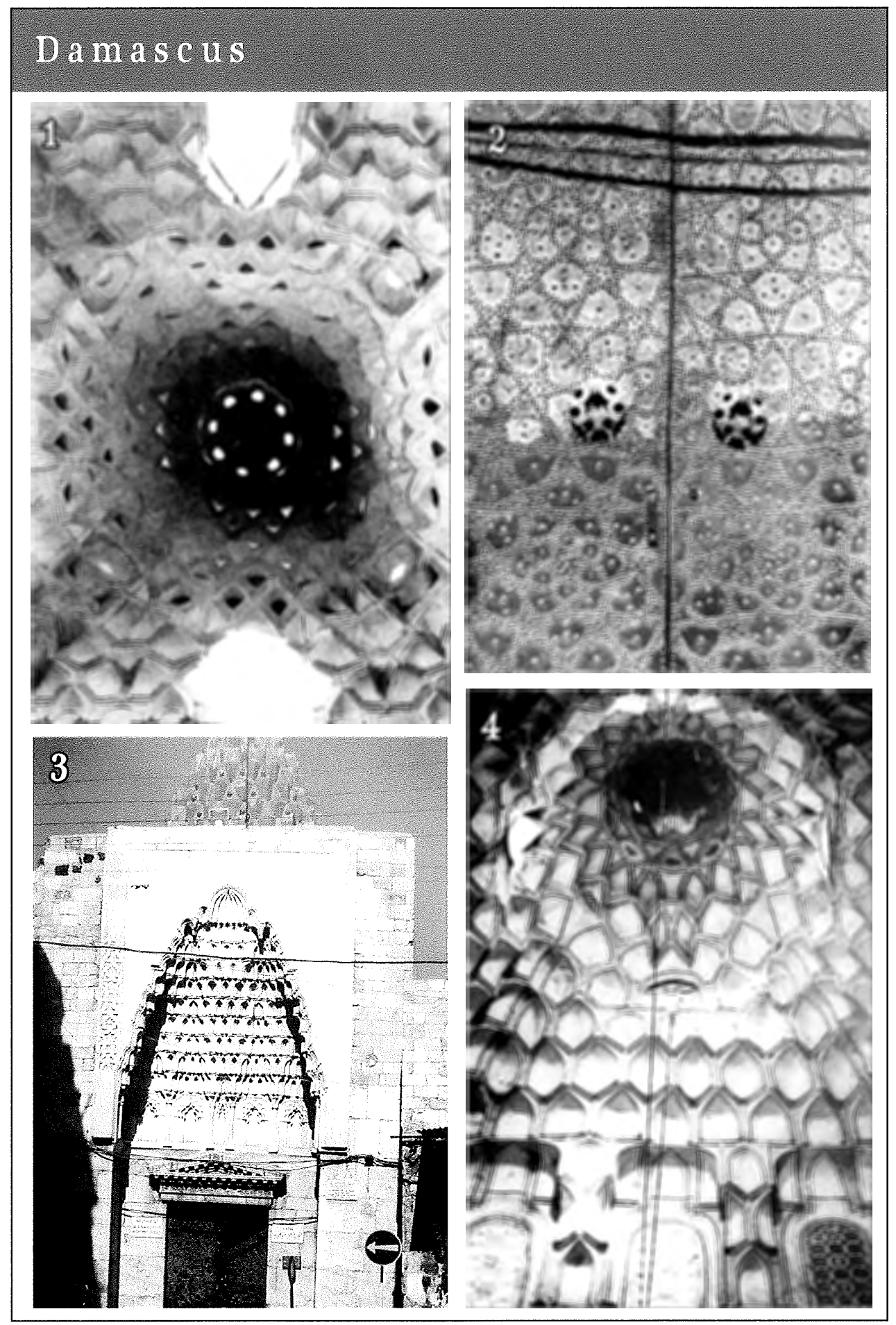

Figure 7.11 Muqarnas and star-and-polygon patterns in twelfth century Damascus: 13: Bimaristan al-Nuri; 4: Madrasa al-Nuriyya. (Image sources: 1: Tabbaa 2001, 119; 2: Tabbaa 2001, 90; 3: Ettinghausen 2001, 229; 4: Clevenot 200). 
They are both similar in form to the Mashhad al-Husayn in their employment of mature muqarnas in portals and dome interiors, yet they were built, as stated, by the Sunni leadership rather than the Shi' a community. Thus the Syrian landscape of the twelfth century was dominated by structures decorated inside and out with muqarnas. In Syria, a major figure in mystical philosophy emerged. Muhyi al-Din ibn alArabi (1165-1240) was born in Andalusia but spent much of his life in Damascus. He wrote some of the most important works on Sufism in all of Islamic history and has been called "the great exponent of unitary mysticism" (Fahkry 1983, 311). His works, such as the monumental exposition of mystical doctrine, the Futuhat al-Makkiyah (the Meccan Revelations) contained detailed elucidations of cosmology, such as "a vision of the universe as an endless flow of existence from and back towards the Divine Being: a flow of which the primary symbol was that of Light... [He attempted] to describe the reality of the universe as it is revealed in the moments of vision. Ibn 'Arabi used the expression wahdat al-wujud (unity of being or existence) [to describe this], and there was much later controversy about its meaning" (Hourani 1991, 176, 178). For al-'Arabi, "mystical experiences confirmed for him the unity of religious forms despite their external divergences" (Glassé 2002, 191). His works operate on many levels of interpretation, and in the last two decades have attracted critical attention in the West. However, his teachings were not broadly appreciated at first, as the multiple levels of interpretation left room for heresies. Yet after the Mongol era, especially in the Turco-Iranian regions, his work gained much wider popularity (Necipoglu 1995, 108). 
The essentialist authors connected to the World of Islam Festival often link decorative geometric pattern to the 'more daring' Sufism of al- 'Arabi and Suhrawardi, with the link being that the works of these authors prompted the use of and gave voice to the 'meanings' of the geometric mode (Necipoglu 1995, 108). However the fact remains that these decorative geometric forms were employed more than one hundred years in advance of either Suhrawardi's or al-'Arabi's writings. The nature of the contact between al-Arabi and the specific monuments of Aleppo and Damascus may not be documented, but closer examination of al-Arabi's works with this angle in mind could produce valuable insights. For example, the statement below could be interpreted with the geometric mode as the underpinning:

Thus the share [of ordinary people] in the pleasure of contemplating [God] is their share in what has been presented to them in images (tukhuyyilat lahum), because the shares of the common people are imaginal and they are not able to transcend material [forms] in [their perception of] the spiritual realities ( $a l$ $m a^{\prime}$ ani) in all those things which they enjoy in this world, the intermediate world, and the other world. (al-Arabi, 2002, the Meccan Revelations, 123)

If the 'images' in the statement above include star-and-polygon patterns or muqarnas, al-Arabi could be saying that the inspiration and state of contemplation provided by these images is as close as 'ordinary people' will get to perception of a multi-layered spiritual world. It could also be interpreted such that the 'images' are a bridge (as opposed to an endpoint) to the perception of the 'spiritual realities'. Al-Arabi himself used geometry to visualize his concepts; figure 7.12 is an example of one of his cosmological diagrams. Thus al-Arabi, in experiencing complex geometric patterns firsthand in the architecture of Syria, may have internalized something of their openended 'meanings' and incorporated such concepts in his work. 


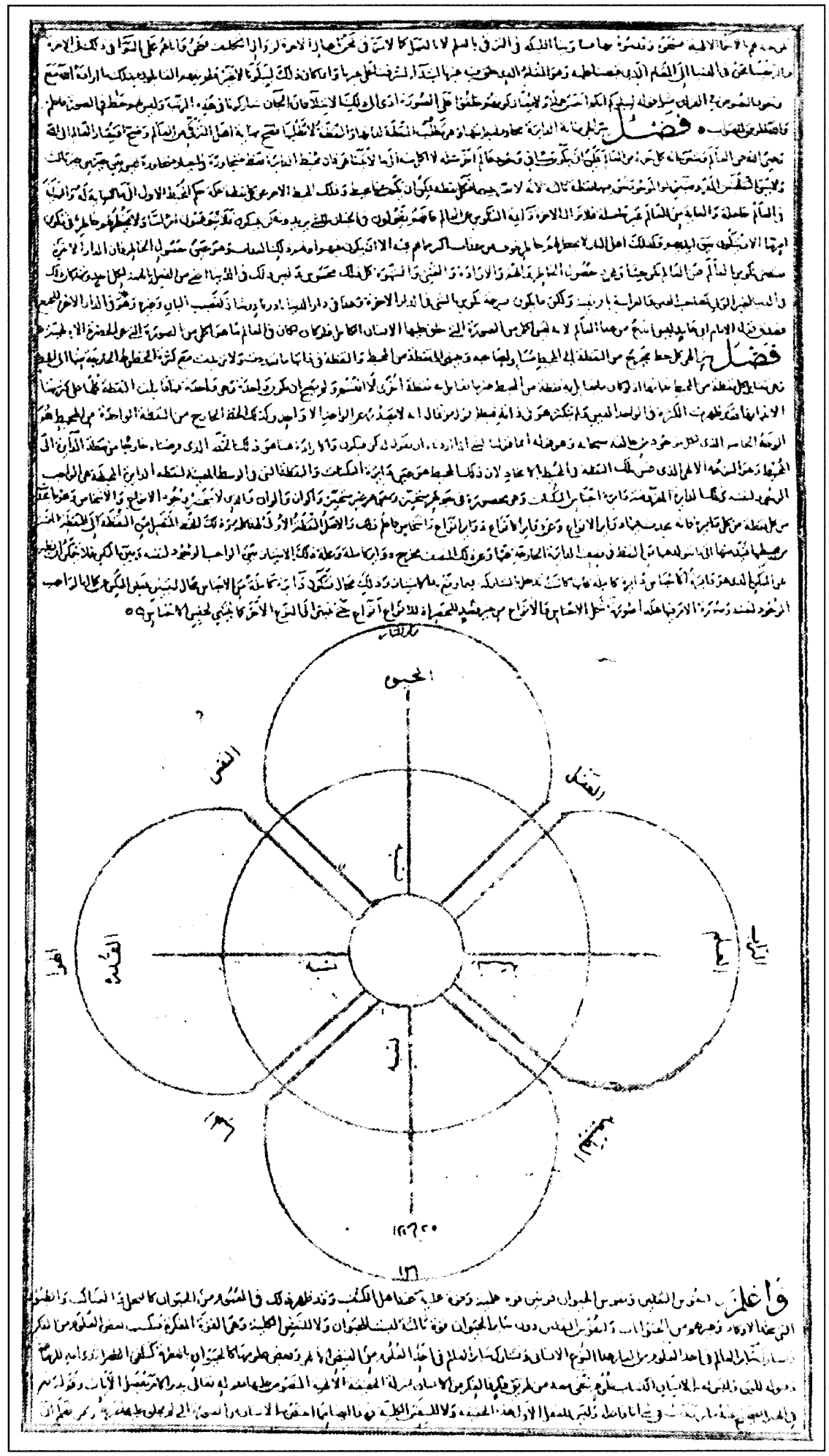

Figure 7.12 Diagram of the Mystical Cosmos by Ibn al-Arabi (Turner 40). 
Use of complex decorative geometric pattern in the twelfth century was not a simple phenomenon. While many hypotheses describing the patterns' use and significance have been put forward, none seem able to capture the variety of circumstances existing in this region during this time. From the distributions provided in figures 7.4 and 7.7 (the full extent of the density overlay and the detail) a new line of enquiry and new areas to examine in greater detail have emerged.

Nasr al-Din al-Tusi, working in Maragheh, and Ibn al-Arabi, situated in Damascus, both profoundly affected the trajectories of Islamic science and philosophy. Massively influential, their works are studied to this day in both Islamic and secular contexts. Could the patterns found in the monuments of twelfth-century Syria and northwestern Iran have helped inspire the mystical writings of al-'Arabi and al-Tusi's advances in astronomy? The spatio-temporal analysis provided here legitimizes asking this question for the first time. That the decorated, built environment may have influenced their work provides a new avenue for research of these important individuals. 


\section{DISCUSSION: THIRTEENTH CENTURY}

The overriding event of the thirteenth century was the invasion of the Islamic lands by the Mongols, which began in 1218 . The changes wrought by their westward advance irrevocably changed the political, physical, and cultural landscapes of the Islamic world. Creating upheaval and chaos in the eastern half of the empire but leaving lands west of Syria unharmed, the Mongols dominated this century. One ruling group not destroyed by the Mongols was the dynasty of the Rum Saljuqs. In this chapter I discuss the Rum Saljuqs' importance and their most famous citizen, Jalal al-Din Rumi; the role of texts specifically connecting art with science; the Mamluk takeover of Syria; and the ramifications of the Mongol invasion to the eastern regions' developments in the sciences and architecture. The timeline below places these events in their temporal context (figure 8.1)

The Rum Saljuqs:

The likely reasons for the high-density pattern complexity region in central Anatolia, shown in figure 8.2, are twofold. First, the Mongols destroyed structures and dynasties on their way west, thereby eradicating existing architecture and preventing the erection of new structures. Second, the Rum Saljuqs embarked on an impressive architectural program throughout Anatolia. Although spared destruction, the Rum Saljuqs had to pay a great deal of financial tribute to the Mongols to remain unharmed. 


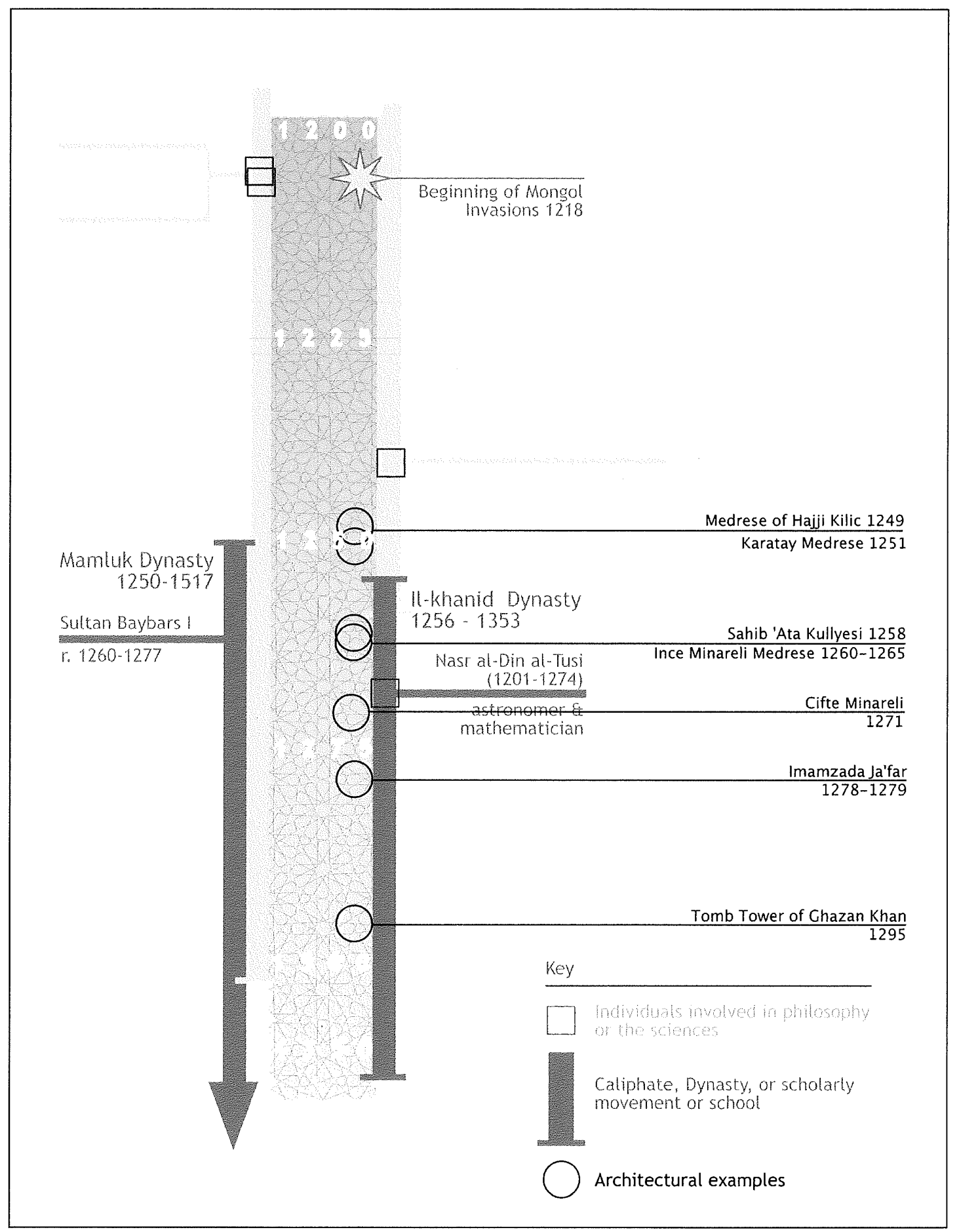

Figure 8.1 Thirteenth century timeline. 


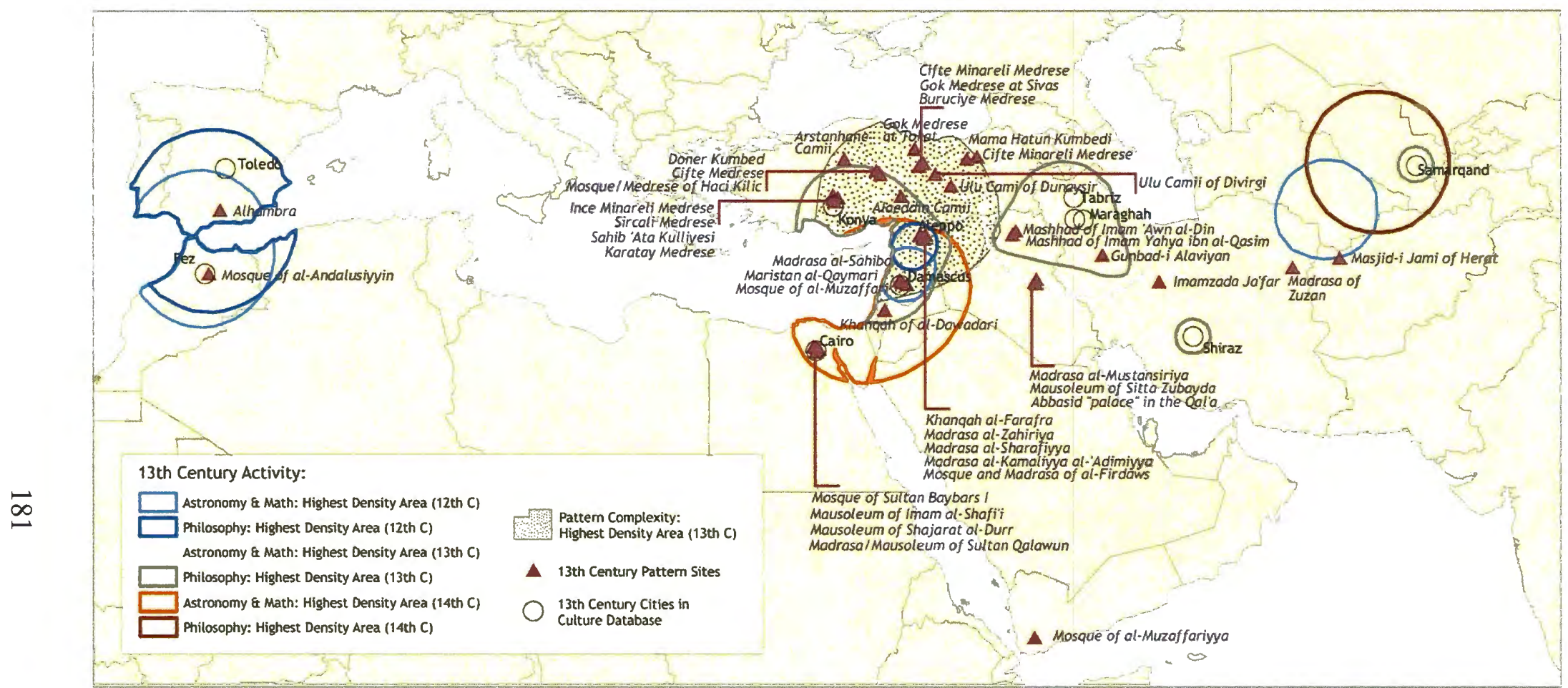

Figure 8.2 Density overlay map of thirteenth century. 
The Rum Saljuqs' empire comprised a diverse population, partly because of its location in an historically mixed area.

[The Rum Saljuqs' territories] contained many non-Muslims and recent converts, with the twin consequences of eclecticism and of a wide range of cultural components, especially from the Christian Caucasus. As a frontier area it attracted Muslim militants, from ghazi (militant) warriors to the adherents of mystical Sufi orders. (Ettinghausen 2001, 234)

Many refugees poured into Anatolia from the regions conquered by the Mongols, further contributing to the mixed population. The extent of the Saljuq's territory in 1243 is shown in figure 8.3. The Saljuqs ultimately took inspiration from the architectures of these various cultures, combining these elements into an original achievement (Ettinghausen 2001, 242). At their capital at Konya and throughout their territory, they built structures often monumental in scale, covered with decorative geometric patterns and muqarnas (figure 8.4).

$\underline{\text { Jalal al-Din Rumi: }}$

Also at Konya we find the well known Sufi, theologian, and poet Jalal al-Din Rumi. Born in Afghanistan of Persian descent, he came to Konya at a young age. His major work, the Mathnawi, made up of six volumes of spiritual teachings, was according to Rumi himself an "esoteric commentary on the Qur' an" (Nasr 2003, 45). Its writing may have begun as early as 1256 and continued sporadically until his death in 1273 (Schimmel 1993, 34). While teaching and writing his magnum opus at Konya, Rumi witnessed the building of the Sirçali Medrese (1242), the Karatay Medrese (1251), the Sahib 'Ata Kulliyesi (1258), and the Ince Minareli Medrese (1260-65) which are all decorated with muqarnas and star-and-polygon patterns. 


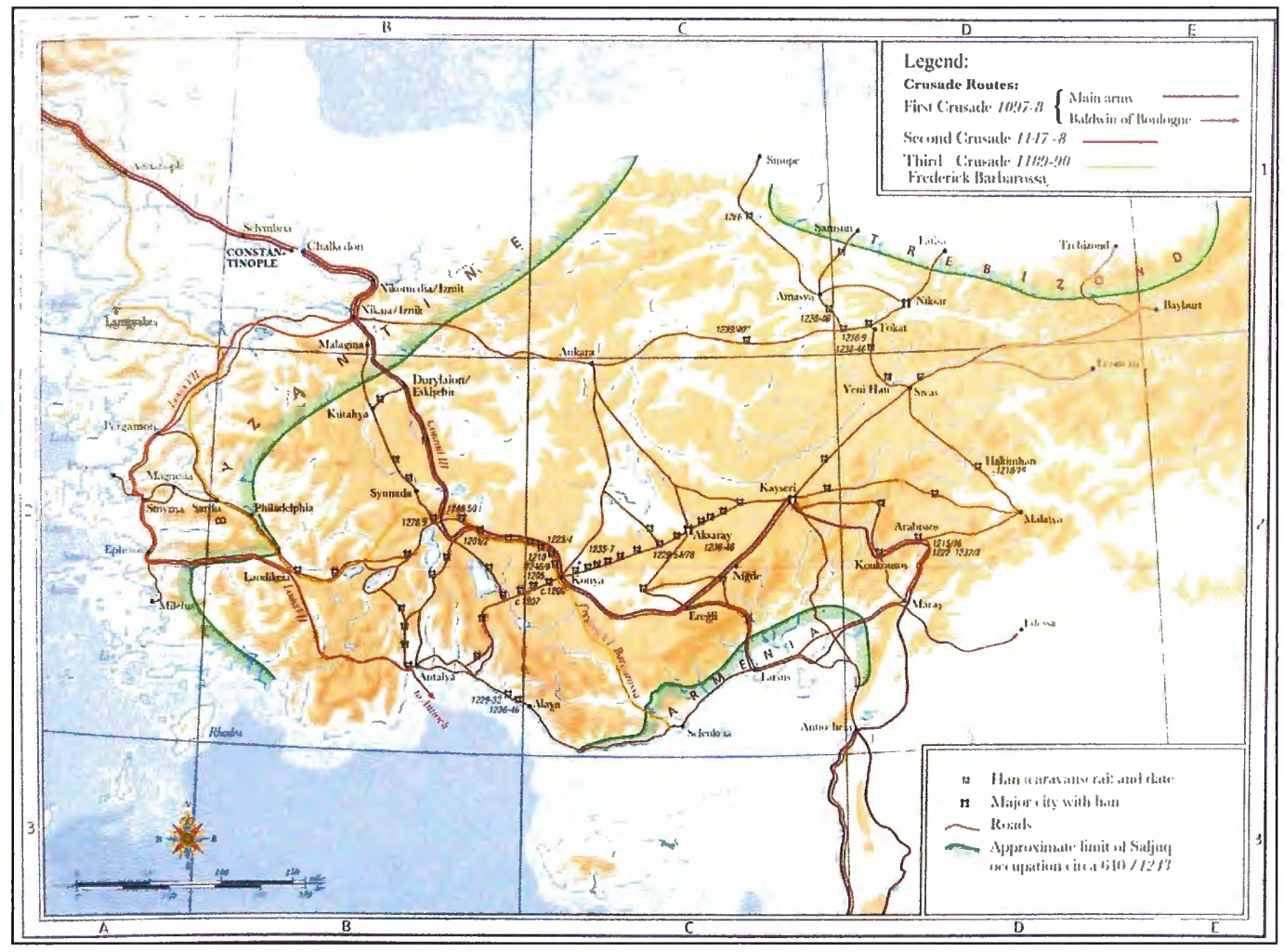

Figure 8.3 Anatolia in the middle of the thirteenth century (Kennedy 2002, 47). 


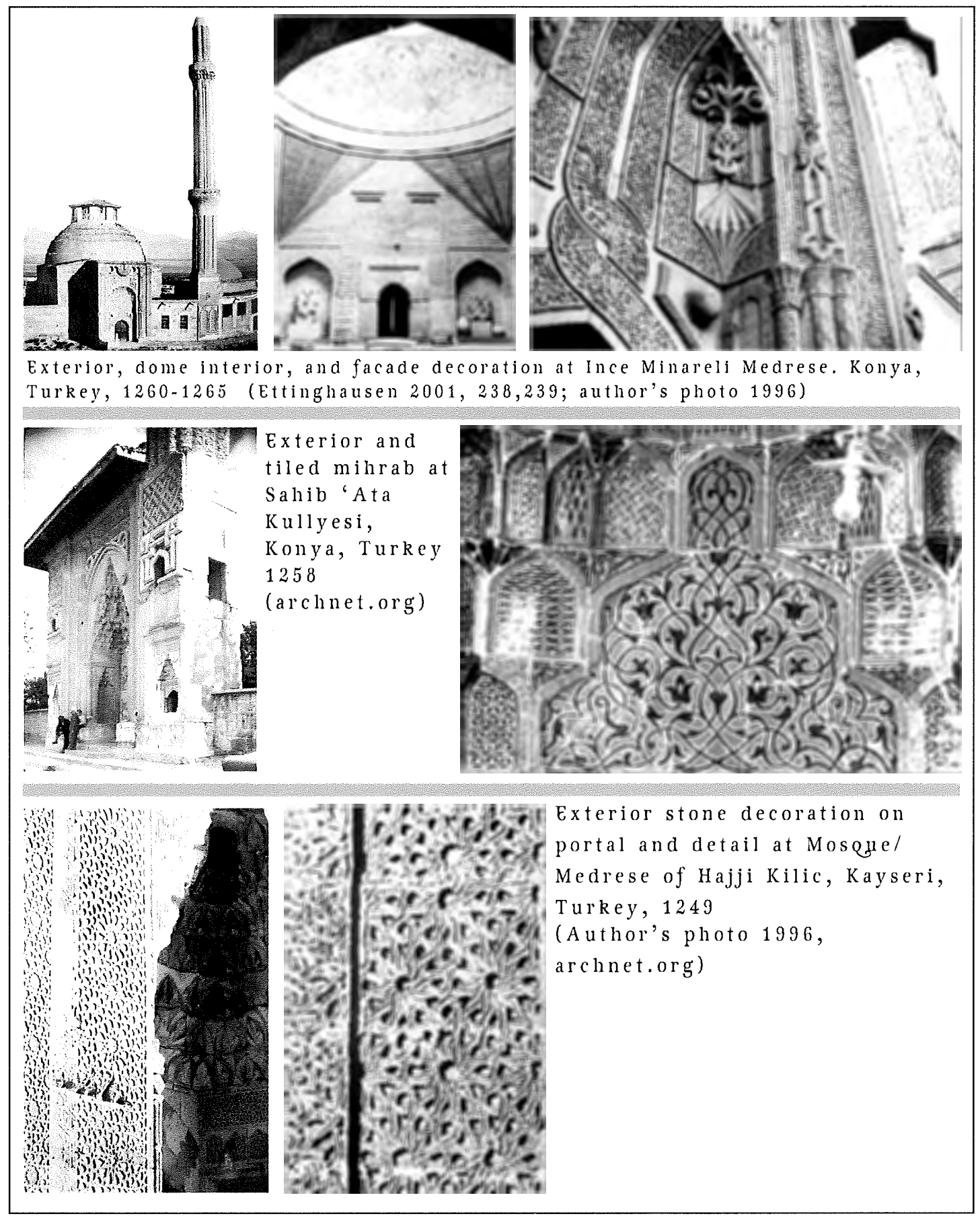

Figure 8.4 Examples of Rum Seljuq architecture. 
The coexistence of such an influential thinker and this clustering of buildings makes one wonder about a possible connection between the two. In figure 8.2 we do not see the type of overlap showing a region of high pattern complexity occurring before a region of high density philosophy, as would be shown by a red line on the map. This possibility of the geometric mode influencing Rumi may be obscured by the one hundred year time-step_-in other words, the 'effect' may have been produced during the same century as the 'cause'. Indeed, Schimmel notes that the politician Jalal al-Din Karatay, patron of the Karatay Medrese, was a "close friend" of Rumi's (1993, 25). Further, Schimmel implies a significant connection between the decoration on this structure and Rumi's Mathnawi:

The knots and stars in the letters lead the spectators' eye higher to the dome whose white, bluish, black and turquoise tiles form a pattern of most complicated stars which are connected with each other and yet remain separate entities so that the eye wanders, without finding a beginning or end, until it reaches the apex of the dome which is open so that at night the real stars can be seen; these are, in turn, reflected in a tiny pond in the middle of the madrasa. This decoration corresponds directly with the character of the Mathnawi: the same greater and smaller units of artistically connected stars and star-like motifs, rising from the foundation of Koranic words...(1993, 51, emphasis mine).

Figure 8.5 shows the elements of the Karatay Medrese referenced by Schimmel. Could Rumi's masterwork have been influenced by the imagery he saw? The relationship between the geometric mode and such a major figure in Sufism requires an exposition more detailed than I can provide here, but certainly, the dome at the Karatay Medrese exhibits an extraordinary example of star-and-polygon decoration, perhaps applied to its interior to inspire such contemplation. 


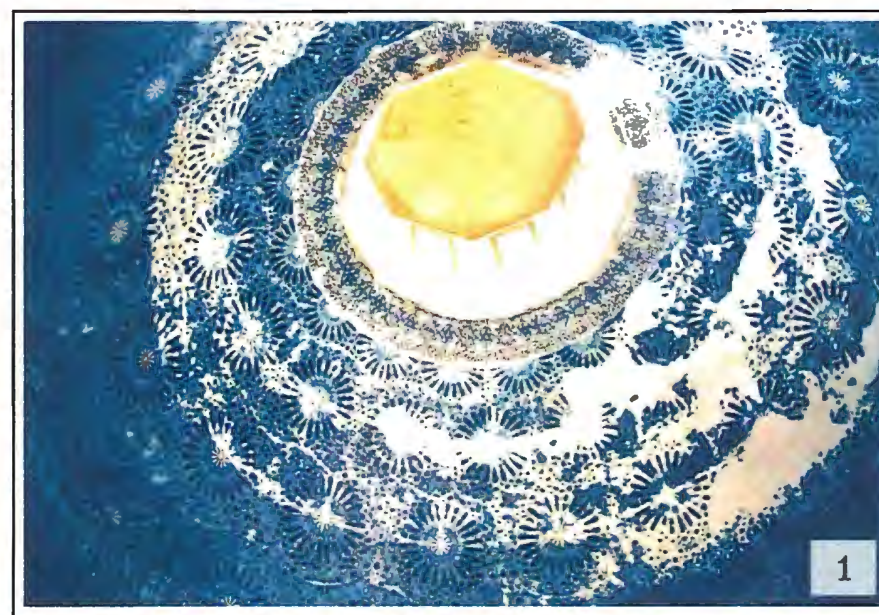

Decoration at the Karatay Medrese Konya, Turkey 1251

Images 1 and show the dome interior and a detail of the starand-polygon decoration; images 3 - 5 show the

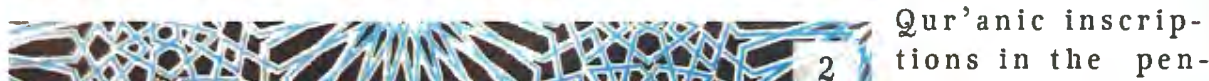

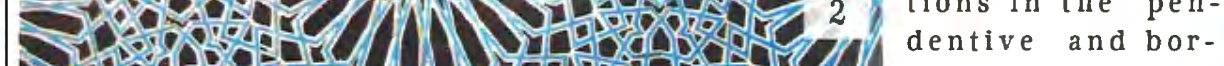

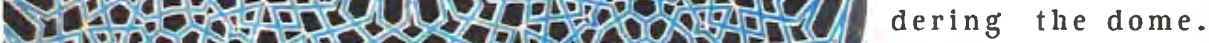

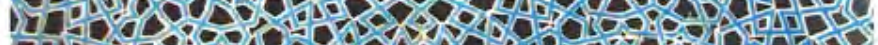

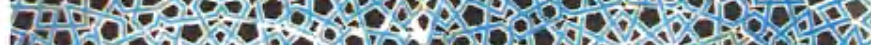

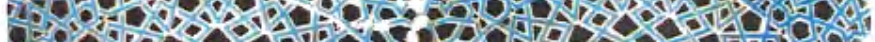
00.4 . 01 .

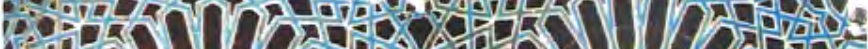

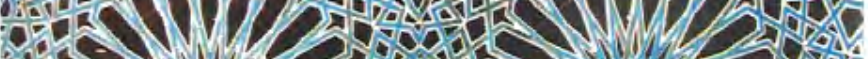

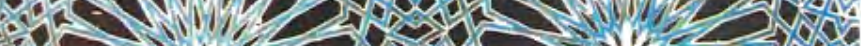

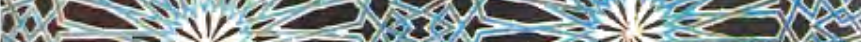

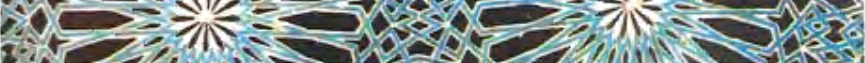

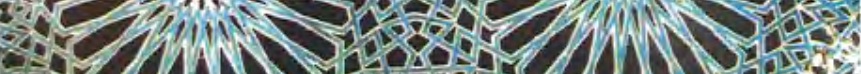

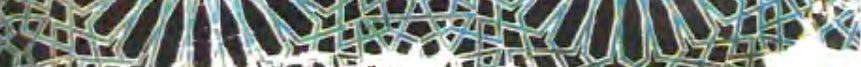
$990.0 \%$

Images 1,3 author's photos, 1996 ;

$2,4,5$ archnet.org
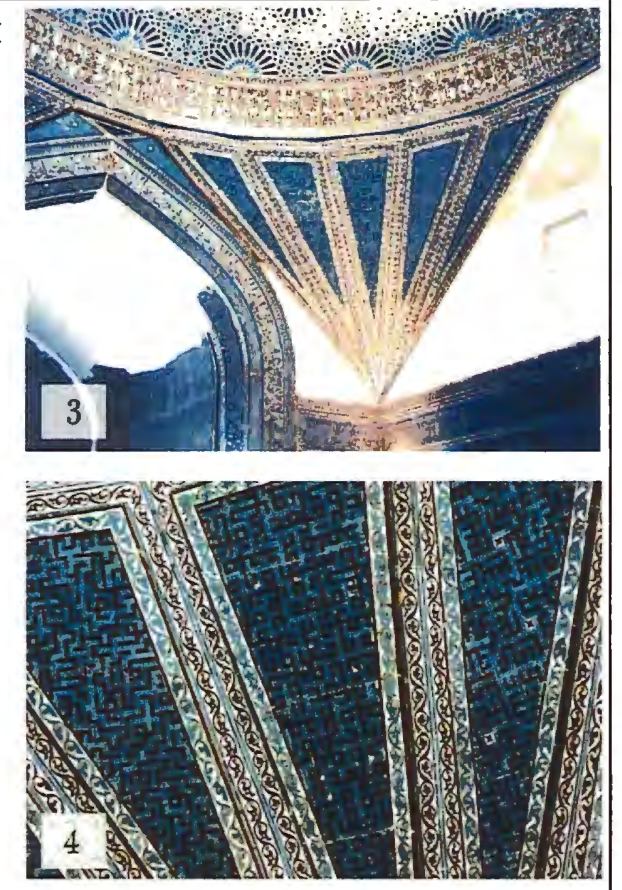

Figure 8.5 Karatay Medrese in Konya.

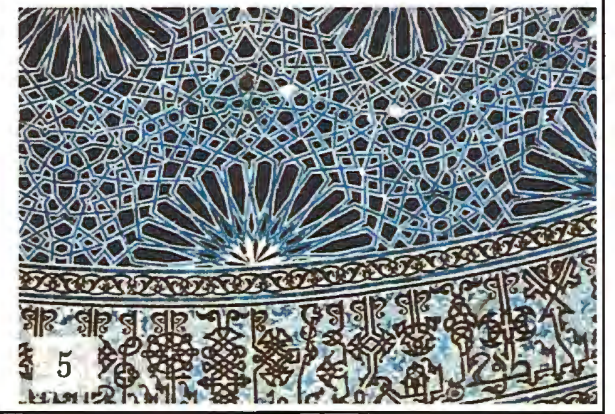

5 \% 
As Rumi himself wrote: "appear as you are, be as you appear. You are not this body, but a spiritual eye-what the eye of man contemplates it becomes" (quoted in Glassé p 236).

\section{The Role of Books: Connecting Science to Art}

Al-Jazari (1150-1220) was a geometer, toolmaker, and engineer from Diyarbakir in eastern Turkey. His book Kitab fi ma'rifat al-hiyal al-handasiyyah (The Book of Knowledge of Ingenious Mechanical Devices), published in the first years of the thirteenth century, provides another textual connection between the exact sciences and decorative geometric pattern. Extremely well-illustrated, the book provides a fascinating glimpse of the state of mechanics and engineering in the Islamic world in the late twelfth and early thirteenth century.

Ettinghausen places Diyarbakir squarely in the sphere of artistic vigor existing at that time: "the rise of artistic patronage under various Turkic groups including the...Zangids and Rum Saljuqs as well as the Kurdish Ayyubids caused a sudden flowering of the local artistic tradition" $(2001,244)$. On the map of the thirteenth century, this certainly holds true, as the region of high pattern complexity encompasses the area Ettinghausen speaks of (figure 8.2). It was in this atmosphere that al-Jazari wrote his book, which consists of diagrams and illustrations of various things like water-clocks, automata, mechanical flutes, irrigation devices, and a decorative geometric plan for a huge set of doors (figure 8.6). He described and illustrated how to execute the pattern, moving from the first steps of how the design was conceived to cutting the wooden models, and ending with how to cast the final 


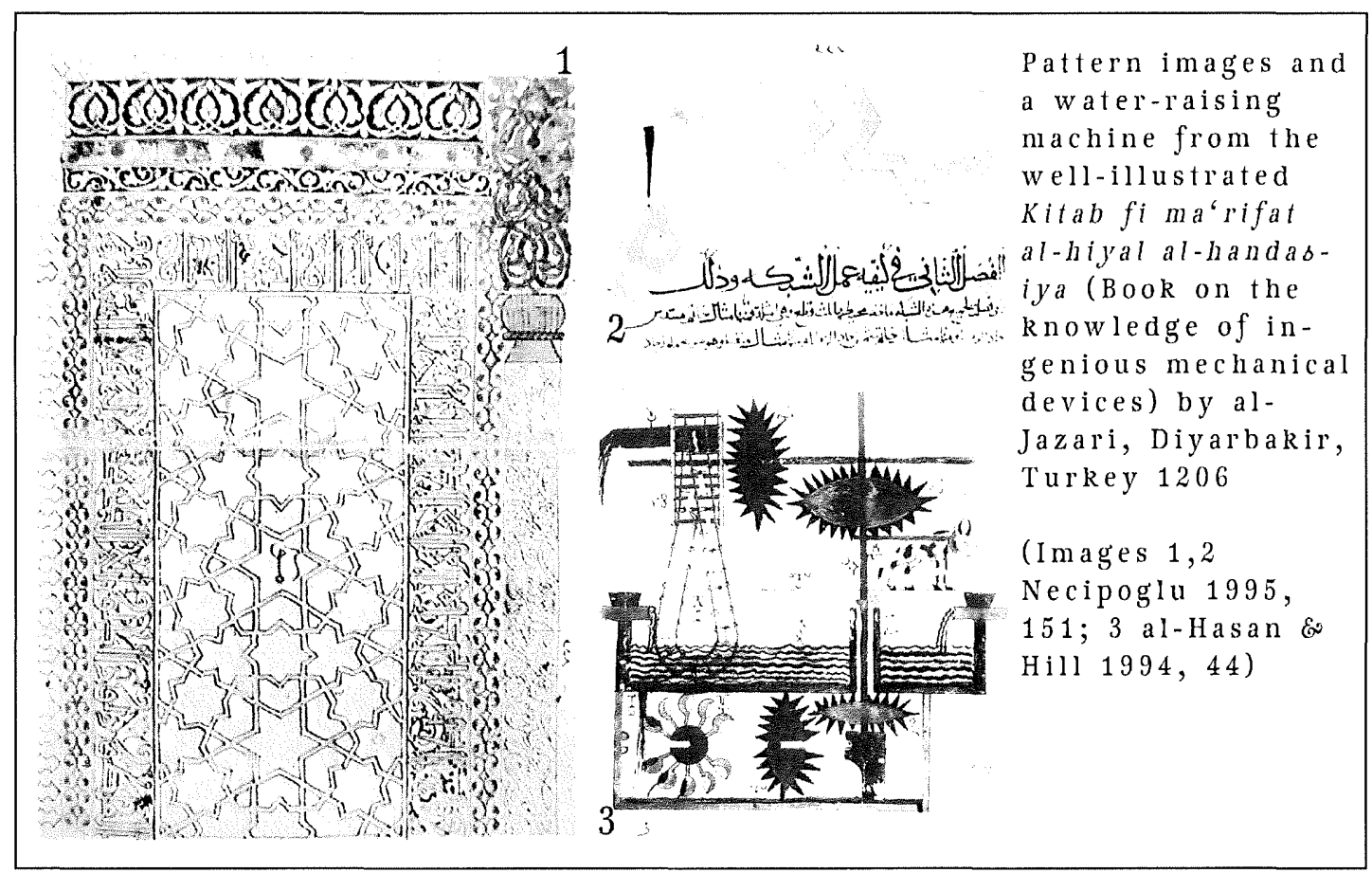

Figure 8.6 Pages from al-Jazari's Book of Knowledge of Ingenious Mechanical Devices. 
brass elements. Al-Jazari wrote the book ostensibly at the direct request of the sultan; it "suggests that he may have been a kind of court engineer whose function was to produce amazing, beautiful, and useful devices for the delectation of the ruler and his circle" (Winder 1983, 216). The book was copied at least fifteen times, with the first copy appearing in 1205 , shortly after its initial creation.

In previous sections of this paper, two other texts connecting mathematics to artistic practice have been discussed. The latter quarter of the tenth century saw the publication of Abu'l-Wafa al-Buzjani's Fi ma yahtaj ilayhi al-sani min a'mal alhindisah (What the Artisan Needs of Geometric Operations), and some time between the eleventh century and the thirteenth appeared the anonymous one, Fi tadakhul alashkal al-mutashabiha aw al-mutawafiqa (On Interlocking Similar or Congruent Figures). These books, and al-Jazari's as well-have been linked to the development and use of geometric decorative pattern (Necipoglu 1995, Tabbaa 2001, Özdural 1995). These authors posit the existence of these books as evidence of a textual tradition of transferring "how-to" pattern-making knowledge as well as the critical involvement of geometers in the evolution of complex patterns. However, as with all other aspects of decorative geometric pattern, the legitimacy of this linkage has been contested.

Jonathan Bloom, one of the most respected historians of Islamic art, disagrees with the idea that these books bore any influence on the development or dissemination of these patterns (1993). He states "a tenth-century builder learned his repertory by following the example of his master, not by borrowing a copy of Buzjani's book from 
the library and reading the instructions" $(1993,21)$. Bloom also believes that these types of books, instead of representing a genre of written works for artisans, fall into a kind of 'lifestyle' genre, providing detailed information on a variety of subjects, to be consumed by an aristocratic elite. Further, he notes that the visual perceptions of medieval builders and artisans were different than the three-dimensional ones we have now-without plans, sections, and elevation views as the norm, envisioning space was a totally different venture. He suggests that the oral tradition is the "real" conduit for transference of the use of pattern and building type from one place to another, and that advanced (textual) architectural notation developed late in Islamic architecture, in the fourteenth century, in conjunction with later forms of (i.e. Timurid and Ottoman) architecture (1993). If these texts were from the tradition Bloom suggests, then their relationship to complex decorative geometric pattern is minimal. Also, there is the possibility that these books were written after the development of complex decorative geometric patterns to codify processes that had already been established in the oral tradition.

The argument that these books 'traveled' (as books are wont to do) is legitimate in saying that a region far away from where a book was written or originally published could have benefited from the knowledge contained in the book. But the same court that patronized the writing of a book by mathematicians specifically for artists to use would likely have wanted to see the results of that transfer of knowledge come to fruition, by patronizing structures incorporating that knowledge. 
If we look to the maps to support either hypothesis about the role of these texts, we do not find consistent evidence to support one or the other. Sometimes a text appears in an area in the century before high pattern complexity (al-Buzjani in the tenth century), sometimes appearing during (al-Jazari in the thirteenth century), and sometimes appearing after (the anonymous Interlocking Figures in the eleventh century). The examples are too disparate to conclude anything about the relationship to where the geometric mode flourished. There is simply not enough information on these texts to know for certain; their relationship to the spatial distribution of regions of high-density pattern complexity is spatially inconsistent.

\section{The Mamluks Take Over Syria}

The Mamluks (1254-1517) were originally slaves, ethnic Turks conscripted into the Ayyubid army. From the ranks of the exceptionally trained Mamluks, the Bahri Mamluks were even more skilled and made up the Ayyubid Sultan's personal elite corps. It was from these ranks that the leaders of the Mamluk dynasty emerged. The Bahris revolted against the Ayyubids and beat back the Mongols from Syria in 1260 at the battle of 'Ayn Jalut. The first stable Sultan of the Bahri Mamluks was Baybars (r. 1260-1277) and under his rule the Bahris crushed the Ayyubids, Mongols, and Crusaders as well, extending Mamluk rule throughout Egypt and Syria.

In addition to establishing themselves in the twin capitals of Cairo and Damascus, the Mamluks began an aggressive program of building, the first monuments of which are represented at Cairo in figure 8.2. Part of the reason for the Mamluks' investment in architecture is that by the end of the thirteenth century, the 
population of Cairo reached approximately half a million, greater than any city outside of China. The mainly Arab population was ruled by Turks - this relationship required some diplomatic handling. The Mamluks endowed great complexes made up of schools, hospitals, and mosques to help strengthen their favor among the people. As with Anatolia, refugees escaping the Mongols fled to Cairo; among them were craftsmen who incorporated building techniques from the eastern parts of the Islamic world (Bloom and Blair 1997).

In the density overlay map for the thirteenth century, there is an area of overlap in Syria (Damascus and Aleppo) that shows a region of high math/astronomy activity in the following (fourteenth) century (figure 8.7). The monuments contributing to the thirteenth century high pattern complexity were built under Ayyubid patronage before 1260, the time of the Mamluk takeover. In the following (fourteenth) century, the orange line surrounds Mamluk-patronized astronomy/math activity. The map is further complicated by the regions of math/astronomy and philosophy activity there in the century prior (twelfth), as patronized by the Ayyubids, shown by the two blue lines. What does this confluence of activity mean?

Regions of high pattern complexity density, high math/astronomy density, and high philosophy density have been occurring in these cities for at least 100 years. The contact between art and science here is blurred because there has been a great deal of activity already; the relationships which were once unique have now been repeated too many times in the same place to untangle their relationships or patterns of correspondence. The region of overlap discussed here is emblematic of what is 


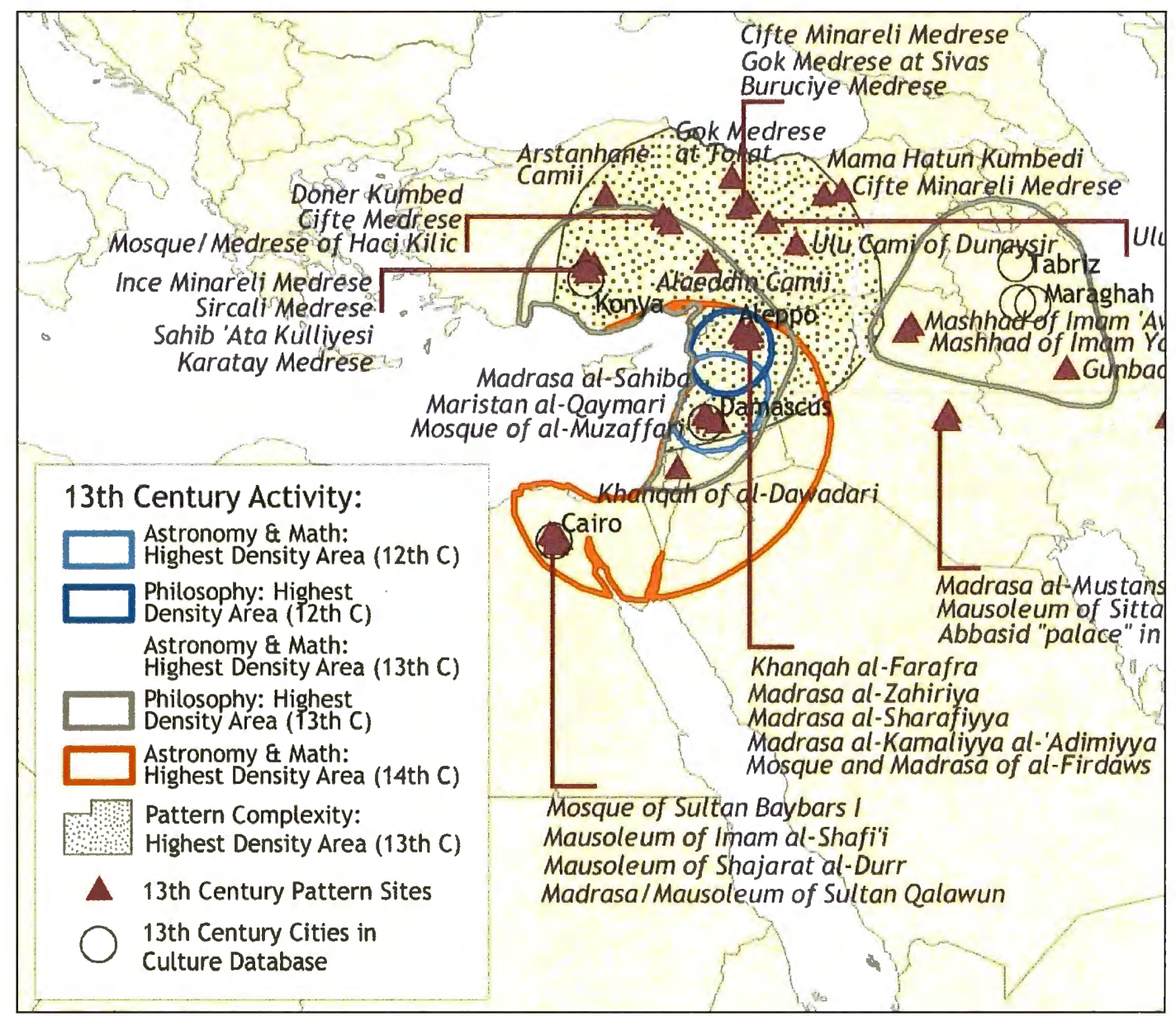

Figure 8.7 Detail of thirteenth century high-densisty pattern complexity region. 
inevitable; as the geometric mode became more and more widespread and layered in a place over time, the relatively clear and transparent quality of contacts in earlier times between art and science decreases. There is no way to identify possible episodes of a two-way interaction between the geometric mode and other cultural phenomena, because the spatial coincidences are no longer unique.

\section{The Pruning of Trees: Mongol Takeover}

The Mongol invasion must be singled out because of its massive effect on the eastern Islamic empire - not doing so would be like overlooking the Civil War in a cultural study of the United States in the nineteenth century. The results of the Mongol conquests included near-catastrophic destruction of local populations, economies, and infrastructure such as irrigation - as well as the decimation of architecture and intellectual and creative continuity. But as much as the Mongols caused chaos and discontinuity, they also formed a link between the Far East and Near East. They did not impart "Mongol" culture to either China or Persia, but rather provided a means for the two to share their cultures (Allsen, 2001).

Hulegu Khan, grandson of Genghis Khan, was in charge of campaigning against the 'Abbasid Caliphate. Hulegu started west in 1253, destroyed the Assassins' (an extremist Ismaili Shi' a sect) stronghold in the Elburz mountains of Syria, conquered Baghdad and slaughtered the Caliph al-Mustasim by rolling him up in a carpet and beating him, thereby ending the 'Abbasid Caliphate's rule of five hundred years. Hulegu's army was defeated at 'Ayn Jalut in Syria in 1260 by the Mamluks of 
Egypt, which spared the western half of the Islamic empire. The relative stability of the west is obvious when shown next to the disarray of the east (figures 8.8-8.9). However, though the west was relatively stable, there were no major developments in Andalusia or North Africa in architecture, the sciences or philosophy in this, the thirteenth century. And although it took some time to get started, Robinson states, "the Mongol Khans and their successors patronized Islamic learning, the arts and sciences, as they had never been patronized before" $(1982,26)$.

\section{$\underline{\text { Patronage: Science }}$}

The Mongols established firm links between their new territories in the eastern Islamic lands, ruled by a dynasty called the Il-khans, and their capitals in China. These courts "supported one another diplomatically, ideologically, and militarily; they exchanged intelligence, commodities, tribute, personnel, and envoys... they also appropriated, apportioned, and exchanged the varied cultural resources of their subject peoples." (Allsen 2001, 56). They also knew to exploit what they conquered rather than re-invent it. The Mongols were a nomadic people, conquering a generally sedentary population. This arrangement presented the Mongols with a problem: social complexity and specialization of talent is greater in sedentary peoples, and the Mongols found their own expertise to be lacking in non-military applications. To remedy this, they did not seek to become specialists themselves, but rather acquired specialists from the sedentary populations they came to control. After first co-opting military and administrative specialists, they sought to bring out "scholars, physicians, and artisans before cities were plundered" (Allsen 2001, 199). Over time, the various 


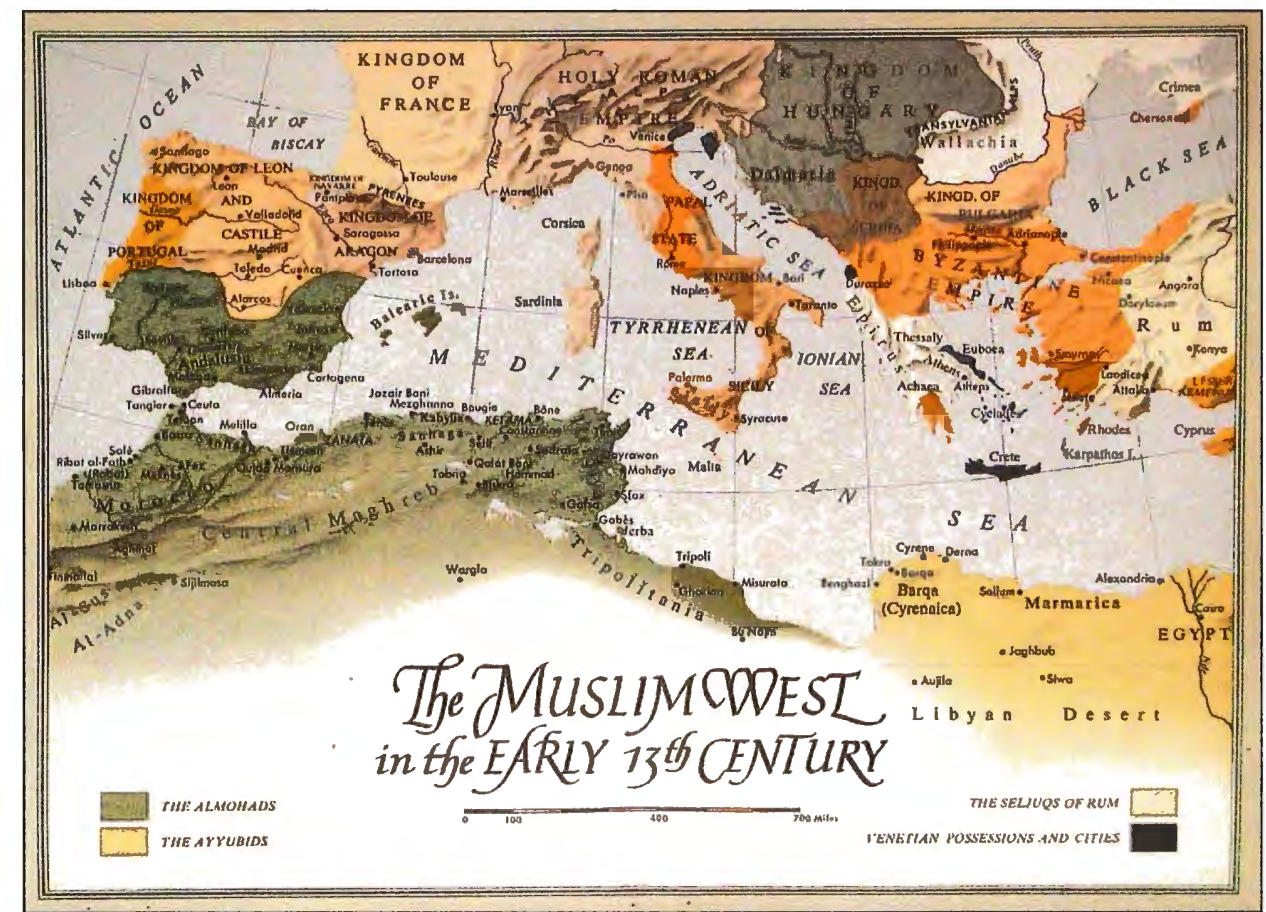

Figure 8.8 The western Islamic lands in the first part of the thirteenth centuryrelatively stable, no major movement (Roolvink 1957, 22).

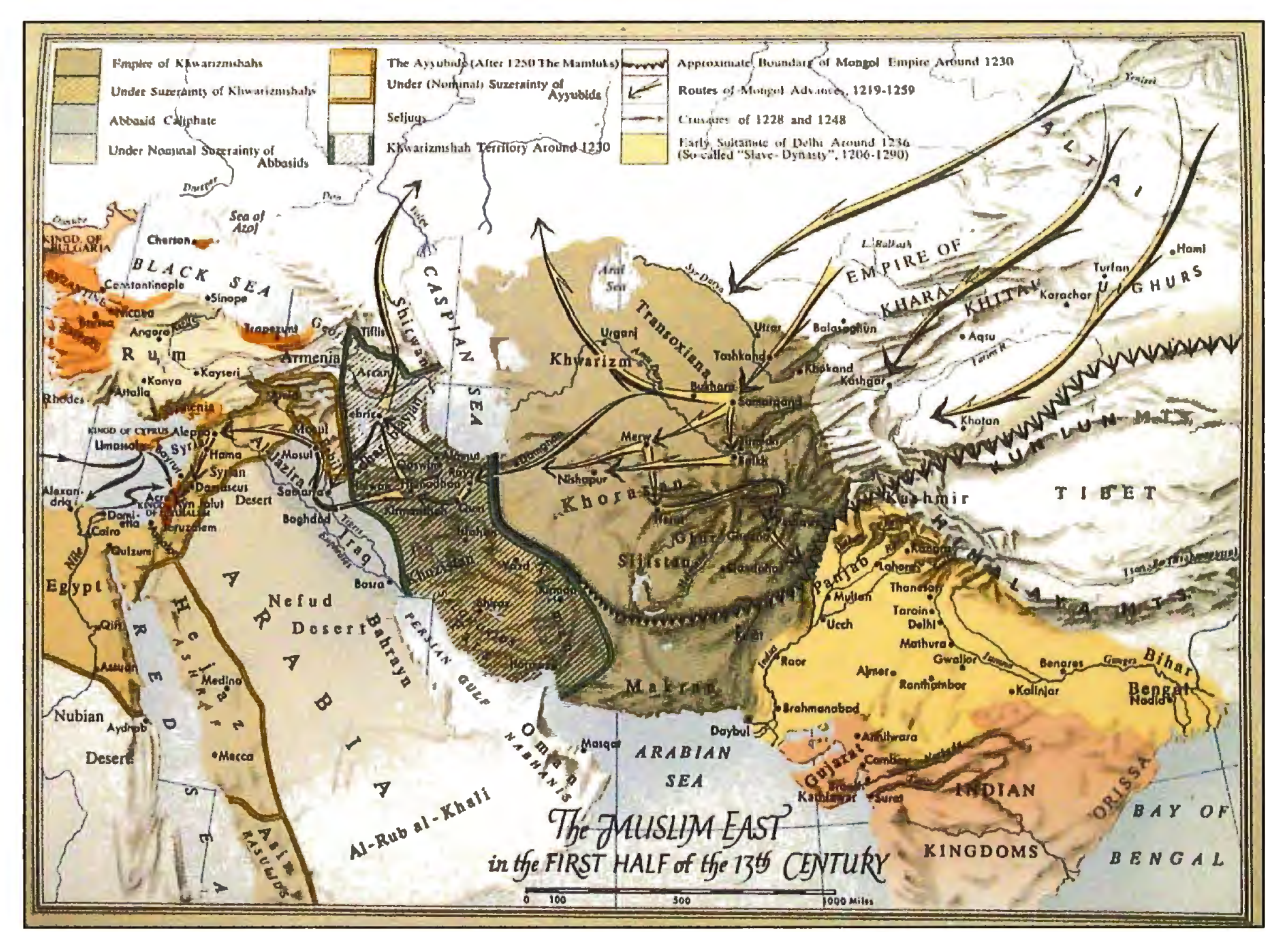

Figure 8.9 The eastern Islamic lands at the middle of the thirteenth century-chaotic, rulers and boundaries volatile, unstable (Roolvink 1957, 22). 
courts used these specialists as a kind of currency, flaunting their assimilated experts to each other.

Thus Il-khanid patronage partly developed out of expediency. Another factor in Il-khanid patronage was founded on Mongol spiritual beliefs. They placed great importance on prognostication, which is based on astronomy —as "managers of time, [astronomers were] specialists who determined the proper moment to begin and end all kinds of activity-economic, military, ritual, and spiritual. And implicit in all this [was] the perceived ability of astronomers to foretell the future. To the Mongols, this was perhaps their most important attribute" (Allsen 2001, 175). Because Islamic belief requires prayer to be oriented toward Mecca at specific times of day, the complimentary studies of geography and astronomy were quite advanced by the time the Il-khans required the services of court astronomers in the thirteenth century. Since astronomy received special attention, the Il-khans invested in building a major observatory at Maragheh, built after 1260 under the auspices of Hulegu. Nasir al-Din al-Tusi, who had been 'rescued' from the Isma 'ilis by the Mongols, headed the observatory. Additionally, Chinese astronomers had been brought to the observatory to share knowledge with the Persians. This collaboration resulted in the famous Zij-I Il-khani (Astronomical Tables of the Il-Khans). On the map, (p. 181) the light and dark grey lines around northwestern Iran represent Il-khanid patronage of the sciences in the late thirteenth century. 


\section{Patronage: Art}

As Glassé argues, the Mongols could not have conquered such vast territories as quickly as they had were it not for the decadence of the ruling powers they overran; he likens the Mongols' conquest to a purge, or the pruning of trees-a necessary episode that produced a much-needed renewal $(2002,186)$. Art historian Sheila Blair attests to this decadence, saying that "despite political unrest and dynastic infighting, on the eve of the Mongol invasions the rulers of eastern Iran, both sultans and local princes, had enormous resources at their command to invest in major building programs and luxury objects with sophisticated decoration" $(1985,88)$. The structures from these eastern Iranian cities that have survived (Gunbad-i Alawiyan, Imamzada Jafar, Madrasa of Zuzan, Masjid-i Jami of Herat) all exhibit star-and-polygon patterns. This implies that the region of high pattern complexity, had the Mongols not destroyed (or otherwise hindered the construction of) so many other monuments from this period, might extend in a band from central Anatolia all the way to eastern Iran. The Il-khans began rebuilding right away but imported more Far Eastern ideas and techniques into Islamic territory. The types of decorative programs they employed increasingly incorporated Chinese-inspired styles as the thirteenth century gave way to the fourteenth (figure 8.10). Necipolgu continues:

the Mongol invasions brought about a cultural split between the Turco-Iranian realms in the east (extending from Anatolia to the borders of China) and the Arab-speaking ones in the west (extending from the Mamluk territories to North Africa and Spain), a split reflected in the different decorative vocabularies that prevailed in each region. $(1995,111)$ 


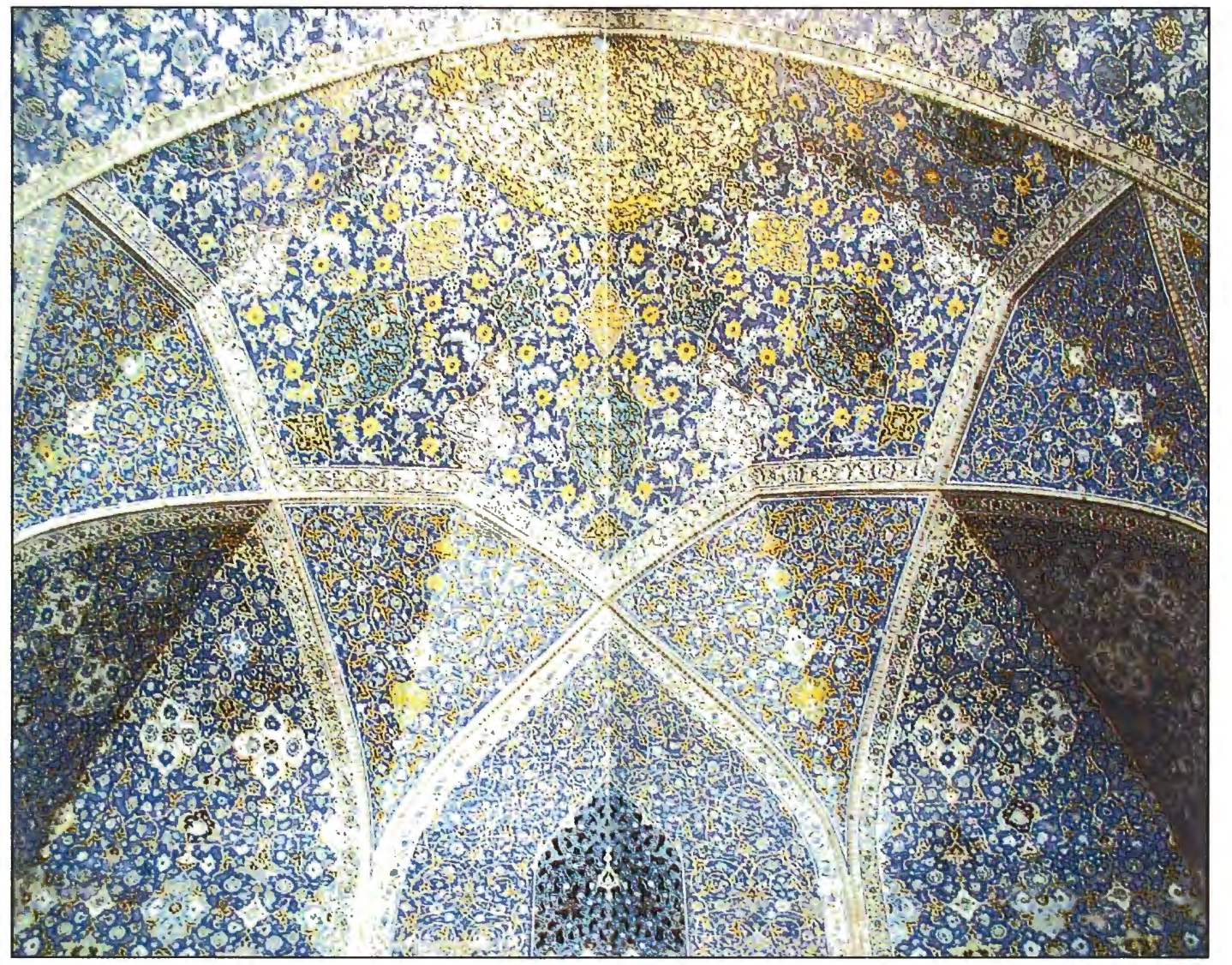

Figure 8.10 Floral arabesques and medallions incorporating the influences from China brought by the Mongols, in tile decoration at the Shah Mosque of Isfahan, 1611 and later (Clevenot 2000, 40). 
Thus these new programs looked different than the western lands' architectural decorative programs. The difference in decoration between the eastern and western Islamic world arrives at a time of increasing ubiquity of star-and-polygon and muqarnas and a decrease in overall science/philosophy activity. Figure 8.11 graphs this relationship. Both regions (east and west) used the geometric mode, leaving muqarnas and star-and-polygon patterns nearly everywhere, but variations, especially chinoiserie-type floriation, would crowd out, instead of exist alongside the geometric mode in the coming century.

Ultimately, what we see, vis-à-vis the density overlay map (figure 8.2) for the thirteenth century, is that the relationships between art, science, and philosophy have started to repeat in the same places, obscuring where and when more distinctive contacts occur. Likewise, the temporal scale obscures possible relationships-for example, Rumi's episode is rendered invisible on the map because of the time step. Thus the utility of these maps for analysis begins to fade. 


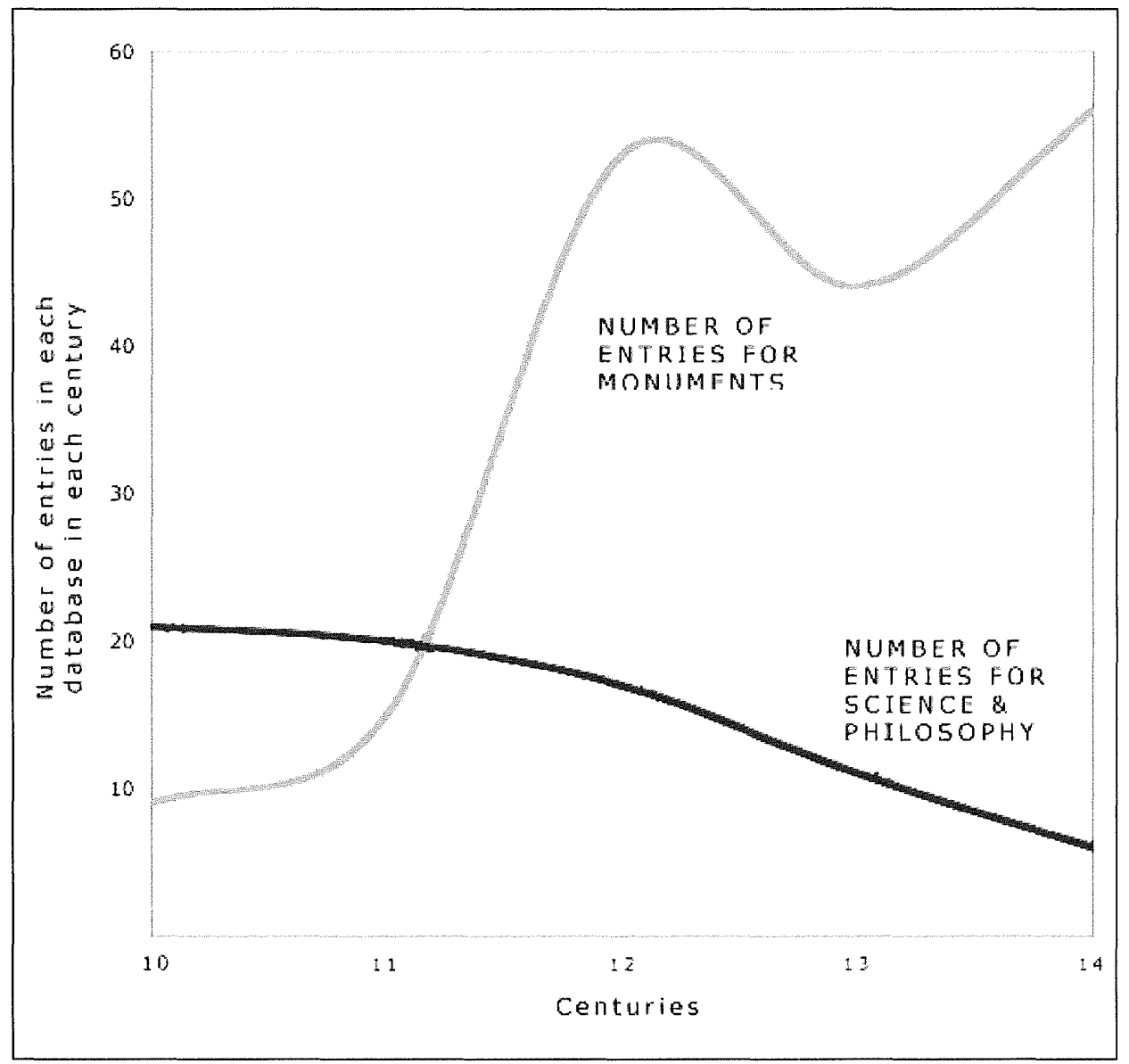

Figure 8.11 As time goes on, the activities in science and philosophy decrease while use of geometric pattern in architecture increases. 


\section{DISCUSSION: FOURTEENTH CENTURY}

The fourteenth century, our last analysis period, was one of decline and reconsolidation. Whereas in the eleventh century there was a great dispersal of power, in this century the opposite process began. Larger ruling groups slowly subsumed the power of the many smaller entities in this period, giving rise to the Timurids (13701500) in Transoxiana, the Ottomans (1342-1924) in Anatolia, and continuing to strengthen the Mamluks (1254-1517) in Egypt and Syria. The consolidation of power in far fewer hands naturally meant less mixing and cross-pollination. In this section I discuss the demise of the Il-khanid dynasty and the emerging Timurid dynasty, under whose patronage the final 'renaissance' of Islamic culture occurred, the decline of science in the Islamic world in general, and the shifts in decorative styles away from the geometric idiom. The timeline shows this decrease in the number of ruling groups (figure 9.1)

\section{$\underline{\text { Il-khans and Timurids }}$}

The Il-khanid dynasty (1256-1353) had their capitals at Tabriz and then Sultaniyya in northwestern Iran. Bloom and Blair state that this was the most important region in the Islamic world in the late thirteenth and early fourteenth century (1997). Indeed, the density overlay map for the fourteenth century illustrates the Ilkhanid patronage of math, science and philosophy, which began in the thirteenth century (blue lines) overlaying the region of high pattern complexity (figure 9.2). 


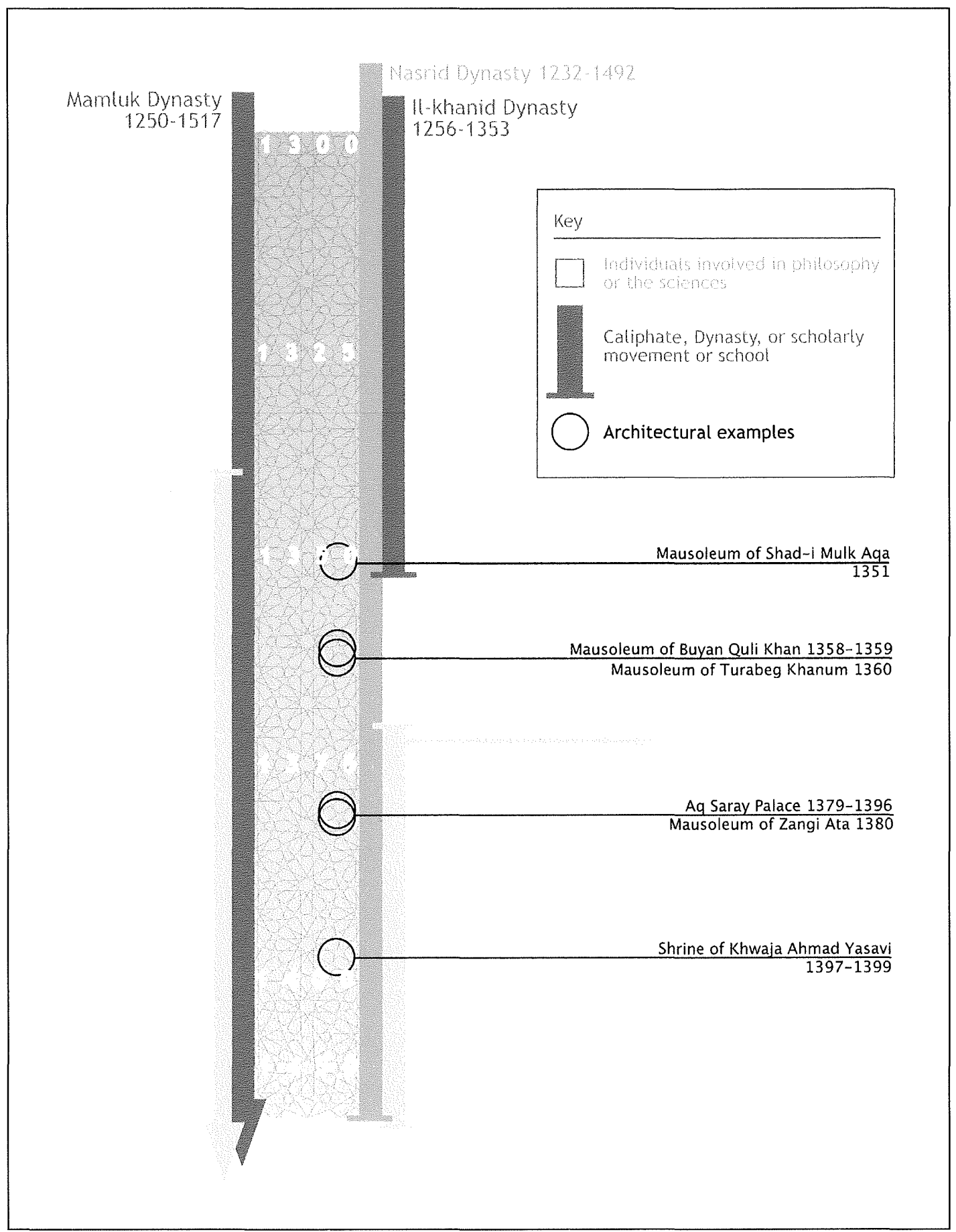

Figure 9.1 Timeline for the fourteenth century 


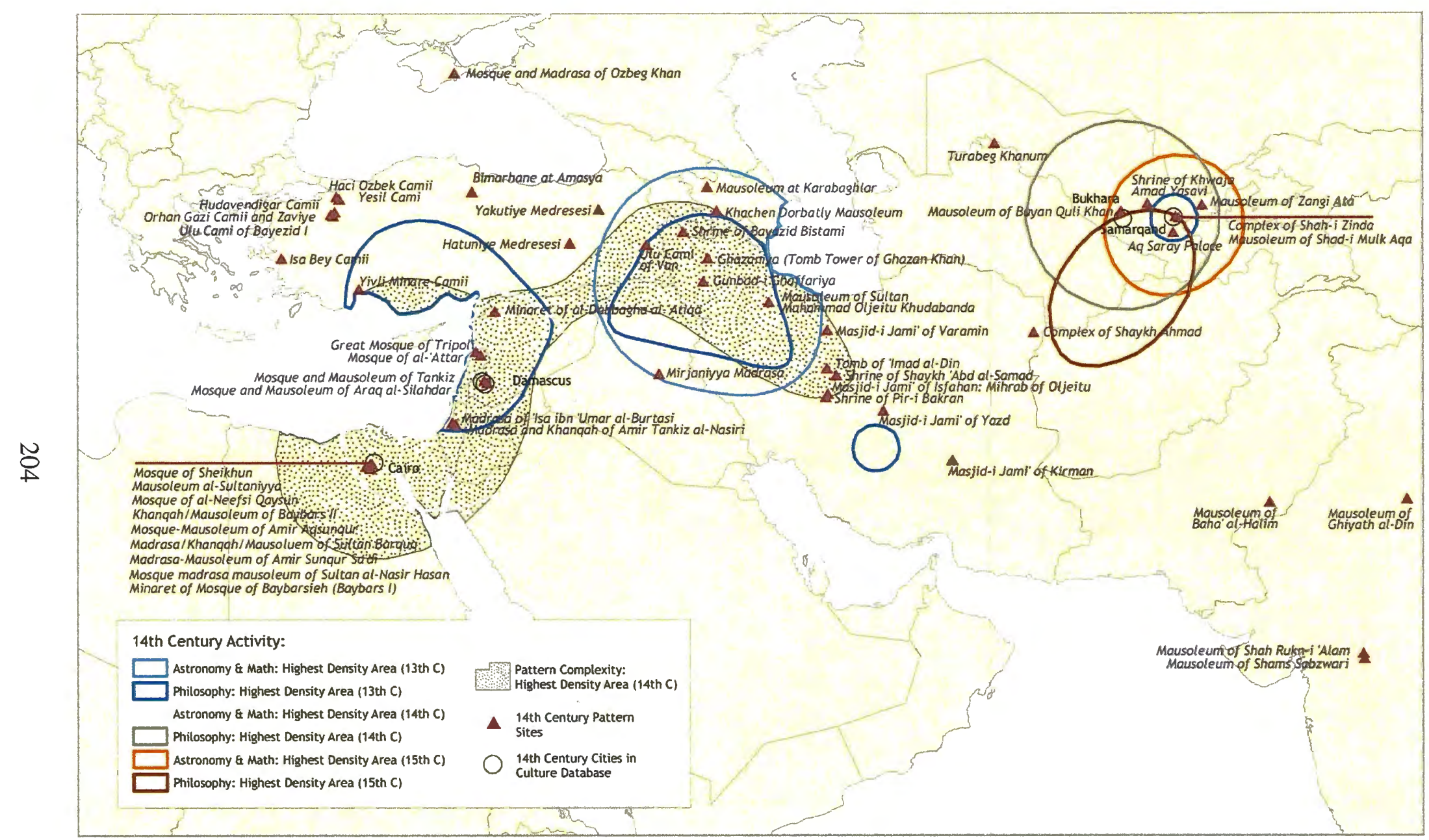

Figure 9.2 Fourteenth century density overlay map. 
The map appears to support the idea of math-before-art in Iran and Syria, but there have already been structures decorated with these patterns there coexisting with science and philosophy activity for two hundred years. Therefore the contact between disciplines at this time is less likely the spark for use of decorative geometric pattern. More likely is that by this time, the decoration was de rigeur and the activity in those regions simply a continuation of artistic activity happening there already, not the result of contact between disciplines.

Timur (known in the west as Tamerlane, r. 1370-1405) was the first leader of the Timurids (1370-1500), the second Mongol dynasty to rule in the Islamic world. His rule was characterized by "destruction and wanton cruelty...[and] the world was despoiled for the greater glory of Transoxiana and in particular of Samarqand, Timur's capital" (Morgan 1986, 201). Timur, in addition to being militarily opportunistic, also saw the political value of architecture: he used "the prodigious booty he amassed to build a massive tomb over the grave of Ahmad Yasavi, [a Sufi leader of the twelfth century] who had been responsible for converting the Turks of Central Asia to Islam" (Bloom and Blair 1997, 166). Building the tomb in 1397-99 earned him political currency with the growing Sufi population. This explicitly Sufi structure could indeed be an example of the essentialists' link between Sufi theology (the concept of tawhid, or divine unity) and the geometric mode. Since it was built to respect the beliefs of a specific section of the population, it may be that Sufi theologians were consulted during its construction. It is interesting to note that the dome interiors are decorated with such tremendous examples of muqarnas (figure 9.3). In much 


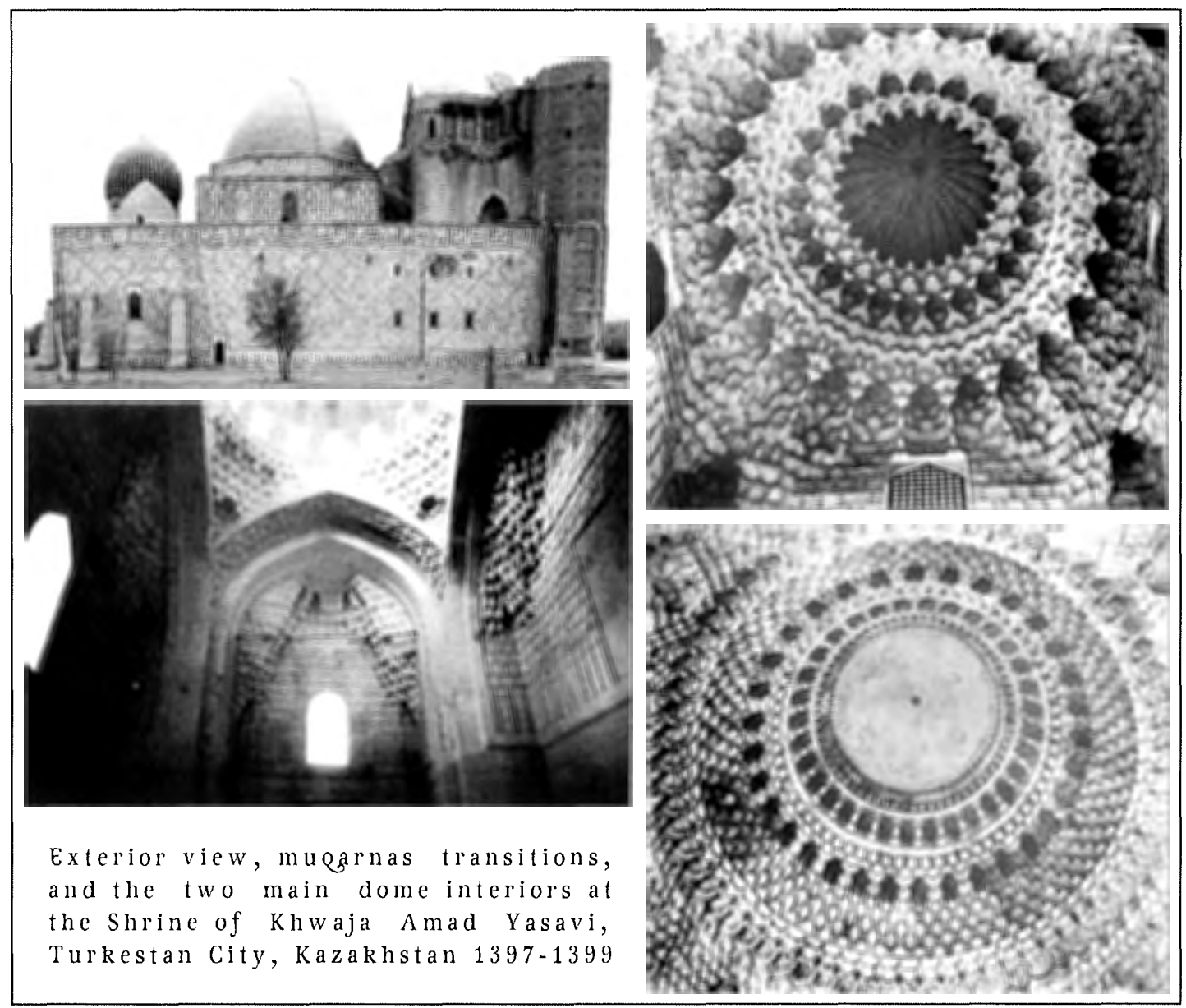

Figure 9.3 Exceptional muqarnas decoration at the Shrine of Ahmad Yasavi. 
of the rest of Timurid architecture of this time, star-and-polygon patterns, not muqarnas, cover dome interiors (figure 9.4). The exteriors, however, are quite similar to that of the Shrine of Ahmad Yasavi. However, without further contextual evidence to support this theory, it is impossible to know for certain if Sufi theologians expressed a preference for muqarnas (or other elements of the geometric mode) to represent them. While the construction of the monument at least tied politics to religion, the decoration generally followed the trajectory (well-established by this point) of using muqarnas and/or star-and-polygon patterns to decorate architectural monuments.

The map (figure 9.2, above) shows a clustering of density areas around Samarqand and Bukhara in this, the fourteenth century. The orange and red lines in the lands furthest east represent Timurid patronage of the sciences in the fifteenth century. His successors' patronage included the observatory of Ulugh Beg and the mathematical achievements of al-Kashi at Samarqand, bringing about a "Timurid renaissance in the fifteenth century" (Glassé 2002, 457). This renaissance included a great many monuments being built in Iran, Afghanistan, and Transoxiana. But this activity does not correspond to or result in a region of high pattern complexity, further damaging the idea that courts interested in mathematics would have a greater tendency to use the geometric idiom in decoration. 


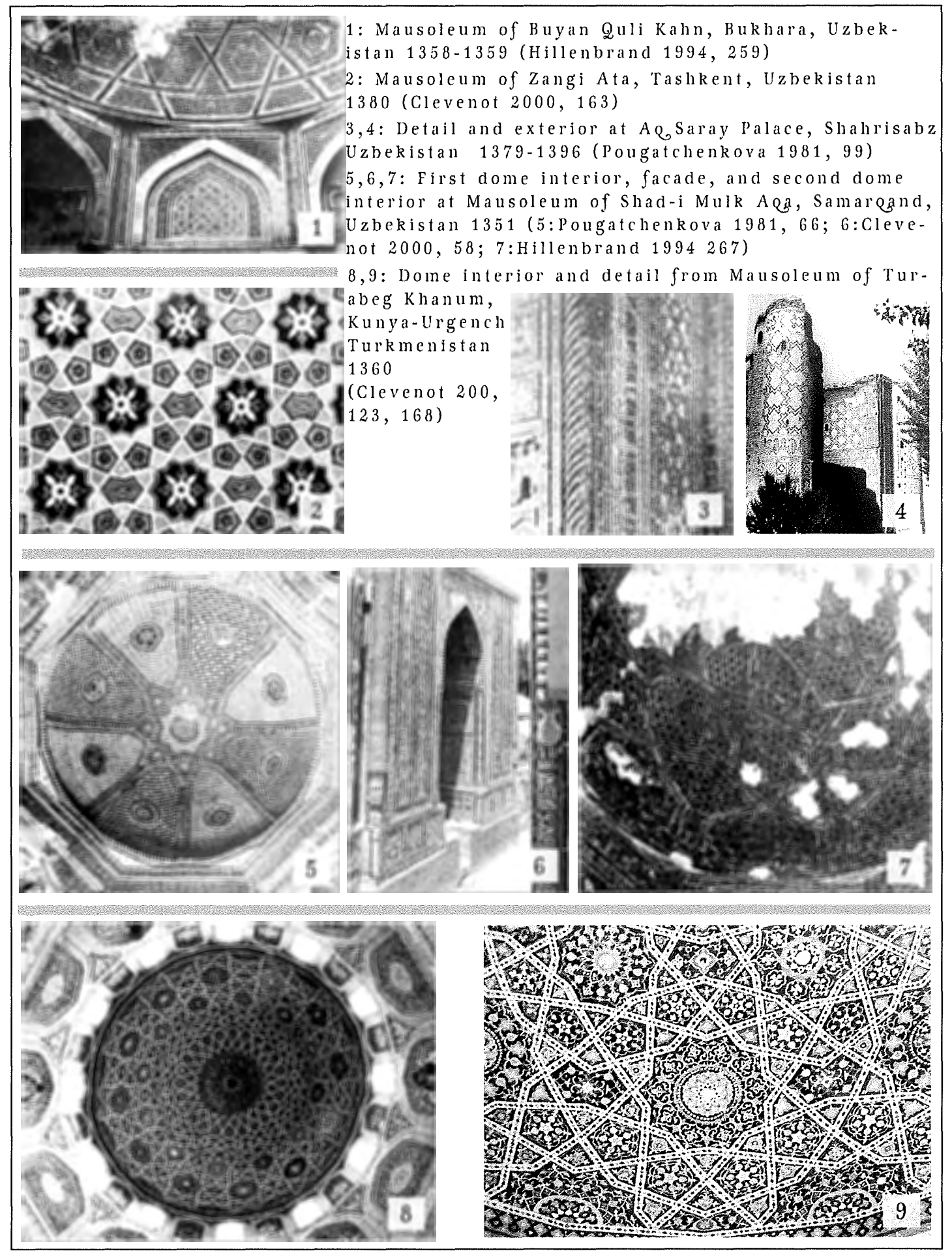

Figure 9.4 Other monuments from the Timurid period in this region exhibit a variety of star-and-polygon patterns in dome interiors, in contrast to the Shrine of Ahmad Yasavi; exteriors are similar to that used at the Shrine. 


\section{Decline of the Sciences}

The decline of Islamic science and philosophy may have begun with the Mongol invasion of Baghdad in 1258 (Qadir 1988, 123). The razing of libraries, schools, and the center of the Caliphate, although just symbolically holding power by that time, struck a deep blow to the continuity of Islamic scholarship that had existed for five hundred years. Daiber, an historian of Islamic science, places the beginning of decline in an even earlier period, noting that the stagnation of sciences in classical Islam started around 1100, when " traditionalism and isolation increasingly impeded unprejudiced research; religious dogma more and more determined and limited the aims of scientific research. Research in nature for nature's sake was not fully developed and on the contrary was replaced more and more by religious teleology" $(1994,129)$. Pines, another historian of Islamic science, places the beginning of the end in this general era, but within a more specific scholarly framework: "by A.D. 1300 or even earlier, and throughout the following centuries, these debates [on the mathematization of Aristotelian physics], expounded again and again in philosophical treatises, had lost their urgency and had been transformed into a mere topic of scholarly tradition... it is this development and the consequent loss of the impulse towards, and the capacity for a radical refutation of Aristotelian physics which constitute the decline of Arabic science" (Pines 1986, 353).

The many causes of the decline of Islamic science are beyond the scope of this paper, but the climate in which the decline occurred is important to note. The problem with the above statements is that they do not point out that while decline occurred in 
most of the Islamic world, the eastern cities of Maragheh and Samarqand witnessed great advances in astronomy under the patronage of the Il-khans and the Timurids. Sabra echoes this in saying that:

[t]he question of periodization has to be approached with due attention to discontinuities, geographical differences, and ups and downs. Spain, for example, is said to have always lagged behind the Muslim East; and the scholars working under the Mongols in Maragheh and Tabriz seem to have more in common with their predecessors of two centuries earlier than with those who came soon after them in Mamluk Syria and Egypt." (Sabra1987, 237).

This last statement is useful in evaluating the contacts between art and science via the density overlay maps. Each time and place is a unique opportunity for advancement, innovation, and contact among the geometric idiom, science, and philosophy. One region, such as Syria in the thirteenth century discussion, exhausts the possibilities, while another, Anatolia, opens up. For this reason, these maps have provided insight into the shifting nature of where these contacts occur.

Sabra values a comparison (as I have provided in figure 8.11 of the preceding section) of the levels of scientific production between the fourteenth and tenth centuries to determine when decline is occurring (1987). My chart shows a steady decline, but an exact date is not clear. Sabra continues: "difficulties arise when one tries to assign a date to the occurrence, in part because decline is a process that occupies a time-interval...but also because we are dealing with a vast geographical area in which not all centers of scientific activity were always in the same phase of development at the same time" (1987, 238-239). The maps over the course of the discussion period $\left(9^{\text {th }}-14^{\text {th }}\right.$ centuries $)$ depict these different centers emerging and 
disappearing over time, as shown by the different high-density regions. But as this blurry period of decline grows more distinct, the decrease in activity is simply too great to identify further areas of meaningful contact between science, philosophy, and the decorative geometric mode.

\section{$\underline{\text { Changes in Art }}$}

As the vitality of science and philosophy decreased, the use of complex decorative geometric pattern peaked, manifesting in its most mature examples. Necipoglu credits the Nasrids in Spain, the Mamluks in Egypt, and the Timurids in the east of this time period as representing the high point, the manifestation of the "last creative impulse" of the geometric mode $(1995,116)$. In the places where pattern was employed, such as Granada, Cairo, Damascus, or Samarqand, it was being used over and over in the same place, over long periods of time. Instead of acting as a vehicle for something special—some unique message associated with a ruling entity like the Sunni Revival; a concept like the Sufis' tawhid (unity), or a more specific contact, such as that of Khayyam, Rumi, al-Arabi, or al-Tusi-it seems to have become in this period simply a style, and the uniqueness, the singularity of the geometric mode has disappeared and is reduced to a mere form. My pattern database reflects this reduction to form-as the total number of monuments increases, the percentage of monuments exhibiting complex patterns and muqarnàs also increases-what was once innovation becomes commonplace. Widespread use results in a muddying of contacts and the inability to identify possible relationships. 
This period witnessed the reconsolidation of power into fewer ruling groups. As the power structures changed and refined, so did the styles employed in architecture. In this later phase, "the Ottomans, Safavids, and Mughals...would eventually develop their own abstract idioms of architectural revetment representing differentiated dynastic tastes confined to relatively autonomous cultural zones. These distinctive decorative idioms no longer assigned geometry the privileged role it had enjoyed" (Necipoglu 1995, 116). With these changes in architectural style following on the heels of the decline in the sciences and philosophy, the era in which the spatial distributions of the geometric mode, science, and philosophy manifested themselves in meaningful relationships was over. 


\section{CONCLUSIONS}

Complex decorative geometric patterns in architecture provide a multifaceted matrix from which to examine many aspects of the culture of the medieval Islamic world. Spatial analysis of the geometric mode and its relationships to other cultural activities renders previously unobserved types of associations visible. These unique relationships appear only after a very detailed examination of the cultural contexts for each century and each high-density region of pattern complexity. The set of density overlay maps, spanning the ninth through the fourteenth centuries, also shows that many of the existing hypotheses concerning the relationships between art, science and philosophy are not applicable to all regions of the Islamic world during this time period. Here I summarize the findings from the density overlay maps and present avenues for further research regarding specific relationships made apparent by the maps.

\section{The Existing Question: Does Science or Philosophy Influence Art?}

So was it necessary for a court or ruling group to have been active in mathematics or astronomy prior to employing the geometric mode? Every density overlay map after the tenth century showed activity in these disciplines overlapping some portion of the regions of high-density pattern complexity. Thus the maps generally showed that math and science did occur before the appearance of complex patterns in architecture in some but not all instances.

But there are many significant examples where math and science do not precede the use of the geometric mode. The density overlay maps showed that some 
courts, such as Transoxiana in the tenth century, used complex decorative geometric patterns in their architecture prior to patronizing mathematics or astronomy. Another example is that of the group of scholars in Cordoba in the twelfth century - their advances in mathematics, astronomy, and philosophy did not coincide with any monuments exhibiting complex geometric pattern in the cities of Cordoba or Granada, either in the previous century (eleventh), same century (twelfth) or the following century (thirteenth). Similarly, the court in Khwarazm (Uzbekistan) in the eleventh century patronized mathematics and astronomy heavily, yet did not exhibit use of the geometric mode in architecture. In sum, in not all places where scientific activity occurred was the geometric mode employed in architecture after the scientific activity.

The argument for certain philosophies needing to be expounded prior to the use of geometric pattern did not hold up well to a spatial analysis either. The essentialist's notion that the geometric mode embodies Sufi-inspired or other esoteric Islamic concepts in all instances and places, has been forcefully criticized already (Necipoglu 1995, Tabbaa 2001). Spatial analysis only reinforces these criticisms. For instance, in the twelfth century, when Sufi orders were increasingly brought into the mainstream of religious thought, the geometric mode had already been in use for nearly two hundred years. Also, Sunni courts that promoted orthodox theology (in opposition to esoteric theology) such as those of the Zangids and Ayyubids, used the geometric mode extensively. Only in specific instances, such as at the Tomb of Ahmad Yasavi in the fourteenth century, is there a closer relationship to Sufi ideology manifesting directly in the geometric mode. 
The more comprehensive hypotheses about complex decorative geometric patterns in architecture also did not hold up under a detailed spatial analysis. The most recently developed hypothesis, first offered by Necipoglu (1995) then developed further by Tabbaa (2001) was that the geometric mode was used by the Sunni revivalist dynasties in Syria to embody and assert their theological doctrine. If indeed it was used as a symbol for their specific type of Sunni theology, ('Ash'arism), to 'win over' people in the battle with Shi'ism, people should have been able to read the code as such. Certainly other artisans and architects, paid to construct and decorate by patrons within these ruling structures, would have been well versed in regional styles. But the artisans and architects of the Shi'a ruling groups, such as the Buyids and Fatimids, did not read the code as a doctrinal exposition of 'Ash'arism-instead, they used the geometric mode to decorate their structures as well. My data and maps demonstrate that Shi' a dynasties of that period, in that region, used these decorative forms even more than the Sunni ruling groups. It is only through systematic evaluation of data gathered at a variety of scales that my databases and maps disprove the existing hypotheses regarding the use of the geometric mode.

\section{A New Question: Does Art Influence Science or Philosophy?}

The density overlay maps show that it was not necessary for a region of high pattern complexity to be preceded by a region of math/astronomy activity. Indeed, the maps present an alternate and previously obscured view. Only after assessing multiple centuries of different activities in a single density overlay map is this previously unexplored type of contact between art and other cultural activities revealed. 
The before/after distinctions on the maps and in the discussion are tied to the regions of high-density pattern complexity and used as a way to locate moments of unique contact among the disciplines of art, science, and philosophy. In the specific places where some activity occurs after the use of the geometric mode, it is necessary to look deeper, to see which scholars worked in what disciplines, which specific monuments came into contact with what ideologies and people. The question, "what might art have affected", instead of "what affected art", does not have any simple answer, yet the following examples emerged from the intricacies of the spatial datasets.

The first example from the density overlay maps includes the activities in the cities of Merv and Nishapur in the tenth century. The detail of the tenth century density overlay map provides the first hints of the geometric mode's unexplored role in the development of other activities (figure 10.1). The orange line shows a region of high-density philosophy activity occurring in the eleventh century. The city generating this zone is Nishapur, whose philosophy activity in the eleventh century was dominated by al-Ghazali. Merv, the only city actually falling in the zone of overlap, does not show activity in the eleventh century. However, a relationship between al-Ghazali and the region of high pattern complexity may actually exist, as Nishapur is only 225 miles from Merv. Were there structures in Nishapur that employed the geometric mode but that are now gone? Because al-Ghazali's work was 


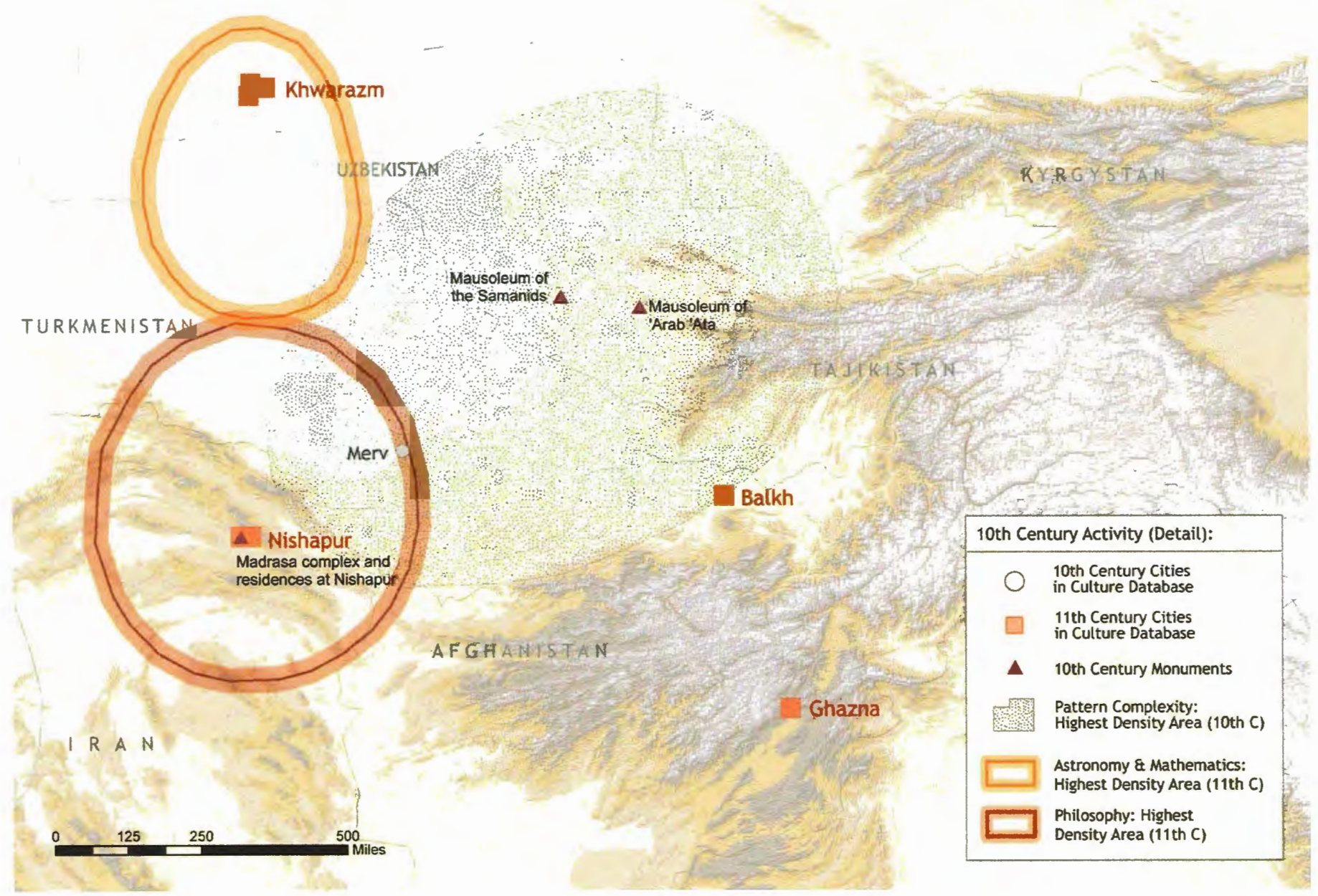

Figure 10.1 Detail of tenth century overlay map. 
so important to the development of a synthetic philosophy of exoteric Islam with Sufism, this possible connection to the region of high pattern complexity begs for further research even though the overlap in this case does not correspond exactly.

The second example is from the twelfth century, which provided a great complexity of information to sort out. The simplified detail of the density overlay map displays only the regions of thirteenth century activity that overlap twelfth century high-density pattern complexity (figure 10.2). Northwestern Iran emerges as one of these regions. The monuments at Maragheh survived the Mongols' attacks and were still standing when al-Tusi was brought there. No monuments were built in Maragheh in the thirteenth century, making the pre-existing one perhaps even more prominent or striking. Additionally, Shani's analysis indicates that those monuments were constructed with communication in mind (1996). Did al-Tusi look at the stars and polygons decorating the Round Tower of Maragheh, contemplating their intricacies, and conceive of a heliocentric universe? Examples of diagrams created by al-Tusi and his contemporary in Maragheh, Qutb al-Din al-Shirazi (figures 7.3 and 7.4) show their use of radial grids, similar to those used to create star-and-polygon patterns, providing additional support for further investigation.

The third example is also from the twelfth century - the other major region of overlap in figure 10.2 contains Damascus and Aleppo. Ibn al-Arabi, active in the thirteenth century, produced writings that are considered among the most important in Sufi literature. This work, produced in Damascus in the shadow of structures heavily decorated by the geometric mode, may be interpreted with these patterns in mind. The 

multi-layered meanings and diagrams in Al-Arabi's work advance this connection, pointing the way to another new avenue of research.

The final examples that surfaced from close examination of the spatial data do not show up on the maps - these are the episodes of 'Umar Khayyam in the eleventh century and Jalal al-din Rumi in the thirteenth. The publication of Khayyam's proofs, in the anonymous treatise on artisans' use of geometry, was in 1074-that is, after the construction of many buildings in the region and further east as well, in Uzbekistan and Kyrgystan, that employed star-and-polygon patterns and muqarnas. In this case, the one hundred year time-step may be preventing the episode from showing up on the map. The detail of the eleventh century density overlay map shows math/astronomy activity of the previous (tenth) and same (eleventh) century overlapping the high complexity region (figure 10.3). The series of events occurring in central Iran in the mid-to late eleventh century is complicated, but the spatial analysis shows reason to look at Khayyam's oeuvre to see if the built environment influenced him. The possibility that the examples of the geometric mode that Khayyam encountered could have spurred his own creativity deserves further investigation.

The thirteenth century provides one final example of the possibility of art affecting another type of activity. The Karatay Medrese in Konya, built in 1251 by a close friend of Rumi, exhibits extraordinarily evocative star-and-polygon patterns inside its dome. Since Rumi's masterwork, the Mathnawi, was begun in 1256, Schimmel asserts that Rumi was directly influenced by the decoration at the Karatay 


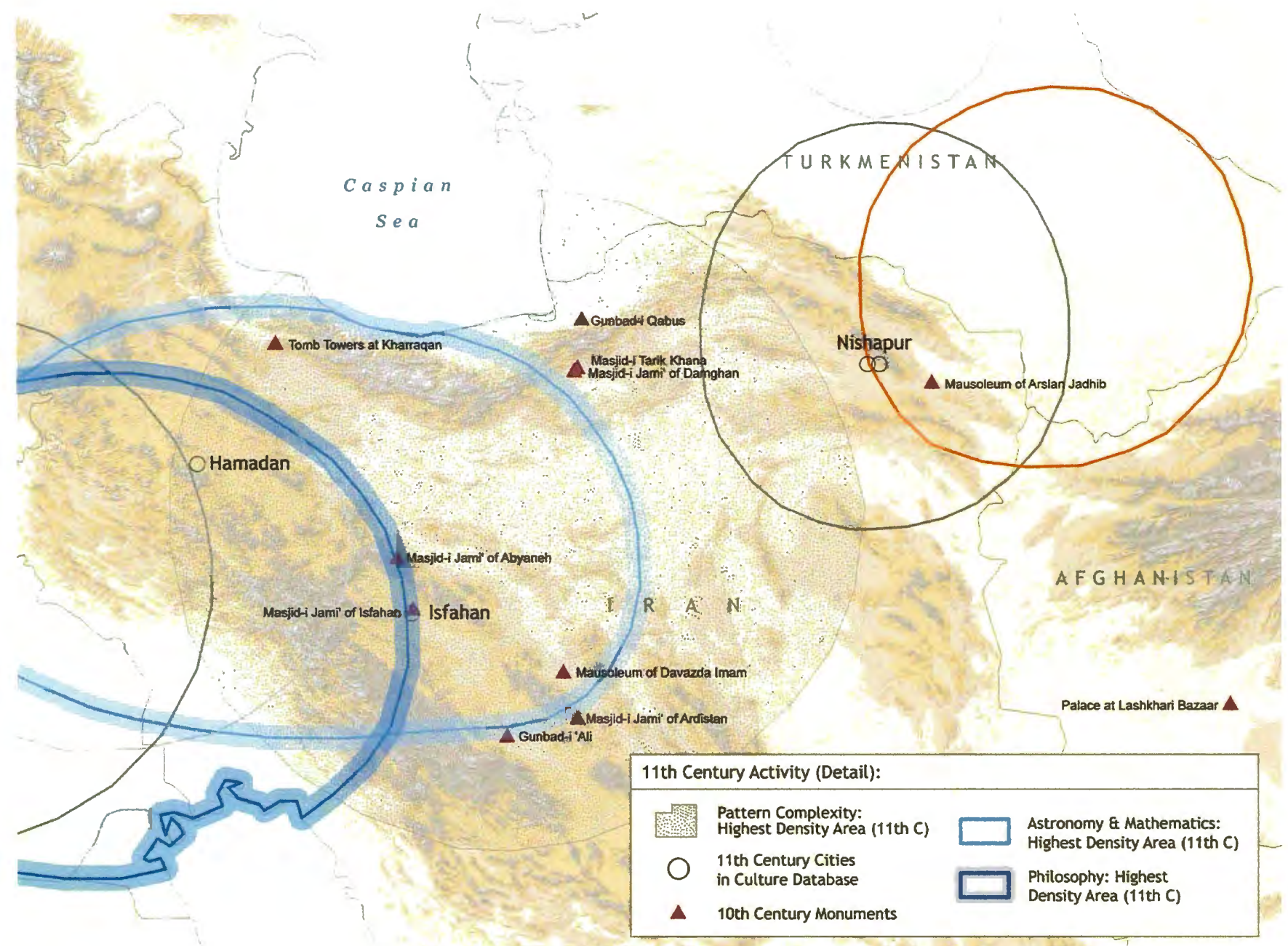

Figure 10.3 Detail of eleventh century density overlay map. 
Medrese, noting parallelisms between the structure, decoration, and the text of the Mathnawi $(1993,51)$. In this case, as with Khayyam, the episode is obscured by the 100-year time step-analyzing the maps without understanding the underlying history would leave these examples unknown.

From this summary of the relationships revealed by the maps, an interesting pattern emerges. Some of the most influential thinkers in the history of Islam-alGhazali, al-Tusi, al-Arabi, Khayyam, and Rumi-all were active in regions proximate to the geometric mode where it already occurred. The consistent spatial analysis used to find these examples leads me to believe that these are not accidents or anomalies, that the quality of contact in these very specific times and places is worth examining in greater detail.

The Other Half of the Equation

Reframing questions and reappraising existing information via spatial analysis can expose relationships where none thought them to exist before. The great expanse of space and time covered in the preceding pages contain a few examples of where and when the disciplines of art, science, and philosophy interacted in unexplored ways. The density overlay maps provided a basis for spatial analysis of the activities of interest, and yielded insight into how to examine the quality of contacts between these disciplines in a new way. Clearly, the current hypotheses of other scholars only go so far in explaining the dynamic between culture, politics, philosophy, and science and how these forces relate to art. This incompleteness in prior research can be remedied with further, more detailed spatial analysis, using the methods outlined here as a 
starting point. This line of questioning leads to other ways of interpreting the limited information that exists from the period, as well as the relationship between art and science more generally.

Indeed, looking only for what contributed to the use of decorative geometric pattern is only half of the equation. We have seen that in some cases, it may be that complex decorative geometric patterns could have contributed to developments in other disciplines, such as with al-Ghazali, Khayyam, al-Arabi, al-Tusi, or Rumi. There is no reason to assume that the exchanges between disciplines were one-way, that individuals or ruling groups were never affected by their surroundings, never inspired or touched by the art enveloping them as they moved through their cities. 


\section{REFERENCES}

Abas, Syed Jan and Amer Shaker Salman. 1995. Symmetries of Islamic Geometrical Patterns. Singapore: World Scientific Press.

The Aga Khan Trust for Culture. Digital Library: Historical Monuments. http://archnet.org Last accessed 12/04.

Ali, Widjan. 1999. The Arab Contribution to Islamic Art from the Seventh to the Fifteenth Centuries. Cairo: The American University in Cairo Press.

Allsen, Thomas. 2001. Culture and Conquest in Mongol Eurasia. Cambridge: Cambridge University Press.

al-Andalusi, Sa'id. 1991. Science in the Medieval World: "Book of the Categories of Nations" (Transl. Salem, Sema'an and Alok Kumar). Austin: University of Texas Press.

Ardalan, Nader and Bakhtiar, Laleh. 1973. The Sense of Unity: The Sufi Tradition in Persian Architecture. Chicago: University of Chicago Press.

Baer, Eva. 1998. Islamic Ornament. New York: New York University Press.

Bakhtiar, Laleh. 1976. Sufi: Expressions of the Mystic Quest. New York: Avon Books.

Barnes, Trevor and James Duncan, eds. 1992. Writing Worlds: Discourse, Text and Metaphor in the Representation of Landscape. London: Routledge.

Barnes, Trevor. 1996. Logics of Dislocation: Models, Metaphors, and Meanings of Economic Space. New York: The Guilford Press.

Behrens-Abouseif, Doris. 1998. Beauty in Arabic Culture. Princeton: Markus Weiner Publishers.

Bell, David and Gill Valentine. 1997. Consuming Geographies: We Are Where We Eat. London: Routledge.

Berggren, J.L. 1986. Episodes in the Mathematics of Medieval Islam. New York: Springer-Verlag.

Berggren, J.L. 2003. Tenth century mathematics through the eyes of Abu Sahl alKuhi. In Jan Hogendijk and A.I. Sabra (Eds.), The Enterprise of Science in Islam: New Perspectives. Cambridge, MA: MIT Press. 
Bierman, Irene. 2003. Disciplining the eye: understanding Islamic Architecture in Medieval Cairo. Lecture at Portland State University.

Blair, Sheila S. 1985. The Madrasa at Zuzan: Islamic Architecture in Eastern Iran on the eve of the Mongol invasions. In Oleg Grabar (Ed.), Muqarnas III: An Annual on Islamic Art and Architecture. Leiden: E.J. Brill.

Bloom, Jonathan. 1993. On the transmission of designs in early Islamic Architecture. In Oleg Grabar (Ed.) Muqarnas III: An Annual on Islamic Art and Architecture. Leiden: E.J. Brill.

Bloom, Jonathan and Sheila Blair. 1997. Islamic Arts. London: Phaidon Press.

Bourgoin, J. 1973, (rpt. of 1879 ed.). Arabic Geometrical Pattern and Design. New York: Dover Publications, Inc.

Broadie, Alexander. 1996. Maimonides. In Seyyed Hossein Nasr and Oliver Leaman (Eds.), History of Islamic Philosophy Part I. London: Routledge.

Brice, William C. 1981. An Historical Atlas of Islam. Leiden: E.J. Brill.

Burckhardt, Titus. 1976. Art of Islam: Language and Meaning. Westerham, World of Islam Festival Publishing Co, Ltd.

Clevenot, Dominique. 2000. Splendors of Islam: Architecture, Decoration, and Design. New York: Vendome Press.

Cosgrove, Denis. 1984. Social Formation and Symbolic Landscape. Madison:

University of Wisconsin.

Cosgrove, Denis and S. Daniels, eds. 1988. The Iconography of Landscape: Essays on the Symbolic Representation, Design, and Use of Past Environments. Cambridge: Cambridge University Press.

Cosgrove, Denis, ed. 1999. Mappings. London: Reaktion Books Ltd.

Crang, Mike. 1998. Cultural Geography. London: Routledge.

Critchlow, Keith. 1976. Islamic Patterns: An Analytical and Cosmological Approach. New York: Schocken Books. 
Daiber, Hans. 1994. Science and technology versus Islam, a controversy from Renan and Afghani to Nasr and Needham and its historical background. Journal for the History of Arabic Science, 10:119-133.

D'avennes, Prisse. 1989. The Decorative Art of Arabia. London: Studio Editions.

D'avennes, Prisse. 2001. Arabic Art. Paris: L'Aventurine.

Demiriz, Yildiz. 2000. Islam Sanatinda Geometrik Süsleme: Bir Envanter Denemesi. Istanbul: Lebib Yalkin Yay.

Department of Mathematics and Computer Science, Clark University. Arabic Mathematics. http://aleph0.clarku.edu/ djoyce/mathhist/arab.html Last accessed on 08/03.

Dhanani, Alnoor. 1994. The Physical Theory of Kalam: Atoms, space, and Void in Basrian Mu'tazili Cosmology. Leiden: E.J. Brill.

Djebbar, Ahmed. 2003. A panorama of research on the history of mathematics in alAndalus and the Maghrib between the ninth and sixteenth centuries. In Jan Hogendijk and A.I. Sabra (Eds.), The Enterprise of Science in Islam: New Perspectives.

Cambridge, MA: MIT Press.

Dold-Samplonius, Yvonne. 2003. Calculating surface areas and volumes in Islamic Architecture. In Jan Hogendijk and A.I. Sabra (Eds.), The Enterprise of Science in Islam: New Perspectives. Cambridge, MA: MIT Press.

Duncan, J and N. Duncan. 1988. (Re)reading the landscape. Environment and Planning D: Society and Space, 6:117-126.

Durkee, A. Nooruddeen, transl. 2003. The Tajwidi Qur'an. Charlotteville, VA: anNoor Educational Foundation.

Endress, Gerhard. 2003. Mathematics and philosophy in medieval Islam. In Jan Hogendijk and A.I. Sabra (Eds.), The Enterprise of Science in Islam: New Perspectives. Cambridge, MA: MIT Press.

El-Said, Issam and Ayse Parman. 1976. Geometric Concepts in Islamic Art. London: World of Islam Festival Publishing.

Ettinghausen, Richard. 1976. The man-made setting. In Bernard Lewis (Ed.), Islam and the Arab World: Faith, People, Culture. New York: Alfred A. Knopf. 
Ettinghausen, Richard. 2001. The Art and Architecture of Islam: 650-1250. New Haven: Yale University Press.

Fakhry, Majid. 1983. A History of Islamic Philosophy. New York: Columbia University Press.

Foote, Kenneth E. et al, eds. 1994. Re-Reading Cultural Geography. Austin: University of Texas Press.

Glasse, Cyril. 2002. The New Encyclopedia of Islam. Walnut Creek: Rowman and Littlefield Publishers, Inc.

Gocer, Asli. 1999. A hypothesis concerning the character of Islamic Art. Journal of the History of Ideas, 60:4 683-692.

Golombek, Lisa. 1997. Topkapi Scroll review. Ars Orientalis:27, 137-139.

Gombrich, E.H. 1979. The Sense of Order: A Study in the Psychology of Decorative Art. Cornell University Press: Ithaca, New York.

Gonzalez, Valérie. 2001. Beauty and Islam: Aesthetics in Islamic Art and Architecture. London: I.B. Tauris Publishers.

Grabar, Oleg. 1992. The Mediation of Ornament. Princeton: Princeton University Press.

Grabar, Oleg. 1998. The iconography of Islamic Architecture. In Priscilla Soucek (Ed.), Content and Context of Visual Arts in the Islamic World. University Park: The Pennsylvania State University Press.

Gutas, Dmitri. 1998. Greek Thought, Arabic Culture. London:Routledge.

Haeri, Shaykh Fadhlalla. 1990. The Elements of Sufism. Shaftesbury, Dorset: Element Books.

Haq, Syed Nomanul. 1996. The Indian and Persian background. In Seyyed Hossein Nasr and Oliver Leaman (Eds.), History of Islamic Philosophy Part I. London:

Routledge.

al-Hassan, Ahmad Y. and Donald R. Hill. 1994. Islamic Technology: An Illustrated History. Cambridge: Cambridge University Press.

Hessemer, F.M. 1990. Historic Designs and Patterns in Color from Arabic and Italian Sources. New York: Dover Publications, Inc. 
Hillenbrand, Robert. 1994. Islamic Architecture: Form, Function, and Meaning. New York: Columbia University Press.

Hourani, Albert. 1991. A History of the Arab Peoples. Cambridge: Belknap Press.

Ibn al-'Arabi. 2002. The Meccan Revelations. Transl. William Chittick and James W. Morris. New York: Pir Press.

Ibn Khaldun. 1968. The Muqaddimah: An Introduction to History $2^{\text {nd }}$ ed. Transl. Franz Rosenthal. Princeton: Princeton University Press.

Jackson, J.B. 1997. Landscape in Sight: Looking at America. New Haven: Yale University Press.

Jackson, Peter. 1994. Maps of Meaning. London: Routledge.

Jarrar, Sabri; Riedlmayer, Andras, and Jeffrey Spurr. 1994. Resources for the Study of Islamic Architecture: Historical Section. Aga Khan Program for Islamic Architecture.

King, David A. 1987. Some early Islamic tables for determining lunar crescent visibility. In David A. King and George Saliba (Eds.), From Deferent to Equant: A Volume of Studies in the History of Science in the Ancient and Medieval Near East in Honor of E.S. Kennedy. New York: Academy of Sciences.

Kennedy, E.S. 1983. Studies in the Islamic Exact Sciences. Beirut: American University of Beirut.

Kennedy, Hugh, ed. 2002. An Historical Atlas of Islam, $2^{\text {nd }}$ Revised Edition. Leiden: Brill.

Kheirandish, Elaheh. 2003. The many aspects of 'appearances': Arabic optics to 950 AD. In Jan Hogendijk and A.I. Sabra (Eds.), The Enterprise of Science in Islam: New Perspectives. Cambridge, MA: MIT Press.

Klein-Franke, Felix. 1996. al-Kindi. In Seyyed Hossein Nasr and Oliver Leaman (Eds.), History of Islamic Philosophy Part I. London: Routledge.

Kunitzsch, Paul. 2003. The transmission of Hindu-Arabic numerals reconsidered. In Jan Hogendijk and A.I. Sabra (Eds.), The Enterprise of Science in Islam: New Perspectives. Cambridge, MA: MIT Press. 
Leaman, Oliver. 1998. "Islamic Philosophy" in E. Craig (Ed.), Routledge Encyclopedia of Philosophy. London: Routledge. Retrieved September 12, 2003, from http://www.rep.routledge.com/article/HO57

Lewis, Peirce. 1979. Axioms for reading the landscape. In D.W Meinig (Ed.), The Interpretation of Ordinary Landscapes: Geographical Essays. New York: Oxford University Press.

Lewis, Peirce. 1994. Common houses, cultural spoor. In Kenneth E Foote et al (Eds.), Re-Reading Cultural Geography. Austin: University of Texas Press.

Light, Andrew and Jonathan Smith eds. 1998. Philosophy and Geography III: Philosophies of Place. Lanham: Rowman and Littlefield.

Lindberg, David C. 1992. The Beginnings of Western Science: The European Scientific Tradition in Philosophical, Religious, and Institutional Context, 600 BC to $A D$ 1450. Chicago: University of Chicago Press.

Livingstone, David N. 1994. Science and religion: foreword to the historical geography of an encounter. Journal of Historical Geography, 20:4 367-383.

Mandoki, Katya. 1998. Sites of symbolic density: a relativistic approach to experienced space. In Andrew Light and Jonathan Smith (Eds.), Philosophy and Geography III: Philosophies of Place. Lanham: Rowman and Littlefield.

Mathewson, Kent. 1994. How the world works. In Kenneth E Foote et al (Eds.), ReReading Cultural Geography. Austin: University of Texas Press.

Meinig, D.W. 1979. The Interpretation of Ordinary Landscapes: Geographical Essays. New York: Oxford University Press.

Meinig, D.W. 1983. Geography as an art. Transactions, Institute of British Geographers, 8:314-28.

Mikesell, Marvin. 1994. Afterword. In Kenneth E Foote et al (Eds.), Re-Reading Cultural Geography. Austin: University of Texas Press.

Mitchell, Don. 2000. Cultural Geography: A Critical Introduction. Oxford: Blackwell.

Mitchell, Timothy. 1989. The world as exhibition. Comparative Studies in Society and History, 31:217-236. 
Montgomery, Scott L. 2000. Science in Translation: Movements of Knowledge through Cultures and Time. Chicago: University of Chicago Press.

Morgan, David. 1986. The Mongols. Oxford: Basil Blackwell.

Nasr, Seyyed Hossein. 1968. Science and Civilization in Islam. New York: Barnes and Noble Boooks.

Nasr, Seyyed Hossein. 1976. Islamic Science: An Illustrated Survey. London: World of Islam Festival Publishing.

Nasr, Seyyed Hossein. 1996. Introduction to the mystical tradition. In Seyyed Hossein Nasr and Oliver Leaman (Eds.), History of Islamic Philosophy Part I. London: Routledge.

Nasr, Seyyed Hossein. 2003. Islam: Religion, History, and Civilization. San Francisco: HarperSanFrancisco.

National Geospatial and Intelligence Agency. Geographic Names Information System. http://earth-info.nga.mil/gns/html/ Last accessed on 09/03.

Necipoglu, Gülru. 1995. The Topkapi Palace Scroll: Geometry and Ornament in Islamic Architecture. Santa Monica: The Getty Center for the History of Art and the Humanities.

O'Leary, DeLacy. 1979. How Greek Science Passed to the Arabs. Chicago: Ares Publishers.

Özdural, Alpay. 1996. On interlocking similar or corresponding figures and ornamental patterns of cubic equations. In Oleg Grabar (Ed.) Muqarnas III: An Annual on Islamic Art and Architecture. Leiden: E.J. Brill.

Park, Chris. 1994. Sacred Worlds: An Introduction to Geography and Religion. New York: Routledge.

Pines, Shlomo. 1986. Studies in Arabic Versions of Greek Texts and in Mediaeval Science. Jerusalem: The Magnes Press, The Hebrew University.

Pougatchenkova, Galina. 1981. Chefs d'Oevre d'Architecture de l'Asie Centrale XIV-XV Siècle. Paris: Les Presses de l'UNESCO.

Powell, Ann. 1998. Neoplatonism and geometry in Islamic Art. Journal of the Association of Art Historians: 21:1:135-139. 
Rashed, Roshdi. 1996. Encyclopedia of the History of Islamic Science, volume 2. London: Routledge.

Qadir, C. A. 1988. Philosophy and Science in the Islamic World. London: Croom Helm.

Robinson, Arthur H. 1982. Early Thematic Mapping in the History of Cartography. Chicago: University of Chicago Press.

Robinson, Francis, ed. 1996. The Cambridge Illustrated History of the Islamic World. Cambridge, NY: Cambridge University Press.

Robinson, Francis. 1982. Atlas of the Islamic World since 1500. New York: Facts on File.

Roolvink, R. 1957. Historical Atlas of the Muslim Peoples. Cambridge, Harvard University Press.

Sabra, A.I. 1983. The exact sciences. In J.R. Hayes (Ed), The Genius of Arab Civilization: Source of Renaissance. Cambridge: MIT Press.

Sabra, A.I. 1996. Situating Arabic science: locality versus essence. Isis 87: 654-670.

Sabra, A.I. 1997. The appropriation and subsequent naturalization of Greek Science in Medieval Islam: a preliminary study. History of Science 25: 223-243.

Said, Edward. 1979. Orientalism. New York: Vintage Books.

Samso, Julio. 2003. On the lunar tables in Sanjaq Dar's Zij al-Sharif. In Jan Hogendijk and A.I. Sabra (Eds.), The Enterprise of Science in Islam: New Perspectives. Cambridge, MA: MIT Press.

Schimmel, Annemarie. 1991. Sacred geography in Islam. In Jamie Scott and Paul Simpson-Housley (Eds), Sacred Places and Profane Spaces: Essays in the Geographies of Judaism, Christianity, and Islam. New York: Greenwood Press.

Schimmel, Annemarie. 1993. The Triumphal Sun: A Study of the Works of Jalaloddin Rumi. Albany:State University of New York Press.

School of Mathematics and Statistics at the University of St Andrews, Scotland. Arabic Mathematics. http://turnbull.mcs.st-and.ac.uk/history/Indexes/Arabs.html Last accessed on 09/03. 
Scott, Jamie and Paul Simpson-Housley, eds. 1991. Sacred Places and Profane Spaces: Essays in the Geographies of Judaism, Christianity, and Islam. New York: Greenwood Press.

Shani, Raya. 1996. A Monumental Manifestation of the Shi 'ite Faith in Late TwlfthCentury Iran: The Case of the Gunbad-i Alawiyan, Hamadan. Oxford: Oxford University Press.

Simakoff, N. 1993. Islamic Designs in Color. New York: Dover Publications, Inc.

Sims, Eleanor. 1980. The 'iconography' of the internal decoration in the mausoleum of Uljaytu at Sultaniyya. In Priscilla Soucek (Ed.), Content and Context of Visual Arts in the Islamic World. University Park, Pennsylvania: The Pennsylvania State University Press.

Sourdel, Dominique. 1983. Medieval Islam. J. Montgomery Watt, (Transl.). London: Routledge.

Spurr, Jeffery B., Adras Riedlmayer, Jarrar Sabri. 1994. Resources for the Study of Islamic Architecture. Aga Khan Program for Islamic Architecture.

http://archnet.org/library/documents/one-document.tct?document id=6053 Last accessed on $08 / 03$.

Tabbaa, Yasser. 1985. The muqarnas dome: its origin and meaning. In Oleg Grabar (Ed.) Muqarnas III: An Annual on Islamic Art and Architecture. Leiden: E.J. Brill.

Tabbaa, Yasser. 1997. Constructions of Power and Piety in Medieval Aleppo. University Park, Pennsylvania: The Pennsylvania State University Press.

Tabbaa, Yasser. 2001. The Transformation of Islamic Art during the Sunni Revival. Seattle: University of Washington Press.

Takahashi, Shiro. Muqarnas: a Three-Dimensional Decoration of Islamic Architecture. Tama University, Japan.

http://www.tamabi.ac.jp/idd/shiro/muqarnas/default.htm Last accessed 12/04.

Thomas, Nicholas. 1991. Anthropology and Orientalism. Anthropology Today 7:2 47.

Thrower, Norman. 1996. Maps and Civilization: Cartography in Culture and Society. Chicago: University of Chicago Press.

Tuan, Yi-fu. 1974. Topophilia. New York: Columbia University Press. 
Tuan, Yi-fu. 1979. Thought and landscape: the eye and the mind's eye. In D.W.

Meinig (Ed.), The Interpretation of Ordinary Landscapes: Geographical Essays. New York: Oxford University Press.

Tuan, Yi-fu. 1995. Passing Strange and Wonderful: Aesthetics, Nature, and Culture. New York: Kodansha International.

Tuan, Yi-Fu. 1999. Maps and art: identity and utopia. In Robert Silberman (Ed.), World Views: Maps and Art. Minneapolis: University of Minnesota Press.

Turnbull, David. 1993. Maps are Territories: Science is an Atlas: a Portfolio of Exhibits. Chicago: University of Chicago Press.

Turner, Howard R. 1997. Science in Medieval Islam: An Illustrated Introduction. Austin: University of Texas Press.

Van Donzel, E.J. 1994. Islamic Desk Reference. Leiden: Brill.

Wagner, Philip. 1994. How the world looks. In Kenneth E. Foote et al, (Eds), ReReading Cultural Geography. Austin: University of Texas Press.

Washburn, Dorothy K. and Donald W. Crowe. 1988. Symmetries of Culture: Theory and Practice of Plane Pattern Analysis. Seattle: University of Washington Press.

Watt, Montgomery. 1985. Islamic Philosophy and Theology: An Extended Survey. Edinburgh, Edinburgh University Press.

Winder, R.B. 1983. Badi ' al-Zaman Isma'il bin ar-Razzaz al-Jazari. In J.R. Hayes (Ed), The Genius of Arab Civilization: Source of Renaissance. Cambridge: MIT Press.

Wood, Denis. 1992. The Power of Maps. New York: Guilford Press.

Ziai, Hossein. 1996. Shihab al-Din Suhrawardi: founder of the Illuminationist school. In Seyyed Hossein Nasr and Oliver Leaman (Eds.), History of Islamic Philosophy Part I. London: Routledge. 